Mapping the boundaries of imagined nationhood: news images published in daily newspapers at the outbreak of the Klondike gold rush (summer 1897)

by

\title{
Claude Fortin
}

A thesis submitted to the Faculty of Graduate and Postdoctoral Affairs in partial fulfillment of the requirements for the degree of

Master of Arts

in

Communication

Carleton University

Ottawa, Ontario, Canada

(C) 2011

Claude Fortin 
Library and Archives

Canada

Published Heritage

Branch

395 Wellington Street

Ottawa ON K1A ON4

Canada
Bibliothèque et

Archives Canada

Direction du

Patrimoine de l'édition

395 , rue Wellington

Ottawa ON K1A ON4

Canada
Your file Votre référence
ISBN: $978-0-494-83075-8$
Our file Notre référence
ISBN: $978-0-494-83075-8$

\section{NOTICE:}

The author has granted a nonexclusive license allowing Library and Archives Canada to reproduce, publish, archive, preserve, conserve, communicate to the public by telecommunication or on the Internet, loan, distribute and sell theses worldwide, for commercial or noncommercial purposes, in microform, paper, electronic and/or any other formats.

The author retains copyright ownership and moral rights in this thesis. Neither the thesis nor substantial extracts from it may be printed or otherwise reproduced without the author's permission.
AVIS:

L'auteur a accordé une licence non exclusive permettant à la Bibliothèque et Archives Canada de reproduire, publier, archiver, sauvegarder, conserver, transmettre au public par télécommunication ou par l'Internet, prêter, distribuer et vendre des thèses partout dans le monde, à des fins commerciales ou autres, sur support microforme, papier, électronique et/ou autres formats.

L'auteur conserve la propriété du droit d'auteur et des droits moraux qui protège cette thèse. $\mathrm{Ni}$ la thèse ni des extraits substantiels de celle-ci ne doivent être imprimés ou autrement reproduits sans son autorisation.
In compliance with the Canadian Privacy Act some supporting forms may have been removed from this thesis.

While these forms may be included in the document page count, their removal does not represent any loss of content from the thesis.
Conformément à la loi canadienne sur la protection de la vie privée, quelques formulaires secondaires ont été enlevés de cette thèse.

Bien que ces formulaires aient inclus dans la pagination, il n'y aura aucun contenu manquant. 


\begin{abstract}
Using a mixed methodology based on a discourse-historical approach, this case study empirically analyzes news images published in 14 daily newspapers at the outbreak of the Klondike gold rush in the summer of 1897. Canadian news images, American news images, and archival photographs from public domain archival sources are compared to expose the mythical aspect of news-discourse in late nineteenth century illustrated daily news. Drawing on Benedict Anderson's paradigm of imagination, this Master's thesis sets out to demonstrate how social, spatial, and temporal boundaries intersect and overlap to form a conceptual matrix for the discursive construction of national identity in the news images under study. It is argued that this was achieved by encouraging readers to participate in collective imaginings that represented race, gender, class, space, artifacts, and institutions, which served to map and reify imagined boundaries of nationhood in the context of the ideology of Anglo-Saxonism.
\end{abstract}




\section{ACKNOWLEDGEMENTS}

There is an old saying in Africa that it takes a village to raise a child. Following that logic, I believe it takes an academic community to research and write an M.A. thesis.

Much credit is due to my thesis supervisor, Dr. Michèle Martin. She was generous, open-minded, attentive, patient, and understanding during the research process and the writing of this manuscript. She recommended relevant books, guided me through the data collection process, offered useful advice, and gave me plenty of freedom to explore ideas. Always supportive, she was a fair critic and an encouraging mentor.

I must also thank Dr. Eileen Saunders for many of the sources she recommended as well as for her sagacious, insightful, and always helpful comments and suggestions. I am most grateful for her input.

A special thanks to Dr. Sheryl Hamilton for providing invaluable information on academic writing on short notice. Thanks, too, to the Communication department coordinator, Michelle Bateman, for being unfailingly conscientious and helpful.

Finally, I owe many thanks in general to the archivists and librarians of Library and Archives Canada, the Library of Congress, the Carleton University Library, the Concordia University Library, and the McGill University Library. And I owe thanks in particular to Christopher Bober at the Concordia University Library, who took the time to show me how to search efficiently for nineteenth century newspapers; Mary Bond at Library and Archives Canada, who answered my email queries with supreme patience and thoroughness, guiding me in the early days of the research process; and Emma Cross at the Carleton University Library, who provided information with regards to formatting. 


\section{TABLE OF CONTENTS}

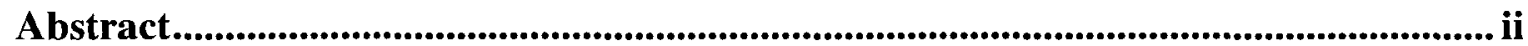

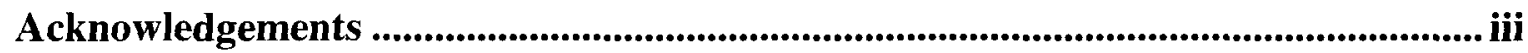

Table of Contents ............................................................................................. iv

List of Appendices....................................................................................................... vii

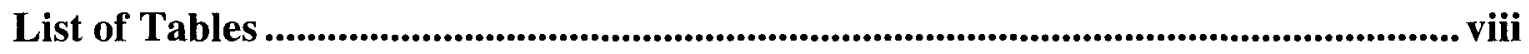

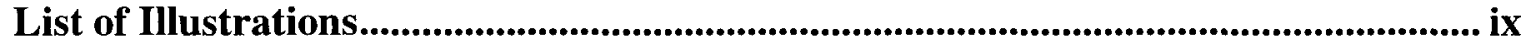

Introduction - News Images Published in Daily Newspapers at the Outbreak of the

Klondike Gold Rush ....................................................................................... 1

Chapter One - Theoretical Approach............................................................ 10

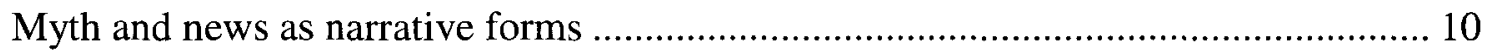

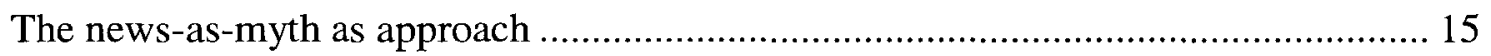

Illustrated news and the discursive construction of national identity ......................... 22

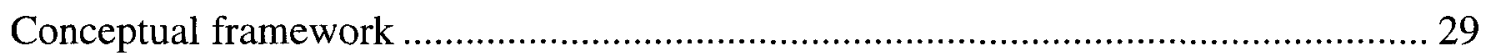

Chapter Two - Research Methodology ........................................................................ 35

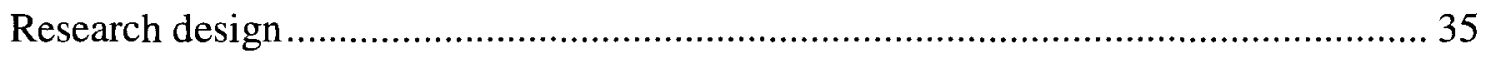

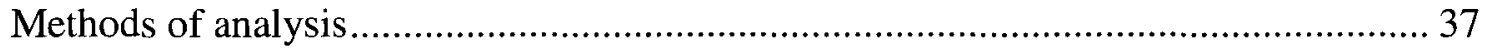

Selection of a type of illustrated news periodical for this case study ........................ 43

Selection of daily newspapers for this case study .............................................. 45

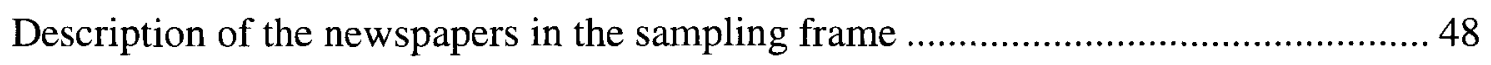

Chapter Three - Fact and Fiction in the Representation of Historical Events......... 51

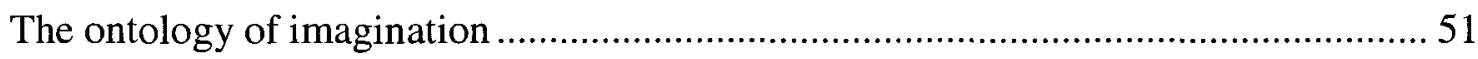

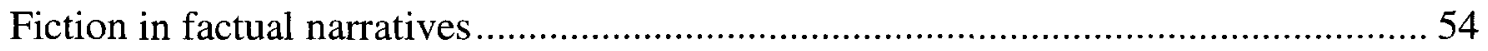

The epistemic foundations of modern news..................................................... 58

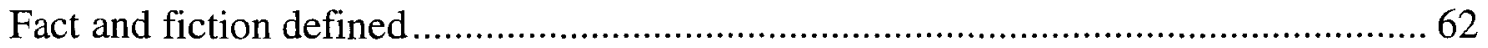

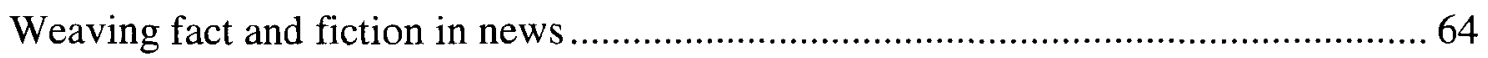


The mythical character of Klondike news coverage ......................................... 73

Two paradigms of journalism during the Klondike gold rush .............................. 76

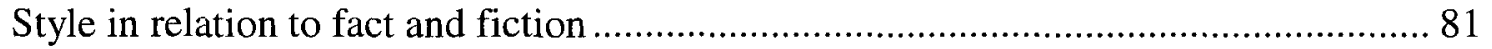

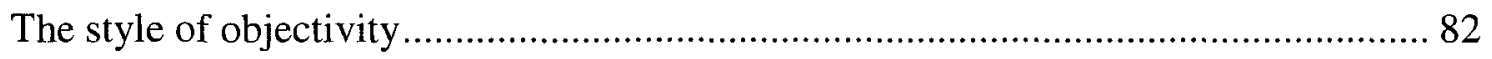

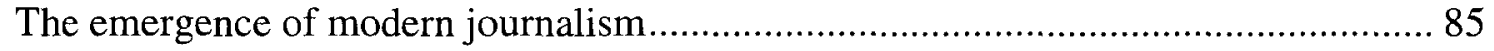

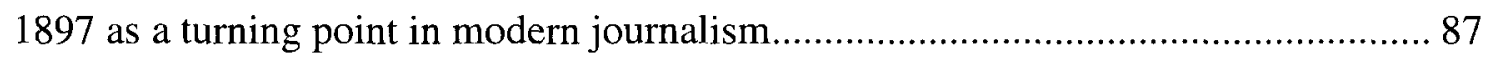

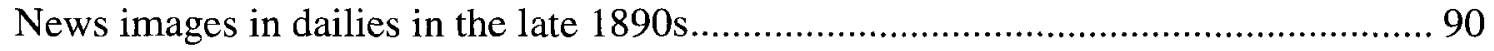

Chapter Five - The Historical Backdrop of the Klondike Myth............................. 93

From the Gilded Age to the Depression of the Eighteen Nineties ............................ 93

From imagining to imaginings: the cult of the self and the pursuit of wealth ............ 97

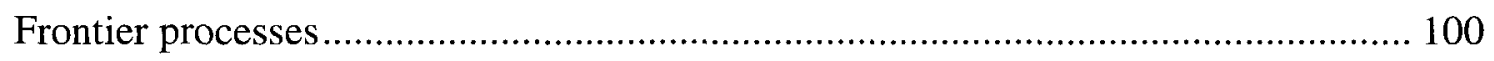

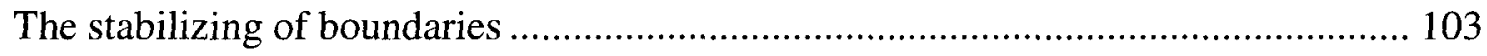

Facts, fiction, and technology: the perfect storm .............................................. 104

The reification of boundaries through the mapping of reality ................................ 108

Social, spatial, and temporal boundaries ........................................................... 110

Chapter Six - Grafting Euroamerican social boundaries of race, gender, and class

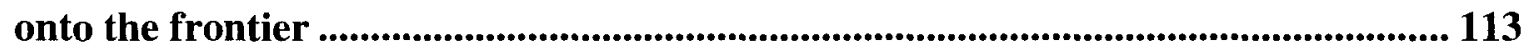

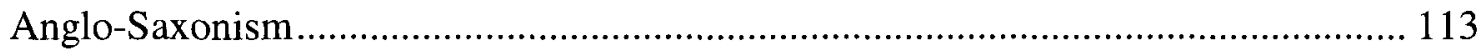

Invisible minorities: the visual rhetoric of exclusion ........................................ 117

Early visual archetypes of Klondike stampeders ........................................... 122

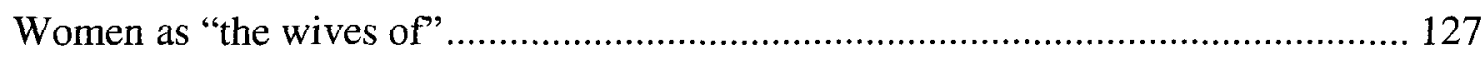

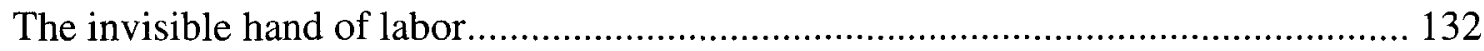

Chapter Seven - The Spatial Boundaries of Property ........................................ 135

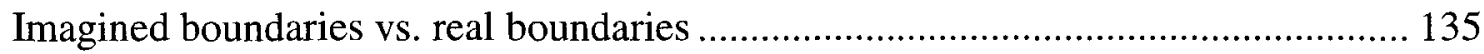

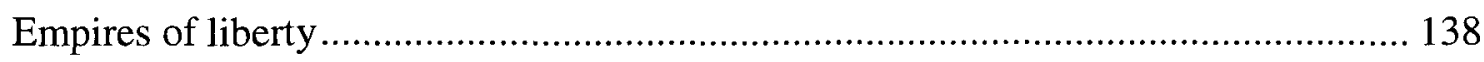

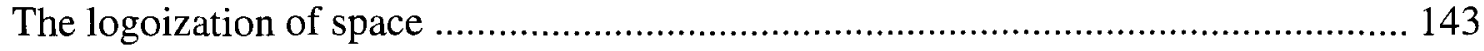

Mapping the boundaries of Anglo-Saxon property .......................................... 146 
Blurring international boundary lines

The permeability of boundaries

Chapter Eight - The Temporal Boundaries of Rhetorical Time............................ 157

The institution of freedom ...................................................................... 157

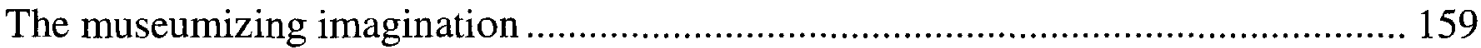

Symbols of imperial hubris ....................................................................... 160

The architecture of the frontier....................................................................... 163

The institution of industry, public services, and liberal professions in the Klondike. 167

Law and order as a symbol of Anglo-Saxon nationhood ................................ 170

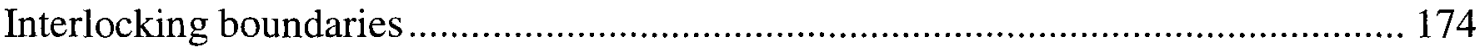

Journalists as the guardians of temporal boundaries .................................. 176

Conclusion: Rethinking Journalism in Mythical Terms.......................................... 182

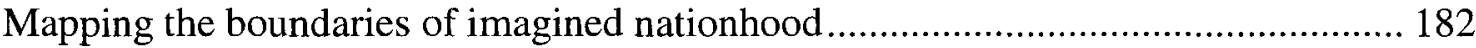

Reflections on different journalism practices in 1897 ................................... 185

The importance of shared imaginings in social life .......................................... 190

The modern newspaper as a palimpsest .................................................... 193

New avenues for future investigation.............................................................. 194

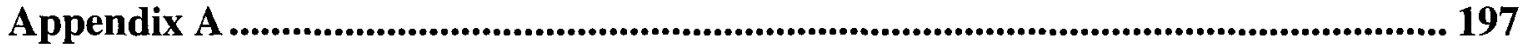

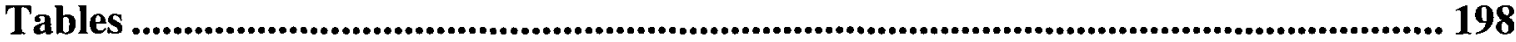

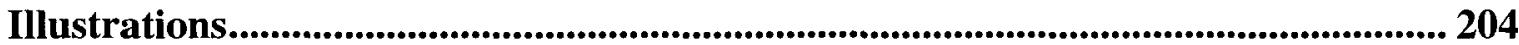

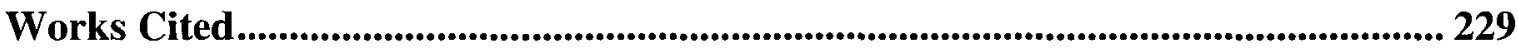




\section{LIST OF APPENDICES}

Appendix A Wodak's (2002) ten programmatic claıms for critıcal discourse analysıs 


\section{LIST OF TABLES}

TABLE A Tables Offering a Descriptive List of the 14 Dally Newspapers in this Case Study

Table A1 Descriptıve List of the Seven Canadıan Daily Newspapers in this Case Study's Sampling Frame

Table A2 Descriptive List of the Seven American Dally Newspapers in this Case Study's Sampling Frame

TABLE B Quantıtatıve Content Analysıs of the News Images in this Case Study's Sampling Frame from July 15 st to July 31 st, 1897

TABLE C Tables of the Relative Index of Story Journalism

Table C1 Calculation of the Relatıve Index of Story Journalısm of the Newspapers Included in this Case Study's Sampling Frame

Table C2 Relative Index of Story Journalism of the Newspapers in this Case Study's Sampling Frame as Laid Out on a Spectrum Rangıng from Lowest to Highest According to the Scores Obtained in Table C1

TABLE D Detals of the First Klondıke News Announcements in thıs Case Study's Sampling Frame 


\section{LIST OF ILLUSTRATIONS}

Fig. 1 Manuscript illustration of Book III, Chap. 18 of Polo's Books of the Marvels of the World. Workshop of the Boucicaut Master, ms fr 2810, folı 76v, c 15 $5^{\text {th }}$ century (before 1413) Reproduced from ArtStor, http //www artstor org

Fig. 2 Manuscript illustration of Book I, Chap. 51 of Polo's Books of the Marvels of The World. Workshop of the Boucicaut Master, ms fr 2810, folio 29v, c $15^{\text {th }}$ century (before 1413) Reproduced from ArtStor, http //www artstor org

Fig. 3 Manuscript illustration of Book I, Chap. 57 of Polo's Books of the Marvels of The World. Workshop of the Boucicaut Master, folı 194v, ms fr 2810, c 15 $5^{\text {th }}$ century (before 1413) Reproduced from ArtStor, http //www artstor org

Fig. 4 Manuscript page of Book III, Chap. 25 of Polo's Books of the Marvels of the World. Workshop of the Boucicaut Master, ms fr 2810 , follo 84r, c $15^{\text {th }}$ century (before 1413) Reproduced from ArtStor, http //www artstor org

Fig. 5 The 'Excelsior' leaving for the Klondike.

(San Francisco) The Examiner, July 26, 1897, p 1 Digital scan from microfilm

Fig. 6 Bicycle adapted for travel to Klondike.

The Montreal Dally Star, August 4, 1897, p 10 Digital scan from microfilm

Fig. 7 Stampeders used many means of transportation.

(San Francisco) The Examiner, July 17, 1897, p 14 Digital scan from microfilm

Fig. 8 The first news image published when the discovery of gold in the Klondike was announced. (San Francisco) The Examiner, July 16, 1897, p 1 Digital scan from microfilm

Fig. 9 Two photographic portraits printed with the halftone process.

The Winnipeg Dally Tribune, July 27, 1897, p 1 Digital scan from microfilm

Fig. 10 Halftone reproduction of photograph of landscape.

The Winnipeg Dally Tribune, July 17, 1897, p 3 Digital scan from microfilm

Fig. 11 Engraving made from photograph.

Ottawa Free Press, July 23, 1897, p 3 Digital scan from microfilm

Fig. 12 Miners' camp in the Klondike, version 1.

San Francisco Chronicle, July 17, 1897, p 1 Digital scan from microfilm

Fig. 13 Miners' camp in the Klondike, version 2.

(San Francisco) The Examiner, July 24, 1897, p 3 Digital scan from microfilm

Fig. 14 Miners' camp in the Klondike, version 3.

(Montreal) La Presse, July 27, 1897, p 1 Digital scan from microfilm 
Fig. 15 Miners' camp in the Klondike, version 4.

(Toronto) The Globe, July 28, 1897, p 6 Digital scan from microfilm

Fig. 16 Miners' camp in the Klondike, version 5.

The Ottawa Free Press, July 31, 1897, p 9 Digital scan from microfilm

Fig. 17 Group portrait of Northwest police officers printed in montage of Klondike images. The Montreal Dally Star, July 20, 1897, p 8 Digital scan from microfilm

Fig. 18 Group portrait of Northwest police officers printed individually.

The Globe, July 21, 1897, p 2 Digital scan from microfilm

Fig. 19 Group portrait of Northwest police officers printed in montage of Klondike images.

The New York Herald, July 19, 1897, p 4 Digital scan from microfilm

Fig. 20 Enlargement of the group portrait of Northwest police officers shown in Fig. 19.

The New York Herald, July 19, 1897, p 4 Digital scan from microfilm

Fig. 21 Cartoon on cover of Life,

Life, Vol 33, March 16, 1899 Digital scan from microfilm

Fig. 22 Stampeders hiking.

(Montreal) La Presse, July 23, 1897, p 1 Digital scan from microfilm

Fig. 23 Stampeders ascending the Chilcoot Pass.

The Montreal Dally Star , August 4, 1897, p 10 Digital scan from microfilm

Fig. 24 Vignettes of stampeders heading for the gold fields.

La Presse, July 28, 1897, p 1 Digital scan from microfilm

Fig. 25 Studio portrait of a Chilkat Indian posed as a packer for the Klondike, Alaska, c. 1897. Eric A Hegg, Erıc A Hegg Photograph Collection, University of Washington Libraries, Special Collectıons, Seattle, Washıngton, NA2346

Fig. 26 Veazie Wilson's party and First Nation packers heading for the Klondike district, c. 1895. Veazie Wilson Reproduced from Esther Lyons (1897), Glimpses of Alaska a collection of views of the interior of Alaska and the Klondike district (Chicago Rand McNally), p 7 Courtesy of Rare Books and Special Collections, McGıll Unıversity Library, Montréal, Québec

Fig. 27 Stampeders carrying outfits on their backs.

(San Francisco) The Examiner, July 19, 1897, p 2 Digital scan from microfilm

Fig. 28 The 'Cleveland' leaving San Francisco.

San Francisco Chronicle, July 25, 1897, p 14 Digital scan from microfilm

Fig. 29 Americans leaving for the Klondike.

(Los Angeles) The Herald, July 25, 1897, p 1 Digital scan from microfilm 
Fig. 30 Stampeders icebound on their way to Dawson City.

(Toronto) The Globe, July 29, 1897, p 6 Digital scan from microfilm

Fig. 31 Stampeders rafting up the Yukon River.

(Winnipeg) The Datly Nor'Wester, July 29, 1897, p 1 Digital scan from microfilm

Fig. 32 Frontiersmen in the Klondike.

The Washington Post, August 1, 1897, p 17 Digital scan from microfilm

Fig. 33 Mining camp near Dawson City.

(Montreal) La Presse, July 29, 1897, p 1 Digital scan from microfilm

Fig. 34 Mining scene in the Klondike.

(Montreal) La Presse, July 29, 1897, p 6 Digital scan from microfilm

Fig. 35 Portrait of a miner and his son.

San Francisco Chronicle, July 23, 1897, p 1 Digital scan from microfilm

Fig. 36 Three portraits of rich Klondike miners.

San Franctsco Chronicle, July 24, 1897, p 1 Digital scan from microfilm

Fig. 37 Portraits of rich Klondike miners.

Seattle Post-Intelligencer, August 1, 1897, p 6 Digital scan from microfilm

Fig. 38 Portrait of Clarence Berry.

San Franctsco Chronicle, July 21, 1897, p 1 Digital scan from microfilm

Fig. 39 Portrait of Mrs. Clarence Berry.

The Montreal Datly Star, July 27, 1897, p 10 Digital scan from microfilm

Fig. 40 Portrait of Mrs. Clarence Berry.

San Francisco Chronicle, July 21, 1897, p 2 Digital scan from microfilm

Fig. 41 Montage of images of Mrs. Clarence Berry.

Sunday Examıner Magazıne, August 1, 1897, p 1 Digital scan from microfilm

Fig. 42 Photograph of Mrs. Clarence Berry, c. 1898.

Glenbow Archives collection, Calgary, Alberta, NA-1786-8

Fig. 43 Portrait of Mrs. Kate Carmack flipped horizontally from left to right, c. 1898.

MacBride Museum of Yukon History collectıon, Whitehorse, Yukon , Image Number 19911011

Fig. 44 African American woman at a lunch room in the Yukon, c. 1898.

Library and Archives Canada, Ottawa, Ontarı, PA-170412

Fig. 45 Swift Water Willie's cabin at Quartz Creek, in the Yukon, c. 1897-1910.

Library and Archives Canada, Ottawa, Ontario, accession number 1955-057, 1tem p 6, C-014550 
Fig. 46 Caricature taking an American perspective on territorial boundaries.

The Washington Post, July 30, 1897, p 1 Digital scan from microfilm

Fig. 47 Caricature taking a Canadian perspective on territorial boundaries.

(Toronto) Dauly Mall and Empire, July 21, 1897, p 1 Digital scan from microfilm

Fig. 48 Canadian map of Klondike.

(Toronto) Datly Mail and Emptre, July 21, 1897, p 7 Digital scan from microfilm

Fig. 49 American map of Klondike.

The New York Herald, July 18, 1897, p 5 Digital scan from microfilm

Fig. 50 Canadian map shading gold fields.

(Winnipeg) The Daily Nor'Wester, July 31, 1897, p 1 Digital scan from microfilm

Fig. 51 American map shading gold fields.

The New York Herald, July 25, 1897, p 2 Digital scan from microfilm

Fig. 52 American map representing the "Land of Gold".

The Seattle Post Intelligencer, July 21, 1897, p 1 Digital scan from microfilm

Fig. 53 Photomontage showing stampeders hiking around and behind three vignettes of Klondike.

(San Francisco) The Examiner, July 18, 1897, p 13 Digital scan from microfilm

Fig. 54 Arrival of the 'Portland' in Seattle.

Seattle Post-Intelligencer, July 29, 1897, p 2 Digital scan from microfilm

Fig. 55 Departure of the 'Excelsior' for the Klondike.

San Francisco Chronicle, July 20, 1897, p 1 Digital scan from microfilm

Fig. 56 The 'Alice' near Dawson City.

The Montreal Datly Star, July 26, 1897, p 5 Digital scan from microfilm

Fig. 57 Departure of the 'Excelsior' for the Klondike.

(Montreal) La Presse, August 2, 1897, p 7 Digital scan from microfilm

Fig. 58 Log house in the Klondike.

San Francisco Chronıcle, July 19, 1897, p 1 Digital scan from microfilm

Fig. 59 Home of one of the early Yukon pioneer who became rich through trade and real estate. (Montreal) La Presse, August 2, 1897, p 1 Digital scan from microfilm

Fig. 60 Landscape in valley near Klondike claims.

(Montreal) La Presse, August 2, 1897, p 1 Digital scan from microfilm

Fig. 61 American trading post supplying Dawson City in the early days of the gold rush.

San Francısco Chronicle, July 21, 1897, p 1 Digital scan from mıcrofilm 
Fig. 62 The first saw mill at the diggings.

(Montreal) La Presse, July 28, 1897, p 5 Digital scan from microfilm

Fig. 63 Custom house near gold fields.

San Francisco Chronicle, July 28, 1897, p 1 Digital scan from microfilm

Fig. 64 Library building at Forty-Mile.

San Francisco Chronicle, July 31, 1897, p 9 Digital scan from microfilm

Fig. 65 Photograph used as a source for the "Library building at Forty-Mile" news image, c. 1895. Veazle Wilson Reproduced from Esther Lyons (1897), Glimpses of Alaska a collection of views of the interior of Alaska and the Klondike district (Chicago Rand McNally), p 51 Courtesy of Rare Books and Special Collections, McGıll Unıversity Library, Montreal, Quebec

Fig. 66 Post office near gold fields.

(San Francisco) The Examiner, July 23, 1897, p 3 Digital scan from microfilm

Fig. 67 North West Mounted Police post.

The Montreal Dally Star, July 26, 1897, p 8 Digital scan from microfilm

Fig. 68 American flag in a Canadian camp.

San Francisco Chronicle, July 25, 1897, p 13 Digital scan from microfilm

Fig. 69 Union Jack and Stars \& Stripes on the White Pass Summit on April 9, 1899.

Dawson City Museum, Dawson City, accession number 19822023

Fig. 70 Party of experts sent to the Klondike as correspondents for "The Examiner". (San Francisco) The Examiner, July 22, 1897, p 1 Digital scan from microfilm

Fig. 71 More correspondents sent by The Examiner (including photographers).

(San Francisco) The Examiner, July 23, 1897, p 1 Digital scan from microfilm

Fig. 72 Correspondents sent to the Klondike by the San Francisco Chrontcle.

San Francısco Chronicle, July 29, 1897, p 1 Digital scan from microfilm

Fig. 73 Studio portrait taken of Klondike stampeders before their departure, c. 1897.

Provincial Archives of Alberta, Ernest Brown Collection, Edmonton, Alberta,

reference number B5278 


\section{INTRODUCTION - NEWS IMAGES PUBLISHED IN DAILY NEWSPAPERS AT THE OUTBREAK OF THE KLONDIKE GOLD RUSH}

Roland Barthes (1957) once wrote that the process by which history evaporates in myths contributes to mystifying man's responsibility in the production of social life (p. 239). ${ }^{1}$ This thesis challenges Barthes's claim and encourages further reflection by asking, "What are some of the roles that fiction serves in news?" If people often prefer to remember myths over facts, one must question not only the negative roles that this can play in the construction of social life, but also the positive ones that could be applied to communication theory and to the field of journalism. This thesis aims to make such a contribution by studying the modern telling of a historical event that has taken on mythical proportions in the news.

The Klondike gold rush is such an event. Over a century ago, it achieved a mythical quality that has only increased with the passage of time. This thesis investigates the hypothesis that this has been due in large part to the way in which it was first covered in the news, and assumes that this would have strongly influenced how it was later retold in the different media engines of popular culture. A gold rush of this magnitude could only build up as rapidly and spread as infectiously as it did through a social process that involved highly expeditious modes of mass communication (Fetherling, 1988, p. 149). One of these was print journalism which was influenced by the fast-evolving

\footnotetext{
1 «Le mythe prive l'objet dont 1 parle de toute Historre. En luı, l'hıstorre s'évapore...on voit tout ce que cette figure heureuse fait disparaître de gênant : à la fors le détermınısme et la liberté. Rien n'est produit, rıen n'est choisı...Cette évaporation mıraculeuse de l'historre est une autre forme d'un concept commun à la plupart des mythes bourgeoıs : l'ırresponsabilité de l'homme [sic] » 1n Roland Barthes (1957) Mythologies (Parıs, Éditions du Seuıl), p. 239.
} 
communication and transportation technologies of the nineteenth century, and what

Coates (1998) has called the "promotional inclinations of the $19^{\text {th }}$ century press" (p. 29).

This is not to frame the event in a technological deterministic argument for it is through imagination and word of mouth that large reading publics would transform the news into tales of adventure. The primary agents of news were journalists, many of whom were dispatched as correspondents to cover the event. Exceptionally however, in the context of the Klondike gold rush, newspapers were so hungry for news updates, that they welcomed the photographic or written contribution of stampeders ${ }^{2}$ and dilettantes alike. ${ }^{3}$ Consequently, newspapers would often combine on the same page factual news reporting with poems, stories, and first-hand accounts, all of which the armchair stampeders could consume in a single reading from the comfort of their home on any given day. In some publications, news coverage of the event was generously supplemented by a vast number of contemporaneous images. These included maps, action shots, views of exteriors/interiors, portraits, and caricatures, amongst others.

2 Unt1l the Klondıke stampede, North American gold-rush stampeders were, for the most part, experienced miners. One of the many ways in which the Klondike gold rush was historically exceptional was that, from the first day of its news outbreak in dalles, there were more greenhorns than miners who rushed to the gold fields in search of wealth Consequently, in this case study, the term "stampeders" simply designates gold-seekers from all walks of life who set out for the gold fields in the mad panic

3 For example, Leslie's Weekly newspaper, which was examıned durıng the research stage of this study, included the following text inviting its readers to contribute their own photographs "NOTICE TO PHOTOGRAPHERS AND OTHERS. Leslie's Weekly is always glad to receive good pictures of interestıng events, and the publishers will pay promptly for all acceptable photographs sent to them Photographs of the life in the mining regions in Alaska and the Northwest Territory will be particularly acceptable" (Leslle's Weekly LXXXV, no 2195, October 7, 1897, p 2) This call for photographs was published three tumes on page 2 of Leslue's Weekly in 1897 September 23, September 30, and October 7. Given that this was the only period that the weekly published this notice in 1897 and that it specifically mentioned the northwest, upon examination of the corpus, it became clear that it referred to the Klondike gold rush 
If myths are socially constructed, it makes sense to study them by means of a frequently issued medium that appeals to as large a public as possible. During the Klondike stampede that took place in the late nineteenth century, illustrated daily newspapers would have constituted such a channel of communication. Barthes (1957) has remarked that images are more effective signifiers of mythical representations than written text (p. 195). With the exception perhaps of brands, images are arguably the only lingua franca that print technologies have reproduced. In newspapers, news images are a polyglot text that speaks to a majority of readers who take part in the shaping of public myths through their consumption of news. In the years that followed the Klondike gold rush, illustrated newspapers would soon compete with, and eventually come to be supplanted by, the mass media of the twentieth century: cinema, radio, and television. But when the Klondike stampede broke out in 1897, illustrated daily newspapers constituted the principal mass medium for the production of public myths.

For these reasons, this thesis proposes to examine the mythical dimension of this historical event at its outbreak by using a historical case study approach that focuses primarily on the analysis of news images published in dailies as line engravings. Broadly speaking, the corpus of this study is composed entirely of newspapers that belong to the tradition of market-based publications that emerged in the nineteenth century with the purpose of presenting current news to a large readership on a daily basis. However, given that the units of analysis are news images, it seems relevant also to refine the principal research domain of this study to illustrated news rather than simply news. While news can be defined as the commodified product of journalism practiced by the market-based 
press (Chalaby, 1998, p. 32), in this study, illustrated news refers more narrowly to a form of news that uses images as its primary mode of representation. ${ }^{4}$

This focus in the research design is based on the assumption that in nineteenth century commercial newspapers, visual representations reached more readers than written ones, an argument Martin (2006) makes in her empirical case study of nineteenth century illustrated periodicals (p. 8). ${ }^{5}$ Although her object of study is a different type of periodical (weekly, rather than daily), issued on more than one continent (Europe and North America), and covering an event of an altogether different nature (a war rather than a gold rush), it served as a guide and a springboard for reflection on issues of visual rhetoric in relation to the nineteenth century illustrated press. Furthermore, it stood out as the only major work on illustrated news that looks at several publications to examine the news coverage of a single event using a case study approach set in a limited time frame. As a similar work, this Master's thesis therefore makes an important contribution to the field of illustrated news by enlarging the body of extant works in this type of research.

One of the few works that exists specifically on the subject of the news coverage of the Klondike gold rush investigates a theoretical concept related to the nationalist rhetoric of news images in the context of this event. Arenson's (2007) empirical study of

\footnotetext{
4 This definition is not inconsistent with Martın's (2006) in Images at War. Illustrated Perlodicals and Constructed Nations (Toronto. University of Toronto Press) She defines the illustrated press as a press "which establishes the priority of the image over the text and which is produced according to the market laws of profit and competition, since a paper is first and foremost a commodity that must be profitable to the shareholders" (p. 7)

5 Although Martın's (2006) empirical analysıs of weeklies predates this case study, an argument can be made that this assumption could be legitımately applied to dailies in 1897 despite the fact that the level of literacy was generally higher in North America 27 years later
} 
Dawson City daily newspaper articles and images from 1898 to 1901 aims to expose the ideology of Anglo-Saxonism and the narrative of the "two Wests" that prevailed in some media at the turn of the nineteenth to the twentieth century. ${ }^{6}$ Given that, on the face of it, the empirical data collected for this case study seemed to support Arenson's argument, one of the objectives of this case study has been to test Arenson's claims by posing the question, "Is a rhetoric of Anglo-Saxonism manifest in the news images under study?"

Thus, this case study seeks to engage a conversation with this historian's work by applying the concepts of Anglo-Saxonism to its analysis of images in the context of the myth of nationhood. What is more, Arenson's (2007) study uses a discourse-historical analysis approach that inspired the use of this methodology in this Master's thesis. However, Arenson's study differs from this case study in a number of ways. First, it examines only photos and cartoons, rather than line engravings. Second, the dailies in Arenson's sampling frame were published more than a year after the first announcement was made, therefore in a period when the gold rush was already well under way. Third, they were published only in Dawson City, rather than in North America. This case study makes an original contribution to the fields of illustrated news as well to Klondike gold rush scholarship by examining early coverage of the event in the broader context of North America, outside the confines of Dawson City, and in a time period that Arenson identifies as critical when he writes, "newspapers played a prominent role in announcing

\footnotetext{
6 The "two Wests" is a concept developed by History scholars such as Paul Sabın. It suggests that there existed, beyond national and geographical borders, two Wests bound by a common ideology and expansionist drive. The first was the West as a North American frontier. The second was the Anglo-Saxon civilization whose boundary was "a shiftıng international frontier of economic, environmental, political, and cultural interaction" in Paul Sabin, (1997, August), Home and Abroad The Two 'Wests' of TwentiethCentury United States History, Pacıfic Historical Review 66 (3), pp 310-311.
} 
(some would say concocting) the Klondike gold rush. News syndicates sent men and women to cover events as they happened, with new technologies that made the rush one of the first real-time international news events" (p. 382).

Arenson (2007) and Newell (1986-97) were the only journal articles that were found to address the topic of news coverage of the Klondike gold rush. With the exception of Arenson, no extant works offer any study of news images published during the event, nor do any examine early news coverage specifically during the period of its outbreak. In contrast to Arenson, Newell does not study the subject of illustrated news, but she does specifically address the subject of news coverage of the Klondike gold rush from 1897 to 1898 from the perspective of the history of communication technology. In focusing on the nature of sources and information flows, Newell's article argues that the news coverage of the Klondike gold rush had a distinct American imprint. Her article provided a good starting point to engage in a reflection on where the news came from as well as how it circulated within the closed network of the market-based press. The news images in this case study's sampling frame showed, for instance, that different dailies reproduced some of the same images. This supports Newell's claim that most of the Klondike-related stories and photographs published in July 1897 in Canadian dailies were sourced directly from the Associated Press Service (p. 102).

A special issue of The Northern Review published in 1998 also contains several Klondike gold rush publicity-related articles that helped contextualize the event from an international perspective and also offered the critical perspective of historians, a century after the event (Burant, 1998; Coates, 1998; Coates \& Coates, 1998; J.F. Davis, 1998; Kuzmiak, 1998). In this issue, Burant presents an article on how this gold rush was 
photographed, offering interesting insights and commentaries on the mythical dimension of its visual representation. Several Klondike history photo essays were also examined in that light (Berton, 1983; Bolotin, 1980; Lyons, 1897; Morgan, 1973; Wilson, c. 1895).

Another important source on the subject of Klondike news coverage was the American government archival website dedicated to this topic and published as a historical resource in the public domain (Mighetto, 1998). This source proved extremely useful in identifying some of the dailies that were most active in publishing material during the outbreak of the news. Surprisingly, the Canadian government has published very little in comparison. Parks Canada ("National Historic Sites", 2009) and the RCMP ("Klondike Gold Rush", 2002) have a webpage or two on the Klondike; limited text copy and a few photos serve as the official Klondike National Historic Site for Canada. The CBC ("Klondike Gold Rush", 2001) also published a single webpage with the most salient details of the stampede. In terms of content, these Canadian public domain sources were, however, too general to be useful to this study.

Major historical works that address the broader subject of the Klondike gold rush as an event include Adney (1974/1899), a first-hand, day-by-day account by Harper Weekly's correspondent on assignment in 1897; Winslow (1951), which largely relies on testimonials; and Berton (1972) which offers the most in-depth and classic historical account of this event from beginning to end. Because Berton's work covers a great deal of ground on the subject of the Klondike gold rush, it provided valuable information on the general context in which the Klondike stampede took place and helped supplement the information extracted from this case study's sampling frame (i.e. articles). 
There are many other works that study the Klondike history in a narrower frame but most of these are unrelated to this case study. For instance, Morse (2003) has studied the environmental impact of the Klondike gold rush in the Yukon and Alaska. Such works have been altogether excluded from discussion. However, two scholarly works in this category have been included because they have proved most useful in deconstructing the visual rhetoric used in the news images of this case study's sampling frame. The first of these is Backhouse (1995), who has served to shed light on the role of women involved in the Klondike gold rush. The second is Porsild (1998), who used quantitative and qualitative sources to show the social stratification that developed early on amongst Klondike stampeders in Dawson City. Her study has been instrumental in demonstrating that early Klondike-related news images did not reflect the great diversity of Klondike stampeders in terms of race, gender, and class.

This Master's thesis will consequently have a strong body of literature to draw from while also making an original contribution by complementing and bridging some of the gaps in the domain of illustrated news, as well as in that of Klondike history, specifically on the subject of the news coverage of the Klondike gold rush.

To introduce ideas that will help cast some light on how news images published at the outbreak of the Klondike gold rush may have influenced the public's perception of this event in the context of the myth of nationhood, Chapter One describes theories that help problematize this issue. Links between news and myth are then outlined to reveal the foundations of this case study's broad theoretical approach, followed by a discussion on the relationship between illustrated news and nationalist rhetoric. The chapter ends with a description of the conceptual framework used in the analysis of the empirical data. 
Chapter Two offers a detailed description of the research methodology used to collect and analyze this empirical data.

To elaborate on this case study's assumption that news images are part fact and part fiction, Chapter Three initiates a discussion that questions the relationship between fact and fiction in modern news by comparing the genre to other forms of factual narratives throughout history. The metaphor of weaving is used to introduce a way of thinking about this relationship in terms of contemporary approaches to modern newsdiscourse that offer a ritual view of communication.

Chapter Four describes the market-based press in the nineteenth century, and more specifically the paradigms of journalism that existed during the Klondike gold rush. It introduces key ideas about the nature of news images in daily newspapers in this era.

Chapter Five describes key elements of the socio-economic context of the Klondike gold rush, focusing on two historically rooted factors that could have contributed to shaping the mythical aspect of this event in the media: frontier processes and the efficiency with which the market-based press produced massive audiences that participated in this news event by simply reading accounts of it on a daily basis.

To uncover the visual strategies that were used to foster myths of nationhood in illustrated daily news, Chapters Six, Seven, and Eight respectively look at the visual representation of categories of race, gender, and class in news images; the logoization of political space through the reproduction of topographical maps; and the creation of historical narratives through the visual representation of patrimonial icons whose discursive value is symbolic (i.e. ships, $\log$ cabins, institutions, flags, etc.). 


\section{CHAPTER ONE - THEORETICAL APPROACH}

This case study constitutes exploratory research, descriptive in nature with the principle objective of exploring some of the possible roles that fiction serves in news in the context of the myth of nationhood. The theoretical approach used in this case study concomitantly emerged from two sources: the empirical data and theoretical works studied over the past few years. The latter constitute a vast array of interdisciplinary sources that have been integrated in an attempt to describe the multiple dimensions of the data in isolation and in its socio-political context. This chapter gives an overview of the theories and concepts used to explain the news images under study, including a brief literature review of the research domains that different theories were drawn from.

\section{Myth and news as narrative forms}

A picture is worth a thousand words. But is it real? Is it true? Is it a fact? Or is it a fiction? A picture is not reality. It is a representation of reality. Like words, it is a text.

Journalism consists of the practice of documenting events to represent them as news. Pictures and words are the journalist's stock-in-trade, but their reach is limited to description, which inevitably falls short of the reality of an event. News, as the product of journalism, can only paint a portrait of an event that is incomplete and therefore inaccurate if we define accuracy as correctness and exactness in all details. News can never be true in the sense that it can never reveal the full extent of what happened. News is not true to life because it is a discourse, a meta-truth. News does not tell one side of a story. It is a story: the story of reality. As a description of reality, news must contain some degree of truth, and some degree of fabrication. Accordingly, the basic premise of 
this thesis is that news is a construction produced from a combination of factual and fictional elements.

Some scholars have used the concepts of fact and fiction to discuss news in terms of the information/story dichotomy, creating paradigms of journalism that oppose these two aspects of news (W.J. Campbell, 2006; Gans, 1979; Hughes, 1968; Schudson, 1978). Drawing such a distinction infers that news covers a spectrum of truth that ranges from an extreme of fact to an extreme of fiction, from true to untrue. More recent scholarship has shown growing interest in studying news as a narrative form that enmeshes fact and fiction, rather than setting them apart. Broadly speaking, this approach is often referred to as "news as storytelling" or "journalism as narrative". What is meant by this is simply that news is presented in the form of a narrative to describe real events, people, or places. According to O'Donnell (2003), this approach includes a wide range of theoretical paradigms that study news as myth (Bird \& Dardenne, 1997; Carey, 1987; Lule, 2001, 2002), as narrative strategies (Zelizer, 1990), as core plots (F. Davis, 1984; Kitch, 2002), as fairytale (Turner, 2000), as master narratives (Rosen 2003), as frames (Gitlin, 1980), as maps of meaning (Hall, 2000) and as ritual (Carey 1998, 2009), with myth being the most commonly used paradigm (O'Donnell, 2003, p. 13). More generally, however, since Barthes's (1957) Mythologies, it has not been unusual to refer to news-discourse as myth (Hartley, 1982; Knight \& Dean, 1982; Lule, 2005; Rutherford, 1982; R.R. Smith, 1979).

Although scholars find themselves at pains to formulate a satisfactory definition of myth, this thesis proposes a comprehensive definition of the concept that highlights its most essential meanings in both a classical and contemporary context: myth is a mutable narrative framed in a historical context that draws on some degree of fact to explain a 
natural or social phenomenon through the use of characters or events. Some journalism scholars who use a news-as-myth approach also include Eliade's (1960) concept of "exemplary patterns" or "exemplary models" (p. 31) in their definition to emphasize the recurring elements in myths and news stories (Coman, 2005; Lule, 2001, 2002;

O'Donnell, 2003). Although this does not seem essential to the definition of myth, it nevertheless has value in that it considers the repetition of certain structural elements as a rhetorical strategy of myth, a strategy arguably also used in news-discourse.

In such a definition the relationship between news and myth can appear manifold, but an important distinction must be made. In its popular meaning, the term myth connotes widely believed ideas that are untrue, while the term news does not (Lule, 2005, p. 102, 105). This does not mean that news creates true ideas or beliefs in the readers it reaches. It means that it remains to be established whether these ideas or beliefs are true or untrue. By association, using an approach that pairs myth and news not only implies the idea that news can be untrue, that it can be a fiction, it also actually suggests that news is untrue, that it is a fiction. A news-as-myth approach is therefore a mode of investigation that, perforce, calls into question the truth value of news-discourse.

This caveat must inform the definition of news if a news-as-myth approach is used. It has already been noted that news is a construction that is produced from a combination of factual and fictional elements. Formally speaking, news is a discourse allegedly rooted in fact and grounded in a historical context. Functionally speaking, at its most essential level, news simply gives information about recent events. Contextually speaking, in modern journalism, news is the commodified product of journalism practiced by the market-based press that emerged in the late nineteenth century. News 
can therefore be construed as a historical explanation, because it is, in a very basic sense, an account of events that have already happened.

Whether it is chronological or not, a historical explanation is always temporal. It can describe an event only in terms of the passage of time. For this reason, historical explanation must invariably take a narrative form (Ricœur, 1981, p. 276). Ricœur has noted that in many European languages the words history and narrative are etymologically related. In English, the word story is contained in the word history; in French the word histoire can mean either story or history; in German, the word Geschichte means both history and tale (p. 288). By defining historicity as "the fundamental and radical fact that we make history, that we are immersed in history, that we are historical beings" (p. 274), Ricœur has exposed its reciprocal relationship with narrativity. It should come as no surprise, then, that since Antiquity most disciplines that study records of events have been plagued with the problem of differentiating the real from the unreal. From the study of history to the practice of photography, disentangling fact from fiction has been an uncertain task.

With this in mind, an awareness of the interconnectedness of historicity and narrativity can, and should, guide the scholar in such inquiries. If historicity and narrativity cannot be separated, how can narrativity illuminate the study of history? Following Ricœur's (1981) prescriptive words, "what we must place at the center of the epistemological discussion is no longer the nature of historical explanation but its function [sic]" (p. 276). As a result, a news-as-myth approach should not be premised on the assumption that news is myth (Barthes, 1957; Goethals, 1993; Koch, 1990; Lule, 2001; Martin-Barbero, 1997; Real, 1996), but rather that some news has mythical 
qualities (Bird \& Dardenne, 1997; Breen \& Corcoran, 1982; Coman, 2003; Hoover, 1988; Lule, 2005; R.R. Smith, 1979). The purpose of news, then, can no longer merely be reduced to providing information about recent events, as was stated above. Instead of describing what news is, a news-as-myth approach can provide a better understanding of what news can do. A cursory overview of the major classical scholarship on myth offers valuable insights to begin this investigation.

Most approaches to the study of myth share the basic assumption that there is an important link between myth and society. This connection was first stated by Bronislaw Malinowksi. The anthropologist construed myths as "charters" whose practical purpose was to explain and confirm the existing facts of social beliefs, customs, and institutions in a given society (Morford \& Lenardon, 1999, p. 4). Influential scholars who later took a structuralist approach to the study of myth such as Walter Burkert, Vladimir Propp, Claude Levi-Strauss (pp. 9-12), and Roland Barthes (1957) studied how the structure of myths provide a framework for social adaptation or domination. Coming from a perspective of analytical psychology, Carl Jung was interested in how myths made use of recurring symbols (i.e. archetypes), which he argued revealed the underlying psychological structures common to all humankind (Morford \& Lenardon, 1999, p. 8). Finally, scholars of comparative mythology such as James George Frazer, Max Müller, and Joseph Campbell set out to show similarities between myths across cultures, suggesting, like Jung, the idea that some symbols and metaphors have a universal reach that connect people across time and space (pp. 2-14). Although most of these approaches tend to be more concerned with interpretation than with mythological thinking and telling, all of them underpin the importance of myth as social process. 
This process merits attention because it has existed since the dawn of civilization and many scholars believe it is still very much at work today in modern media. One of the leading scholars on this subject writes, "[news-as-myth] research traditions recognize that myth is essential to all societies. And they affirm that myth has taken modern form in the news" (Lule, 2002, p. 279). Such a perspective underscores the idea that news is a narrative form that feeds the imagination rather than a dry record of information that strives to be scientifically rational. Schudson (2002) has contended that a literary view of news could encourage more communication and political participation because it would reach beyond the Habermasian model of rationality (p. 484). It could be also argued that it would be more comprehensive because it would include rationality and imagination, reason and emotion, understanding and creativity. Following Bird and Dardenne's (1990) claim that the content of news is best understood and remembered when it is told as a story (p. 34), it could be argued by extension that news that self-consciously makes use of mythical narrative forms has a greater impact.

\section{The news-as-myth as approach}

Lule (2002) offers a literature review of authors who use a mythological approach to the study of news. Although it does not appear to be exhaustive, it identifies two broad theoretical traditions that he describes as structural-functional approaches because they focus on the important functions of news and myth in society (p. 279). The first tradition construes news and myth as socio-cultural forms (Campbell, C.P., 1995; Campbell, R., 1991; Carey, 1987, 2009; Pauly, 1987; Smith, R.R., 1979) while the second focuses on the political and ideological role of myth and news (Barthes, 1957; Breen \& Corcoran, 
1982; Hall, 1988; Hartley, 1982; Koch, T., 1990; Tuchman, 1981). In both these traditions, news and myth are social rituals.

This underscores the idea that the first important link between news and myth is that it has a social dimension. They are both forged in the act of communication. In cultures that relied on oral traditions, myths and news were communicated through speech (Stephens, 2007, p. 17). Print technologies made it possible to reach even larger publics spread out across space and time. Broadcast technologies opened up the social dimension of news and myth even further. Today, new media is forcing journalism to rethink the news genre. Although many scholars focus their analysis of news as the raw material of myth on broadcast television news (Breen \& Corcoran, 1982; Carey, 1987; Hoover, 1988; Silcock, 2002; Smith, R.R., 1979), elements of their approach can arguably be transposed to other eras and other mediums if news is construed as the product of journalism practiced by the market-based press that emerged in the nineteenth century. Hartley (1982) presents a news-as-myth paradigm that is useful to this study:

[Myths] are a product of the active generative process of language, formed and reformed according to the relations between social groups and forces. Thus one of the primary functions of the news in any medium is continuously to signify myths through the everyday detail of "newsworthy" events. (Hartley, 1982, pp. 28-29)

Hartley's (1982) quote highlights the second important link between news and myth: the active role that all social actors play in its production. To see news as the raw material of myth challenges old paradigms which have fallen out of fashion such as the hypodermic needle paradigm or models of communication in which journalists or audiences are seen as passive transmitters or receivers of information. Many contemporary approaches to the study of mass media not only take into account the role 
of all those involved in the production process, but the role of audiences as well, sometimes involving the audience as a labour force in itself when seen through the lens of Marxist theory (Smythe, 1977). In an altogether different tradition, Zelizer (1997) describes this active role of the audience as the humanistic view. He notes, "Rather than conceptualize power of one group over another, humanistic inquiry supports a view of power as also having ritual or communal dimensions" (pp. 24-25).

Of particular interest to this study is the constitutive model of communication that presents news as an interactive social ritual (Carey, 1998; Fish, 1989; Fiske \& Hartley, 2003). This seems the most consistent with the concept of myth. A myth cannot be broadcast because it brings together the past, the present and the emergent in a process that involves listening, speaking, repeating, adapting, and transforming. In such a perspective, audiences are not passive. They may be consumers of news but they participate in its making by the act of imagining it, interpreting it, and retelling it.

Cognitive science has found that the brain reacts exactly the same way to an imagined situation than to one experienced in reality (Goleman, 2006, p. 20). This implies that more often than not no distinction is made between the real and the unreal in what motivates one's thoughts and actions. Or to put in in the words of American sociologist W. I. Thomas (1929), "If men define situations as real, they are real in their consequences" (p. 572). By this, Thomas means that whether something is real or not, one's imagining of it as real creates one's sense of reality. This in turn results in a course of thoughts and actions that have real consequences. Such a process is how collective imaginings can shape reality. It also illustrates a way in which the line between the imagined and the real is easily breached. It is thus not paradoxical to suggest that fiction 
informs the making of reality, not only in terms of consciousness, but also in how consciousness results in choices and action that become grounded in reality.

This elicits the third link between news and myth: it takes the form of a narrative that simplifies and dramatizes elements of reality. All narrative forms use culturally constructed codes of storytelling. Familiarity with these structures is as essential to effective communication as with the alphabet or grammar of a language. Bird \& Dardenne (1997) argue that even so-called factual reports such as the chronicle or the inverted pyramid form use a form of narration that operates within specific codes which have come to be culturally perceived as "objective". In this perspective, the distinction some scholars make between "information journalism" and "story journalism" is understood as a convention (p. 340). The imagined dichotomy between factual news and dramatized news is an approach that has been used to delineate the two ends of a spectrum that emerged in journalism in the late nineteenth century market-based press: information journalism vs. story journalism (Campbell, 2006; Schiller, 1981; Schudson, 1978). In this case study, these paradigms have proved useful in the selection of a sampling frame. For instance, The San Francisco Examiner that is included in the sampling frame is at the story journalism end of this spectrum while The New York Times is at the other extreme, the information journalism end. However, like Bird \& Dardenne (1997), this case study espouses the broader view that these are genres used in the telling of news (p. 340). In reality, there is a greater diversity of narrative forms and literary styles in news that lie between the two ends of this spectrum.

This idea that there can be a taxonomy of narrative forms in news evokes a fourth link between news and myth, namely their intertextual nature. Kristeva's (1970) concept 
of intertextuality speaks to the relationship between the constructed nature of a text and its temporality. According to her, intertextuality is "the sum of knowledge that makes it possible for texts to have meaning" (Culler, 2001, p.114). What this means is that the reader's appreciation of a text is directly related to the body of knowledge acquired from prior texts. It also means that texts are constructed according to (or if they break convention, in contrast to), rules that have been previously established by other texts. These rules are broadly referred to as symbolic systems and sometimes more narrowly as codes of knowledge or codes of meaning. Similarly, each narrative form, that is to say, each genre, has recurring patterns that point to how a story is told rather than what is told in a story. The inverted pyramid structure of print news which Schudson (2005) calls the "standard journalistic literary matrix" (p. 124) is an example of this. The same can be said of myth. Myths are not only known by their characters and plots, but also as a narrative form that uses specific conventions.

As a methodological tool, intertextuality is a concept applied to interpretation (the reader), rather than to production (the author). Kristeva (1970) organized the relationship between the reader, the author, and the text by describing them as different dimensions of the discursive space. This space is defined by a horizontal axis which links the author to the reader and a vertical axis which links the text to the texts that preceded it (pp. 86-87). The intersection of these two axes constitutes the text itself. Kristeva proposes that a text

\footnotetext{
7 "Ces trois dımensions sont le sujet de l'écriture, le destınataire et les textes extérieurs (trois éléments en dialogue) Le statut de l'énoncé se définıt alors (a) HORIZONTALEMENT · l'énoncé dans le texte appartıent à la fors au sujet de l'écriture et au destınatarre, et (b) VERTICALEMENT l'énoncé dans le texte est orienté vers le corpus littéraire antérieur ou synchronıque" in Julı Kristeva (1970) Le texte du roman, approche sémiologıque d'une structure discursıve transformattonnelle (The Hague, Mouton), pp 86-87
} 
is to be understood as a mere point on these two axes, a mere point in a larger discursive space (p. 87). ${ }^{8}$ Thus, Kristeva's concept of the discursive space not only takes into account a given text or cultural form but also its context, its origin, and its possible influences. The concept of intertextuality has proven paramount in selecting methodological tools for the analysis of news images in this case study because it stresses the importance of using a frame of reference that exists beyond the text itself; both the image as unit and its social context are considered.

The discursive space in which a text exists as a mere point is to be construed as a spatio-temporal structure. Kristeva (1970) was concerned with the role of time in narrative forms because temporality places emphasis on process. Zelizer's (1997) notes that "narrative helps us explain journalism by stressing elements that are formulaic, patterned, finite, yet mutable over time" (p. 26). This points to two opposing temporal characteristics of narrative form that dialectically work together: order and mutability. Order is made possible by the symbolic system that circumscribes communication. In news and myth, a visible order of signs is created to "help construct our view of the world, by allowing us to share stories within culturally and socially explicit codes of

\footnotetext{
8 "Mais dans l'univers discursif du livre, le destınatarre est inclus unıquement en tant que discours lu1même Il fusionne donc avec cet autre discours (cet autre livre) par rapport auquel l'écrivain écrit son propre texte, de sorte que l'axe horizontal (sujet-destınatare) et l'axe vertical (texte/contexte) coincident pour dévoıler un fait majeur l'énoncé (le texte) est un croisement d'énoncés (de textes) où on lit au moins un autre énoncé (texte) Aınsı le statut de l'énoncé comme unıté mınıma s'avère être le médıateur quı relıe le modèle structural à l'environnement culturel (histonque), de même que le régulateur de la mutation de la diachronıe (de l'hıstoire) en synchronie (en structure hittéraire) Par la notion même du statut, l'énoncé est mis en espace, 1 fonctionne dans trois dimensions (sujet/destınatarre/contexte) comme un ensemble d'éléments sémıques en DIALOGUE, ou comme un ensemble d'éléments AMBIVALENTS" in Julia Kristeva (1970) Le texte du roman, approche sémiologique d'une structure discursive transformationnelle (The Hague, Mouton), pp 87.
} 
meaning" (p. 26). Whenever the story is retold, however, this order is altered, even ever so slightly, but the codes with which it is produced appear to remain stable.

It is important to understand that in practice, this stability is an illusion. Narrative forms are symbolic systems that also change over time, but at a pace that is so much slower that they appear stable in comparison to the speed at which details of a given narrative can change. However, for the sake of this discussion, we can describe them as enduring. An intertextual approach that draws a parallel between news and myth as similar, stable narrative forms seems well suited to the study of the news coverage of the Klondike gold rush because it can account for the structuration of the myth of nationhood in news form by comparing images that reinforce the myth with images that discredit it. But the intertextual approach invites reflection on still another important phenomenon. Because it draws attention to narrative form as well as to the details of a narrative, it raises an important set of questions related to the set of rules that define how the story is told rather than what is told in the story. Rules are laid out to fulfill a purpose, to give a direction.

Thus the fifth link between news and myth is their common purpose. What can the narrative form in news and myth do? Bird \& Dardenne (1997) argue that when considered as a narrative form, news "teaches" its readers, not about "facts," "names," "figures," and "details" but about the existence and prevalence of the symbolic system in which they live (p. 335). Broadly speaking, Geertz (1973) describes symbolic systems as models of and models for culture (p. 93). This case study however, makes the argument that one of the primary purposes of news and myth as symbolic systems is not to provide models of and for culture, but to signify that order has been created to organize social life. 
This order is found in symbolic systems and their sub-systems: units of texts. In this case study, the units of texts under investigation are primarily news images, which make illustrated news its principal research domain.

\section{Illustrated news and the discursive construction of national identity}

As an area of study, illustrated news in the nineteenth century comprises a surprisingly narrow body of literature and remains relatively unexplored. One category of journal articles discusses the use of very specific instances of images published in nineteenth-century illustrated periodicals as a springboard, or evidence, to explore a narrow historical topic (Arenson, 2007; Diffley, 2006; Dowling, 1999; Kuhn, 2006; Patterson, 2009), but the majority of journal articles by authors who have contributed more than a single piece on illustrated news are generally studies that have led to major works (Bacot, 2001 mai/juin \& novembre/décembre; Brown, 1996; Martin, 2003; Sinnema, 1995) or derived from them (Martin, 2009). Such books either cast a wide net in describing and classifying the general history of the illustrated press in several countries of the western world (Bacot, 2005) or in specific countries such as England (P.J. Anderson, P.J.; Jackson, 1969), France (Watelet, 1999) or America (Brown, 2002), Or else, they tend to focus on a specific newspaper to describe its emergence and impact (Aurenche, 2002: Sinnema, 1998) or its role as the repository of a broader social history (Bishop, 1977; Hibbert, 1975). Although Hogarth (1972) explores the visual representation of a specific theme in one of his works (i.e. the old West), Martin (2006) is the only major work that uses a case study approach to examine the illustrated news coverage of an isolated historical event. 
Martin's (2006) work looks at an international war from an international perspective by comparing illustrated weeklies from different countries. The Northern Review has devoted a whole volume to the importance of putting the Klondike gold rush in an international context, since it was, after all, an international event (Coates, 1998; Coates \& Coates, 1998; J.F. Davis, 1998; Kuzmiak, 1998). During the preliminary investigation of daily newspapers performed for this study in September 2010, a clear pattern emerged around the themes of boundary disputes and territorial rights in Klondike-related news articles and images. These themes were especially manifest in the recurrence of engraved maps that visually rendered the international boundary line between Canada and the United States in significantly different ways, as well as in the large number of articles and caricatures on this subject. Such evidence in the empirical data supports the idea that in 1897 , the Klondike gold rush was an event of international scope that commanded international attention. To underscore this, the research design of this case study has borrowed from Martin's (2006) methodology by comparing news images from different nation-states, namely Canada and the United States.

These findings in the empirical data also speak to the myths of the nineteenth century. Epochs have their public myths, and places have their public myths, too, for public myths are collectively forged in the contingencies of time and space. The abundance of scholarship on the emergence of nationalism suggests that nationhood has been one of the dominant public myths since the nineteenth century. While the myth of nationhood persisted throughout much of the twentieth century, today it competes with, and nurtures, the twenty-first century cosmopolitan myth of globalization. Given that the Klondike gold rush was an international event that converged onto a North American 
frontier where myths of nationhood were still in the making in the nineteenth century, it seems appropriate to adopt a framework for this case study designed around the analysis of this particular public myth, especially as the data foregrounds the idea of national boundaries. What is meant by myth of nationhood is simply a type of public myth constructed around the concept of national identity in the interest of the ideology of nationalism. The meaning of the word ideology here is not to be reduced to theoretical questions of politics and power. Instead, it draws on Martin's (1997) definition of ideology as being "a system of ideas, principles and mental representations that serve to guide a set of social practices" (p. 67) to designate more broadly the epistemological foundations of political, economic, social, and cultural phenomena.

A.D. Smith (1999) has classified the literature on nationalism in four categories: primordialist, perennialist, ethno-symbolic, and modernist (p. 3). Spearheaded by the works of Nairn (1977), Gellner (1983), and Hobsbawm (1992), the last of these four paradigms is currently considered to be the dominant one (A.D. Smith, 1999, p. 6). In the modernist approach, nationalism is construed as a by-product of modernity and its institutions, with the French Revolution markings its beginnings (p. 6). An offshoot of the modernist approach is B. Anderson's (1991) Imagined Communities (A.D. Smith, 1999, p. 6) in which nationalism, nationality, and nation-ness are construed as cultural artefacts that were slowly created over an extended period of time, beginning around the end of the eighteenth century (p. 4). Given that this case study is primarily concerned with deconstructing the meaning of news images to understand the function and possible applications of public myths, B. Anderson's (1991) approach seemed the most relevant as it places strong emphasis on the relationship between media texts and collective 
imaginings. For this reason, the overarching theoretical framework applied to this study has drawn largely on B. Anderson's (1991) approach to nationalism.

Because it foregrounds processes of "imagining" and "creating", it could be argued that B. Anderson's (1991) discussion of nationalism places the emphasis on ontology over epistemology (pp. 5-7). Following his lead and Martin's (1997) definition of ideology as stated above, this case study construes the concept of nationalism anthropologically rather than politically (B. Anderson's, 1991, p. 5). A nation is perceived to be an ontological process that reflects a set of social practices. It is understood as "an imagined political community... as both inherently limited and sovereign" (p. 6). Nationhood is simply the sense of identity that results from this.

Although these definitions suggest personal cognitive processes, it is important to understand that they are not disassociated from social processes. In relation to studies on nationalism or news reports, Van Dijk (2003) has paved the way in critically theorizing cognition in relation to social structures and discursive practices. This directly relates to one of B. Anderson's main arguments, namely that "not just any language per say...but the written language invented nationalism [sic]" (Wodak, de Cillia, Reisigl, \& Liebhart, 2009, p. 22). B. Anderson's theoretical framework is therefore similar to Van Dijk's triadic model of critical discourse analysis because it conceives recorded text as the repository of the cultural artefacts of nationalism, nationality, and nation-ness. This underscores the discursive aspect of nationalism and the way in which print media fulfills an epistemological function in processes of nation-building. 
It is therefore interesting to note that existing works on illustrated news often identify nationalism and nationhood as recurring themes in the nineteenth century illustrated press (Arenson, 2007; Bacot, 2001, 2005; Brown, 2002; Diffley, 2007; Dowling, 1999; Martin, 2003, 2006; Sinnema, 1995, 1998). Given that the nineteenth century was the era of nation-state construction (Wodak, de Cillia, Reisigl, \& Liebhart, 2009 , p. 18), it seems almost a given that themes dealing with national identity would emerge in news periodicals published in that era, just as one would expect religious themes to be present in Early Christian or Renaissance art. Martin's (2006) study is a case in point. As a work on the political economy of media, it investigates the industrial production of illustrated news in the nineteenth century (p. 6). However, her empirical analysis is predicated on the theme of nationalism. She sets out to prove that the nineteenth century illustrated press served a political agenda by circulating content that played up nationalistic rhetoric rather than content that was merely entertaining (pp. 7-8). To do so, she uses an international and interdisciplinary approach to compare the illustrated news coverage published in weekly newspapers from England, France, Germany, Italy, Canada and the United States during the Franco-Prussian war in 1870-71 (p. 7). Similarly, some of the literature on illustrated news in the nineteenth century provides a number of useful insights and references in the role that nineteenth century news images played in the discursive construction of national identity. However, this case study departs from the methodology used in those works in a number of ways.

First, there is a significant difference between the usual corpus used by scholars and the one chosen for this case study. For the most part, scholarly works published on the subject of illustrated news in the nineteenth century focus on weekly publications, not 
dailies. ${ }^{9}$ This is largely due to the fact that from about 1865 to the mid-1880s, news images were made from wood engravings that were time consuming to produce (Brown, 2002, p. 235). It took many years to perfect a system of production that would accommodate the fast production rate of dailies, and each newspaper made this transition at its own pace in accordance with its resources and priorities (Williams, 2002, p. 8).

Until the late 1890s, few dailies could have been described as forming a corpus of "illustrated news" proper. It is therefore not surprising that comparative studies of illustrated news in that era took weeklies or monthlies as their object of study. This case study will attempt to bridge this gap by focusing exclusively on dailies, making an original contribution to research in the domain of illustrated news by studying this particular type of news periodical in the late nineteenth century

A second point of distinction between this case study and a large part of the existing literature on illustrated news in the nineteenth century is that it is concerned with the coverage of an event (Arenson, 2007; Diffley, 2007; Kuhn, 2006; Martin, 2003, 2006) rather than investigating a theme (Hogart, 1972), an idea (P.J. Anderson, 1991; Bacot, 2001 mai-juin; Bishop, 1977; Dowling, 1999; Hogarth, 1967; Patterson, 2009; Sinnema, 1995, 1998), or the medium itself (Aurenche, 2002; Bacot, 2001, novembre-décembre; Bacot, 2005; Brown, 2002; Jackson, 1969; Watelet, 1999). Recorded events are phenomena that have actually occurred. As such, they are historical explanations that take a narrative form (Ricœur, 1981, p. 274). One can surmise that the coverage of an event must therefore contain some degree of fact and some degree of fiction. Studying the

\footnotetext{
9 With the exception of Arenson (2007), as well as Brown (2002) who included the New York Daily Graphic in his analysis.
} 
coverage of an event lends itself to a richer discussion in the context of this thesis since 1ts aim is to probe questions related to the relationship between facts and fiction in news.

Third, this case study addresses a very specific methodological problem in works concerned with the discursive construction of national identity, namely the pervasive use of the concept of collective memory in many of these analyses. Bell (2003) argues that this has resulted in substantial confusion in this field of study. The reason for this is semantic. The author points out that collective memory is activated through a process of social interaction between individuals who experienced an event at which they were present. He writes, "[collective] memory is thus anchored in common experience [italics added]" (p. 65). For this reason, Bell suggests that when a study sets out to analyze data that narrates and represents an event, it is more appropriate to conceptualize the discursive construction of national identity as a process of myth-making rather than one of remembering. For how can readers remember an event that they did not personally, let alone collectively, experience? Bell (2003) aptly remarks that in B. Anderson's (1991) approach that base their analysis on verbal or visual text widely disseminated through mass media, representation, rather than memory, is the constitutive feature of national identity formation processes (p. 69). Yet many of these works use the concept of collective memory. This can lead to ambiguity because memory is an action grounded in experience: the act of remembering "having been there". ${ }^{10}$ The result is that the concept

10 The use of the phrase "having been there" is not to be confused with Barthes's (1977) idea that all photographs connote an awareness of someone or something "having-been-there" (p 45) His use of this expression does not imply that the viewer was in the settung that was photographed Rather, it specifically alludes to the belief that the subject in the image, whether it is the viewer or not, was there when the photograph was taken In short, having-been-there in Barthes's work designates an object of spectatorship, while in the context of this discussion on collective memory, it refers to being the subject of expenience 
of collective memory applied to representation is often used out of context. Bell (2003) suggests replacing it with the term collective remembrance to describe the process of sharing the memory of an event that has been personally experienced in the past (p. 65).

However, when what is remembered is a text that represents an event, rather than the event itself, for the purpose of analysis, it seems more accurate to use the word imaginings, as does B. Anderson (1991). If this imagining is shared by many, then we can simply talk about collective imaginings, rather than collective memory. Memory does not lie in representation. It is in the mind of the beholder. Representation can trigger memory for one who was there, but it can only capture the imagination of one who was not. This underscores the critical difference between the experience of a real event and of an imagined one. One who reads about an event in the newspaper without directly taking part in this event is imagining this event, not remembering it. When these imaginings are shared by a large number of people who do not experience this event first hand, we are in the process of myth-making. The larger the public, the greater the reach of the myth. How then is one to understand myth-making in relation to news images?

\section{Conceptual framework}

From a cognitive perspective, myth and news, like other narrative forms, call upon the faculty of imagination. Coman (2005) writes, "myth and news are products of the same processes - logical and narrative - common to human techniques of taking possession of and signifying the real world" (p. 115). A cognitive approach to the symbolic aspects of narrative forms in the media is not uncommon in the current scholarship (Allen, 2005; Bird \& Dardenne, 1997; Coman, 2005; Rothenbuhler, 2005) 
with some authors drawing on important works in hermeneutics, structuralism, anthropology, and phenomenology (Bachelard, 1994; Dilthey, 1976; Geertz, 1973; LévisStrauss, 1976; Ricœur, 1981) to analyze symbolic patterns as " reflections, if not expressions, of communicative and cognitive structures" (Rothenbuhler, 2005, p. 177).

Of particular interest is Bachelard's (1994) discussion of the relationship between imagination and memory as individual, cognitive experiences. It may help clarify the confusion that often arises between these two cognitive processes as remarked above. According to him, "All memory has to be re-imagined. For we have in our memories micro-films that can only be read if they are lighted by the bright light of imagination" (p. 175). Following this reasoning, imagining is either at the root of thinking, remembering, and creating, or else all are inextricably connected, as Bachelard (1994) suggests when he writes, "dreams, thoughts and memories weave a single fabric" (p. 175). Whatever the case may be, it seems indisputable that the "bright light of imagination" is paramount to the production and consumption of myth and news. This is a position that Dayan (2005) refers to as the "paradigm of imagination" in media studies that emphasizes "the importance of the cognitive instruments that allow us to conceive the society in which we live, to build images of this society. Such images are crucial to political action, historical projects, and the very experience of belonging" (p. 172).

It is on such images that the lens of this case study places its focus. Given that the root of the word imagination is "image", considered in its etymological meaning, it 
signifies a mental process contingent on visual impressions (Guénon, 1984, p.42n3). ${ }^{11}$

When Dayan (2005) argues that for B. Anderson, imagining begins with the process of "prefiguration", he means that it is a mental process whereby one "generates an image of', for instance, an imaginary community (p. 172-173). If B. Anderson's (1991) principal argument is that a nation is imagined, what is the image of a given nation? Where is this image found? How does it take a visual form in one's mind? What defines this visual form?

Answering such questions requires an empirical approach that takes into account the visual aspect of imagination. For this reason, the study of news images, rather than written news, seems more congruent with a methodology that places imagination at the center of an investigation of the mythic functions of news, especially in relation to the myth of nationhood. For a nation has a face. It looks like somethıng. Both written news and news images may appeal to the imagination and its visual processes, but as Barthes (1957) pointed out, images have a more immediate and powerful impact (p. 195). ${ }^{12}$

This is an idea supported by findings in cognitive science: Although both visual and verbal signals are processed in the neo-cortex, part of a visual signal is instantly diverted to the amygdala where it triggers an emotional reaction before the visual cortex or the language areas of the brain have even begun analyzing these signals (Goleman,

\footnotetext{
11 "Le mot "imagıné" doit être entendu ıcı dans son sens le plus exact, puisque c'est bien d'une formation d'images qu'ıl s'agıt essentiellement » in René Guénon, (1984/1932) Les états multıples de l'être (4 ${ }^{1 e m e}$ éd ) Parıs Édıtıons Guy Trédanıel Véga, p 42.

12 « l'ımage est, certes, plus impératıve que l'écriture, elle impose la sıgnıficatıon d'un coup, sans l'analyser, sans la disperser » in Roland Barthes (1957) Mythologıes (Parıs, Édıtıons du Seuıl), p 195.
} 
1995, p. 19). ${ }^{13}$ This involuntary emotional reaction to visual information speaks volumes on the importance of adopting an approach that considers both emotions and reason in the interpretation of news images. Using a news-as-myth approach steeped in the paradigm of imagination tradition has the advantage of factoring them both, because myth does not place reason over passion. Myths appeal to reason, emotions, creativity, and imagination; it call upon all the faculties of the mind. Who is to say that news should not?

This case study takes the position and makes the assumption that the mind is the primary means of production of human experience. This is not to say that it is the only means, but certainly it is considered here to be the dominant one. Such an argument is obverse to a technologically determinist one. What is being argued is that different human experiences of space and time are not a priori technology-driven or technologydependent. They are ontological. It is a process that, for the sake of simplicity and metaphor, could be described as the movement of the mind. But this process could also be described as being inasmuch as the experience of being is so intimately tied with consciousness. From a cognitive perspective, different modes of experience must be possible in the human brain for technology to have the faculty to expand or extend it. After all, communication technologies only mediate experiences. For this reason, in this

13 "A visual signal first goes from the retına to the thalamus, where it is translated into the language of the brain. Most of the message then goes to the visual cortex, where it is analyzed and assessed for meaning and appropriate response, if that response is emotional, a signal goes to the amygdala to activate the emotional centers. But a smaller portion of the original signal goes straight from the thalamus to the amygdala in a quicker transmission, allowing a faster (though less precise) response. Thus the amygdala can trigger an emotional response before the cortical centers have fully understood what is happening" in Daniel Goleman, (1995) Emotional intellıgence (New York Bantam Books), p 19 
case study, media technologies are construed as technologies of imagination, to borrow the expression from Dayan (2005, p. 173)

It is because print is a technology of imagination that news can foster shared imaginings such as myths. But this does not answer the question: how are imaginings shared? Or to put the question in hermeneutical terms, how are they coded? Specifically, in the case of illustrated news, what visual strategies are used to foster myths of nationhood?

Approaches that foreground the deconstruction of media text seek to uncover the underlying structures of consciousness: the structures of the imagining mind. And here it is necessary to ask, what defines these structures? This case study adopts the view that the structures of text, of consciousness, and of the imagination are all defined by boundaries. A boundary is a separation that sets the limits of something. Thinking about what a boundary does can help develop this definition. A boundary demarcates what something is and what it is not. It defines the nature of a concept by circumscribing it. Although it is true that the term boundary prosaically evokes the one-dimensional idea of a line, in relation to multi-dimensional concepts such as nationhood, it is more useful to create a sister concept that captures this complexity. In this case study, the term boundaries will be used to designate a matrix of lines that forms the single, paradigmatic entity that defines a concept, and that structures what it is and what it is not. In this case study, the word mapping is used to describe the process of constructing such a matrix.

B. Anderson (1991) argues that a common print-language was necessary to unite reading publics into imagined "national" communities (p. 134). This case study makes 
the argument that it is the mapping of boundaries that structured the imagined communities of nations. In fact, this idea is consistent with an argument that B. Anderson (1991) himself makes when he discusses how censuses, maps, and museums were the grammar deployed by colonial states to construct and reinforce nationalist ideologies in the nineteenth century (p. 163). What these three elements of grammar all have in common is that they define reifying boundaries: the census uses categories such as race, class, and gender to define what this case study calls social boundaries; the maps use graphic lines of demarcations to define spatial boundaries; and what B. Anderson (1991) calls the museum (which this case study defines more broadly as the repository of a grand narrative of history) circumscribes the temporal boundaries that represents a nation's history in the form of constructed patrimony. 


\section{CHAPTER TWO - RESEARCH METHODOLOGY}

Reality is complex. It cannot be reduced to a few concepts. Conversely, empirical research must maintain a focus. A research methodology is therefore always a compromise between trying to capture multiple perspectives and finding a simple way of expounding them. This case study is a case in point. More than 353 news images were examined and collected during the data collection phase. Organizing this large sampling frame and choosing methodological tools suited to the content inherent in the news images and the context they were published in required careful consideration. This chapter describes in detail how this was accomplished.

\section{Research design}

Wodak's (2002) set of ten programmatic claims for critical discourse analysis (pp. 14-15) reproduced in Appendix A provides the general framework for the research design of this case study, because it is especially suited to studies that investigate the influence of the discursive construction of national identity on social structuration and stratification (Wodak, Cillia, Reisigl \& Liebhart, 2009).

Wodak (2002) recommends a problem-oriented approach that is concerned with social issues rather than isolated linguistic units; she names themes such as "racism, identity, social change" as examples (p.14: item 2). This is the orientation taken by this empirical case study, which analyzes the discursive aspects of nationhood in illustrated news and aims to explore the possible functions of fictional elements in news in the context of the myth of nationhood. 
Although the object of study is principally made up of a sampling frame of 353plus news images published in 14 Canadian and American daily newspapers in July 1897 (see Tables A1 and A2), the ultimate goal is to provide valid descriptive inference from the data observed and to open up new avenues of research for future investigation in this research domain, specifically in relation to the visual rhetoric of national identity in illustrated news. This is consistent with Wodak (2002), who states that "practice and application are aimed at...the goal of changing certain discursive and social practices" ( $\mathrm{p}$. 15: item 10).

Wodak (2002) points out that such "a problem-oriented approach entails the use and testing of middle-range theories", although grand theories may serve as a foundation (p. 15; item 9). In this case study, B. Anderson's (1991) paradigm of imagination constitutes the overarching theoretical framework, while middle-range theories are tested against the empirical data. Thus, the overarching theoretical framework is inspired by $\mathrm{B}$. Anderson's argument that collective imaginings are formed by the social, spatial, and temporal boundaries that are reified and reproduced in print media. However, middlerange theories are also being tested within this framework. Specifically, in relation to the discursive construction of national identity, Arenson's (2007) claim that the ideology of Anglo-Saxonism prevailed in the Canadian North West in the years of the Klondike gold rush is the underlying assumption used in the analysis of the news images. In relation to modern journalism practices and its ethics of factuality, Schudson's (1978) theory that two paradigms of journalism existed in the 1890s is also used to discuss the journalistic practices of the newspapers as sources for the news images under study. 
This Master's thesis takes its inspiration from both the social sciences and the humanities traditions. As Wodak (2002) recommends, it uses an interdisciplinary methodological approach with "theories [that] draw on neighboring disciplines" (p. 14: item 1) such as cognitive science findings and the scientific research methods of the social sciences. The result is a somewhat eclectic methodology (p.14: item 3) in which "categories and tools for the analysis are defined in accordance... with the specific

problem under investigation (p. 14; item 8) and "methodologies are ...adapted to the data under investigation" (p. 14; item 1).

\section{Methods of analysis}

The mixed methods research design of this case study combines a discoursehistorical analysis with a quantitative/qualitative content analysis, comparative analysis, and semiotic approach. Each of these methods are used in synergy with each other to tailor a bottom-up/top-down approach that takes into account the nature of the empirical data, rather than "fitting the data to illustrate a theory" (Wodak, 2002, p. 14: item 4).

News images are described in the historical background in which they are embedded. This is consistent with Wodak's (2002) claim that, in a discourse-historical approach, the interpretation should include, analyze, and integrate as much available information as possible on the historical context (p. 14: item 7). This not only implies making use of primary sources, but also of multiple secondary sources that are used to tease out the intertextual nature of discourse (p. 14: item 6). Many secondary sources were used in this case study but Berton's (1972) classic work, Klondike: The last great gold rush, 1896-1899, was the original impetus behind this research project. Elegantly 
literary and historical, his study relies largely on scholarly sources, archival documents, popular media, and especially, on newspaper articles published during the gold rush. It raises important questions around the relationship between fact and fiction in the coverage of a news event that has become a salient chapter of Canadian history.

Berton's vivid portrayal of the Klondike gold rush triggered an interest in studying Klondike-related images from popular culture. This in turn spurred personal reflections on the mythical dimension this event took as it was being covered in the news. As a result, this case study is the product of an abductive approach (Wodak, 2002, p. 14: item 5). Once news images were determined to be the unit of analysis, the theoretical framework and methodology were designed by constantly moving back and forth between theory and empirical data. For instance, in the early stages of research, a preliminary examination of daily, weekly, and monthly illustrated newspapers was performed at the Library of Congress. This first survey suggested possible orientations for the theoretical and analytical approach. The recurrence of certain themes and patterns in the content of the news images was manifest. Content analysis was therefore chosen as one of the methods of analysis to produce a quantitative and qualitative description of the symbolic content of the text (Wodak, 2002, p. 14-15: item 8).

Quantitative content analysis consisted of creating categories of news images such as representations of people, maps, ships, departure scenes, landscapes, portraits, and frontier cities, to name a few. The categories have been defined according to a single criterion: the frequent recurrence of a theme or motif across different dailies. The categories retained are those that yielded 8 or more recurrences. Table B shows the resulting taxonomy. The two last columns shaded in gray represent additional categories 
added to supplement the analysis, but they are excluded from the total count of images because they cross-reference categories that have already been counted. For instance, the news image that contains a "flag" in The Examiner is also classified in the category "frontier cities". Thus the columns are shaded in gray to avoid a double count of this news image.

Many of the news images could have been classified in more than one category. For instance, a departure scene on a dock with a large ship could be classified either in "departure and arrival scenes" or "ships". The visual nature of the news image determined which category it has been placed in. If the image is visually dominated by a ship, then it has been included in the "ships" category. If the image is dominated by a crowd of people, then it has been classified in "departure and arrival scenes". This is not only a matter of the space taken up in the image, but also a qualitative, thus subjective, evaluation of which visual theme dominated the image.

Where a small image was included in a larger one, the small image has been counted separately if it had been contained in a frame of its own. Compare, for instance, Figure 36, which is counted as four distinct images, to Figure 37, which is counted as a single one. There are several montages of news images in this case study's sampling frame. An example can be seen in Figure 17 or Figure 24. Again, if an image was contained in a frame, such as the small vignettes in circular frames of Figure 24, they have been counted and classified individually in the quantitative content analysis.

Most of the caricatures are political satires, but some are social satires. Since they self-consciously represent an editorial opinion and do not purport to be factual, they have 
been classified in a distinct category, as shown in Table B. They have been included in the analysis because as engravings often placed near more "objective" news images, they contribute to the visual representation of the event under study. Conversely, a category labelled "miscellaneous" was created to include images of bags of gold or bottles of gold dust. A "gold object" category could have been included, but since this category is not germane to the analysis, it has been placed in a nondescript category.

This case study uses a content-analysis method that is both quantitative and qualitative. Content analysis is a hybrid approach. Some scholars describe it as quantitative because it systematically counts and codes the content of text. Other scholars insist that it is a qualitative approach because the process of defining categories in which the manifest content is to be classified is subject to interpretation. In essence, it is around these categories that the arguments were first organized, which highlights the way in which an abductive approach has informed the research process.

The data were collected by saving electronic copies of the whole page on which each news image appeared. A printout of this newspaper page was then made. Electronic copies of the news images were useful in zoning in on details and cropping the images to visually isolate them for the content analysis stage. Qualitative content analysis was helpful in looking at each news image individually to attempt, on the one hand, a formal evaluation of the news image (i.e. framing, scale, shading, subject, etc.), and on the other hand, a rough interpretation of the latent content to do a first reading of the meaning underlying the themes that emerged most often. Its shortcoming as a research method was that it allows the examination of the news images only as isolated units, therefore out of context. This provided limited possibilities for descriptive inference. 
As a result, discourse analysis has been used in this case study predominantly to look at each news image as a unit of text in the context of its larger visual environment (i.e. the newspaper) with its own symbolic order, actualized by the experience of reading (Barnhurst \& Nerone, 2001; Chartier, 1994). The print copies of the whole page facilitated comparison between the 353-plus news images. This gives a sense of the context in which each news image was published, but it also allows intertextual links to be made with other elements on the page. For instance, some of the news images are discussed in relation to other news image placed on the same page or in relation to a news article. This method is necessary to deconstruct possible meanings in the news images. It follows Wodak's (2002) claim that a discourse-historical approach needs to use methods that contextualize the object of study in its environment (p. 14: item 4) and to take into account other texts in that environment or in closely related ones (p. 14: item 6).

Comparative analysis has been used to freely explore and underscore this approach. This could mean comparing or relating a news image to another news image, news headline, or news article from the same page or from the page of a different newspaper of this case study's sampling frame. It usually involved comparing news images drawn from Canadian dailies to American dailies or else to newspapers that rated differently on the relative index of sensationalism scale (see Tables $\mathrm{C} 1$ and $\mathrm{C} 2$ ). Comparative analysis was also extended to other genres: some news images were compared to Klondike-related archival photographs from 1897 or 1898 which were browsed from Klondike history books and websites during the initial research process. This has allowed the analyses to go beyond the narrow context of news images published in dailies by enlarging the frame of reference to include documentary images. This 
method has been used, in the main, to demonstrate the inaccuracy or the bias of the content of some of the news images in the context of the myth of nationhood. It follows Wodak's (2002) claim that discourse-historical analysis needs to be investigated in the context of "multiple genres and intertextual and interdiscursive relationships" so they can be recontextualized (p. 14: item 6).

In addition to these methods, Barthes's (1977) semiotic approach to the analysis of images is used to make a connection between news images and the written captions that describe these images or small portions of text juxtaposed with or placed near them (i.e. article, text box, etc.) to supplement the meaning of these images. Barthes's semiotic method triangulates between three levels of meaning: the visual rhetoric of the image, the denoted message of the image, and the denoted/connoted messages of the caption/text that relates to an image. According to Barthes, captions have either an "anchorage" or "relay" function in relation to the image (p. 38). In this case study, most of the captions have an anchorage function that is both denotative and connotative. Some of the analyses have included captions/text to draw attention to its connotative function(s).The purpose of this is to expose the rhetorical function of the news images as presented in the larger context of the newspaper and its bias. Once again, this methodological choice is guided by Wodak (2002), who argues that "tools for the analysis are defined with the specific problem under investigation... [which] entails some eclecticism, as well as pragmatism" (p. 14: item 8) and a regard for intertextuality and interdiscursivity (p. 14: item 6).

The cut-off date of the news images described in Table B is July $31^{\text {st }}, 1897$. A few of the news images that are discussed and compared in Chapters Six, Seven, and Eight are not part of the 353 news images used in the quantitative/qualitative content analysis 
shown in Table B. Figures $6,23,32,37,41,57,59$ and 60 were published in the newspapers of this case study's sampling frame in the week after July $31^{\text {st }}$, between August $1^{\text {st }}$ and August $4^{\text {th }}$. These news images were included in the analyses because they were representative of the ones used in the content analysis and they were used to support their analyses. Table B was intended to define a general taxonomy of early Klondikerelated news images, of which the early August 1897 images seemed a natural extension.

Finally, text-only articles were included in the data-collection process to cross reference and contextualize the news images and their caption. These articles were most useful in establishing the dates on which each newspaper first published Klondike-related news at the outbreak of the gold rush (see Table D).

\section{Selection of a type of illustrated news periodical for this case study}

Daily illustrated newspapers were selected as the corpus because one of the main objectives of this research is to study the coverage of the outbreak of an epic news event such as the Klondike gold rush. Placing the focus on daily coverage over a period of a couple of weeks has made it possible to draw from a rich diversity of newspapers while refining the theme of inquiry from the broad subject of storytelling in the news to the specific one of how a news event is first told in the early stage of its coverage. Being more specific, this phenomenon, yet unexplored in the context of the Klondike gold rush, may provide valuable information on the impact that early news coverage can have and thus how news-as-myth first takes shape.

Indeed, the way the news was covered in terms of visual content was significantly different in dailies than in weeklies and monthlies. First, dailies overwhelmingly 
presented process line engravings, while weeklies and monthlies presented a mix of engravings and photographs. Second, the images published in dailies seemed more "archetypal" in the sense that they presented clear patterns of themes that recurred frequently. This may have been due to the fact that nineteenth century dailies had to select their news images more carefully because they lacked the means to include in each issue as many images as weeklies and monthlies. In other words, stories had to be told with fewer news images of greater iconic value. This resulted in less diversity.

A third aspect that distinguished the dailies from the weeklies and monthlies was that coverage was much more uneven in the dailies. Weeklies and monthlies tended to stick to certain formats, telling news stories that seemed similar rather than exclusive. In contrast, there was much more variation in how the dailies covered the event in the first couple of weeks of the outbreak, perhaps because they were scrambling to gather information. Table D provides an example of this variation. It shows that the dates of publication of the first news article announcing the big gold strikes in the Klondike in each of the 14 newspapers of this case study's sampling frame was spread out quite evenly over five different days. Furthermore, Table D also shows that these newspapers published their first Klondike-related news images across a period of 15 different days.

Once it was decided that dailies were to be the object of study, this served as a guide to determine the temporal limits of the sampling frame. The first day a daily newspaper published an article on the discovery of gold in the Klondike was July 15, 1897 (see Table D). The last day a newspaper published its first Klondike-related news image was July 30,1897 , which is sixteen days after the first news image was published 
(see Table D). For this reason, it was established that the sampling frame should range from July $15^{\text {th }}$ to July $31^{\text {st }}$, which includes exactly 17 days, a period of roughly $2 \frac{1}{2}$ weeks.

At this point, only American dailies had been examined. Later in the fall, a preliminary survey of Canadian dailies in Montreal confirmed that Canadian newspapers also broke the news and published their first Klondike-related news image on different days. Moreover, the news images in Canadian newspapers offered some interesting contrasts to those published in American dailies. For instance, several news images dealt with issues of territorial rights, including maps that presented contrasting views on which country the Klondike gold fields belonged to at the time. This signalled the possibility of investigating the theme of nationhood by comparing American and Canadian dailies.

\section{Selection of daily newspapers for this case study}

The key factor in including a daily newspaper in the sampling frame was simply whether or not it contained Klondike-related news images between July $15^{\text {th }}$ and July $31^{\text {st }}, 1897$. Of the numerous newspapers surveyed, it was surprising to see how few published news images.

To select American newspapers, volume 7 of the Chronological Index of Newspapers for the period 1801-1967 in the collections of the Library of Congress was used to pre-select two to three dailies in the three different states that historical sources ${ }^{14}$

\footnotetext{
14 A good source to identıfy heightened commercial activity around the Klondike gold rush as well as the titles of newspapers cited as having published influential artıcles in the weeks that followed the first public announcement of the discovery of gold in the Klondike is Lisa Mighetto, Marcia Babcock Montgomery et al (1998, November). "Hard Drive to the Klondıke Promotıng Seattle Durıng the Gold Rush "National Historical Park. National Park Service of the U S Department of the Interior. Klondike Gold Rush Seattle Unıt. Retrieved April 9, 2010 from http //www nps gov/klse/historyculture/collections.htm
} 
had identified as being actively involved in the Klondike gold rush: California, Washington, and New York. In the state of California, The Herald in Los Angeles, the San Francisco Chronicle, and The Examiner in San Francisco were surveyed; in the state of Washington, the Spokane Review, the Tacoma Daily News, and the Seattle PostIntelligencer; and in the state of New York, the New York Tribune, the New York Sun, The New York Herald, and The New York Times. In that sample, and in decreasing order of importance, the newspapers that yielded the highest content of illustrated news relating to this event were The Examiner in San Francisco, the San Francisco Chronicle, the Seattle Post-Intelligencer, The New York Herald, The Herald in Los Angeles and The New York Times. Given the international scope of the Klondike gold rush and the salience of questions surrounding the international boundary line, The Washington Post was added to the sampling frame to include an important daily from the nation's capital. This amounted to seven American newspapers.

To select Canadian newspapers, titles of the more popular and heavily used newspapers in the nineteenth century were first identified with the help of general works on the history of journalism (Canadian Press Association, 1908; Lunn, 1941; Kesterton, 1984, Rutherford, 1975, 1982). Library and Archives Canada also has an online listing, arranged geographically by province and city, of all newspapers available on microform. By cross-referencing this list to the titles found in the works mentioned above, it was possible to identify a number of newspapers which, on the one hand, had sufficiently large circulations to justify inclusion in the sample of this study, and on the other hand, were worth investigating as potential sources of illustrated news. Canada was divided into four regions the Maritimes, Quebec, Ontario, Western Canada (comprising the 
Prairies and British Columbia). Two to four newspapers per region were then surveyed, focusing on issues published from July 15 to July 31,1897 . These included for the Maritimes, the Halifax Herald; for Quebec, La Presse in Montreal, The Gazette in Montreal, The Montreal Daily Star, Le Nouveau Monde in Montreal, and Le Soleil in Quebec; for Ontario, The Ottawa Free Press, the Ottawa Journal (the Evening Journal), The Toronto Star, The Toronto Globe, The Toronto World, and the Daily Mail and Empire in Toronto; for Western Canada, The Calgary Herald, The Winnipeg Free Press, The Winnipeg Daily Tribune, The Daily Nor'Wester in Winnipeg, The Victoria Times, The Vancouver News-Advertiser, and The Daily World in Vancouver. Newspapers that did not include images were eliminated. A total of nine dailies remained. As had been done with the American sampling frame, one daily from the nation's capital was selected; The Ottawa Free Press was accordingly retained because it was the only one that contained news images. The Winnipeg Daily Tribune was eliminated because it was the only newspaper of the sampling frame that contained photographs rather than engravings, which would have resulted in inconsistencies in the unit of analysis. The Daily World in Vancouver was also eliminated because it included only a single news image, namely a large map published on July 31,1897 . In the end, the seven Canadian dailies that contained the most images were retained.

This selection process yielded a sampling frame made up of fourteen daily newspapers. Table A1 offers a descriptive list of the seven Canadian daily newspapers and Table A2 offers a descriptive list of the seven American daily newspapers. These lists include information on location, the year the newspaper was founded, who had editorial control, subscription price, number of pages, circulation, ideology, and 
readership. These tables show that the fourteen newspapers selected for this case study's sampling frame offer sufficient diversity to represent a wide range of journalistic practices during the period under study. This has the advantage of presenting a wide range of ideologies, readerships, journalistic practices and geo-political regions. For instance, there are two newspapers from Quebec, four from Ontario, one from Western Canada, two from the state of New York, one from D.C., one from Washington State, and three from California.

As mentioned, during the preliminary selection process, newspapers were identified according to the region where there was the most activity around the Klondike gold rush. Newspapers were then eliminated if they had too low a circulation or if they did not contain news images of the event in the first $2 \frac{1}{2}$ weeks after the outbreak. Consequently, taken altogether, the fourteen newspapers of the sampling frame are most likely representative of the illustrated news coverage of the Klondike gold rush in North American dailies during the first few weeks of the event. Other dailies that famously covered the event in illustrated news form but which were not included in the sampling frame are The Call in San Francisco, the World in New York, and Hearst's Journal in New York. Because of cross-ownership, however, one can surmise that many of the news images in Hearst's Journal would have compared to the ones published in The Examiner, which was the newspaper that yielded the most news images (see Table B).

\section{Description of the newspapers in the sampling frame}

Tables A1 and A2 also show that the newspapers in this case study's sampling frame represent a varied sample of editorial ideologies ranging from left-wing to right- 
wing political leanings, which include democratic, liberal, conservative, imperialist, republican, and independent. As well, the sampling frame is mostly constituted of highcirculation newspapers, although a few mid-range circulation newspapers have been included, namely The Daily Nor'Wester in Winnipeg, the Ottawa Free Press, The Herald in Los Angeles, and The Seattle Post-Intelligencer.

This case study's sampling frame also includes a mix of newspapers that fall within a spectrum defined by "information journalism" at one extreme and "story journalism" at the other. This refers to what Schudson (1978) identified as the two major paradigms of journalism that existed in 1897. These paradigms are discussed in depth in Chapter Four, and later referred to during the analyses of the empirical data in Chapters Six, Seven, and Eight. One of the main characteristic of story journalism is its degree of sensationalism, often measured by its use of illustrations.

Given that the research domain of this case study is illustrated news, it has made sense to classify newspapers in the sampling frame according to their degree of sensationalism. W.J. Campbell (2001) uses a score method to rate the "yellow index" of each newspaper (p. 158). Some of the criteria he uses to establish the scores have been discarded because they are not relevant in this study, for example "prominence to report about sports" (p. 154), but many of his other criteria have been retained to establish a relative index of sensationalism specifically for the purpose of this case study. These criteria are laid out in Table $\mathrm{C} 1$ to establish how each newspaper of this case study's sampling frame rated on the relative index of sensationalism. Both Schudson (1978) and W.J. Campbell (2001) have been used as sources to define this relative index of sensationalism that rates each newspaper's degree of information journalism or story 
journalism in relation to one another. Table $\mathrm{C} 2$ shows the result of this classification, with The New York Times at the "information journalism" end, and The Examiner at the "story journalism" end. 


\section{CHAPTER THREE - FACT AND FICTION IN THE REPRESENTATION OF HISTORICAL EVENTS}

\section{The ontology of imagination}

"The West of the popular imagination, unlike the West of the scholars, is an almost timeless sort of place. At some point in our lives, often when we were very young, we came to know it as a landscape peopled with brave men and women, unforgettable pioneer heroes who helped build the nation." (Cronon, Miles \& Gitlin, 1993, pp. 4-5)

At first glance, this quote seems to contradict one of the key ideas that supports B. Anderson's (1991) main thesis in Imagined communities, namely that nationalism is contingent on the omniscient experience of "homogeneous, empty time" that has been made possible by books and newspapers (pp. 24-26). For one first assumes that the "West of the scholars" makes a direct reference to books and newspapers. Upon reflection however, it becomes clear that the authors are suggesting that the musings of the popular imagination take place in the same sort of "homogeneous, empty time" as that which exists in narrative works, a sort of infinite, fictional time, a "timeless" time that belongs to the narrative mind. Thus the quote speaks to the power of imagination, the power of myth. This indeed seems to be what B. Anderson (1991) meant: social practices shape one's perception of oneself and others, and one's understanding of the world.

Inspired by an argument originally made by Walter Benjamin (1973), B. Anderson (1991) suggests that print-capitalism made a new experience of time possible, an epistemological turn that revolutionized how people imagined themselves and others. If the story of one's life could be imagined to unfold like a novel, then one could come to 
see the self as a character in that novel. Fiction would thus inform identity formation processes. B. Anderson argues that prior to this shift in time-sense, what existed instead of modern narrative time was a "medieval conception of simultaneity-along-time" (p. 24), neither temporal, nor causal, which is best summarized by this mysterious passage from the Apocalypse: "And sware...that there should be time no longer" (Revelations 10:6, King James Bible) in which the past, the present, and the future all exist as one: the here and now. In this ontological moment, time and space become one (Ouspensky, 1969/1920, p. 303). This medieval experience of time was a meditative one induced by religious imagery and sacred texts (B. Anderson, 1991, pp. 22-24).

This is a very big claim. One that can easily be contested. For instance, the ontological experience of the "here and now" is described in the mystical, sacred texts of all religions across time and it is still very much alive today in the spiritual teachings of different cultures. Conversely, over two thousand years ago, Ancient Greek tragedy existed as a narrative form that rivals today's theatrical and cinematographic productions. Consequently, it could be argued that both these very distinct experiences of time have existed for millenaries and still exist today. But the complexity of this debate extends beyond the scope of this discussion. However, the idea of a modern sense of time related to the narrative mind is one that merits attention. In this calendrically linear time, ${ }^{15}$ imagination does not only transport people through time, it also allows them to journey

15 B. Anderson (1991) uses the adverb "calendrically" to designate the modern narrative tıme-sense because he claims that it derives from measuring time with clocks and calendars and that it has a linear quality as this quote suggests (p 24): "The idea of a sociological organısm moving calendrically through homogeneous, empty time is a precise analogue of the idea of the natıon, which is also conceived as a solid community moving steadily down (or up) history" in Benedict Anderson (1991) Imagined communities : reflections on the origin and spread of natıonalısm. (London, New York : Verso), p. 26 
through space. On just a little spare change, one can travel far and wide when reading a newspaper, or sometimes even for free, when borrowing books from the library. For after all, what constitutes the experience of imagining?

It may be true that print-capitalism made foreign lands and historical moments accessible to the masses through books, newspapers, postcards, and photographs. It may be true that this in turn endowed people with what sometimes seems like a magical ability to travel through time and space. It may be true that modern media enabled large numbers of people to develop this faculty in new ways. But it remains that the mind is the paramount means of production of human experience or as Carey writes (2009), “The mind - the associative, cooperative mind - its extension in culture and realization in technique is the most important means of production. The most important product of the mind is a produced and sustained reality. (p. 74).

It is the movement of the mind that pulls people into awareness of themselves and others. In this short journey on earth, the experience of life begins and ends in the mind; in the consciousness of being; in perception, thought, sensation, and emotion; and in the kaleidoscope of imagination. The journey that one imagines is the journey that one remembers. Perhaps this is why there is an uncanny relationship between the travels and the travails of the mind.

This relationship is not new and it bears heavily upon narrative forms that seek to describe reality, prosaically, poetically, or metaphorically. This may explain why some scholars have found evocative links between travel writing and news (Fishkin, 1985; Spurr, 1993; Ward, 2004). Ward (2004) puts them both in a category he calls factual 
narratives (p. 61). Given that the news images of the Klondike gold rush were often produced by correspondents or amateurs that journeyed to the land of gold alongside stampeders, segueing to the subject of travel writing may enrich this case study's discussion on how the lines of demarcation between the description of a journey and its mythical embellishment have been blurred in factual narratives throughout history.

\section{Fiction in factual narratives}

Journalism historian, Stephen Ward (2004) notes that Richard Hakluyt's Principall navigations, voiages, traffiques \& discoveries of the English nation made by sea or overland to the remote and farthest distant quarters of the earth at any time within the compass of these 1600 originally published in 1589 was the first significant collection of documents, letters, and first-hand accounts of voyage narratives made widely available through the instrument of the printing press (p. 62). In the years that followed, Hakluyt published several volumes of this historical compilation that featured the exploits of England's famous discoverers abroad, legendary figures such as Sir Richard Grenville and Sir Walter Raleigh. It is noteworthy that these works included imposing portraits of these men, their visual identity stamped onto the book of conquests of the British Empire. ${ }^{16}$ Such images suggest the rhetorical aspect of Hakluyt's works, which may have contributed, a hundred years after its first publication, to the production of an iconic engraving of England's Famous Discoverers: Captain Davies, Sir Walter Raleigh, Sir

\footnotetext{
16 These portraits can be retrieved from: http.//digitalrussell mcmaster.ca/russell-librarysearch/results/field_second_subject\%3A\%22Discoveries+ın+geography+--+English.\%22
} 
Hugh Willoughby, and Captain Smith that still belongs to the patrimonial heritage of the British Empire. ${ }^{17}$

But Hakluyt's was actually not the first work of travel writing to be published. Marco Polo's Books of the Marvels of the World, which describes his travels in the 13thcentury was written a little less than three centuries earlier. The manuscript pages illustrated in the early $15^{\text {th }}$ century to represent the "factual narratives" of Polo's Books of the Marvels of the World are most instructive. Although they were produced more than a century after the work was first published and well after Polo's death, they are nevertheless attempts to visually render the written accounts of his travels. Many of the images of natives and creatures encountered abroad may seem fantastic today (see Figures 1,2, 3 and 4), but at the time, these images would surely have vividly impressed the imagination of those who had not travelled there, shaping their first imaginings of these foreign lands and peoples.

The manuscript of Polo's Books of the Marvels of the World produced by the Workshop of the Boucicaut Master has represented some of the better known images associated with Polo's account. Artists from that workshop depicted bizarre images such as the dog-headed creatures described by Polo in Book III, Chapter 18 (see Figure 1); the Sciopods from Book I, Chapter 51 (see Figure 2); and the Blemmyaes from Book I, Chapter 57 (see Figure 3). Even the more realistic representations seem exaggerated. In Figure 4, for instance, natives are portrayed as inferior and uncivilized, depicted as shorter, wearing only loin-cloths, and submissive in regard to the great white man.

17 This engraving can be retrieved from: http://www.nmm.ac.uk/server/show/conMediaFile.2143 
Regardless of whether they represented fact or fiction, these images would have contributed to the formation of what B. Anderson (1991) calls collective imaginings.

Comparing the work of the Workshop of the Boucicaut Master with that of other manuscript workshops across Europe suggests that the portrayal of these strange peoples from faraway lands was not merely a product of the fanciful imagination of the limners that illustrated Polo's words. For instance, the Workshop of Johannes and his school have interpreted this image in a very similar way. ${ }^{18}$ Interestingly, the German cartographer Sebastian Münster (1488-1552) later incorporated yet another version of Polo's Blemmyaes randomly depicted next to Sciopods and dog-headed creatures in Cosmographia published in 1544 to describe the creatures that live in India. ${ }^{19}$ This speaks to a fact that every art historian knows well. Throughout history, visual art has usually been the primary source of visual art. Münster, and possibly other limners, may have copied the images from the Workshop of the Boucicaut Master's manuscript rather than creating images by using Polo's writing as a primary source.

According to historical records, Christopher Columbus read Marco Polo's work after it was first printed two centuries later in 1477. More than fifteen years later, Columbus then published his own voyage narratives titled Account of 1492 Voyage in the Americas for King Ferdinand and Queen Isabella of Spain, and their court officials in April 1493. In this work, Columbus wrote, "There I found very many islands, filled with

18 This illustration from circa 1400 in Lı Livres du Graunt Caam, ms. Bodl. 264, folio 260r, can be retrieved from: http://1mage.ox.ac.uk/show?collectıon=bodleıan\&manuscript=msbodl 264

19 An engraving of Munster's depiction of the peoples of India can be retrieved at: http://www.columbıa.edu/1tc/mealac/pritchett/00generallınks/munster/ındıa/page 1080.jpg 
innumerable people, and I have taken possession of them all for their Highnesses, done by proclamation and with the royal standard unfurled, and no opposition was offered to me" (Library of Congress online exhibition). Although one could not speak of nationalism at this time, empire building seems to have inspired its own private imaginings.

At this point, it would be tempting to believe that travel writing was a legacy passed down by generations of great historical figures from the Venetian, the Spanish, and the British Empires. However, Classics professor, Dr. J.S. Burgess (2010) has discussed numerous examples of Ancient accounts that narrated the past from a geographical and ethnographical perspective, citing Homer's Odyssey from 800 B.C.E. as the best known work. "Ancient travel writers", said Dr. Burgess, "tended to conflate real travel accounts with mythical narratives that described hybrid, monstrous characters such as the Cyclopes. It is a well-known fact that travelers in the real world have been known to tell unbelievable tales". Given that the accuracy of some of the stories in Marco Polo's Books of the Marvels of the World, has been often called into question throughout history, as Dr. Burgess remarks, this practice is clearly not limited to Ancient Times. At the very least, there is evidence that it carried well into the Middle Ages.

Stephen Ward (2004) makes a surprisingly similar point when he writes that in the sixteenth and seventeenth centuries: "Travel writing reported on exotic journeys and the customs of natives. Fraudulent reports of monsters and marvels were so common that some writers were called 'travel liars'” (p. 62). Ward remarks that faced with this problem, the Royal Society of London had to set certain standards to limit inaccuracies in works claiming to be factual or scientific. Thus, to improve fact gathering practices in the 
seventeenth century, they prescribed the use of reliable sources, accuracy, and impartiality in such works (p. 62). Could this have played a part in the development of modern journalistic norms of objectivity?

\section{The epistemic foundations of modern news}

Scientific objectivity and a culture of facts may have gained in importance in the sixteenth century, but modern journalistic norms were only created when journalism became a profession in its own right, three hundred years later in the nineteenth century. Chalaby (1998) identifies nine discursive norms of objectivity in modern journalism: neutrality, impartiality, balance, fairness, retreatism, truthfulness, factuality, accuracy, and completeness (p. 130). In theory and practice, these norms have provided the framework for modern news for over a hundred and fifty years. However, Schudson (1978) argues that it was only at the turn of the twentieth century that journalists started to use objectivity as their primary guideline (p. 5); In practice, concern for this norm was still nascent in the period that concerns the empirical data of this case study. Nevertheless, these norms reveal a great deal about the epistemological conditions of modern society: the methods that are used to create, communicate, and interpret knowledge. To understand modern news, it is necessary to reflect on its epistemic foundations.

Chalaby (1998) has made the argument that the professionalization of journalism gave rise to new paradigms in information gathering and dissemination that resulted in "a new discursive genre... which displayed entirely new philological characteristics" (p. 2). According to him, modern news as it exists today was invented between the 1830 s and 
1920s by American and British journalists (1996, p. 304). The principle claim made by Chalaby about the nature of journalism's "news-discourse" is that it is defined by "factcentered discursive practices" such as reporting and interviewing purportedly invented by Americans (p. 311).

Conversely, some journalism scholars are critical of the idea that modern news is a new genre that represents a rupture from old news systems (Lule, 2005; Stephens, 2007). Instead, they argue that there are striking similarities between modern news and older news systems or narrative forms, sometimes presenting modern news as an extension or repetition of an older discursive practice. For instance, these scholars often describe Ancient Rome's "daily gazette", the acta diurna populi Romani, as a precursor of modern newspapers (Giffard, 1975-76; Lule, 2005; Stephens, 2007; Ward, 2004). In this view, different cultures across time and space may choose different methods of knowledge, but the smallest common denominator in culture remains the range of human experience, not epistemological paradigms. Like B. Anderson (1991), this scholarship places the emphasis on ontology rather than epistemology (see p. 6).

When scholars favor an epistemological approach in theorizing modern news, the argument goes that advances made in communication and transportation technologies in the nineteenth century are the driving force behind modern newspapers and the professionalization of journalism. For instance, Slater (2002) writes that: "It was technology...that led to the creation of mass media. There can be no newspapers without printing presses" (p. 350). Ward (2004) writes that "shifts in journalism practice include new ways to gather news caused by the invention of new communications technology [italics added]" (p. 32). Such statements relate to the concept of technological 
determinism which "posits that all important human phenomena - cultures, distribution of power, belief systems, industrial structures, and so forth - are explainable by the evolution of... industrial devices" (Babe, 1990, p. 9). This implies that technology would be the leading cause of changes in human practices, values, thoughts, and actions. To put it otherwise, this belief purports that human beings accommodate technological progress (p. 30). Thus, according to the tenets of technological determinism, epistemic changes are the result of technological changes. In this perspective, the modern newspaper must be the product of modern technology. And so must modern journalism's new discursive practices.

Evidence of Ancient Rome's "daily gazette" nuances such ideas. In terms of content, there was little difference between the format of the acta diurna and the modern newspaper (Giffard, 1975-76, p. 132). They both offered a mix of factual chronicles of political, social, and cultural events as well as human interest stories (Stephens, 2007, p. 55-56). Except for commercial advertisements and images, the content is roughly comparable. This speaks to the idea that there may be significant differences between epistemologies of the ancient world and of the modern one, but there are also striking similarities. The existence of the acta diurna over two thousand years ago is evidence that technology is not the primary cause of epistemic changes of news systems. Modern technology and new means of mechanical reproduction, therefore, neither invented the symbolic system of modern news, nor its methodology, nor its guiding principles.

There is no question that technology has contributed to the production of modern newspapers, just as social, political, economic, and cultural conditions did, but they are all variable elements in the production of modern news, not essential causes. They cannot 
even be called factors because factors imply causality and if modern technology or modern culture were the cause of modern news, then how could the acta diurna have existed without them? Whatever means are used to represent news, whether it is a rotary press or two million scribes that make copies of a daily newssheet, it remains that the driving force behind the production of news, like myth, is the need to understand, explain, represent, and share human experience. This is a cognitive argument that posits that the epistemic foundations of news is to be found in the workings of the human mind, in particular, in the ability to imagine.

This position supports the news-as-myth approach used in this case study because it takes as an assumption that the human need to inquire, contingent as it is on cognitive ability, remains constant, while the methods and tools used in the process of inquiry are variable. Thus modern news is primarily defined in relation to its function. Its epistemic foundations are not construed as external (i.e. technology), but internal (i.e. cognitive and discursive). In keeping with the humanist tradition, human beings are seen as both the subject and object of inquiry. In this perspective, news, culture, and technology are not the cause, but the product of human imagination and will. They are elements that exist to enable the fulfillment of fundamental human needs. They are at the service of imagination. This does not prevent their reflexive character. They can impress or affect the human imagination, but they remain its product. There is no news, there is no technology without the human mind and will. 


\section{Fact and fiction defined}

Making sense of what is fact and what is fiction is a problem that has been shared by the readers of ancient newssheets and modern newspapers alike. Roman historians understood that the acta diurna comprised a motley mix of facts and opinions, of nonfiction and fiction. There are records of patricians complaining of the "tittle-tattle" content which consisted in gossip and rumors (Ward, 2004, p. 46). Giffard (1975-76) also notes that "according to Livy, as early as 449 BCE people made plain their lack of confidence in the reliability of the official minutes of the senate" (p. 109). This, however, did not make the acta diurna any less popular. Like today, people wanted news and the acta diurna provided it. Unreliable news was better than no news at all. But it is noteworthy that even in ancient times, people questioned the accuracy of the information and they were critical of bias and sensationalism.

What the ancient newssheets and modern newspapers have in common is that they are both the product of discursive reasoning: rational inquiry that uses argumentation and discourse (i.e. representation) as a method of knowledge. In newspapers, content is made up of information that is collected and then represented in words or in images. Not everything in life can be expressed in words or images. There are feelings and experiences for which there are no words. For instance, the experience of awareness itself cannot be expressed into words or images, nor can that of intuition. In fact, the only thing that can be expressed in words and images are concepts, mental representations of ideas that are the object of rational inquiry.

This is why the dichotomy between fact and fiction can be said to be artificial; It only exists in representation, in the divisions constructed by discursive reasoning which 
is itself based on logic. Logic is the system that is used to define concepts and provide a framework for their comparison. Aristotle laid down the axioms of logic as follows: ( $A$ is A); (A is not Not-A); (Everything is either $A$ or Not-A). When applied to the concepts of fact and fiction, Aristotle's axiom of logic takes this form: (Fiction is fiction); (Fiction is not non-fiction); (Everything is either fiction or non-fiction). This demonstrates that a concept can only be defined in relation to its opposite, namely what it is not. Thus facts can only exist if there are non-facts; fiction if there is nonfiction. In this case study, fiction and non-fact are synonymous terms, and non-fiction and fact are synonymous terms. This however, does not explain what is fact and what is fiction.

A fact may be defined as an element of reality that has manifested as phenomena in space and time. A Kantian perspective of this definition implies that this element of reality cannot be fully known because it transcends subjective experience. Reality is not in the mind. It exists out there, as a thing-in-itself. The mind can only grasp elements of reality by giving them form through the act of representation. In this perspective, a fact, like truth, is a mystery, waiting to be unraveled. It is real. It is true. But it is outside of human experience. A fact claims to be reality but it can only be made to appear through language. This may explain why a fact is so elusive.

A fiction is a non-fact, that is, an element of reality that has not manifested as phenomena but exists as an idea, a concept, or a thought which is an "unactualized possibility" that can be given form through language. By virtue of Aristotle's axiom of logic, a concept can only exist if it has an opposite. Thus we can say that a fact relates to an event that has occurred in reality while fiction relates to an event that has not occurred in reality. 
There is a second level of fact and fiction in language or discourse. Given that representation is not reality, it can only yield an incomplete understanding and rendering of reality and its events. Even when it strives to only present facts, it can only present some of the facts, some of the elements of reality, not all of them. Because there are elements of reality missing, news represents an event that has not truly occurred in reality, because it did not occur as it is represented. Thus there is an element of fiction that is always present. Conversely, there is always an element of reality even in the most outlandish genres of fiction (i.e. sci-fiction or the fantastic), for human beings created language in the image of reality. It follows that within representation, there are necessarily facts and non-facts, fiction and non-fiction.

\section{Weaving fact and fiction in news}

The metaphor of weaving is used to illustrate how this case study views the relationship between fact, fiction, and representation in the context of news. In her book Socrates' Ancestor: An Essay on Architectural Beginnings, McEwen (1993) argued that in Ancient Greece, crafts and architecture preceded and influenced Western philosophical and political thought. Social reality was woven through the human activity of creating a certain order in space and time. In architecture, shipbuilding, dancing, design, and textiles, the act of creating and recreating patterns and motifs through craftwork gave order a visible form. McEwen's thesis is that Western thought emerged in parallel and in relation to crafts because physical structures and symbolic structures echoed each other. The crafting of structures in everyday life made order appear in the polis (p. 43). She identifies myths as one of these structures, "Odysseus plies the seas to make a hitherto unknown world appear" (p. 70-71), but she also includes in them the product of all crafts 
and activities performed by the individuals that constituted the polis, "heralds, prophets, doctors, bards, lawgivers, and magistrates, as well as builders" made the public realm appear (72-73) and "the city was made, and continually remade, in a making that was itself a discovery of kosmos" (p. 46). ${ }^{20}$

Similarly, communication and journalism are crafts that shape the world and make social life appear by weaving a specific structure (i.e. order) into it. As Chalaby (1998) remarks, modern journalism seeks to present facts. But to be understood, as well as to be communicated from one person to another, facts must have a substantial form; they must be made to appear in representation. When applying the metaphor of weaving to journalism, one can say that facts are like warp threads, laid out on the loom as they are selected and collected. This process can be described as paradigmatic. In relation to news-discourse, Hartley (1982) defines paradigmatic relations within language in terms of the presence or absence of verbal or visual elements, regardless of how they are combined (p. 20-21). In practice, this simply means which facts are included and which are not, what elements of reality are presented. Since some elements are always excluded, paradigmatic relationships imply that some of the facts are always missing. In this way, the paradigmatic process creates fiction by omission.

Conversely, the idea that facts are laid out and combined on the loom in a specific order relates to what Hartley (1982) calls syntagmatic relations within language. In newsdiscourse this refers to how elements of reality are combined in relationship to each other. The concept of syntagm implies sequence, namely that elements are combined in way

20 "Kosmos" designates a pattern or ordering. 
that they follow each other in a very specific order. This idea is contingent on what B. Anderson (1991) describes as calendrically, linear time related to the narrative mind (pp. 24-26). Because it is sequential and linear, syntagmatic combinations inevitably construct narratives in some form or other. To summarize, paradigmatic relations within language refer to the selection of elements while syntagmatic relations refer to their combination. Together, they determine the structure of news.

In weaving, fabric is created from the interlacing of the warp threads to the weft threads which cross over and under it at a right angle. The weft threads of fiction are what tie the loose warp threads of facts together to give them a solid, substantial form. In news-discourse, what we can know of elements of reality is only their appearance as patterns in fabric, patterns that represents an ordering of facts. Because this ordering is paradigmatic and syntagmatic, it is narrative. Thus, in news, events can only be represented as stories, even when the style is dry and scientific, because it follows a narrative sense of time, a sequencing (Hartley, 1982, p. 81). In the realm of journalism, one could say that news-discourse is produced by weaving fact and fiction. The metaphor of weaving could also be applied to myth in the same way. Thus, in this case study, news, and myth are forms of discourse created by a system of production which includes the loom, the threads, the weaver, and all the other elements used in their production.

The kosmos, the order that news creates is therefore made of up of a combination of what has been actualized (facts) and what has not (fiction). This gives news, myth, and representation in general, a very specific quality: it is grounded in the reality of what has happened (fact) but contains the elements of the possible that has not manifested (fiction). Representation and language are therefore a means by which humankind can not only 
understand and explain the world, but also, simultaneously imagine it differently. This is why using a methodology that construes news as a narrative form that appeals to the imagination is important. If news is construed as a discourse of hard facts, then no space is made for imagining change. What fiction provides in news is the possibility of something new. This impresses a prescient meaning on the word news which comes to not only mean new information about what has happened (fact), but also new information on what is possible, what could be actualized in the future (fiction).

\section{A ritual view of modern news}

Although this reasoning springs from a humanities-based tradition, it is surprisingly consistent with social constructivism and the constitutive model of communication theory that includes, for instance Carey's (2009) ritual view of communication as culture whereby "reality has been made - has been progressively made - by human activity...the history of the species is simultaneously the history of the transformation of reality" (p. 56) and "culture must first be seen as a set of practices, a mode of human activity, a process whereby reality is created, maintained, and transformed, however much it may subsequently become reified into a force independent of human action" (Berger \& Luckmann, 1966, qtd in Carey, 2009, p. 50). In particular, with regards to language and communication, Carey (2009) writes, "Then we must substitute the view that language - communication - is a form of action - or better, interaction - that not only merely represents or describes but actually molds or constitutes the world [italics added]" (p. 64). 
Carey (2009) points out that mass communication scholarship is in dire need of a more wholesome approach that integrates the humanities (p. 53). He is critical of approaches to the study of mass media that take positivism as their starting point. For Carey, culture is not to be confused with science. He finds fault with an Enlightenment tradition that drew on Descartes to make "science paradigmatic as a whole for culture" (p. 54) and scientific discourse that claims to be "the only mode in which truth can be formulated" (p. 38). Carey favors pragmatism, an approach that relies on communicative interaction to arrive at a relative, practical truth through intersubjective agreement, over the absolutist value of scientific objectivity (p. 70).

Ward's (2004) treatise on journalism ethics describes in detail and depth the different meanings of the concept of objectivity throughout history and the influence of each of its variant in modern journalism ethics (p. 18-19). He points out that in the course of the nineteenth century, a positivistic definition of objectivity came to prevail in culture at large, and in the press in particular (p. 37). According to him, the rationale for this was both philosophical and political, couched as it was in the ideology of liberalism which "sought to bring into existence a rational, liberal society" (p. 179). The press became an instrument to achieve this enlightened goal. But to do this, it had to reach the largest public possible. It had to become popular. By espousing norms of objectivity which, in the nineteenth century, primarily advocated political neutrality, impartiality and factuality, it invited everyone indiscriminately into the liberal marketplace of ideas (p. 190-191). Another reason why the nineteenth century press sought to attract as wide a readership base as possible was to maximize advertising dollars; They had become 
independent businesses, increasingly relying on advertising revenue to finance their operations (p. 183).

This is the context in which journalism emerged in the period between the midnineteenth and late nineteenth century. In reference to the social history of the press, Chalaby (1998) makes a distinction between the public (pre-journalistic) phase and the journalistic phase separated by what he refers to as the "rupture" that occurred in this period (p. 3). In the pre-journalistic phase, newspapers were the mouthpiece of a partisan press, subsidized by political parties and funded with subscriptions. Driven by liberalism and its imperatives of market forces, over the second half of the nineteenth century, newspapers were industrialized.

The rupture that Chalaby (1998) mentions roughly coincides with what Lippman referred to as the "“commercial revolution' in the American press" (Schudson, 1978, p. 17) and with what Habermas described as the broader historical forces that reorganized the relationship between the public sphere and the private realm in the 19 th century. According to Habermas (1991), one of the results of this structural transformation was, paradoxically, the end of the liberal public sphere in the late nineteenth century which saw the press change from "organs of public information and debate [to] technologies for managing consensus and promoting consumer culture" (p. xii). In other words, Habermas (1991) argues that liberalism's political ideals (i.e. the public sphere) were cannibalized by the economic ones it had set in motion (i.e. free trade).

Habermas' preoccupation with the role of the press in creating and preserving a vital public sphere is echoed in the canonical Dewey-Lippman debate that has pervaded 
in communication scholarship (Carey, 2009; Nerone, 2006; Peters, 1989; Rosen, 1997;

Russill, 2008; Schudson, 1999; Splichal, 2000). Jansen (2008) has been quite critical of how this debate was framed in secondary sources; She argues that it has often been presented in ways that obscure the meaning and scope of Lippmann's ideas, particularly in Carey's work (p. 72; p. 101,n4). Bearing in mind this caveat on how Lippman's ideas are presented, Carey's interpretation of the Dewey-Lippmann debate is used as a springboard for further discussion.

According to Carey's (2009) Reconceiving “Mass” and "Media”, Lippman (1922) argued that the liberal ideal of democracy could only be achieved if the press provided citizens with information that was as accurate as the scientific facts of positivistic science, or as Carey (2009) wrote, "when the individual minds that make up the public possess correct representation of the world" (p. 62). In contrast, Dewey (1927) argued that it is through human interaction that democracy is to be achieved, not through accurate representation. For Dewey, the value of information lies in its practical applications, specifically how it can "clarify our purposes, advance our mutual understanding, and permit cooperative action" (Carey, 2009, p. 61).

It would seem at first glance that Lippmann and Dewey argue at opposite poles. It is outside the scope of this case study to engage in a detailed discussion of how their ideas resonate or differ. Suffice to say that in more ways than one, Jansen (2008) has found that many of their ideas converge, especially in relation to the fragility of public opinion and democracy (pp. 91-93). However, this case study argues that one of the major differences between their ideas as they are represented in Carey's (2009) essay seems to be that Lippmann is concerned with the methods used to gather and disseminate 
information while Dewey is concerned with what happens later with this information, namely, the methods by which the public itself engages with it. In other words, the weakness in Carey's essay is that the ideas that are being compared are related to different actions. Still, some points of this debate are germane to this case study.

In the context of the role of the journalism, the Dewey-Lippmann debate as described by Carey (2009) offers a way to think about the relationship between fact and fiction in news. Lippmann was saying that the role of the press is to provide pure fact to a public that will thus be perfectly informed and make democracy possible. Dewey was saying that the press does not have to provide pure facts for democracy to be possible. The public can make due with a mix of fact and fiction because the important thing in democracy is to engage in conversation, interact, be involved, make compromises, and find common ground. The role of the press in Dewey's perspective is to provide news of substance the public can relate to. He wrote, "the purpose of news is not to represent and inform, but to signal, tell a story, and activate inquiry" (p. 62).

It is interesting to compare Dewey's position with Lippmann's in Public Opinion: "the function of news is to 'signalize an event' while the function of truth is to 'bring to light the hidden facts and set them into relation with each other'. (Lippmann qtd in Schudson, 1978, p. 175). This underscores the fact that, on the one hand, Lippmann attributed to news a similar purpose than Dewey, and on the other hand, in the rhetoric of modern journalism ethics, news is often confused with truth. The scientific method that Lippmann allegedly advocates in journalism is based on identity and difference: the importance of knowing what is true and what is not true. The pragmatic method that Dewey places his faith in stresses the idea of commonality and agreement: the 
importance of understanding another's point of view and sharing. Such a perspective on news underscores one of its fundamental characteristics: news fulfills a social function. It is on this basis that a news-as-myth approach has been used in this case study.

News and myth provide an order that simultaneously includes repetition and change, stability and instability. This fluidity speaks to both the commonality of human experience and its uniqueness, providing a frame for the possibility of an individual identity and a collective one, an indispensable asset in social interactions. Throughout history, fact and fiction have been interwoven to provide a space for people to meet and relate to one another. This discursive space is the sine qua non condition for social life.

Like myths, news stories are not really new. More than any mass medium, the news thrives on the ritual repetition of stories. The news tells us the same stories again and again. Like myth, news tells us not only what happened yesterday but what has always happened. Flood and fire, disaster and triumph, crime and punishment, storm and drought, death and birth, victory and loss - daily, the news has recounted and will recount these stories. (Lule, 2005, p. 105) 


\section{CHAPTER FOUR - KLONDIKE NEWS IN THE CONTEXT OF MODERN JOURNALISM}

\section{The mythical character of Klondike news coverage}

As if echoing Lule's (2005) idea that the repetition of stories connects us to the timeless thread of human experience (p. 105), Berton (1972) has referred to the Klondike gold rush as the "Klondike odyssey" (p. 183; p.187) and to the stampeders as argonauts (p. 103; p. 117; p. 199; p.145). As mythical as it sounds, the expressions are actually fitting if one considers that in 1897-1898 alone, one million people made plans to leave home and family to seek their fortune in the gold fields; one hundred thousand actually set out (p. 116); thirty thousand made it to Dawson City (Berton, 1983, p. 237); some tragically never arrived (Berton, 1972, p. 190); and some, like Odysseus, faced so many obstacles that by the time they arrived in Dawson City in August 1899, the gold rush was already over (p. 232).

Berton's (1972) colorful in-depth account of the event from beginning to end provides valuable information on the general context in which it took place. Some of the facts detailed in his book seemed a bit exaggerated or farfetched. Surprisingly, most of the empirical data collected in the daily newspapers of this case study's sampling frame confirmed them. Perhaps not so surprisingly...since after all, these were some of the primary sources used by Berton himself.

This speaks to the mythical quality of the news coverage in some of the dailies. In reference to the stampeders, the term "argonauts" was in fact widely used in 1897 newspapers. Berton (1972) did not invent it. He merely borrowed it. For instance, a 
caption under an engraving of people boarding a ship leaving for the gold fields reads: "Hope of fortune animates the argonauts in the Williamette" (San Francisco Examiner, Aug. 1, 1897, p.14).

The press was publishing facts polished with the glow of fiction, but they were facts nevertheless. The empirical data, specifically Figure 5, confirms Berton's (1972) description of the massive stampede that broke out in the first few weeks after newspapers announced that large quantities of gold were freely available near Dawson City in the Yukon (p. 93). This may seem like a fantastic dramatization penned by Ancient epic poets, but the empirical data of this case study's sampling frame also confirmed Berton's claims that from all over the world, women and men of all ages, social classes, and cultural backgrounds left everything and travelled by bicycle (see Figure 6), hot-air balloon, horseback, dogsled, raft, foot and makeshift, hybrid means of transportation (see Figure 7) to undertake the long journey to the gold fields (pp. 116123).

For instance, an article in The Toronto World published on July 24, 1897 reads:

RICH MEN ARE GOING, TOO.

They are Forsaking Offices for the Chance of Finding Gold in the Klondike Placers.

Seattle, Wash, July $23^{\text {rd }}$ - Two thousand men, fully provisioned for Alaskan winters and bent on seeking a fortune in the golden placers of the Klondike will be scattered along the routes between this city and Dawson City in the next ten days. Many will be fully outfitted for the trip over the mountain pass by way of Dyea, while others will take easier routes up the Yukon River to Dawson City. 
One thousand men, women and children crowded Schwabacher's dock yesterday to witness the sailing of the Portland. It was a sight exceeding even the scenes in California during the gold excitement of ' 49.

There were hundreds of miners and tenderfeet in the crowd who would have gladly given a hundred dollars to have purchased a berth from one of the hundred and fifty of the Portland's passengers.

Syndicates Sending Men Out.

It must not be supposed that poor men only are being sent to the Klondike. Rich men are daily forsaking their offices for the golden chance winning a fortune in a day on Bonanza Creek or Eldorado. If they cannot go themselves they are sending relatives and younger sons, outfitted for two years in the Yukon basin, and supplied with ample funds to buy claims at any reasonable price. One of these is Judge H. G. Bond, a millionaire, formerly from New York, whose son, Marshall Bond, left yesterday with four prospectors in his employ.

Three big lumber mills at Ballard, adjoining this city shut down today, because of resignations from the working forces. The men are still going to Klondike. The Tacoma mill, among the largest on the Pacific coast, is hampered for want of men because of heavy desertions. The workmen prefer taking a chance in the Klondike to working for $\$ 1.25$ per day in a sawmill. ("Rich men are going, too," 1897).

Another small column titled To the Klondike for pleasure published in the New

York Times the next day reports:

Morristown, N.J., July 24 [sic] - Mr. and Mrs. W.D. Sloane, relatives of the Vanderbilts, left Madison last evening for Alaska. They went in a special car to Buffalo, will proceed to Chicago, by way of the Great Lakes and thence to Seattle.

From there they sail for Juneau, and will then go overland to the Klondike. They have gone for pleasure, and have no need for prospecting. ("To the Klondike for pleasure," 1897). 
A comparison of these entries from The Toronto World and from The New York Times is instructive. Founded in 1880, The Toronto World was the "first of the Canadian penny presses" (Babe, 1990, p. 92). In the 1880s and 1890s, it was considered a people's journal "which had perfected a sensational style and a Radical purpose suited to the tastes and interests of the common man [sic]" (Rutherford, 1982, p. 56). Along with La Presse and The Montreal Daily Star, Rutherford described The Toronto World as espousing a style of journalism designed to attract the largest popular readership possible which contrasted with that of newspapers that adopted a more factual style.

\section{Two paradigms of journalism during the Klondike gold rush}

This calls to mind the thesis that there were two forms of journalism in North America in the 1890s: "story journalism" and "information journalism". According to Schudson (1978) and Campbell (2006), these two paradigms of journalism slowly developed in parallel to one another from the late 1880 s to the mid-1890s and came to a clash in the market-place of ideas in 1897 because of structural socio-economic changes. ${ }^{21}$ Sotiron (1997) writes that Canadian newspapers changed in a way very similar to Schudson's description of American ones after the 1880s (p. 7). In Schudson's (1978) study, The New York Times serves as the classic example of the "information model", which places its emphasis on a style that informs, while dailies owned by Joseph Pulitzer or William Randolph Hearst often serve as examples of what he calls "story journalism”, which seek to entertain by using liveliness of style (Schudson, 1978, pp. 88-

\footnotetext{
$21 \quad 1897$ is the year that marked the end of the second worse economic depression in North American
} history and the beginning of a third wave of capitalist expansion that would last until WWII. 
120). In the context of this taxonomy, The Toronto World was more on the "story journalism" end of the spectrum (see Table C2). Schudson's (1978) concept of the two models of journalism in the 1890s has been useful in selecting a diverse range of newspapers, but it is not an absolute. In fact, it can be misleading in the context of a discussion on fact and fiction in the news.

For instance, The New York Times entry transcribed above was brief, succinct, and unadorned. However, from a paradigmatic and syntagmatic perspective, specifically in terms of what information is selected and combined, it reads like a narrative. The column describes the detailed itinerary of very wealthy people who are travelling to the Klondike for pleasure. The element of narrative, linear time is emphasized by the naming of each of their stopovers. The article ends with the sentence "They have gone for pleasure, and have no need for prospecting" ("To the Klondike for pleasure," 1897) which is not so much describing a fact (i.e. an element of reality of an event that has happened), as it is describing an opinion, an intention, or a sentiment. Or, to draw a metaphor from the rules of English grammar, it does not reflect an indicative mood but a subjunctive one "expressing what is imagined or wished or possible". ${ }^{22}$ The expurgate style of writing reflects a certain quality of Anglo-Saxon reserve and stolidness often associated with factuality. However, factuality is not a matter of literary style. It is related to whether an event is real or not, whether it has happened, is happening, or will happen

22 "subjunctive adjective" Oxford Dictionary of Englısh Edıted by Angus Stevenson. Oxford Unıversity Press, 2010 Oxford Reference Onlıne. Oxford Unıversity Press. Carleton Unıversity. 5 June 2011 $<$ http://www.oxfordreference.com/views/ENTRY html?subview=Main\&entry=t140.e0824300> 
for sure. If an impression of factuality is created by style rather than by truth value, then it is purely rhetorical, that is, it is not based on fact, but on opinion meant to persuade.

By contrast, The Toronto World article offers an obvious motley mix of fact and opinion. One could argue that this style creates more transparency in the sense that the style of writing makes it clear that it is not purely factual. For instance, in the passage that reads, "It must not be supposed that poor men only are being sent to the Klondike," the modal verb "must" in the verbal group "must not be supposed" of the first sentence announces a rhetorical style that aims to persuade. But in the three sentences that follow, opinion and rhetorical style are gradually replaced by harder and harder facts. The last sentence of the paragraph is "One of these is Judge H. G. Bond, a millionaire, formerly from New York, whose son, Marshall Bond, left yesterday with four prospectors in his employ". The whole paragraphs uses opinion to work its way into this one fact. One could also argue the obverse, namely that one hard fact is used to support the opinion that readers must realize rich men are just as motivated to go to the Klondike as poor ones. Either way, fact and opinion are both used, just as is the case in The New York Times example which begins with hard facts and ends with the couple's purported intentions.

The title of each article underscores this. The New York Times article is titled "To the Klondike for pleasure" which can only be an opinion: an intention cannot be a fact because it is not an event that has happened or that will happen. Whereas The Toronto World article is titled "Rich men are going, too" which turns out to be a fact when we are confronted with the evidence that Judge H. G. Bond's son has left and is on his way to the Klondike. Perhaps ironically, The New York Times article actually provides more evidence of the World's opinion that rich men are going too. 
This brief qualitative analysis of the empirical data has been included to demonstrate an important idea in the context of this case study: a framework that creates a dichotomy between "information journalism" and "story journalism" can reinforce the idea that some newspapers adhere to what Chalaby (1998) calls "fact-centered discursive practices" and a factual ethic, while others do not. This results in a taxonomy of newspapers that classifies journalism according to its factual value. Viewed in the context of today's journalism norms of objectivity, it suggests that "information journalism" was more factual, more accurate than "story journalism". Yet, this is not at all what Schudson (1978) meant in the context of journalism in the 1890s:

At the turn of the century there was as much emphasis in leading papers on telling a good story as getting the facts... reporters sought as often to write 'literature' as to gather news...in the 1890 s, changes in the ideals of journalism did not translate into occupational norms so much as make newspaper ideals and practices consonant with the culture of dominant social classes...even at the New York Times, it was uncommon for journalists to see a sharp divide between facts and values. Yet the belief in objectivity is just this: the belief that one can and should separate facts and values [sic]. (Schudson, 1978, p. 5)

To illustrate the rhetorical character of taxonomies, one can imagine organizing the newspapers that constitute the sampling frame of this case study by placing them in either of the categories that represent Schudson's two models of journalism. Given that the dominant norms of modern journalism listed in Chapter Three are neutrality, impartiality, balance, fairness, retreatism, truthfulness, factuality, accuracy, and completeness (Chalaby, 1998, p. 130), in the context of academic research, newspapers listed under the "information model" would inevitably appear as having more authority as factual organs of information. This idea would be reinforced by the fact that they are 
listed in a category called the "information model" in contrast to a category called the "story model". Since all the newspapers not listed in the "information model" category would be listed in the "story model" category, the resulting table would create the impression that both categories are absolutes. Such a discursive strategy would be deceptive.

It is easy to fall prey to this rhetoric in academic works. One could imagine that a footnote or an in-text citation could also be included next to the name of each newspaper to show that journalism scholarship has described the newspapers in "information journalism" or "story journalism" terms. For instance, one could cite Sotiron (1997) when he contrasts The Toronto World and The Montreal Daily Star with newspapers that "emphasized the information aspects of news" (p. 16). Classifying the newspapers in this way would lead the reader of this case study to believe that "information journalism" newspapers might be more factual. This is not the case. Schudson (1978) clearly states in the quote above that in the 1890s, both "information journalism" and "story journalism" presented a mix of facts and values. The empirical data of this case study confirmed this.

For this reason, Table $\mathrm{C} 2$ was created to provide a relative index of "story journalism" in which most newspapers of this case study's sampling frame fall somewhere within the spectrum that exists between "information journalism" and "story journalism". It is relative in that newspapers are compared in relation to each other. Furthermore, it is relative in that this index is a very rough evaluation of each newspaper in the context of this sliding scale. Table $\mathrm{C} 1$ provides the criteria and calculation method used to devise Table C2. It is noteworthy that these criteria mostly refer to style and 
graphic characteristics. Consequently, neither Tables $\mathrm{C} 1$, nor $\mathrm{C} 2$ allow for the measurement of the factual content of the newspapers in relation to their fictional content.

\section{Style in relation to fact and fiction}

Schudson's (1978) two paradigms of journalism oppose the word "information" to the word "story"; this evokes the idea that his paradigms are to be construed in terms of fact vs. fiction. However, the empirical data collected in this case study suggests that an in-depth qualitative analysis of newspapers in the 1890 s would probably reveal that there are far less differences between proportions of fact and fiction, or fact and opinion, in different newspapers than is suggested by the terms used to describe Schudson's models. What was glaringly different in the newspapers of this case study's sampling frame was the style in which fact and fiction were interwoven and presented. To this effect, it is most interesting that when Schudson (1978) refers to his two models of journalism, he specifically uses the word "style" to distinguish them. For instance, in the chapter titled Two journalisms in the 1890s, Schudson (1978) writes "But what defined sensationalism in the 1880 s was less substance than style: how extravagantly should the news be displayed?" (p. 95). Conversely, in describing Julius Chambers' apprenticeship as an "information journalist", Schudson (1978) writes "Shanks forces Chambers to acquire a form of composition very difficult to overcome in after years [sic] - a style accurately described by John Hay... as the 'The Grocer's Bill'. That meant, Chambers recalled: facts; facts; nothing but facts"' (p. 77).

Style does not determine whether information is fact or fiction. Style is not as much a method of gathering information, as it is a method of presenting it. Chalaby 
(1996) claims that "historically, the discursive practices which can be identified as journalistic were neither literary nor political in character" (p. 311). This idea is at odds with Ricour's (1981) argument that historicity and narrativity are directly related to one another (p. 274). It is also at odds with Schudson's (1978) arguments that on the one hand, "story journalism" adopted a lively literary style that contrasted with that of "information journalism" in the 1890s, and on the other hand, that both "information journalism" and "story journalism" presented a mix of facts and values (i.e. opinions) in the 1890s, two ideas that the empirical data confirmed as demonstrated in the comparison of The Toronto World and The New York Times entries. Consequently, different styles of journalism in the 1890s actually do not help in distinguishing a journalism of fact from a journalism of fiction, or help in measuring factuality in news-discourse.

\section{The style of objectivity}

Scholarly arguments that support the view that factuality in journalism is based on norms of objectivity that inform practices of news gathering do not make a clear case either. Chalaby (1996) for instance, states that "from the 1850s onwards, AngloAmerican journalists began to make the typically journalistic claim to be neutral and objective" (p. 311). He then claims that in the nineteenth century, the Americans and the British invented new methods such as news reporting and interviewing that allowed journalists to stick to the facts and distance themselves from opinions (p. 311). It is true that both "story journalism" and "information journalism" used these techniques in the 1890s. Chalaby (1998) remarks however, that popular daily newspapers in the late nineteenth century that would qualify as organs of "story journalism" prioritized the coverage of extraordinary events and played them up as media events by representing 
them through dramatic strategies that included reporting "every detail of these events, drawing maps, interviewing witnesses and public officials and suggesting hypotheses" to create a mise-en-scène (p. 101). Thus, on the one hand, Chalaby is claiming that interviewing and reporting were new "fact-centered discursive practice" that allowed a scientific objectivity in news that did not exist before, and on the other hand, he is claiming that such practices were subverted to produce fiction, rather than fact, in the case of sensational news. But if fact-centered discursive practices are what guarantee journalistic objectivity then why and how do they so often not produce news that is objective?

On this subject, Ward (2004) remarks that on the field, news reporting in the nineteenth century was not a passive empiricism that consisted in recording information in a stenographic manner, but an active empiricism of looking for good stories, investigating, selecting, and eliminating information (p. 197). These actions are neither apolitical, nor are they neutral, nor are they objective, if such terms imply absence of human agency. Thus, this case study takes the position that Chalaby's (1996) statements about the principle of objectivity and journalistic norms speak to the rhetoric of modern news-discourse: the claim that it has truth value. This thesis is the cornerstone of Ward's (2004) detailed treatise on the development of journalism ethics. In this work, he argues that in the context of modernity, norms of truth and factuality served the rhetorical function of bringing together and binding the producers of modern news with its audience by giving the press a role that it would seem indispensable in fulfilling (p. 33).

Consequently, in the context of this case study what is retained from Chalaby's (1998) thesis is simply the idea that the professionalization of journalism emphasized 
certain methods of gathering and disseminating information that constitute a distinct epistemological paradigm used to produce the type of modern news-discourse that has prevailed in Canada and the United States since the mid-nineteenth century. However, contra to Chalaby, this case study takes the position that these methods are not de facto objective since from a Kantian perspective, no epistemology guarantees truthfulness or factuality.

Nor are these methods entirely new. The acta diurna described in Chapter Three offered factual accounts of the deliberations of the senate; news of the law courts; dates and names of births, marriages, deaths; accounts of events; reports of gladiator matches; self-publicized descriptions of debauchery amongst emperors; or banal news stories such as "the story of the execution of a man whose dog simply would not leave his dead master's side, even going so far as to follow his master's corpse into the Tiber River in an effort to keep it afloat" (Stephens, 2007, p. 57). This type of reporting seems very similar to what Chalaby (1996) describes as the "fact-centered discursive practices" invented by Americans (p. 311). Indeed, one surmises that the reporter-scribes must have resorted to interviewing in some form or other to collect some of their information. This is not mere hypothesis since the Greek historian Herodotus was practicing modern interviewing techniques centuries before in Ancient Greece: "My job throughout this account, is simply to record whatever I am told by each of my sources" (Herodotus qtd in Ward, 2004 , p. 40). Thus, ancient methods of news gathering and dissemination seem surprisingly similar to those of modern journalism and the ethics of objectivity it lays claim to. 


\section{The emergence of modern journalism}

What then is the context in which the news images examined in this case study were produced?

The professionalization of journalism was a gradual process that took place during the industrialization of the press in the nineteenth century. It was a necessary adjunct to the marketplace of ideas that newspapers were becoming in order to attract more readers. What is called "news" today is the product of journalism practiced by the market-based press that emerged in this transitional period of the nineteenth century when newspapers went from being organs of opinion to organs of information in order to appeal to a majority of readers, beyond questions of partisanship (Ward, 2004, p. 192) This explains why modern journalism is described as apolitical, neutral, and objective; It is no longer the platform of publicity for political parties. This however, does not mean that questions of power, ideology, or identity are not at stake in modern news-discourse. It simply means that modern news is no longer defined by boundaries of political affiliation. What boundaries is it defined by? This case study argues that the boundaries that define modern news are constantly shifting because it caters to liberal democratic regimes. More specifically, as Ward (2004) writes, "The market, not elites, defined what was news and information" (p. 193). Thus, the turning point in modern journalism was not the creation of a non-partisan press but of a press accessible to all.

Indeed, journalism historians roughly agree on the fact that the creation of the penny press in the 1830 s is the original landmark of this market-based press which forms the corpus of this case study (Bacot, 2005; Barnhurst \& Nerone, 2001; Schudson, 1978; Stephens, 2007; Ward, 2004). As a popular press intended for a mass readership, the 
penny press required means of mass production. This inevitably led to the implementation of a system of newspaper production that coordinated new print technologies with a specialized, skilled labor force (Ward, 2004, p. 181-182). A journalist was a cog in this wheel or to refer to the metaphor of weaving presented in Chapter Three, the journalist is the worker who operates the loom.

Although the penny press laid the foundation for the professionalization of journalism and the commodification of news, the development of the modern masscirculation newspaper occurred at a distinct pace and under considerably different circumstances in Britain, France, Germany, the United States, and Canada (Ward, 2004, p. 182). For this reason, there is a great deal of variation in how journalism historians chart this evolution. Given that this empirical study is concerned with Canadian and American newspapers in 1897, it lends more importance to sources that examine the nineteenth century evolution of the popular press in Canadian newspapers (Kesterton, 1984; Rutherford, 1975, 1982; Ward, 2004) and American ones (Barnhurst \& Nerone, 2001; Campbell, 2001, 2006; Schudson, 1978; Sloan \& Mullikin Parcell, 2002; Stephens, 2007).

This scholarship identifies several phases in the development of the market-based press. The first roughly spans from the 1830s to the time of the American Civil War. The second phase begins around 1865 and finishes in the middle of the 1890s. The third phase picks up at that point and lasts until WWII. It is noteworthy that the phases of development of the market-based press historically coincide with what Lacroix (1997) has described as the long waves of capitalist development each brought to a close by a specific structural crisis (p. 20). This is logical, if not obvious, given that what defines 
and drives the market-based press is the market itself. It confirms that there is a direct relationship between paradigms of journalism and waves of capitalist expansion. It also suggests that each phase of journalism is characterized by continuity and growth, while structural crisis are the points of rupture where change is not only possible, but necessary as well.

\section{7 as a turning point in modern journalism}

1897 , the year of the outbreak of the Klondike gold rush, marks one of these points of rupture. It is the year that roughly corresponds to the end of the second phase and the beginning of the third phase of development of mass-circulation newspapers. Mullikin Parcell (2002) has remarked that the Klondike gold rush provided daily newspapers such as the Seattle Times a reason to include more graphic material, including maps, drawings of the camps, and guides to the gold fields to give "readers a better understanding of the accompanying stories" (p. 329). Since the 1880s, illustrative material had become increasingly popular in a few daily newspapers, especially the type of sensational newspapers that Schudson (1978) associates with "story journalism" (p. 96), where editors felt that "graphics were needed to spice up the page" (Mullikin Parcell, 2002, p. 329). These newspapers practiced what is commonly referred to as yellow journalism which is characterized, amongst other things, by the "lavish use of pictures" (Mott, 1941, p. 539).

As Table C1 shows, the data examined in this case study confirms that the newspapers that were rated at the far end of the "story journalism" spectrum were indeed the ones that used the most news images in their coverage of the Klondike gold rush. For 
instance, the very first Klondike-related news image published at the outbreak of the event in this case study's sampling frame appeared on page 1 of The Examiner in San Francisco on July 16, 1897 (see Figure 8). The Examiner and the San Francisco Chronicle were the two newspapers most associated with "story journalism" in this case study's sampling frame (see Table C2) and they were indeed the first two newspapers to publish Klondike-related news images (see Table D). Conversely, the two newspapers that were rated at the "information journalism" end of the spectrum each only published a single image (see Table $\mathrm{C} 1$ ) and they did so much later than the other newspapers, more than ten days after the first news images came out in The Examiner and the San Francisco Chronicle (see Table D).

However, the newspapers that lie in the middle of the spectrum do not provide as clear a distinction. As Table $\mathrm{C} 1$ shows, some newspapers such as The Globe in Toronto and The Ottawa Free Press, had a style that was closer to "information journalism" yet they used many images in comparison to other papers, while others such as the Toronto World or the New York Herald had a style that was closer to "story journalism" yet their use of images was in the average range (see Table $\mathrm{C} 1$ ). This may be due to the fact that a shift occurred in the journalism practices in the 1890s and at the turn of the century. Once publishers understood that circulation figures rose when dailies included more illustrations, it became clear that news images could attract a larger readership. Morano (2002) notes that this was the primary incentive for the newspaper industry at large to adopt some of the graphic strategies of yellow journalism in the late nineteenth century (p. 320). 
Campbell (2006) argues that 1897 was a pivotal year in American journalism (p. 5). According to him, one of the major changes that occurred in journalism practices that year was a technical innovation that allowed the increased use of images in massproduced daily newspapers which would lead to "the eventual ascendancy of graphic illustrations (or 'visuals') in newspaper design” (p. 22). In January 1897, Stephen H. Horgan, one of the inventors of the halftone technology, perfected its transferring process by embedding halftones in high-speed rotary presses for the first time in history (p. 22). The halftone technology had been successfully used to reproduce photographs in newspapers since 1880 , but because it could only be done with flatbed presses at the time, it was an impractical method for large circulation dailies which of necessity, had to be printed on high-speed mechanical rotary presses (p. 21). Horgan's breakthrough changed this, inaugurating an era of journalism that increasingly used photographs to tell the story. In practice, however, many more years would be needed to make the process cost efficient and worth investing in (Mullikin Parcell, 2002, p. 330).

The data collected in the very large preliminary sampling frame of this case study empirically confirmed this. All the news images found in the dailies surveyed during the preliminary research stage were printed with the process line engraving technology, except for three photographs published with the halftone technique in The Daily Winnipeg Tribune in July $1897 .{ }^{23}$ Two of these photographs are portraits (see Figures 9) and the third is a landscape view taken at a very odd angle (see Figure 10).

\footnotetext{
23 Figures 9 and 10 were scanned from microform at a resolution of $600 \mathrm{pp}$ to be examıned and included in this thesis Upon close examination of these three photos, doubts arose about whether it was the halftone process or another reproduction technique that had been used to reproduce the photographs in the
} 


\section{News images in dailies in the late $1890 \mathrm{~s}$}

As rare as they were found to be in the dailies surveyed in this case study, photographs, did have a very important function in illustrated daily newspapers in the nineteenth century. For instance, the photograph in Figure 10 was found to have been used to produce a line engraving that was printed six days later in The Ottawa Free Press (see Figure 11). From her empirical research, Martin (2006) has observed that as early as 1857, engravings printed in weeklies were often created from photographs (p. 27). As she notes, engravings inspired by photographs rather than by sketching are more limited in what they can represent (p. 44). ${ }^{24}$ Because of this, one might expect that news images produced by engraving techniques in the late nineteenth century would have taken full advantage of the limitless possibilities of drawing a sketch from imagination, rather than copying a photograph. Instead, what the empirical data collected in this research has shown, is that in 1897, photographs were commonly used as the source material for news images produced as line engravings. As Martin (2006) has remarked, this underscores the fact that news images were produced in an assembly line system that involved division of

newspapers To determine which reproduction technique had indeed been used, a digital copy of Figures 9 and 10 were sent by email to Mrs Ala Rekrut, the Preservation Manager at the Archives of Manitoba. She was not able to confirm with absolutely certainty that the photos had been reproduced with the halftone technique, but she remarked that they most likely had, based on the fact that she saw "dot screens and other digital image pixel patterns which have masked the traces of the original halftone screen pattern" in Figure 9 and "a diagonal 140\% half tone screen-type pattern . In the mid tone areas of the Chilcott Pass image at about 130-140\% image size" in Figure 10 (Ala Rekrut, personal communication [email], July 7, 2011).

24 Martın argues that the technologies used to represent news images were instrumental in how meaning was constructed. To illustrate her point, she discusses the example of an engraving drawn from imagination which could depict a murder at any moment from evidence and descriptions, and remarks that it would have been unlıkely for a photographer in the nineteenth century to capture the event live Furthermore, she argues that, "Whatever its realısm, a drawing was the result of an artıst's ımagınation, while a photo taken on the spot could hardly be manıpulated after the fact" in Michèle Martın (2006) Images at War Illustrated Periodicals and Constructed Nations (Toronto University of Toronto Press), p 44. 
labor between the artist who was at the scene (i.e. photographer or sketcher) and the engraving artist who rendered this image from a studio (p. 54).

Figures $12,13,14,15$, and 16 show three different engravings respectively published in the San Francisco Chronicle, the San Francisco Examiner, La Presse, the Globe, and The Ottawa Free Press on different dates in the second half of July 1897 . The caption printed on the bottom of the engraved news image from the San Francisco Chronicle (Figure 12) reads "One of the First Houses on the Clondyke, [sic] (From a photograph received by the steamer Excelsior.)" which confirms that the primary source is a photograph. On close examination, if the cabin is taken as a reference point, it becomes obvious that all five engravings represent the same scene, and therefore, that they were all drawn from the same photograph. From one engraving to another, characters may have been more or less foregrounded, positioned differently in space or altogether left out, but the general organization of the space, its framing, the landscape, the design of the cabin, and the iconography of the image in general is consistent in all five engravings. Figures 12,13, and 14 respectively published in the San Francisco Chronicle, the San Francisco Examiner, and La Presse speak to the idea of artistic licence and sensibility by demonstrating that the same scene can be interpreted in different ways, while Figures 14, 15, and 16, which are the engravings respectively published in La Presse, the Globe, and The Ottawa Free Press are almost identical suggesting that the same engraving was used in three distinct Canadian newspapers on different days of the last week of July 1897.

Newell (1987) found that a large number of Canadian and American newspapers had covered the Klondike gold rush by using the Associated Press Service, an American 
news agency, as a primary source for stories and images (p. 102). The empirical data surveyed in this case study's sampling frame supported Newell's finding. In fact, not only was the same engraving often reproduced in different Canadian newspapers, but sometimes even in Canadian and American ones. For instance, a look at Figures 17, 18, and 19, shows the same engraving of a portrait of four "NorthWest Police" officers published in The Montreal Daily Star, the Globe, and the New York Herald. Figure 20 shows a close-up of this particular image in Figure 19. Comparing the two close-ups (see Figures 18 and 20) reveal that they are identical. What is more surprising though, is that the montage of images in the Canadian Montreal Daily Star (see Figure 17) is also identical to the montage of images in the American New York Herald (see Figure 19). A comparative study of this case study's news images has yielded numerous other instances of the same engraving being published in these newspapers on different dates.

Martin (2006) observed this phenomenon in the news coverage of the FrancoPrussian war in European weeklies in 1870 (p. 82; p. 162; p. 192). Although she acknowledges that cost efficiency may have been the rationale behind this practice of recycling and selling engravings from one newspaper to another, she also suggests that it is more likely that whoever owned the engraving tried to maximize its value by selling it to different newspapers (p. 82). This raises interesting questions regarding sources of information used to produce news-discourse in the nineteenth century press. 


\section{CHAPTER FIVE - THE HISTORICAL BACKDROP \\ OF THE KLONDIKE MYTH}

\section{From the Gilded Age to the Depression of the Eighteen Nineties}

When newspapers first announced that great quantities of gold had been discovered in the Klondike in July 1897, America was in the throes of the second biggest economic depression in its history (Berton, 1972, p. 94). The Depression of the Eighteen Nineties broke out in May 1893 in the wake of a sharp drop in the stock market which has been compared in significance to Black Tuesday in 1929 (Hoffman, 1970, p. 285). This crash was one of many events that caused the 'Panic of 1893', leading to farm distress, strikes, foreclosures, bankruptcies, shut downs, layoffs, high unemployment, and an increase in homelessness all across North America. ${ }^{25}$ Sullivan (1926) wrote: "this panic, in its ramifications, was one of the direct causes of the economic distress among great masses of average Americans during the early 1890's [sic]" (p. 170). Berton (1972) remarked that "Canada suffered just as badly" and "the slump that followed was the blackest the continent had known" (p. 94).

Berton (1972) also suggested that this depression had been thirty years in the making, "creeping", as it were, from the time of the American Civil War (p. 94). This thirty year period coincides with the second phase in the development of the marketbased press and roughly with Lacroix's (1997) second long wave of capitalist expansion

\footnotetext{
25 For detailed statistical analyses, see Charles Hoffmann (1970) The depression of the nineties; an economic history (Westport, Conn.: Greenwood Pub. Corp.). On the subject of farm distress, see pp. $272-$ 274 and pp. 280-281; on strikes, pp. 67-70; on bankruptcies, pp. 56-63; on shut downs, p. 83; on lay offs, p. 86; on high unemployment, p. 74 and pp. 108-110.
} 
(p. 20). The Depression of the Eighteen Nineties signaled the peak of the structural crisis which caused a rupture between two distinct eras. The result of this rupture was the beginning of new paradigms of capitalism and of journalism at the turn of the century in a period that overlapped with the Klondike gold rush.

Contra to Schudson's (1998) thesis that American newspapers either adopted an information or a story model of journalism in the 1890s, Rutherford (1982) posits that in the last few years of the nineteenth century, each Canadian paper had its own brand of journalism tailored to the largest market they could appeal to (p. 77). This is why their position on the spectrum of "story journalism" in Table C2 is to be understood as relative. If a strategy used by sensationalistic newspapers was attracting readers, even the most conservative newspaper was willing to try it. More than in the past, there was now an economic imperative for a newspaper to be competitive as a business. This sink or swim scenario shaped the new paradigms of journalism. W.J. Campbell (2001) has attempted to put yellow journalism in context by showing that it had a profound influence on strategies deployed in American modern journalism at the turn of the century (p. 2). As discussed in the previous chapter, this was one of the factors that prompted most newspapers to include more images. In this sense, the depression stimulated experimentation and innovation.

Most historians seem to agree that although the causes of the Depression of the Eighteen Nineties were complex and multifold, the years 1896-1898 were a turning point that marked the end of an era and the beginning of another (Hedges, 1939, p. 126; Link, 1967, p. 16). In particular, 1897, the year that inaugurated the Klondike stampede seems to have been a landmark, mainly because that was the year that saw the end of the 
Depression of the Eighteen Nineties (Hedges, 1939, p. 272). Link (1967) identified four factors that explain the return of economic prosperity during this period: the U.S. election of William McKinley in 1896 that stabilized a climate of political tension and uncertainty; an unexpected growing demand for wheat abroad from 1896-98; the economic stimulus of the American-Spanish war in 1898; and finally, a sudden, dramatic increase in the insufficient gold supply which had been one of the key causes of the depression of the Eighteen Nineties (p. 15). Hedges (1939) has in fact identified the discovery of gold in the Klondike as one of the factors that contributed to increasing the world's gold supply thereby helping put an end to the depression (p. 127).

But as Lacroix (1997) has argued, each long wave of capitalist development is "composed of a specific mode of accumulation of capital or accumulation of collective wealth, a type of productive force... [and] a type of social division on labor in national and global spaces [sic]"' (p. 20). Indeed, what preceded the Depression of the Eighteen Nineties was the Gilded Age, most often recalled as a period of great wealth, spanning from about the 1870s to the Panic of 1893 (Link, 1967, p. 5). It was a period of rapid industrial and economic expansion due to improvements in agriculture, "mining, transportation, distribution, and financial activity" (Hoffman, 1970, p. 271).

The Gilded Age was an era of heightened industrial productivity in the United States. It enabled a class of newly rich to build up their fortunes thanks "to the economic, political, and other advantages they had enjoyed since the Civil War" (Sullivan, 1926, p. 287). The lack of regulation that existed in the United States during this period gave businessmen an unprecedented freedom to compete in a market they could transform into an economy dominated by an oligarchy of industrial monopolies (Link, 1967, p. 6). Link 
describes it as a "generally acquisitive age, and the amassing of wealth was [the goal of the businessmen of the day], money their standard. Monopoly, subversion of representative government, and corruption of private and public morals - these were often necessary means in the fierce struggle for wealth and power" (p. 5).

The economic revolution of the Gilded Age took place in a climate of political laissez-faire that produced rich industrialists and money-lenders-turned-financiers at the expense of the livelihood of the working man. The newly acquired great fortunes were a result of the exploitation of natural resources and human labour. To make things worse, these conditions "favored the money-lenders and bankers and wreaked hardship on the debtor classes, for those who had borrowed money when it was cheap found that they must repay it when it was expensive" (Berton, 1972, p. 94). By exercising control over economic development, the finance industry contributed in widening this gap between the rich and the poor.

Thus, the term Gilded Age does not so much describe a golden era as it does one in which a thin veneer of gold has given a surface impression of luxury, glitter, and glamour. The broader picture of the Gilded Age revealed that in the rapidly growing urban centers that served the rationale of industry, most people lived in dire poverty “amid squalor and misery" (Link, 1967, pp. 6-7). They were Thomas Carlyle's 'havenots' while the 'haves' were the money-lenders and "those who had a talent for moneymaking or were otherwise favorably situated" (Sullivan, 1926, p. 287). Indeed Kindleberger (1978) even refers to the postbellum period from 1873 to 1896 as a "Great Depression [sic]" rather than one of economic growth (p. 213). As Berton (1972) writes, "it was an age of millionaires, but it was also an age of hoboes" (p. 94). This resulted in a 
tense social climate in what was in effect a two-class system. Between the rich and the poor "ran those currents of injustice, suspicion, and envy which composed the politics of the time" (Sullivan, 1926, p. 287). This may partly explain why in Tables A1 and A2, the readership is so polarized. It was either "highbrow" or "lowbrow" for the middle class seems, for the most part, to have been compromised in that era.

\section{From imagining to imaginings: the cult of the self and the pursuit of wealth}

It is noteworthy that during the Gilded Age, America saw, for the very first time in its history, a class of idle rich, which in turn produced a class of rich heirs. Sullivan (1926) describes this second generation as those whose plight was to fight "Harvard indifference" and imagine new ways of spending their time (pp. 287-288). ${ }^{26}$ Such a class had already existed in Europe since the French Revolution but its inception in North America dates to the Gay Nineties that closed the Gilded Age. Some of the nouveaux riches of the New World needed models for living that they could identify with. It is noteworthy that one of these models came, not from real life, but from fiction imported from Europe.

For over a century, English and French novelists had been portraying breeds of aesthetes who pursue the high life of love, pleasure, and fantasy (Baudelaire, 1972, p. 419). One of these archetypes is crystallized in the character of the dandy who indulges in "a kind of cult of the ego" (p. 420) and "who does not work for his living" and "attracts

26 The expression "Harvard indifference" describes the "definite cult of cleverness, exquisiteness, and boredom...exemplified by Whistler, Wilde, 'The Green Carnation,' etc." in Mark Sullivan (1926) Our times; the United States, 1900-1925. Volume 1: The Turn of the Century (New York, Scribner's), pp. 288 (Arthur Ruhl qtd in footnote 1). 
attention through his appearance" (Schmid, 2002, p. 83). In other words, the dandy imitates the European bourgeois man by self-consciously adopting the lifestyle of aristocrats. In Baudelaire's (1972) words:

[He is like] the wealthy man, who, blasé though he may be, has no occupation in life but to chase along the highway of happiness, the man nurtured in luxury, and habituated from early youth to being obeyed by others, the man, finally, who has no profession other than elegance... These beings have no other status but that of cultivating the idea of beauty in their own persons, of satisfying their passions, of feeling and thinking." (p. 419)

Dandyism is a phenomenon that emerged in England and France in the late eighteenth century, but only appeared in North America at the very end of the nineteenth century. The star cult of the dandy in the United States coincides not only with the Gilded Age, but also with the beginning of a realist movement in American fiction in which Americans were starting to take an interest in their own stories rather than "in the romances of English titled life" (Sullivan, 1926, 202). Americans increasingly wanted to express and expand their own individual and collective identity (p. 201). Popular print media such as newspapers and novels were tools to experiment and shape these new identities for, in the fin de siècle, "all at once, America found that she was full of materials for fiction" (p. 202; Pattee qtd in $n 1$ ). The dandy is an example of one of many fictional characters that provided North America with new models for living.

B. Anderson (1991) has argued that print-capitalism played a large part in how models of nationalism, once imagined, were "modelled, adapted and transformed" (p. 141). He credits the Americas with the invention of the concept of collective identity now called nationalism (p. 191). But in terms of models of individual identity, there was 
surely a cross-fertilization of influences between Europe and America, for novels and newspapers could also be said to have facilitated the spread of models of individualism and of the cult of the self. Lifestyles promoted by the modern novel, were both models for and models of life. Like many fictitious characters of modern novels, the dandy promoted an idea of happiness achieved through wealth, leisure, beauty, and selfcultivation. The realist movement may have at times championed the struggles of the ordinary man, but it could be argued that this would have made wealth even more enticing.

In this sense, it is possible that print-capitalism played a part in preparing a fertile ground for the mystique of great wealth that captured the imagination of Klondike stampeders at the end of the depression. This nuances Berton's (1972) argument that the extreme poverty experienced by most during the Depression of the Eighteen Nineties "was perhaps the chief reason for the intensity of the stampede that followed" (p. 95). Novels and newspapers may also have contributed in cultivating certain values and ideals which moved dynamically back and forth between the private and public spheres. Schmid (2002) proposes that in the nineteenth century, readers could attempt to escape their own individual fate by temporarily identifying with fictional characters; This allowed them to participate in collective imaginings that were objectified in the public sphere (p. 81-82). By borrowing from fiction new individual identities in the private sphere, they could consolidate a sense of collective identity in the public sphere. In this perspective, even the armchair stampeder could take part in the Klondike gold rush by keeping up with its characters and stories in daily newspapers. 
Berton (1972) has identified three other factors that could explain the proportion taken by Klondike gold rush: the absence of military conflict on the international arena in 1897; a certain utopianism that fuelled a romantic conception of adventurously travelling to faraway lands; and the growing influence of sensationalistic journalism. (pp. 95-96). This case study sets forth the hypothesis that there were two other historically rooted forces that may have contributed in shaping this event. The first one is that the Klondike gold rush is a historical chapter in a much larger westering "frontier process" that was taking place in that period. The second one is that faster and more efficient channels of communication of the market-based press were creating massive audiences which could be turned into a force of their own that produced individual imaginings in a very short time. Once shared, these imaginings, whether adopted or contested, would quickly become the raw material of a public myth. This case study makes the assumption that these two factors were intertwined, suggesting that it is the synergy between them that created the unique circumstances of the Klondike gold rush.

\section{Frontier processes}

The case of the Klondike gold rush is perhaps better understood through the lens of what Cronon, Miles \& Gitlin (1993) have called "frontier processes", which conceptualizes the complex interplay between productions of power, space and nature that transform a continental frontier into a region, or an unmapped territory into a political entity (p. 7). The authors explain that frontiers are fluid, dynamic spaces. North American frontiers in particular "were classically areas where the authority of the state was weak, where law was either the result of customary practice or makeshift invention" (p. 16). In frontier communities, people of different ethnic origins, classes, and religious 
beliefs had to learn to live side by side as peacefully as possible since they depended on each other for survival (p. 10). However, a frontier is unstable because it is a contested space. It is not a new space. It is an old space that new settlers are intent on occupying at the expense of those who are already there. Lamar \& Thompson (1981) have given the following definition of the concept of frontier:

\begin{abstract}
"We regard a frontier... as a territory or zone of interpenetration between two previously distinct societies. Usually, one of the societies is indigenous to the region, or at least has occupied it for many generations; the other is intrusive. The frontier "opens" in a given zone when the first representatives of the intrusive society arrive; it "closes" when a single political authority has established hegemony over the zone" (p. 7).
\end{abstract}

More simply, a frontier can be defined as a set of contested boundaries. Indeed, Cronon, Miles \& Gitlin (1993) have identified six characteristics of "frontier processes": species-shifting; market-making; land-taking; boundary-setting; state-forming; selfshaping (pp. 11-20). The authors have remarked that boundary-setting encompasses the other five characteristics of frontier processes (p. 16). They have discussed the emergence of different forms of boundaries in frontier processes in these terms: "economic boundaries of trade and production; the social boundaries between kin groups, tribes, and communities; and the political boundaries that defined who had power over whom" (p. 16); as well as the terrestrial boundaries that defines who controls the land (pp. 15-15). These boundaries form a matrix, so to speak, of rules that organize social life.

Frontier processes is therefore a set of process in which existing boundaries first become contested, then destabilized, and finally transformed into new boundaries, once again stable. In the case of the Canadian West, how did colonial frontiers become 
national regions? Cronon, Miles \& Gitlin (1993) have remarked that the frontier is often conceptualized as a clash between the rigid structures of the Old World (i.e.

Euroamerican mores and practices) and the freedom and opportunities of the New World: "the familiar frontier tension between reproducing the old and embracing the new" (p. 12). The authors argue that focusing on the invader helps perpetuate a narrative of conquest where civilization triumphs over savagery. They suggest that in fact, it is more accurate to speak of the frontier as a dialectical process in which the new emerges from the meeting and friction of two (or more) established cultures (p. 7). As they so eloquently point out, "the Europeans saw themselves as "discovering" the Indians, but of course, the discovery was mutual. Just as colonists gathered information about "new" frontier lands and their inhabitants, Indians soon learned the opportunities and threats the invaders offered" (pp. 10-11).

Cronon, Miles \& Gitlin's (1993) thesis offers information on what happens when frontiers become regions, but it does not explain by which process boundaries are transformed. The authors, however, provide a clue when they write, "People who moved to frontier areas carried a whole world inside their heads, but they transformed that world in the very act of bringing it to a new place" (p. 10).

Boundaries are a mental construct, a product of the imagination and of the logos, the process of conceptual thinking. The transformation of boundaries occurs first and foremost in the mind. But the matrix of boundaries that define the rules of social life in a frontier are intersubjective, that is, they are thoughts and beliefs shared by those who form a frontier community. Whether one agrees or opposes these ideas is of secondary importance. What is paramount is that they exist. An example drawn from a theory of 
neuro-linguistic programming can help illustrate this. If one person says to another, "don't think of a black cat", the result is that the second person will inevitably think of a black cat. The existence of a concept does not hinge upon whether it is presented or construed in negative or positive terms. A concept manifests through the act of thinking (i.e. cognitive) or naming (i.e. discursive). Thus the transformation of boundaries is a process that involves both cognition and communication because a boundary is an imaginary construct. It can be given authority by being expressed and represented in different forms, but it is first and foremost a product of the imagination.

\section{The stabilizing of boundaries}

How do boundaries become more stable? If boundaries are a product of the imagination so is their stability. Thus the real question is how does one create the illusion of stable boundaries? Specifically, in the context of the Klondike gold rush, the question is what strategies were used to redefine boundaries on this frontier of the Canadian West? Recall that the second factor this case study put forth to explain the proportion the stampede took was that the faster and more efficient channels of communication of the market-based press were creating massive audiences which could be turned into a force of their own that produced history. Throughout history, news and myth have been communicated through word of mouth or else recorded and consumed on fixed media. This case study takes the position that the act of recording on print media played no small part in stabilizing and reifying boundaries, specifically boundaries of imagined nationhood in the Klondike episode. 
In his writing on Actor-Network theory, Latour (1986) argues that processes of visualization and cognition are used, not only to communicate, but also to persuade and dominate by creating a self-perpetuating illusion of accuracy. According to Latour, the rhetorical power of print media lies in the fact that it is, on the one hand, optically consistent (p. 10), and on the other hand, reproducible and mobile (p. 11). The optical consistency of print media is its immutable character which results in the creation of stable, visual traces intended to describe events (p. 10). The reproducibility and mobility of print media enable its dissemination, its ability to reach people that are far apart and to mobilize their thoughts, to bring their imaginings together, so to speak. Latour argues that the function of immutable mobiles is not to accurately represent facts but to act as rhetorical devices (p. 20). He describes visual culture as a space where "fact and fiction, words and images" meet (p. 10). He writes: "No matter how inaccurate these traces might be at first, they will all become accurate just as a consequence of more mobilization and more immutability" (p. 11). Although Latour casts his argument in the context of power and domination and in relation to science and technology, elements of his thesis can be used to conceptualize how boundaries can be stabilized with the use of news images.

\section{Facts, fiction, and technology: the perfect storm}

Ward (2004) remarks that the rhetoric of scientific objectivity has gone hand in hand with the use of technology since the scientific revolution: "In early modern science, instruments were the generators of objective facts" (p. 63). An apparatus such as the microscope could reveal a hidden truth invisible to the naked eye. Ward argues that this mutually defining relationship between objectivity and technology brought to bear heavily on modern journalistic norms (p. 187). Indeed, nineteenth century news-discourse 
developed concomitantly with technologies such as photography and the telegraph commonly used as "tools for news" (p. 186).

In the nineteenth century, there was a widespread perception that photographic images could capture reality and that the telegraph assisted journalists in producing facts (p. 197). The former offered a copy of reality while the latter could distill it to its quintessence: its basic facts. Did such technologies have a purifying effect on information? This belief was so entrenched that even journalists used technological metaphors to reinforce the factuality of their news-discourse. For instance, when describing the information model of journalism in the 1890s, Schudson (1978) writes that the Chicago reporter George Ade expressed "that his ambition was to be known as a 'realist' and a man with 'the courage to observe human virtues and frailties as they show on the lens"" with the ideal that "...the newspaper story, the magazine article, and the novel could be, and should be, photographically true to life." (p. 73). Similarly, Ward (2004) writes that "In 1894, C.F. Bell, a manager at the Times instructed a war correspondent that "telegrams are for facts; appreciation and political comment can come by post"” (p. 188).

As Latour's discussion (1986) demonstrates, the idea that technologies of reproduction can generate facts is a myth. It is easy to dispel this idea in relation to the telegraph and to photography. In the case of the telegraph, one can simply argue that the telegraph can be used just as efficiently to transmit opinions as facts. The telegraph is a technology that is also sensitive to what Hartley (1982) calls the paradigmatic and the syntagmatic relations within language: what facts are included/excluded and in what order the included facts are presented (p. 20-21). Information transmitted telegraphically 
is not necessarily factual simply because it is concise. To expunge literary style does not magically transmute information into facts.

A news-discourse that lists information in a plain way is called a chronicle. Bird \& Dardenne (1997) point out that this genre of news has always existed, even in oral cultures (p. 339). Schudson's information model of journalism resembles the chronicle genre in style, as opposed to the narrative genre associated with the story model of journalism. For practical reasons, the telegraph may have been more suited to the chronicle, but the belief that the telegraph was a technology that helped news-discourse become more objective is rhetorical. It derives from beliefs associating scientific objectivity to scientific instruments.

In relation to photography, scholarship in this field has put a great deal of focus on making a distinction between the real and the constructed. What is commonly called the "myth of photographic truth" is simply the false idea that photographic images represent the real. Marien (2006) draws examples from the history of photography to prove that photography has always been part fiction by describing techniques such as $\mathrm{Le}$ Gray's combination printing in the early 1850s (p. 78); Baldus's composite negatives in the same period (p. 58); and Southworth \& Hawes' staged photographs as early as 1847 (p. 43). In its early days in the nineteenth century, photography was often called the science of photography, but some referred to is as the art of photography because they knew that framing, exposure, and printing were ways to hide and reveal the truth of a photographed scene, to narrate it, so to speak. In aesthetic studies, the most interesting works of photography and cinema often consciously play on the medium's capacity to record and render both the real and the unreal. To this effect, Barthes (1957) has 
remarked that the mythopoetic plays on this same duality when he writes that a reader experiences myth as a story that is both true and unreal (p. 215). ${ }^{27}$

Consequently, one could argue that technology cannot make facts or make information more factual. Indeed, the effects created by lighting, depth of field (focus), and focal length captured on photographic media could be said to actually offer new ways of seeing that the human eye cannot produce on its own. An extreme example of this is a portrait taken with a fish-eye lens. Like a convex mirror, it completely deforms the subject's feature in such a way that the eye itself cannot. It also alters appearance in a non-realistic way. Thus, photography may even produce more fiction than it does fact. And like the microscope, it does not offer more facts than the naked eye. It only offers the possibility to see them differently. Some would say, in a fictional way.

Ward (2004) has argued that the discourses of facts that emerged in journalism in the nineteenth century had its roots in the scientific revolution's cult of technology (p. 196). News-discourse at the turn of the century was produced with scientifically-inspired instruments, practices, and norms of modern journalism that created the illusion that the truth could be known by being recorded, rather than alluded to by being represented.

Latour (1986) has argued that science and technology emerged and gained authority thanks to the rhetorical power of immutable mobiles which offer consistent information recorded on mobile, reproducible media. He emphasizes that it is not the inscription per se that is rhetorical but the agonistic relationship between those who

27 "Le lecteur vit le mythe à la façon d'une histoire à la fois vraie et irréel," in Roland Barthes (1957) Mythologies (Paris, Éditions du Seuil), p. 215. 
present it and those who consume it (p. 5). According to Latour's definition, newspapers could be considered immutable mobiles. While the nineteenth century scientific rhetoric of truth reinforced the legitimacy of news-discourse, the massive audiences mobilized by newspapers-as-immutable-mobiles guaranteed its impact on an unprecedented scale. As Latour pointed out, the wider the diffusion, the more the immutable mobile is believed to be accurate (p. 11).

By sheer virtue of their number, newspaper readers became part and parcel of the process of producing news-discourse by collectively and simultaneously participating in an intersubjective collective imagining mobilized by news-discourse. Thus, the rhetorical character of science, technology, and visual culture came together to create the perfect storm in which history was made by mobilizing the imagination of a large number of individuals and keeping these imaginings more or less consistent. Variations did occur on a local level and on other levels such as class. A highbrow newspaper did not promote the exact same imaginings as a lowbrow one. But there was still an overall consistency in how the world was being represented: the boundaries were similar.

\section{The reification of boundaries through the mapping of reality}

This case study argues that it is through such rhetorical strategies that national boundaries were stabilized, and subsequently reified in the context of the Klondike gold rush. The wide reaching nature of news images as a lingua franca in the efficient publishing and distribution circuits of 1897 daily newspapers in North America helped create imagined boundaries of nationhood amongst readers who never left home and travelled vicariously through the images they saw in newspapers. The fact that the 
Klondike gold rush occurred in a frontier, a place where boundaries are by definition contested, contributed in reinforcing a rhetoric, not to say a myth, of nationhood that had already been in the making for well over a century. For in the imagination of the armchair stampeder, the Klondike was not only a physical place, it was also the symbolic site of national imaginings where soft boundaries could become hard ones. In this sense, print media played an important role in the reification of boundaries because they repeatedly appealed to the imagination of a large number of people at a given time.

Analysis of the empirical data revealed that a number of strategies were deployed and repeated in news images at the outbreak of the gold rush. For instance, the indispensable role played by First Nations peoples in this episode of Canadian history is obscured by their absence in the news images surveyed in this case study. This visual omission placed them outside the social boundary associated with the transformation of the frontier into a Canadian region. Their absence served to map the boundaries of nationhood in that era.

In news-discourse, the inclusion and exclusion of information refers to the paradigmatic relations within language described by Hartley (1982) who argues that news events are constructed into stories intended to provide a map of reality for the reader. Following Hartley's idea, the word mapping can be used in this case study to describe the process of setting boundaries. Given that the concept of boundaries designates a matrix, rather than a single line, a two dimensional structure rather than a one-dimensional one, the term mapping seems more evocative of this spatial distinction. In its strict mathematical sense, the term mapping essentially means to associate different elements into a set, a definition that seems to match the process of creating a matrix. But more 
significantly, it is germane to this case study because it is a term widely used today to discuss how news-discourse selects, organizes, and presents facts to publicize an event. ${ }^{28}$ For this reason, it complements the concept of boundaries in the context of this case study.

One of the reasons why "mapping" has become such an operative word in the analysis of news may be because it is a term that can simultaneously refer to two distinct forms through which news-discourse manifests, namely the representational and the conceptual. News-discourse represents an event with words and/or images that enables readers to imagine it in his mind. The actual physical, spatial map of words and images printed on the newspaper page provides readers with a prefabricated mental map that makes an impression on their imagination. This echoes Dayan's (2005) idea of "prefiguration" in relation to B. Anderson's (1991) writing on imaginings: the act of imagining an event in one's mind is both a mental and visual experience. The same can be said of the act of imagining a boundary.

\section{Social, spatial, and temporal boundaries}

B. Anderson (1991) has argued that national imaginings in the nineteenth century were given tangible forms in three institutions of power: the census, the map, and the museum (p. 163). To use Geertz's metaphor once again, these institutions functioned as both models for and models of imagined communities. They are symbolic systems

\footnotetext{
28 "Map (verb): 2. chiefly (Mathematics) associate each element of (a set) with an element of another set; 3. [no obj.] (map on to) chiefly (Mathematics) be associated with or linked to" in "map verb" Oxford Dictionary of English. Edited by Angus Stevenson. Oxford University Press, 2010. Oxford Reference Online. Oxford University Press. Carleton University. 24 May 2011 <http://www.oxfordreference.com/views/ENTRY.html?subview=Main\&entry=t140.e0498950>
} 
through which boundaries are reified, and over time, re-enacted, thus made to become stable. Given that B. Anderson (1991) specifically discusses them as tools used by colonial powers to construct the national imaginings of their dominions (p. 164), it seemed fitting to adapt his three-prong concept into an analytical tool for this case study.

In his chapter titled "Census, map, museum", B. Anderson (1991) has described the census as a strategy used by colonial states to shape the imaginings of "the nature of human beings it ruled", while the map defined "the geography of its domain", and the museum reinforced the "legitimacy of its ancestry" (p. 164). In terms of nationhood, the census, the map, and the museum therefore circumscribe the boundaries of race/gender/class, territory, and patrimony, respectively. In the context of this case study, race, gender and class are construed as categories used to define "social boundaries" between people; territory delineates "spatial boundaries" which find their representation in maps and landscape; and patrimony consists of selected artifacts that stand as the repository of a grand narrative of history which circumscribes the "temporal boundaries" of a nation, the history that legitimates it. The last three chapters of this case study use each of these categories to analyze news images published at the outbreak of the Klondike gold rush.

The analysis in the next three chapters will also be informed by the concept of Anglo-Saxonism which Arenson (2007) has described as a hybrid type of national identity that, on the one hand, hinges upon ideas of race, and on the other hand, underscores a tension that B. Anderson (1991) called the "inner incompatibility of Empire and nation" (p. 93). Arenson (2007) has argued that the frontier community that developed in the Yukon as a result of the Klondike Stampede represented an "early 
testing ground" for an "emerging world view" that "united American and British symbols and destinies" (p. 380). By this, he meant that in the Klondike, Canadian (Dominion) identity and American identity were not so much in competition over national borders as they were allied in a joint project that connected the American notion "of Manifest Destiny and continental expansion to a global imperialist calling through a sense of racial dominance that went beyond national differences" (p. 378). It is noteworthy that the ideas set forth by Arenson lend themselves to a rich discussion of B. Anderson's (1991) argument which states that, although a common vernacular language may have been instrumental to circumscribing the imagining of a nation, it sometimes yielded a plurality of "nations" - as was the case in Latin America (p. 67). Thus, the next chapters attempt to test Arenson's (2007) claim by posing the question: "Is a rhetoric of Anglo-Saxonism manifest in the news images under study?" 


\section{CHAPTER SIX - GRAFTING EUROAMERICAN SOCIAL BOUNDARIES OF RACE, GENDER, AND CLASS ONTO THE FRONTIER}

\section{Anglo-Saxonism}

The concept of Anglo-Saxonism specifically relates to the historical period of the Klondike gold rush. S. Anderson (1981) defined it as an ideology that posits "that the civilization of the English-speaking nations was superior to that of any group of people on the planet" (pp. 11-12). Drawing on the scholarship of numerous authors that have described this Anglo-American diplomatic rapprochement, S. Anderson (1981) argues that it was only influential in a narrow window of time, between roughly 1895 and 1904 (p. 13). ${ }^{29}$ During this period, "after well over a hundred years of American Anglophobia and British condescension toward Brother Jonathan, distrust and loyalty gave way to a relationship that was close and fundamentally friendly" (p. 11). In fact, this rapprochement could best be described as a racial alliance:

A belief in the innate superiority of the "Anglo-Saxon race" was part of the prevailing orthodoxy in both Great Britain and the United States in the late nineteenth and early twentieth centuries. Articulate Englishmen and Americans at all levels of society declaimed about the supposed racial affinity of their two countries and described Great Britain and the United

29 In Race and rapprochement : Anglo-Saxonism and Anglo-American relations, $1895-1904$ (Rutherford [N.J.] : Fairleigh Dickinson University ; London : Associated University Presses), Stuart Anderson (1981) cites the following works as important sources on this subject: L. M. Gelber, The Rise of Anglo-American Friendship (London: Oxford University Press, 1938); R. H. Heindel, The American Impact on Great Britain, 1898-1914 (Philadelphia: University of Pennsylvania Press, 1940); C. S. Campbell, AngloAmerican Understanding, $1898-1903$ (Baltimore: Johns Hopkins Press, 1957); A.E. Campbell, Great Britain and the United States, $1895-1903$ (London: Longmans, Green and Co., 1960); R.G. Neale, Great Britain and United States Expansion (East Lansing, Mich.: Michigan State University Press, 1966); and B. Perkins, The Great Rapprochement (New York: Atheneum, 1968). 
States as natural allies because of the racial bond [italics added]. (S. Anderson, 1978, p. 222)

Although this ideology mostly served the political agenda of statesmen and diplomats at the time, its popularity was legitimated by beliefs in ideas of racial superiority that were widespread in late nineteenth-century society throughout most of the Western world. Charles Darwin's On the Origin of Species by means of Natural Selection; or, the preservation of favored races in the struggle for life, first published in 1859 , is often cited as one of the canonical works used to give authority to new forms of racism in the nineteenth century. According to Flew (1997), Darwin himself did not espouse the racist beliefs that are often associated with his work (p. 95). ${ }^{30}$ However, this did not stop many scientists of the time, such as Darwin's half-cousin Sir Francis Galton, from subverting the meaning of some of the ideas expounded in On the Origin of Species to lend authority to their own theories of biological determinism, which can be defined as "the belief that the character, abilities, and even destiny of each individual were strongly influenced, if not absolutely mandated, by biological inheritance" (Cole, 2001, p. 97). Anglo-Saxonism is an offshoot of nineteenth-century biological determinism and its companion concept of race, which proposed a classification and conception of humanity based primarily on differential physical characteristics (Horsman, 1981, p. 60).

In practice, the concept of Anglo-Saxonism is a form of racism that has no scientific applications whatsoever. Many scholars argue that racism is an intellectual

30 On the subject of Darwin being opposed to racial injustice, see also Wilkıns, J. S., (2008), Darwın, in A. Tucker (Ed.), A Companıon to the Philosophy of History and Historiography Blackwell Companions to Philosophy (pp. 404-415) (Chichester, U K. , Malden, MA : Wiley-Blackwell), pp. 408-413. 
construct that emerged in the eighteenth and nineteenth century as a result of new scientific discourses, especially biological science applied to theories of society. This appears a short-sighted to modern scholars such as Fredrickson (2002) who argues that it had its roots in the fourteenth and fifteenth century (p. 6). Fredrickson's discussion of the history of racism is useful in that it underscores the fact that, notwithstanding its different definitions, sources, and forms, racism is a discourse that "directly sustains or proposes to establish 'a racial order', a permanent group hierarchy that is believed to reflect the laws of nature or the decrees of God" (p. 6). In other words, racism is not only a historical construct, it is also a political one. Anglo-Saxonism is a form of racism that applies its conclusion to the organization of social relations in spite of the fact that it seeks its legitimacy in the premise of the science of biology. Like all forms of racism, the rationale of Anglo-Saxonism is therefore a non sequitur in that its conclusions do not follow from its premises because the former deals with the political and the latter with the biological.

Accordingly, this case study construes Anglo-Saxonism as a rhetorical device used by a group that defines itself in terms of race to vie for power. As a racist discourse, it both competed with, and was complementary to, the discourses of nineteenth century nationalism and new imperialism. Indeed, S. Anderson (1981) suggests that at the turn of the century, there was a synergy between nationalism, imperialism, and racism (p. 18), an idea that B. Anderson (1991) also takes up in Imagined Communities (p. 150). Seen in this light, the establishment of a relationship between race and nation can be viewed as a strategy used to political ends.

What then could some of these political ends have been in the nineteenth century? History reveals that the world in the nineteenth and early twentieth century was the 
theatre of new imperialist policies first practiced by the great European colonial powers, and later by the United States as well. In fact, the period ranging from the mid-1880s to 1914 is commonly referred to as the "age of imperialism". This period overlaps with that of Anglo-Saxonism.

But this gives rise to the question, are the self-contained and self-preserving concepts of race and nation not inimical to the expansionist forces of imperialism? Indeed, what could explain the claim set forth by scholars that a synergy existed between race, nationalism, and imperialism at the turn of the century? At first glance, it does seem counterintuitive to suggest that racism and nationalism could work in tandem with imperialism. When the terms race and nation are used almost interchangeably, they suggest ideas of homogeneity and purity that one would imagine would be sullied by the conquest and annexation of other races and nations. However, a race or a nation can exist only if it is distinct from other races or nations. Aristotle's axiom of logic only admits a concept (i.e. $A$ is $A$ ) by defining it to its opposite (i.e. $A$ is not Not-A). For this reason, a racially-based idea of national identity can only discursively exist in relation to other racial and national identities set in a national or transnational frame.

To understand how imperialism ties in with racism and nationalism in AngloSaxonism, one must look at the nature of this relationship. The literature on this subject is consistent: the Anglo-Saxon race must dominate and exploit other races because it is said to be superior. Figure 21 is an "anti-imperialist" political cartoon making fun of Rudyard Kipling's poem, which exhorted Americans to "take up the white man's burden" of bringing civilization to savage peoples (Life, Vol. 33, March 16, 1899. p. 1). The image shows Uncle Sam traveling with John Bull. Each of them is carried by their respective 
colonial subjects: Uncle Sam by a Filipino and John Bull by an East Indian. This cartoon was making the argument that American imperialism was not expansionism, but rather a form of disguised colonialism. It was published at the height of Anglo-Saxon rapprochement just two years after the gold rush.

\section{Invisible minorities: the visual rhetoric of exclusion}

Figure 22 is an image printed on the front page of the Canadian daily La Presse on July 23rd, 1897. It belongs to a category of images that iconically represents the Klondike stampeder, carrying heavy loads of supplies. Figure 23 is another such image from page 10 of the Montreal Daily Star published on August 4th, 1897. It is impossible to identify race in such images because the figures of the stampeders are too small. However, the portraits that were often juxtaposed next to such images typically represented white frontiersmen. An example of this can be seen in Figure 24, a montage of images published on the front page of La Presse on July $28^{\text {th }}$, 1897. In the same way that film montage creates a relationship between the subjects of different shots, when images are juxtaposed on the page of a newspaper, new fictional meanings are produced by virtue of the fact that they become visually connected to each other (Eisenstein, 1991, p. 228). ${ }^{31}$ From a cognitive perspective, these associations occur in what Goleman (2006) calls the low road, namely "circuitry that operates beneath our awareness, automatically

\footnotetext{
31 As one of the fathers of film montage, Eisenstein demonstrated how new meanıng(s) emerged from the juxtaposition of images : "It would perhaps be most pertınent also to mention that the transition from single set-up cinema to 'montage' cinema in itself also reflected the process which occurs at a certain stage in the development of any consciousness, namely the transition from a reflection of phenomena themselves to a reflection of the relations between phenomena [sic]" in Sergei M Eisenstein, (1991), Towards a theory of montage, in M. Glenny \& R. Taylor (Eds.), M. Glenny (Trans.), S. M. Elsenstein : selected works (Vol. 2) (Bloomington : Indıana University Press ; London : BFI, p. 228.
} 
and effortlessly, with immense speed" in contrast to the high road of frontal cortex thinking which is slower, more methodical and the seat of rational thinking (p. 16). This means that before one can be critical of how these images are constructed and what they represent, the first impression one receives through the faster low road is that white men were doing the hard work of packing. This idea becomes a de facto cognitive truth until it is challenged by one's "rational" high road. It creates, so to speak, a visual archetype. Is there truth to this archetype?

Figures 25 and 26 are two photos that were taken by photographers during the later part of the stampede in 1898. Figure 25 shows a Native Chilkoot packer posing for E.A. Hegg, a Klondike photographer, in a makeshift studio in the Yukon. Berton (1972) reports that it had been common practice since the 1880 s for frontiersmen to hire the Chilkoot Indians as packers to carry whole outfits (i.e. supplies) during their journey (p. 9). Due to an unprecedented rise in demand, during the Klondike stampede, the Chilkoots increased their prices and "without ever sinking a pan into the creekbeds of the Yukon, the canny Chilkoots became rich men $[$ sic]"' (p. 9). Indeed, most Klondike stampeders who could afford it hired Chilkoots as packers in exchange for money. This is confirmed not only by the literature but also by photographs now in public archives. Figure 26 shows a party of nine men leaving for the Klondike district. The five men with heavy loads on their backs are First Nation packers, while the four non-Native men are conspicuously free of any charge. This photograph was taken in 1895 , two years before the gold rush, but the literature confirms that hiring Natives as packers was still common practice in 1897. Berton (1972) has described Native peoples as being very involved in the stampede and frontier life, not only as packers, but also in performing a number of 
other tasks that could range from peddling fresh water (p. 85) to being hired by white men as runners and messengers (p. 16). This is not to suggest that Natives were being exploited, but rather that their contribution as packers was for the most part visually obscured from early Klondike news images published in dailies.

Tappan Adney, a Harper's Weekly correspondent during the stampede, observed on August 26, 1897 that "formerly the Chilkoots monopolized the packing, not allowing other Indians to enjoy the profits, and seriously objecting even to white men packing their outfits over; but now this monopoly is completely broken" (Adney, 1994/1899, p. 94). This corroborates Cronon, Miles \& Gitlin's (1993) idea that the First Nation peoples were not only an important part of the social fabric of frontier communities, but they also vied for power whenever they had leverage to do so (p. 17). However, the authors point out that "once European empires extended their hold over the continent and stabilized the boundaries among themselves - once regions and nations began to be delimited - law flowed more and more from state authority and coercion" (p. 17). The territorial boundaries of the Canadian North West were stabilized precisely during the period of the Klondike gold rush. Did the visual rhetoric of social boundaries as seen in such news images influence this process in 1897-98? Did it help legitimate the rule of law of AngloSaxon nations in a land once occupied mostly by First Nation peoples?

In her study of the politics of indigenous representation in Quebec, Wilkinson (2011) has found that First Nation peoples were represented differently in this province than in the rest of Canada. She writes, "the figure of the Native was used as an icon for the French Canadian plight particularly from the middle to the end of the nineteenthcentury" (p. 19). In art forms such as sculpture, this translated visually into the 
representation of Natives as the archetype of the "noble savage" which, in Quebec, served as an allegory for French-Canadian nationalism. In other words, in the nineteenth century, rather than being excluded from representation, Natives were used as symbols in French-Canadian art. To support this, Wilkinson cites Native historian Amelia Kalant's argument that French Canadians are historically perceived as having cultivated a different relationship with Natives than Anglo Canadians or Anglo Americans, a relationship of integration rather than domination (p. 18). If we consider this perspective, how would such a relationship of domination have translated visually in Klondike-related news images?

Of the 353-plus news images surveyed in this case study only one acknowledges the presence and contribution of the First Nation peoples. It is an engraving (see Figure 27) with a caption underneath that reads "Human pack animals on the great Yukon: Means of transportation to the gold fields of the far north are confined to boat and dog sledges and the Natives. Indian men and women are employed by the fortune-hunters to carry their supplies" (The Examiner, July 19, 1897, p. 2.). However, the relationship between the image and the caption are paradoxical and confusing. Instead of depicting Natives, the image over the caption shows a man and a woman dressed in non-Native clothes, the sort of clothes that typically would be associated with white stampeders. Because there are no visual representations of Native peoples at all in the news images of this case study's sampling frame, it is unclear whether other Canadian and American newspapers shared the racist beliefs this caption insinuates. Adney (1994/1899) made his own views very clear in his factual news accounts, portraying Natives as greedy and callous: 
Twenty or thirty Indians will take up packs and put a whole outfit over in two days. They are not trustworthy, and are wholly unscrupulous. They do nothing even for each other without a price, and I have carefully noticed that they make no distinction between themselves and whites even for the same service. If one engages them at a certain price and some one offers them more, they lay down their packs and take up new ones; or if on the trail they hear of a rise in the scale, they stop and strike for higher wages...they are shrewd, hard traders, who are making money fast and saving it [sic]. (Adney, 1994/1899, p. 95)

This is an overt expression of racism on the part of the Harper's Weekly correspondent. One can surmise that other articles also expressed racist views. However, a careful examination of the news images from this sampling frame demonstrated that visible racial minorities were not represented at all; Natives were not the only groups that were excluded from representation. Cronon, Miles \& Gitlin (1993) have noted that many "frontier communities fostered a genuine mixture, or at least coexistence, of European and Native traditions (and eventually African and Asian traditions as well) in which no side enjoyed clear cultural superiority" (p. 10). However, this so-called coexistence did not translate visually in Klondike news images. This signals a gap between the reality of the event and the fiction of its representation. Coates (1998) notes that Asians have been completely excluded of the Klondike gold rush's historical meta-narrative, even though they were present (pp. 29-30). There was not a single representation of an Asian person that could be identified as such in the news images of this case study's sampling frame.

In fact, there are no visible minorities in the 64 individual portraits and 20 group portraits of this case study's sampling frame (see Table B), nor in any of the scenes that include human figures. When considered altogether, the news images surveyed for this case study rhetorically appear to build up visual archetypes that are consistently white 
(i.e. Caucasian). One of these archetypes is that of the white stampeders braving and conquering nature. On Anglo-Saxonism in the context of colonialism/imperialism, Kramer (2002) wrote, "Analytically, it cut deeply across the boundaries of national politics, pride, and history, calling forth visions of a heroic racial diaspora that snaked through the borders of states and broke fearlessly through frontiers" (p. 1324). Specifically, in relation to the Klondike gold rush, Porsild's (1998) work has sought to expose the Anglo-Saxon bias and stereotypes that are pervasive in both popular and academic sources (p. 17). By analyzing statistical data on the Yukon in 1898, Porsild's (1998) study has brought great nuance to the portrait of Klondike stampeders; it has dispelled "the popular image of the Klondike [as] a frontier of white, male adventurers who overcame great physical and geographical obstacles in their quest for gold" (p.13).

\section{Early visual archetypes of Klondike stampeders}

The news images of this case study's sampling frame however, tell another story, one of a mythical nature. They included a number of very specific archetypes to represent those who were part of the early Klondike adventure. Creating archetypes is a strategy used in mythological narratives (J. Campbell, 1991, pp. 60-61). In fact, archetypes are one of the key components of myth; they can be defined as biologically grounded characters representing an elementary idea (p. 60). In a sampling frame of 353-plus news images, it is possible to identify certain archetypes by paying attention to the recurrence of characters that hypostatize common themes or ideas.

The archetypal figures represented in this case study's news images all appeared to be white. This statement however, can appear problematic when images are black and 
white process line engravings without tonal variance. It may be more accurate to state that none of the archetypes presented in this case study's news images could be identified as belonging to a visible minority. Because archetypes are biologically grounded, they are visual forms. One archetypal figure took the form of city-bred, citizen stampeders setting out for the Klondike (Figures 28 and 29) or testing their survival skills in nature (Figures 30 and 31), usually depicted in the context of an action scene. Content analysis showed that there were 8 news images in the former category and 64 in the latter, accounting for respectively $2 \%$ and $17.5 \%$ of all the news images in this case study's sampling frame (see Table B). Considered in the context of the classic narrative nature/culture dichotomy, the themes associated with this archetype could be culture/city life/civilization.

A second archetype represents miners and frontiersmen as rugged white men wearing a simple shirt, pants, and almost always a hat (see Figure 16, 32, 33 and 34). They are sometimes braving the elements (see Figure 32) or manipulating tools (see Figure 34), which sets them in a dialectical relationship to the nature/culture dichotomy. They represent both nature and culture, while striving to transform nature into culture. In this case study's sampling frame, there were a total of 12 mining scenes, which made up $3.5 \%$ of its news images. These offered pictures of the frontiersmen in action, toiling to make their dreams of wealth come true.

There was also a third archetype that narratively brought the nature/culture dialectic full circle. In the first archetype, the idea of culture is predominant (i.e. the city man against nature). In the second archetype, the idea of nature is treated with almost equal importance as that of culture (i.e. the frontiersman in harmony with nature). The third archetype could be viewed as representing a dialectal progression that results from 
the dynamic encounter of the first two archetypes; in this case, how man's domination of nature feeds culture. This archetype took the form of static images of miners whose hard work had led to great success. An example of this is the portrait of a miner and his son dressed in nice city suits, sitting prim and proper in front of a nondescript background (see Figure 35) in a hand-drawn frame with a caption that reads, "Two miners from the Klondike, N.A. Picotte and Son [sic]" (San Francisco Chronicle, July 23, 1897, p. 1). It is noteworthy that the subjects of this news image are identified by name. This personal touch emphasizes the ordering force of culture. It is a sign of civilization.

Levi-Strauss (1976) has argued that myths are structured in a form that opposes two binary concepts, such as life vs. death, or good vs. evil. By using a mechanism of mediation (i.e. metonymically-related concepts that can yield a third 'mediating' concept), "mythical thought always progresses from the awareness of oppositions toward their resolution" (p. 224). Myth becomes a dynamic dialectical transaction that allows "a double process of opposition and correlation" (p. 225). Levi-Strauss' ideas imply that myths have the power to help social actors reconcile what seems irreconcilable. His cultural anthropological approach to myth provides a model that promotes a form of mental understanding as well as a means to adapt to the environment. Indeed, its applications can be to help repair the fragile scars of social fabrics.

It can also serve to create a narrative about man's role and meaning in the world, a narrative that serves to reassure him. To look at the three early visual archetypes of Klondike stampeders in the context of the nature/culture dialectical relationship tells a story that has strong mythical qualities. But it is not a universal statement about man's condition in the world. Rather, it is a scenario in which man emerges triumphant in his 
relationship with nature, a scenario in which he overcomes the chaotic, disorderly forces of the universe to come out in control.

For this reason, this third archetype can be described as mundane because it simply hinges on the theme of upward mobility. There is no great liberating myth here except the idea that money is the measure of power and success which are earned through hard work. These may have been the public myths of the nineteenth century in North America. They certainly are today. By examining both the news articles and the news images of this case study's sampling frame, it becomes clear that this third archetype of white men's moving up in the social hierarchy included not only the miners who had struck it big on the Klondike, but also the frontiersmen who had reaped great profit by starting up businesses and investing in real estate, mining, or trade.

The representation of this third archetype of the frontiersman-cum-millionaire was usually isolated in the form of individual portraits (see Figure 36). Both Canadian and American newspapers published them, but they were most often featured in the San Francisco Chronicle and in The Examiner, also from San Francisco. Both papers put great emphasis on portraying these men as important figures. Although it is true that this made these figures stand out from the others, it is also true that it made them become representative of the event. According to Hartley (1982), one of the four principles used to organize news-discourse is to create a matrix of individuals who stand in for the event. They are the characters of news-discourse, "composed of individual persons who are in control of their destiny, so that actions are the result of their personal intentions, motives and choices [sic]" (p. 81). These figures become a structuring principle for mapping social boundaries. This is, of course, paradoxical. On the one hand, there can be only a 
few Klondike celebrities. On the other hand, they are given a greater proportion of coverage, which gives the impression that they play the largest role in the event. In fact, they can even come to stand in for the event itself if they are given disproportionate coverage.

In most of the news images surveyed, these figures were proportionally balanced in relation to the unidentified characters represented in group portraits or scenes including human figures. In fact, they could even be said to be anecdotal were it not for the fact that information such as their full name, and sometimes even the amount of their fortune, were juxtaposed to their image, as in Figure 37. It is true that there were far more feature articles on these Klondike celebrities than there were news images. This may be because in the first week after the outbreak of the gold rush, it was difficult to find photographs of these individuals to draw sketches from.

However, even in the first three weeks after the outbreak, The Examiner, owned by Hearst, and the San Francisco Chronicle, owned by De Young, placed great emphasis on both news articles and news images that featured the stars of the Klondike. Schudson (1978) refers to the editorial choice of including illustrations that catch the eye as the self-advertisement strategies of story journalism (pp. 95-96). Indeed, both papers, which were in direct competition for the San Francisco readerships, were known for practicing yellow journalism (see Table C2). As discussed in Chapter Two, one of the points of distinction between story journalism and information journalism is in the use of pictures. The Examiner published 93 of the 353 news images surveyed in this case study, which constitutes 29\% (see Table C1). The San Francisco Chronicle published 103 of the 353 news images surveyed in this case study, which constitutes $26 \%$. This means that the 
news images in these two newspapers added up to more than half the news images of all 14 newspapers included in this case study's sampling frame. By contrast, the newspapers that typify Schudson's definition of information journalism, namely The New York Times and The Washington Post, each included one news image of the 353 news images surveyed in this case study, which translates into $0.3 \%$ within the whole corpus.

Thirty per cent of news images in the San Francisco Chronicle and $28 \%$ of news images in The Examiner were individual portraits (see Table B). In both papers, a third of the individual portraits specifically represented early Klondike celebrities. The most famous of those celebrities was Mr. Clarence Berry. He is represented at the top of Figure 37 and was most often represented alone, as seen in Figure 38. He was the miner who returned with the most bags of gold on one of first steamers transporting Klondike miners and their fortune. He arrived in Seattle on the first steamer "Portland" that docked on July 17th, and from then on, he became emblematic of Klondike millionaires in early news images.

\section{Women as "the wives of"}

Surprisingly, his wife, Mrs. Clarence Berry, received equal coverage in newspapers that featured Klondike celebrities. In fact, The Montreal Daily Star published a glamorous news image of her (see Figure 39) and none of Clarence Berry himself. This image had also been featured the previous week in The Examiner. Mrs. Clarence Berry was sometimes called "the Klondike bride", which alludes to a fourth archetype presented in news images, namely the archetype of "the wife of" the frontiersmen. The stories of these women were featured with just as much detail as those of the men. Mrs. 
Clarence Berry was profiled in many newspapers, possibly because the story of the Berrys appeared to offer the perfect mix of glamour and romance.

One could even surmise that these stories tended to be substantially fictionalized. Yet the newspapers presented them as first-hand interviews. For instance, the news articles juxtaposed to the news images in Figures 40 and 41 told Mrs. Clarence Berry's story from her perspective. Her husband had been her childhood sweetheart. She had been engaged to him for a few years while he was away on the frontier. About a year before her husband struck it rich in the Klondike, he had made a trip from the Klondike to California to marry her ("How I mined", Sunday Examiner Magazine, August 1, 1897, p. 1). Berton (1972) wrote that the tale goes that Clarence "strapped [his bride] to a sleigh [and] dragged her over the mountains and down the river to Forty Mile," a town near the Klondike (p. 63), a fact confirmed by Mrs. Berry"s testimony in an interview ("A woman's story”, San Francisco Chronicle, July 21, 1897, p. 2). Yet, it is hard to believe that the woman in Figure 39 had been living it hard on the frontier for over a year, especially given the fact that she seems to be wearing make-up. Such a news image certainly must have created a significantly idealized impression of life on the frontier and of the role of women in the Klondike gold rush.

Figure 42 is an archival photograph that shows the real Mrs. Clarence Berry whose maiden name was Ethel Bush. According to Berton (1992), in California she had been "a sturdy waitress named Selma" (p. 63). In Figure 42, she is seen working her husband's claim. Clarence Berry is the man shovelling dirt into her pan. To her right is another woman also panning for gold in her nice dress and wide-brimmed hat. According to Backhouse (1995), this woman is Edna Bush, Ethel's younger sister. The photograph 
was taken in 1898 after the Berrys returned to the Klondike in the spring of that year (p. 153). This photo indicates that some women participated in mining activities, but Backhouse (1995) claims that, in reality, few women did (p. 157). Their largest contribution to field work seems to have been during the spring clean-up in the gold fields (p. 156). Many of the women who participated in the early days of the Klondike gold rush were married to the frontiersmen and this fact was usually emphasized when they were featured in the news. Thus, they were relegated to being "the wife of" and their role was "to keep house, cook and provide companionship" (p. 156) as shown in the different vignettes of Figure 41.

In the annals of Klondike history, there is another legendary "wife of" who was altogether excluded from early news coverage. None of the news images or news articles in this case study's sampling frame mention her name at all. Yet she may have been the most pivotal female figure of the Klondike gold rush. Her name is Kate Carmack (see Figure 43). She was Native, belonging to the Tagish peoples. Her Native name was Shà Tlâ. She was "the wife of" George Carmack, one of the three men who first discovered gold on the Klondike a year before the massive gold finds that would trigger the stampede. Her brother Skookum Jim Mason (Kèsh) and her nephew Dawson Charlie (Káa Goox) were the other two men of that party. Their original gold find on August 16, 1896 was the turning point that triggered the succession of events that led to the Klondike gold rush (Berton, 1972, p. 370). But even Kate Carmack's married name does not appear in any of the news articles or news images of this case study's sampling frame.

It is intriguing that there were so many articles on Mrs. Clarence Berry and none at all on Kate Carmack. The fact that Mrs. Berry arrived on one of the "treasure ships" in 
mid-July 1897 could explain why this is so. Still, the question is one that is worth investigating. If it is assumed that Kate Carmack was not represented in early news images because there were no photographs or drawings of her that arrived with the first steamers that docked in Portland and San Francisco, then logically, no image of her was available for representation in any of the cities that published newspapers from this case study's sampling frame.

However, Figure 43 actually represents a photo that has been deliberately flipped horizontally from left to right to demonstrate, for the purpose of this case study, that it singularly resembles the portrait of Mrs. Clarence Berry represented in the central, oval frame of Figure 41. Although small details in the dress, the chair, the background and the setting differ, the hairdo and the pose match almost perfectly, especially the way the right arm leans on the corner of the table. None of this would be remarkable if other representations of Mrs. Clarence Berry such as Figures 39, 40, and 42 closely resembled her image in Figure 41. However, there are major differences in Berry's facial features, especially in the thickness of the lips, the eyebrows and eyes; and most notably the hairdo. Kate Carmack's hair is styled almost identically to the woman in Figure 41, including the motif of the two little curls in the center of her forehead.

It would be impossible to know if Kate Carmack's photograph served as one of the primary sources for the engraving made of Mrs. Clarence Berry in the oval frame of Figure 41 were it not for archival information regarding Figure 43. In fact, Carmack's photograph was allegedly taken in California in 1898 , which corroborates the story that she and her husband travelled there at that time. However, the research process of this case study has revealed that many archival documents, especially photographs, have been 
incorrectly tagged. Thus, although it is unlikely, it is nevertheless possible that the photo was taken earlier. When historical narratives exclude information, it can never be retrieved without the aid of written records or oral history. Currently, there is no historical proof that the woman in Figure 41 is Kate Carmack. However, the news images in this case study's sampling frame do prove that Kate Carmack was excluded from representation in the early news coverage of the Klondike gold rush. Could her Native origins have played a part in this?

Backhouse (1995) reports that Kate's husband George Carmack wrote to his beloved sister about his marriage as early as June 1897, lying about his wife's ethnic background, presenting her as an Irish woman who "talks very broad English" (p. 6). The press did eventually take an interest in Kate Carmack when she travelled to Seattle and then California in 1898 and 1899, but it was to portray her as an ignorant savage (p. 6). Being married to a Native woman was so stigmatized at that time, that the marriage suffered tremendous pressures and George Carmack eventually came to deny that he was legally married to her (p. 6-7). He abandoned Kate and their daughter in California in 1899 and married Marguerite Laimée on October 30, 1900 (p. 10).

Early news images of the Klondike stampede represented "the wives of" Klondike celebrities in a dignified way that racism towards Native women could not support. Backhouse (1995) refers to Kate Carmack as "the first woman of the Klondike" (p. 10) yet she acknowledges that the press largely contributed in her tragic fate by not only failing to give her such dignified coverage, but also by portraying her in racist ways in 1898 and 1899 (pp. 6-10). Kate Carmack died in poverty after her husband abandoned her and abducted their only child (p. 10). B. Anderson (1991) stresses the idea that in the 
triad of nationalism, imperialism, and racism of the nineteenth century, racism finds its origins in ideologies of class (p. 149), echoing Fredrickson's structuralist argument that racism is primarily the expression of a struggle for power. From an analytical perspective, it has been difficult to separate race from class when reflecting on groups that were excluded from representation in this case study's news images.

\section{The invisible hand of labor}

Coates (1998) has noted that the camp followers and domestics who provided a variety of essential services in the migration movement of the Klondike gold rush were most often excluded from representation, or else their participation was downplayed in factual accounts at the expense of more newsworthy individuals (pp. 27-28). Using a mix of existing quantitative and qualitative historical source material, Porsild (1998) has examined community life in Dawson City from 1896 to 1905 and found that amongst the Klondike stampeders who arrived and stayed in Dawson City were many African Americans, Asians, Scandinavians, Eastern Europeans, and Natives that coexisted in a stratified society in which race and class divisions were maintained (p. 88). Why then do we not see any of them in the 353-plus news images? The fact that some archival photographs support Porsild's findings makes this all the more puzzling.

Figures 44 and 45 belong to the photo collection of Library and Archives Canada. They were also published on pages 86 and 159 of Porsild's (1998) book. Figure 44 shows an African American woman who worked in a small business near the Klondike selling lunches, bread, cakes, and pies to hungry miners c. 1897/1898. Figure 45 shows one of the miners who struck it rich on the Klondike. The African American woman standing on 
the far left is identified as a housekeeper in the Library and Archives Canada database. Her large white apron and her rigid stance a bit removed from the other figures supports this idea. These photographs were probably taken some months after the outbreak of the gold rush, possibly even a year or a bit later. However, since the journey was long and travellers could arrive only in the spring when waterways were accessible, one can surmise that such African American women would have travelled alongside stampeders between 1897 and 1898 .

Porsild (1998) has observed that Klondike stampeders gained status in their community by employing African Americans and Asians as domestic or cooks in Dawson City (p. 160). Figure 45 gives a good example. Known by the name of Swiftwater Bill, the frontiersman wearing the suit on the far right in Figure 45 is in fact one of the iconic Klondike miners who struck it big. Library and Archives Canada has labelled the photograph, "Swift Water Willie's cabin". The fact that he alone is identified by name emphasizes the idea that these successful frontiersmen were the stars of the Klondike gold rush, while others remained in the shadows.

It is easier to reflect on how the ideology of Anglo-Saxonism defined social boundaries during the Klondike gold rush if the event is viewed in the light of the frontier processes theory. Cronon, Miles, and Gitlin (1993) argue that there was a dual force at play on the frontier. On the one hand, because of its remoteness from the metropolitan center of power, the frontier offered more mobility than in the rigid hierarchies of established cities and regions, more possibilities for defining one's role, place, and identity in social life (pp. 9-10). On the other hand, frontier settlers tended to reproduce the Euroamerican social structures they already knew (p. 20). 
The year of the gold rush was the year when the Klondike as frontier was transformed into the Klondike as region. Cronon, Miles, and Gitlin (1993) note that social boundaries emerged as frontiers developed into commercially and politically active regions and "as that happened, individuals became increasingly conscious of the class identity - the self - implied by their birth, their work, their social status, even their dreams" (p. 20). Thus, Anglo-Saxon institutions and the notions of social identity they circumscribe were imported in the frontier, but they could only truly gain legitimacy when population growth and economic activity created a greater need for social life to be organized more efficiently. The context of the Klondike gold rush is a prime example of this phenomenon. 


\section{CHAPTER SEVEN - THE SPATIAL BOUNDARIES OF PROPERTY}

\section{Imagined boundaries vs. real boundaries}

Drawing on Geertz's (1973) examples of the models of and models for culture (p. 93), an image can be described as the visual formulation of a problem and its solution. It is then a blueprint, or a model of something. Or as Geertz (1973) suggests, if this blueprint is used to build a design, it becomes a model for something. ${ }^{32}$ In cognitive science research, an image seen for the first time creates a concept in the mind by forming neuronal connections, the pathway of an idea that suddenly emerges into consciousness (Goleman, 1995, p. 224-225). From a cognitive perspective, an image is therefore a model of an idea. Each individual perceives this image differently and reinterprets it in their mind's eye by virtue of their own experience. The new image that results from this process becomes a model for an idea; it can be actualized when it is expressed or acted upon. This process speaks to the reflexive character of images between mind and matter.

\footnotetext{
32 "The term 'model' has, however, two senses - an 'of' sense and a 'for' sense - and though these are but aspects of the same basic concept they are very much worth distınguishing for analytic purposes In the first, what is stressed is the manipulation of symbol structures so as to bring them, more or less closely, into parallel with the pre-established nonsymbolic systems, as when we grasp how dams work by developing a theory of hydraulics or constructing a flow chart. The theory or chart models physical relationships in such a way - that is, by expressing their structure in synoptic form - as to render the apprehensible; it is a model of 'reality' In the second, what is stressed is the manipulation of the nonsymbolic systems in terms of the relationships expressed in the symbolic, as when we construct a dam according to the specifications implied in a hydraulic theory or the conclusions drawn from a flow chart. Here, the theory is a model under whose guidance physical relatıonships are organized it is a model for "realıty"' in Clifford Geertz, (1973) The interpretation of cultures, selected essays (New York Basıc Books), p. 73
} 
In this case study, imagined boundaries are construed as concepts that appeal to the human imagination and take a discursive form. In real life, these boundaries can manifest as reified forms (i.e. institutions, laws, etc.) that social actors either accept or resist. Needless to say, there can be a gap between the boundaries that exist in a nation and those that exist in its national discourse. For instance, a nation can describe itself as egalitarian while having elitist institutions and practices. Hall (1996) has remarked that the imagined boundaries of a nation form the narrative of the nation that people can identify with and that provide "a way of constructing meanings which influences and organizes both our actions and our conception of ourselves" (p. 613). In this perspective, such a narrative can function as a model for something to be actualized in real life.

One could argue that the reach of this narrative is not weakened regardless of whether one agrees or disagrees with it. In fact, sometimes opposition can serve to reinforce a narrative. Recall that because of the axiom of logic, a concept exists only if it can be defined by its opposite. Thus, discursive forms always imply both consensus and opposition. According to Hartley (1982), consensus is the fourth principle used to organize news-discourse. It would probably be more accurate to nuance this by stating that consensus and opposition are used to organize news-discourse. Hartley (1982) indirectly makes this argument when he gives examples of how certain dissident groups or individuals are portrayed as threats in news-discourse (p. 84). An instance of this in the context of the Klondike gold rush is the way in which Kate Carmack was portrayed as an "ignorant savage" by the press when she made her way to Seattle, and later California with her husband. 
Hartley (1982) points out that consensus is contradictory in that it requires both unity and fragmentation (p. 82). This is not really a contradiction. It is in fact a logical proposition. Cohesion can exist only when there are divisions to begin with. Parts are only parts in relation to a whole, and vice versa. Consensus does not refer only to agreement about where the boundary lines are drawn in news-discourse. More importantly, consensus/dissent reinforces the idea that order exists in the form defined by boundary lines. In this sense, news-discourse allows for both consent and dissent; one can agree or disagree with what has been written, how boundaries are set, how order is represented, etc. But the very fact that one participates in news-discourse by imagining boundaries that map a social order contributes to reifying these boundaries and reinforcing the idea that they exist.

For the sake of analysis, social boundaries have been distinguished from spatial and temporal boundaries, but social, spatial, and temporal boundaries can overlap or intersect with one another. This depends on the discursive context in which they are deployed and the function they serve. Different rhetorical purposes call for a different grammar of boundaries. In effect, boundaries form a temporal-spatial matrix that provides social actors with a given sense of order in space and time. Social boundaries allow them to position themselves within this matrix. This could be construed as one possible definition of the term "identity". News-discourse contributes in discursively constructing this matrix by representing different boundaries over and over again, sometimes with shifts and changes. This chapter will examine how spatial boundaries can rhetorically evoke and reinforce social boundaries in relation to the ideology of AngloSaxonism. 


\section{Empires of liberty}

One could argue that the original rationale behind the creation of the social boundaries of Anglo-Saxonism was legitimated by temporal and spatial boundaries. The boundaries are temporal in that they go at least as far back as the British Empire's colonization drive in the late sixteenth century. They are spatial in that breadth of empire and economic prosperity were the visible signifiers of this alleged, yet intangible, signified racial superiority and its self-perpetuating rhetoric. As early as 1585 , Richard Hakluyt (1552/3-1616) published a collection of travel writings that recorded the earliest conquests of the British Empire (Ward, 2004, p. 62). Copy from the catalogue of a University of Pennsylvania library online exhibition includes this description of the massive work Hakluyt intended for an English-speaking audience: "a dense homage to English genius and a gallery of examples, both English and foreign, that would move the English to redouble their quest for empire [italics added]" (Pollack \& Ryan, n.d.). It is noteworthy that this catalogue copy suggests that Hakluyt's book and its illustrations had some influence on the course of history.

It is a fact that over the next three centuries the area of the British Empire was to increase exponentially until, in 1900 , three years after the early days of the Klondike stampede, it reached one fifth of the habitable zones of the world (S. Anderson, 1981, p. 21). The Canadian postal service released a Xmas Map Stamp in 1898 depicting a map of the world in which British territory is colored in red. ${ }^{33}$ This stamp bore the caption, "We hold a vaster empire that has been" (see http://www.mapstamp.org). As bold as this may

\footnotetext{
33 It was a convention to use the color red to designate territories belonging to the Britısh Empire on world maps.
} 
sound, it was true: "The British Empire was more than four times the size of the Roman Empire at its greatest extent, and forty times the size of the contemporary German Empire" (S. Anderson, 1981, p. 21). Moreover, in the early twentieth century, the British Empire not only owned a fifth of the world's land, it also ruled over one-fourth of its population.

At the end of the nineteenth century, the United States was a worthy ally for the British Empire because it comprised one of the largest national territorial expanses in the world and the second largest population; it had conquered and dominated the native population in the span of a century; it had the most sophisticated communication and transportation systems in the world; it was the world leader in the production of the raw materials of modern life (e.g. wheat, coal, iron, steel); and the value of its industrial production surpassed that of Great Britain and Germany combined (S. Anderson, 1981, p. 22). Most importantly, its founding fathers and the most prosperous members of its population were from the same so-called superior Anglo-Saxon race.

If the British Empire was so powerful at the end of the nineteenth century, why then did it need to create an ideological alliance with the United States? It is important to note that this rapprochement was short lived and not supported by everyone. AngloSaxonism served a very specific political agenda, namely that "the two leading branches of the Anglo-Saxon race should work together for their mutual benefit, and should be constantly on guard to protect their varied and worldwide interests against the ambitions of rival races and nations" (S. Anderson, 1981, p. 12). In other words, this alliance was in the interest of presenting a united front in the face of the competing races and nations whose increasing power threatened the Anglo-Saxon hegemony at the turn of the century. 
Thus, the Anglo-Saxon rapprochement of 1895 and 1904 played itself out over strategic disputes on the international scene: the Venezuela boundary dispute in 1895-96 (C.S. Campbell, 1976); the Boer War in 1896 (S. Anderson, 1978); the Spanish-American war in 1898 (Neale, 1966); the annexation of the Philippines in 1898 (Kramer, 2002). Recall that the Klondike gold rush broke out in 1897 and lasted until 1898, the peak period of Anglo-Saxonism.

Winseck \& Pike (2008) have argued that globalization processes began in the late nineteenth century and that they were "defined by the 'internationalization of control" rather than the "struggle for control"' (p. 28). They frame this historical process as one that secured the interests of "private structures of control" against a backdrop of interlocking states, laws, technologies, and understandings. Their study looks at how the complex structural relationships between media industries and private or public institutions shape economical, technological, legal, political, and military boundaries. It is interesting to consider this perspective in the context of the highly mediated Klondike gold rush. Extrapolating from Winseck \& Pike's (2008) conclusions, one could surmise that the media coverage of the Klondike gold rush played a very important role in shaping, not a national identity, but an international one: the nationhood of Anglo-Saxons who already dominated the international scene in that era.

Conversely, it is important to understand that Anglo-Saxonism was an ideology that was not espoused by everyone in North America. Some Americans embraced it, some did not. The same can be said of those who lived in the Dominion of Canada in the late nineteenth century. Because Anglo-Saxonism served the political cause of an elite in an international context, it was unlikely that it was an ideology that had serious appeal for 
most North Americans (Kramer, 2002, pp. 1338-1341). The American national identity was an already crystallized source of pride for the people (p. 1341), while the British perceived the American "race" as inferior (p. 1347). Even amongst members of the upper classes, this racial ideology was far from being shared by all.

Figure 46 illustrates this well. It shows a caricature published in The Washington Post two weeks after the first announcement of the gold strike in the Klondike. It shows John Bull trying to grab the Klondike for the Dominion of Canada while Uncle Sam watches helplessly. Bull is using a net on which the words "government taxes" are overlaid. The long handle he holds bears the inscription "British aggression" ("The same old", The Washington Post, July 30, 1897, p. 1). What is most telling however is that the gold mines he is making a grab for are represented as being "in Alaska", therefore on American territory, when in fact, they were in Canada. Published on July $30^{\text {th }}, 1897$, this caricature can only refer to the gold mines in the Klondike, rather than the ones in Alaska that were discovered much later. This means that even as much as two weeks after the first announcement of the discovery of gold in the Klondike, The Washington Post was presenting the rich mining region as located on American territory. There were many such images in American papers. This one was published in The Washington Post, which was considered one of the most elitist "information journalism" newspapers of this case study's sampling frame as indicated in Table $\mathrm{C} 2$. This speaks to the idea that its highbrow readership (see Table A2) did not favorably regard the Canadian claim to this territory. Some Americans looked upon Canadians with suspicion rather than through the rhetoric of the Anglo-Saxon brotherhood. 
Certainly, many Canadians did not identify with the idea that Americans and Britons were one big happy family. Figure 47 is a caricature from the Canadian daily The Daily Mail and Empire, which was the mouthpiece of British Loyalists in Upper Canada. Here an oversized Uncle Sam is represented as overstepping his boundary by standing on Canada and looking down on John Bull as he warns, "I want you to keep out of my ocean" ("Does he own", The Daily Mail and Empire, 1897, July 21, p.1). In theory, this was an elitist paper with a highbrow readership (see Table A1 and Table C2). However, Rutherford (1982) points out that market competition forced newspapers to become more class-inclusive in the late 1890s. In the case of The Daily Mail and Empire, this meant publishing two editions: “A quality paper such as Toronto's Mail and Empire, its morning edition for the "classes," published an evening edition for the "masses' [sic]" (Rutherford, 1982, p. 77). The Daily Mail and Empire's readership is therefore not as clearly defined although in practice, one could argue that there were many other newspapers in Toronto that would have secured most of the popular readership.

The main point, however, is that for many Canadians and Americans there was a sense of indignation and enmity centered on the subject of territorial boundaries around the Klondike, rather than a fraternal alliance. This tempers the idea of the prevalence of Anglo-Saxonism at the turn of the century. It might be more accurate to say that there was a strong push and pull between the British and the Americans during the high period of Anglo-Saxonism. This in itself dominated the debates and left little space for the voice of other "races" to be heard.

At first glance, comparing Figures 46 and 47 sets the focus on the mapping of spatial boundaries on land (Figure 46) or maps (Figure 47). However, one could argue 
that a rhetoric of social boundaries is latent in these images. Anglo-Saxonism is not altogether absent from their visual rhetoric if the focus is on what was included and what was excluded from representation. What we see are Anglo-Saxons. What we don't see are First Nation peoples. Cronon, Miles \& Gitlin (1993) have argued that western expansion of the North American frontier should, indeed must, be viewed in a colonialist perspective:

North American frontiers emerged when Europeans invaded Indian territory... [these frontiers were] part of the worldwide expansion of European economies and nation-states that traces back to the fourteenth century and before. As such, we can best know the history of the American West if we read it as a chapter in the much larger history of European colonialism. (p. 9)

Whose liberty did the Anglo-Saxon empires defend? Whose human rights did their principles of democracy serve? How does free speech translate fact and fiction into news?

\section{The logoization of space}

B. Anderson (1991) discusses in detail the logoization of space in the service of nationalism (p. 175). In practice, this means representing spatial boundaries on a map in such a way that clearly identifies a portion of territory with a nation. In other words, it generates an image of a nation as a territory. Using the term "logoization" alludes to the practice of branding. Indeed, maps could be seen as a form of branding. The Xmas Map Stamp mentioned above is an excellent example. B. Anderson (1991) remarks that spatial boundaries usually intersect with social ones (p. 174). But he goes further by arguing that 
since the nineteenth century, temporal boundaries have been used in tandem with social and spatial boundaries to create narratives of nationalism reified by historical map.

Hence, the appearance, late in the nineteenth century especially, of 'historical maps,' designed to demonstrate, in the new cartographic discourse, the antiquity of specific, tightly bounded territorial units. Through chronologically arranged sequences of such maps, a sort of political-biographical narrative of the realm came into being, sometimes with vast historical depth. In turn, this narrative was adopted, if often adapted, by the nation-states which, in the twentieth century, became the colonial states' legatees. (B. Anderson, 1991, pp. 174-175)

The importance of maps in the discursive construction of national identity should not be overlooked. Maps constituted one of the most important categories of news images surveyed in this case study. Table B shows that 47 maps were published in the 353 news images published from July $15-31,1897$, representing a total of $13 \%$ of all the news images. Half of these maps were published by Canadian newspapers while the other half was published by American newspapers. Furthermore, Table D shows that 9 of the 14 dailies surveyed in this case study presented at least one map as the first Klondike-related news image published from the moment of the outbreak. Over and over again, news images and news articles in this case study's sampling frame alluded to a tussle between Americans and British on who owned the Klondike gold fields. This tension never led to anything other than the publication of caricatures, maps, editorials, and articles during that period. No armed conflicts were reported. There were no physical struggles over this quarry. This in itself is interesting: The tussle was purely discursive.

Different visual strategies were used in this duel of news images between the two nations of a common "race". Although generally speaking, the Canadian and American 
maps resembled each other, there were graphic differences in scale, shading, emphasis, wording, and boundary lines that emphasized some details over others. For instance, Figure 48 shows a map published in a Canadian newspaper. The caption above the map reads "The Yukon Gold Fields". The map represents "Alaska" and "British America" with a straight vertical boundary line between the two. The Alaskan territory takes up a bit more space than British America. However, it is shaded with many diagonal lines while British America is left white. The eye is naturally drawn towards the clear white of British America, while it pulls away from the diagonal lines on the Alaskan territory, mainly because the eye seeks to rest on what is most legible and quiet in an image. Using a series of diagonal lines to shade the American area creates a visual impression that this zone is pushed into the background and marked out. The Klondike is placed in British America, marked as a big square icon to the right of the international boundary line that separates Alaska from British America. This simple graphic technique not only makes it clear that the Klondike is on Canadian territory, but also that the demarcation between Canadian and American territory leaves nothing to the imagination. Furthermore, the middle area of this map has the words "gold fields" diagonally overlapping on both the Canadian and American side, but the big clear caption "The Yukon Gold Fields" above emphasize the idea that those fields belong to the Yukon.

Figure 49, a map published in an American newspaper, shows a very similar territorial expanse as Figure 48. In fact, the expanse is almost identical. Figures 48 and 49 however, look very different because there is no shading at all in the latter. The map in Figure 49 is only a line drawing. Nearest to the center, the word "Alaska" is written diagonally in bigger lettering than other words on the map. The word "British Columbia" 
is written in much smaller lettering on the extreme right lower part of the map, almost on the edge. The placement of the boundary line is similar to the one in Figure 48 but it does not stand out at all because it is done as a discreet dotted line that more or less disappears amongst the numerous curvilinear lines that symbolize continental waterways. The words "Klondike region" also appear in a similar place to the right of the boundary line as it does in Figure 48. However, the fact that the space is not shaded and seems open makes it more visually difficult to situate the Klondike in the larger scheme of the map. With the word "Alaska" pointing in the direction of the word "Klondike region", one could even assume that the latter is in Alaska, or at the very least, by virtue of association, that they are strongly connected. The caption "Gold Fields in the Northwest" placed underneath this map creates even more ambiguity with small print that reads: "Map showing the location of the Klondike Region, Where the Rich Discoveries Have Been Made. It is 600 Miles from Juneau from Which It Can Be Reached Overland. It Can Also be Reached by Boat up the Yukon River. Whose Mouth Is at St. Michael's, in Behring Strait [Sic]" (The New York Herald, July 18, 1897, p. 5). Given that Juneau, St. Michael and a large part of the Yukon River belonged to Alaska at that time, and that there is no mention of Canada, one could assume that the Klondike region is freely accessible to the United States.

\section{Mapping the boundaries of Anglo-Saxon property}

Another type of map placed its focus on the representation of the gold fields; shading it in different ways would serve to support one idea over another. Figure 50 shows a map published in a Canadian newspaper. The territorial area of this map is represented differently than in Figures 48 and 49: Alaska constitutes a third of the total surface area instead of more than half. The Canadian portion of the map stretches all the 
way east to Hudson Bay, creating the impression that the Canadian territory is more important in size than the American one in the North West frontier. Moreover, the gold fields are represented as an area that can roughly be described as oval; this area has been shaded and overlaid with the words "GOLD DISTRICT", placed almost in the center of the image. Here, the dotted boundary line intersects over this area on a very small section just at the edge of the left of the shaded zone of the gold fields. The word "Klondike" is placed in the same position in relation to the boundary line as it is in Figures 48 and 49, except that it is small and disappears amongst the little dots that are used to shade the gold region. Furthermore, this map has neither title, nor caption. It was printed right underneath the name of the newspaper, The Daily Nor'Wester, and the date of publication on the first page. Around this image are two different articles about the gold in the Yukon, in columns respectively to the left and below center of the map. Thus, the emphasis in this map is not on the Klondike, but on presenting a very large area of Canadian territory that is rich in gold. It serves as a visual argument that most of the gold is on Canadian territory.

In contrast, Figure 51 shows a map that makes a similar argument but with an American bias. It was published in an American newspaper seven days before the publication of the map in Figure 50. Graphically, it completely differs from the maps previously discussed in this chapter. Firstly, it shows a territorial expanse that is much greater and that includes Siberia to the left. This results in Alaska being placed almost in the center of the image, while the Canadian portion of the map is relegated to less than a third of the right hand side of the map. Alaska therefore is clearly made the focus of attention. Secondly, the shaded area that represents the gold field could be described as a 
much larger oval shape that includes a large extension to the left. In fact, the region looks like an upside down sock, a very different shape than the one shown in Figure 50. This sock-shape also covers a different territorial expanse. In Figure 51, the boundary line is such that less than one-fifth of the gold region is located in Canada; in other words, the visual argument made in Figure 50 has been reversed. This gives the unequivocal impression that most of the gold fields belong to the United States.

A third strategy of the map's visual rhetoric actually functions to legitimize the map itself. The format of the map is much more official with longitude and latitude lines identified by numbers. Unlike the maps in Figures 48, 49, and 50, the map in Figure 51 is neatly framed as official, archival maps are. The title beneath this frame is written in big letters, "MAP OF ALASKA. SHOWING KNOWN AREA OF GOLD-PRODUCING ROCKS IN 1896". Underneath this title are printed the words: "Prepared by J. Edward Spurr, of the United States Geological Survey" (The New York Herald, July 25, 1897, p. 2). The effect of this is threefold. On the one hand, the map appears to be more scientific and more official. On the other hand, it is identified as a map of Alaska prepared by an American scientist, which completely eclipses the Canadian dimension of this map. And finally, the fact that it was done in 1896 , at least a year before the first news announcements that triggered the Klondike stampede, suggests that a temporal boundary is included to reinforce the spatial boundaries laid out on the map. As B. Anderson (1991) argues, what legitimated nineteenth century maps was that they were made to appear as historical and thus unquestionable (p. 174).

The contrast between Figures 50 and 51 could not be greater. The visual arguments they make are completely different in terms of the territorial placement of the 
gold fields. Figure 50 has them on Canadian territory while Figure 51 has them mostly on American territory. It is particularly interesting to see how different graphic strategies are used to make each of these arguments. These maps appear to be good illustrations of the rhetorical power of what Latour (1986) has called immutable mobiles, especially with regards to the practice of framing the map in Figure 51 with all the trimmings of screntific language (e.g. lines of longitude, scientific credit). The most important aspect of the maps in Figures 50 and 51 is however, that they stake a claim of ownership of the gold fields by circumscribing a clear boundary around them.

When viewed in the context of social boundaries, what becomes salient is that these images trump the fact that the Klondike had been, and still was, occupied by First Nations. Historically speaking, in 1897 the international boundary line between the Yukon and Alaska was still soft. For all intents and purposes, during the New Imperialism drive of the nineteenth century, Britons and Americans were using very similar strategies in North America. They were still conquering natives, grabbing their land, and colonizing them, albeit, the Britons under a colonial regime and the Americans under a republican one. By keeping the debate between two of "the families of the AngloSaxon race" and avoiding the issue of First Nation peoples' territorial rights, Canadians and Americans were mapping, not only territorial boundaries, but also social ones. ${ }^{34}$ Seen from this perspective, the ideology of Anglo-Saxon exceptionalism primarily implied

34 At the turn of the century, the Anglo-Saxon race was comprised of many groups sometımes called the "Anglo-Saxon famılıes" which included the United Kıngdom, the United States, Canada, Australia, and New Zealand. Because the last four had a stronghold over the Pacific Ocean, some rhetorically referred to a large part of that ocean as an "Anglo-Saxon Sea", accordıng to Paul A Kramer, (2002, March) Empires, exceptions, and Anglo-Saxons Race and rule between the Britısh and United States Empires, 1880-1910 (The Journal of American History 88(4)), pp 1334-1335 
racial exclusion by placing the emphasis on spatial boundaries that not only mapped out territory, but perhaps more importantly, rights of property on the resources of those territories to be exclusively negotiated between Anglo-Saxons.

For it is important to remember that it was as a result of the Klondike gold rush that the Yukon became a Canadian territory. The Klondike gold rush started in the summer of 1897. On June 13,1898, eleven months after the outbreak of the Klondike gold rush, the Parliament of Canada passed the Yukon Territory Act that established the Yukon as a new geographical and political entity within the Canadian federation (Government of Yukon, n.d.). Before 1898, the Yukon had simply been lumped together with a huge unmapped expanse called the North-Western territories, which the Dominion of Canada had bought from the Hudson's Bay Company in 1867 during the Canadian Confederation. But how had the Hudson's Bay Company come to claim proprietorship of the North-Western territories to begin with?

The Hudson's Bay Company was actually called the "Governor and Company of Adventurers of England trading into Hudson's Bay" and it was chaired by the governor himself. Its purpose was the commercial exploitation of the resources of the British Colonies in the north and out west, and its principal activity until 1870 was the fur trade. By virtue of the fact that it commercially exploited the resources of the North-Western territory, the Hudson's Bay Company simply claimed its ownership. It had originally been set up as a private joint-stock company but in 1864, four years before the Dominion government bought the North-Western territories, it went public with its shares (Virr, 2001). The history of the Hudson's Bay Company so closely parallels that of the two East India Companies in India, that there can be no doubt that Canadian frontier processes 
were part and parcel of the colonization strategies deployed by the British Empire around the world. India eventually came to reclaim its independence and form a nation-state of its own. First Nation peoples in North America never did. Could the rhetorical strategies of Anglo-Saxonism have constituted a force too powerful to contend with? In India, there were the British to contend with. In North America, there were the British and the Americans, unified by the rhetoric of Anglo-Saxonism. Of this ideology, Kramer (2002) writes:

Anglo-Saxonism was also directional, its historical development moving in space. Its rise in England was identified as only one stage in a relentless Western movement that had begun in India, had stretched into the German forests, and was playing itself out in the United States and in the British Empire's settlement colonies. (Kramer, 2002, p. 1322).

\section{Blurring international boundary lines}

Figure 52 shows a map published in an American newspaper a week after the outbreak of the news of the first gold find in the Klondike. The map depicts the land as pure white and the seas as shaded with vertical lines. Crooked lines of different width fill up the white space to represent the numerous waterways. A few major towns are identified by name. The word "Klondike" appears in bolder, larger letters just on the right of the dotted vertical line that indicates the position of the international border between Canada and the United States. Yet not a single word on this map identifies Canada in any way, except the curved words "N.W. Territory" on the upper right corner, quite difficult to see. The most visible place name on this map is the word "ALASKA" vertically written in large, double-edged font a little to the left of the center of the map. On center top, the title of the map is simply "THE LAND OF GOLD". The long caption underneath 
the map reads, "Showing the Yukon Country, With Klondike and Bonanza Creeks, Where the Recent Rich Discoveries Have Been Made. The Overland Route From Seattle By Dyea, Chilkoot Pass, the Lakes and River, Is Shown, as well as the Outside Route by the Way to Dawson City and St. Michael's and the Yukon River. The Dotted Line shows the International Boundary [sic]" (The Seattle Post-Intelligencer, July 21, 1897, p. 1). Although this last sentence in very fine print informs the reader that there is an international boundary line on the map in Figure 52, every other graphic element in the design of the map gives the impression that this is one large expanse of territory that is all unified together. The shading of the surrounding bodies of water emphasizes this visual unity by providing a strong contrast that affects one's reading of the space.

The map in Figure 52 creates an impression that this continental space identified as the "The Land of Gold" is one big expanse that belongs together. Or to put it another way, it belongs to a single entity and has a single identity. The Americans who saw this map in the Seattle Post-Intelligencer one week after the beginning of the stampede would have been led to believe that the "Land of Gold" up in the Klondike was open to them. And even though an international boundary line existed at the time, strangely, there was indeed some truth to this in practice. Berton (1972) has noted that on the trails and in Dawson City, the number of Americans participating in the stampede was greater than the number of Canadians (p. xii). A large part of the gold claims belonged and were exploited by Americans as the portraits in Figure 37 show. Many of the men who owned the major trade posts supplying the Klondike region, men such as Jack McQuesten and Arthur Harper, were Americans. Soon after the gold rush started, Dawson City was even called the "San Francisco of the North" (p. 354). Statistical evidence often presents the 
Klondike gold rush as an event that involved more Americans than Canadians. But like all facts, statistical evidence is woven with fiction in that it presents information in a selective and biased way.

Porsild (1998) compared the citizenship of Klondikers to their ethnicity, which she assessed on the basis of place of birth, native language, and reported skin color. This meant classifying French-Canadians in a different ethnic group to English-Canadians, but it also meant that many Americans were placed in the ethnic category of African American (p. 202) and the ethnicity of a Swedish-born American was Swedish, rather than American. After comparing statistics of legal citizenship to ethnicity, Porsild (1998) concluded that "while the majority of Klondikers might have been American citizens they were not Americans by birth [sic]" (p. 202). The same was concluded for Canadians. Porsild's (1998) conclusions nuance the common view that the Klondike was populated primarily by Americans and Canadians. In fact, as Coates (1998) has noted, the idea that the Klondike gold rush is a Canadian or American story is a simplistic view (p. 32). He argues that the context of this event was global and that one of the high stakes in this particular gold rush was the commodification of the frontier and the corporatization of its resources (p. 31).

\section{The permeability of boundaries}

It is true that Figures $48,49,50,51$, and 52 show maps that all have a similar international boundary line. It is also true that this line is framed completely differently from one map to the other. But what is most intriguing is that Americans could publish maps and articles that made claims on the Klondike gold fields without rebuttal from the 
British, other than news articles and maps that disagreed and argued the contrary. This underpins the strength of an alliance that overrode questions of national identity. Can one imagine Mexico publishing articles and maps that lay claim to American territory without a more forceful American reaction? The fact that Canadians and Americans were able to negotiate each other's presence and each other's visions without diplomatic or military hostility should not be overlooked. This aspect of the news coverage of the Klondike gold rush again supports B. Anderson's (1991) idea that nationalism is not a clear-cut concept. It exists in a fluid relationship alongside imperialism, racism, and class struggle. This in turn suggests that social and spatial boundaries were somewhat fluid. They could be changed to suit the rhetoric of the day.

Although it is not representative of the news images drawn from other dailies of this case study, Figure 53 is evocative in this respect. It shows p. 13 of the American newspaper The Examiner, published only three days after the outbreak of the news of the big gold strikes in the Klondike. Three vignettes showing frontier scenes are drawn in a rectangular frame and placed diagonally in relation to each other, taking up more than half the surface of the page. The top one shows a saw mill at Dawson City; the middle one depicts frontiersmen braving the elements in their makeshift sailboats; and the third one simply illustrates one of the gold mines with a small, barely visible human figure in the background. The caption underneath reads: "IN THE GOLDEN NORTHWEST, WHERE THE CLONDYKE YIELDS MILLIONS [sic]"' (The Examiner, July 18, 1897 , p. 13). Around the neatly framed vignettes are scores of human figures carrying supplies on their backs, as if journeying to the Klondike. They walk alongside the frame of the vignettes but some of them even disappear behind the image along with ships, dog- 
sleighs and the faraway mountains. What is most striking in this image is that the visual boundaries of the edge of vignette frames are visually disrupted, either by figures walking on their edges or disappearing behind them or else by the fact that they are left open or overlaid with objects. For instance, several bags of gold encroach on the bottom frame line of the middle vignette, breaking the continuity of the frame's boundary line.

Metaphorically speaking, Figure 53 speaks of the dual idea of continuity/discontinuity of boundaries. The boundaries are not sealed tight. They exist but they can shift. They can be negotiated. In fact, they are transformed into a liminal zone that suggests fluidity and expansion. The playfulness of the graphic design celebrates creativity and fine art. Indeed, The Examiner published sophisticated news images that often broke out of the graphic templates seen in the 13 other newspapers. The rules of graphic design are broken, or at the very least, they are significantly challenged. The graphic artists are playing with the boundaries, so to speak, of graphic design, and by extension, of the messages that the news images communicate. Figure 53 evokes the idea that boundaries are present but permeable enough to be crossed and perhaps redrawn. There is an impression of chaos created by the small figures walking in all directions.

This particular page calls to mind a fundamental idea about boundaries, namely the fact that they exist first and foremost as a product of the imagination. Boundaries find their expression in representation, and later in institutions and laws. Boundaries are laid out to structure order within chaos. Figure 53 however, shows a bit of both: chaos and order. It allows them to coexist and co-create each other. And it makes the image far more dynamic and thought-provoking than other images in this case study's sampling 
frame. What is most magical about Figure 53 is that, in its playfulness, it boldly states that the imagination knows no boundary. 


\section{CHAPTER EIGHT - THE TEMPORAL \\ BOUNDARIES OF RHETORICAL TIME}

\section{The institution of freedom}

In reference to Anglo-Saxons, American missionary Josiah Strong (1889) wrote:

In 1700 this race numbered less than 6,000,000 souls. In 1800, Anglo-Saxons (I use the term somewhat broadly to include all English-speaking peoples) had increased to about $20,500,000$, and now, in 1880 , they number more than $100,000,000$, having multiplied almost five-fold in eighty years (pp. 35-36)...If it should continue for a hundred years, our population in 1980 would be $697,000,000$ (p. 39)...There can be no reasonable doubt that North America is to be the great home of the Anglo-Saxon, the principal seat of his power, the center of his life and influence. (Strong, 1880, p. 40)

At the turn of the century, Josiah Strong was “one of America's most respected clergymen" (Anderson, S., 1981, p. 25). Much of the literature on Anglo-Saxonism suggests that it is a form of racial exceptionalism that distinguishes itself by its proselytizing mission. This idea again intersects with one of B. Anderson's (1991) arguments, namely that national imaginings parallel religious ones (p. 10). Perhaps more interestingly, he posits that with the disappearance of religious modes of thought, PostEnlightenment rationalism created a vacuum of meaning that invited new national mythologies (p. 11). In this perspective, it can be argued that political assimilation came to replace religious conversion. Or, as some authors suggest, it might have been an extension of it. In a world that was purportedly becoming more secular, there are numerous recorded instances of politicians claiming that their Anglo-Saxon imperialist 
mission had been bestowed upon them by a divine authority, while their values and institutions were an extension of their faith (Anderson, S., 1981, p. 25).

The Anglo-Saxonist rhetoric of conversion has always been couched in a discourse of free speech and democracy. Once Anglo-Saxons had liberated themselves through their political institutions, their mission was to liberate other oppressed peoples around the world by sowing the seeds of their political traditions in foreign lands (Kramer, 2002, p. 1322). This vast operation included the usurpation of private propriety (i.e. land and natural resources) and the exploitation of the indigenous "savages" for commercial ends, in the name of freedom and democracy. As briefly discussed in the previous chapter, one of the means by which this was accomplished was by implanting institutions that legitimated their claims, institutions such as the Hudson's Bay Company. Anglo-Saxon political and economic institutions were like Trojan horses that instilled a language of order, force, and power, a discursive matrix of social, spatial and temporal boundaries into their colonies. Until the eighteenth century, Church and Court were the institutions responsible for setting such boundaries and maintaining them. With the rise of liberalism in the Age of Enlightenment, this responsibility was transferred to the institutions of modernity: government and private industry. Pre-modern and modern institutions did, however, have at least one thing in common: a mission to bring and maintain order. What made Anglo-Saxon institutions distinct was their claim to civilize other races for the sake of progress.

As increasingly wide-ranging groups are brought under Anglo-Saxon dominion, 'the term Anglo-Saxon' practically ceases to be a race designation... It stands rather for a civilization; for ideals and institutions, originating indeed with a 
certain ethnic type of mankind, but no longer its exclusive property. (Kramer, 2002, p. 1323)

\section{The museumizing imagination}

Institutions and artifacts may have been used as tools to civilize and modernize peoples and places conquered by Anglo-Saxons, but they have also been used discursively to legitimate their historical narrative. How is this done? Institutions and artifacts are simply represented as the repositories of what Hall (1996) calls the "narrative of the nation...presented in national narratives, in literature, in the media and in everyday culture" (p. 613). B. Anderson (1991) calls this strategy the "museumizing imagination" (p. 178) because it creates temporal boundaries where there were often none. It places institutions and artifacts in a historical context so far back that they are out of reach for any cognitive function other than the imagination (cf. memory). This makes it very difficult to call into question their authenticity. It also places them in a mythical context, namely in the museum of the imagination. Here, the museum is not a real, physical place, but an imaginary one, a mental construct that reaches the mind of readers.

B. Anderson points out that the "museum" of a culture is always represented and reproduced in its print media (p. 181). In fact, mass reproduction is part and parcel of the museumizing process. Considering this, one can hypothesize that the news images printed in daily newspapers during the outbreak of the Klondike gold rush served not only to inform the public about the event, but also to museumize its story in visual culture. As widely disseminated immutable mobiles, such news images would have contributed to reinforcing the legitimacy of a culture's patrimony, and by extension, the 
historical dimension of its property rights. Early Klondike news images not only represented the event as it happened, they also represented it as history in the making. Because the periodicity of the daily emphasized a historical narrative form, these news images could have, at times, seemed to exist in what B. Anderson (1991) calls "homogeneous, empty time," pushing temporal boundaries back to infinity (pp. 24-26).

By observing which visual motifs regularly recurred in the news images of this case study's sampling frame - motifs in the form of archetypes, artifacts, and institutions - it was possible to tease out an overall picture of the event that featured certain characters, landscapes, frontier cities, artifacts, emblems, buildings, etc. Table B shows that most of the categories were portraits, landscapes, or action scenes, but others that stood out were artifacts and/or institutions. These categories included ships, architecture, and civic institutions. While archetypes have been defined as biologically grounded characters who represent an elementary idea, artifacts and institutions can similarly be defined as inanimate objects that represent an elementary idea. They function as symbols in mythical narratives. A discussion on how media was also sometimes represented as an institution in and of itself is also included in this chapter.

\section{Symbols of imperial hubris}

The artifacts represented most frequently in the sampling frame were ships. Among the 353 images, there were 32 ships, representing $9 \%$ of the total number of news images. This is a very significant proportion. The ships that were included in this count are large vessels that have at least one very tall mast and a steam engine. However, rafts and makeshifts boats were omitted from this category. Within the image and its frame, 
the ships took up most of the space and the background were nondescript (see Figures 54, 55,56 , and 57).

One cannot overlook the fact that, as symbols, ships evoke the British Empire, which boasted the greatest naval force in history. Great ships are artifacts that can function as symbols of imperial hubris, especially when they have tall masts and sails. They are often shown in a diagonal position (see Figures 54, 55, 56, and 57), which makes the image more dynamic. This also gives the viewer a sense that there is movement and direction, suggesting a sense of purpose and moving forward. Ships can trigger many associations, not the least of which is that from as far back as Antiquity, ships were associated with craft, civilization, conquest, and assimilation. In fact, in Ancient Greece, a land and set of islands surrounded by the sea, ships were one of the artifacts most often painted on vases and ceramic pieces.

McEwen (1993) has documented some of the mythopoetic meanings of ships in Ancient Greece and their relation to the polis, to civilization and to Western thought. Amongst many of these, she refers to ships as "city states in movement". She also writes:

The transcription of the Odyssey dates from a period of colonization that saw, and influenced, the rise of the polis; a period when colonists, all, were sailors first. Thus, the account of Odysseus's long sea voyage in the second Homeric epic can be read as the weaving of another city, a polis, which, like the open city of the Phaeacians, "famed for their ships," where all is harmonious, all eu kata kosmon, is entirely different in nature from that of the monolithic, impregnable citadel [sic]. (pp. 94-95)

McEwen (1993) frames the meaning of Odysseus's ships as a symbol of "eu kata kosmon", by which she means "good order" or "an order that is good and harmonious to 
all" (p. 42). Recall that in the metaphor of weaving, this order is what gives Western thought its visible structure through culture. It is an order that circumscribes human activity in the polis, the city as symbol of civilization. Ships can therefore be a symbol of a certain type of order in civilization, but also, because of their movement, they are symbolic of the penetration of civilization into the chaotic forces of nature.

B. Anderson (1991) has argued that colonial regimes used the map to create a historical narrative that rhetorically purported to reach back in time, often as far back as Antiquity, which symbolically represents the dawn of civilization (p. 181). In modern times, ships may have a different meaning than they did in Ancient Greece, but there is no doubt that they have been a symbol of the Anglo-Saxon civilizing mission since Hakluyt produced his collection of travel writing narratives. Indeed, the figures shown in the museumized engraving titled England's Famous Discoverers: Captain Davies, Sir Walter Raleigh, Sir Hugh Willoughby, and Captain Smith, were all skilled captains before they earned the title of "discoverer". As McEwen (1993) writes, "colonists, all, were sailors first" (p. 94).

In reference to the reproduction of images of the state's patrimony, B. Anderson (1991) writes that "it was precisely the infinite quotidian reproducibility of its regalia that revealed the real power of the state" (p. 183). One could argue that the number of ships represented in the news images of this sampling frame is simply representative of a mode of transportation widely used during the stampede. However, there were other such modes of transportation that were hardly represented at all. For instance, there were only two images of horses, both being mounted by North West Police law officers. Yet horses were one of the predominant modes of transportation used by stampeders as Adney's 
(1994/1899) account memorably describes (pp. 71-75). Dog-sleighs were also one the primary modes of transportation. Indeed, it is the only other mode of transportation represented in the news images of this case study's sampling frame with a total of 7 news images. Why were there fewer news images of these less "civilized" means of transportation in the sampling frame of this case study? Could this have been because of their association with the indigenous way of life?

\section{The architecture of the frontier}

Another recurrent motif in the news images were close-ups and wider shots of buildings that can simply be described as log cabins (see Figures 12, 13, 14, 15, 16, 58, $59,60,61,62,63,64$, and 65). Log cabins are not specific to Anglo-Saxon culture since they have existed since Antiquity. In the seventeenth century, they were commonly built in many European countries, and very popular in Russia and Scandinavia. Weslager's (1955) historical study has shown "that the log cabin made its American debut with the Swedish and Finnish settlers on the Delaware River" with German settlers soon following suit (p. 256). Yet, the log cabin is the archetypal building associated with the North American frontier as is evidenced by its ubiquity in the Western genre in popular culture (e.g. film, illustration). Although its design was appropriated from European and Slavic cultures, in North America, it has functioned as a symbol of Western civilization expanding its frontier westward.

Figure 58 shows a small $\log$ cabin with two men in its foreground. The caption underneath the engraving reads "One of the First Houses Built at Dawson City (From a photograph) [sic]" (San Francisco Chronicle, July 19, 1897, p. 1). In this news image, the 
caption functions as an anchor that is both denotative and connotative (Barthes, 1977, pp. $39-40$ ). One could say that denotative meaning is closely related to the concept of factuality since its function is simply descriptive. For instance, the word "log cabin" would be denotative when applied to this image. Connotative meanings, on the other hand, produce fictional narratives. The caption tells the reader that this is a special house because it is "one of the first houses built in Dawson City". Here, the connotative meaning of the caption transforms the log cabin into the museum artifact of a culture carried over by frontiersmen.

Barthes (1977) notes that captions that anchor images have a primarily ideological function: "the text directs the reader through the signifieds of the image, causing him to avoid some and receive others; by means of an often subtle dispatching, it remotecontrols him towards a meaning chosen in advance... anchorage is a control bearing a responsibility [sic]" (p. 40). If ideology is construed as "a system of ideas, principles and mental representations that serve to guide a set of social practices" (Martin, 1997, p. 67), what set of values and beliefs does the caption in Figure 58 serve? First, the caption designates the log cabin as a home, specifically the home of these frontiersmen, thus tracing a social boundary. Second, it situates this home in Dawson City, in the context of the Klondike gold fields, thus suggesting a spatial boundary. Third, it creates a historical narrative for this home, which establishes temporal boundaries. With a simple image of a $\log$ cabin and its underlying caption, a news image creates a matrix of social, spatial and temporal boundaries of a new society on the frontier. This matrix of meaning, the mapping of boundaries produced by a simple caption, bears a story that sets the imagination in motion. Paradoxically, the phrase "From a photograph" in parenthesis 
suggests that this image is scientifically objective. In the nineteenth century, the use of technologies such as photography was most often associated with science; specifically, they were seen as fact-producing instruments. The interplay of the image and the caption in Figure 58 yield a powerful symbol of the Anglo-Saxonization of the West. With the caption, meaning is no longer denotative.

Figure 59 offers a similar example of this relationship between image and text. It also shows a log cabin, but a much more sophisticated one, seen from a further distance with almost undistinguishable human figures in front of the house. With two stories in the main section, the cabin is so big that one would expect it to be a storehouse or a commercial building given the scarcity of resources on the frontier. However, the caption reads "The House of Joseph Ladue (Ledoux), near the Yukon river" (La Presse, August 2, 1897, p. 1). ${ }^{35}$ Again, the caption has both denotative and connotative meanings that anchor the image. Firstly, it informs the reader that this is a home. The cabin is presented frontally from a distance and it takes up a wide expanse of space in relation to the trees behind it and in relation to the frame. The angle of view is also from below. Because of this visual treatment, the building seems solid and majestic. Given the scale of the average log house, the fact that it is described as a home emphasizes this visual impression.

Secondly, the caption informs the reader that it is not just any home, it is the home of Joseph Ladue. Although Ladue is not specifically mentioned in any article on that day in La Presse, the daily had published an individual portrait of him with the caption

35 'La Maison de Joseph Ladue (Ledoux), sur les bords de l'Yukon." (La Presse, August 2, 1897, p. 1). 
"Joseph Ladue, owner of Dawson, Alaska" the previous week on July 23, 1897, and several articles had mentioned him by name since July $19,1897 .{ }^{36}$ The caption therefore serves to inform readers that this $\log$ cabin is a house that belongs to a wealthy, successful, powerful frontiersman, who became, through news exposure, one of the celebrities immortalized in the mythological meta-narrative of the Klondike gold rush. Figure 60 is the image published just below Figure 59 on page 1 of La Presse that same day. ${ }^{37}$ It shows a very wide shot of a landscape with a few roads. On the sides of each of these roads are speckled a series of small log cabins. The juxtaposition of these two images next to each other on the newssheet creates a link between them. Ladue's log cabin "mansion" is indirectly contextualized and compared to the small one-story houses that litter the valley a few miles from Dawson City.

Like the caption "One of the First Houses Built at Dawson City" of Figure 58, the caption for Figure 59 transforms Joseph Ladue's log house into a symbol. It is not however, only a symbol of the civilizing forces of Anglo-Saxonism (in spite of his French name, Ladue was an English-speaking American), but also of the ideology of Anglo-Saxonism, in the sense of its beliefs and values: the importance of individualism, entrepreneurship, wealth, and power. Ladue made his fortune running one of the first trading posts along the international boundary line with Arthur Harper, Leroy N. Jack McQuesten, and Al Mayo, four men who "were largely responsible for developing and

\footnotetext{
36 "Joseph Ladue, propriétaire de Dawson, Alaska" (La Presse, July 23, 1897, p. 1).

37 As a point of reference, a google book search indicates that Joseph Ladue is mentioned in 26 different occasions in Pierre Berton, (1972), Klondike; The Last Great Gold Rush, 1896-1899 (Revised ed.), (Toronto: McClelland and Stewart).
} 
sustaining the mining activities in the Yukon" (Berton, 1972, p. 13). In this sense, they are historically considered the founders of the Yukon, one of Canada's three federal territories. Ironically, all of them were American citizens.

\section{The institution of industry, public services, and liberal professions in the Klondike}

Figure 61 shows a low angle view of one of the trading posts run by McQuesten and his partners at the outbreak of the Klondike gold rush. It was located in Circle City on American territory. Because of its strategic location near a waterway that led from the Pacific Ocean to Dawson City, it was one of the principal businesses that supplied Klondikers once they arrived to the gold fields. This engraving of a log cabin uses a different visual grammar to those shown in Figures 58 and 59. It is shown diagonally, which makes the elements in the image more dynamic. The low-angle view accentuates the height of McQuesten's store, which occupies most of the frame and towers over the small human figures. The building is imposing in size and the storefront sign "McQuesten \& Co." is written in big bold letters over two vertical windows. It is not presented as a home but as a symbol of trade and industry around which the residents of Circle City have assembled. Because of the size of the human figures, it is difficult to identify them but the way they are dressed suggests that they are not First Nation peoples. Rather, they are Westerners who have been grafted onto the frontier. Presented in a daily newspaper, this image provides information about frontier life, but more importantly, it immortalizes one of the symbols of Western civilization and in particular, of the AngloSaxon trojan horse that was strategically used in colonization and expansionism to appropriate land and resources: trade companies (e.g. the East India Companies and the Hudson's Bay Company). 
Other symbols of industry that evoke a nascent regional economy include the first sawmill in the Klondike (see Figure 62) reproduced in three dailies of this case study's sampling frame on different days. ${ }^{38}$ The caption underneath the image reads: "IN THE LAND OF GOLD: Saw mill at Klondike to produce wood for the miners' cabins [sic]". It is interesting this caption connects the sawmill in Figure 62 to the log cabins in Figures 58 and 59, the former producing the raw material for the building of the latter two. ${ }^{39}$ Although the news image of the sawmill was not published on the same day as the images of the frontier homes, it still alludes to a spatial and temporal bond between all these images. It serves to create, so to speak, a matrix of spatial and temporal boundaries that circumscribed the social boundaries of human industry.

In the news images surveyed in this case study, the log cabin, however, is not only used to create a visual vocabulary of home architecture and a fledgling economy. It is also used more generally to represent civilizing institutions offering services to the public such as the customs house in Circle City where the notary public registered official claims and trade (see Figure 63) and the library building at Forty Mile (see Figure 64). ${ }^{40}$ It is noteworthy that in all these images, it is the caption that reveals what function the log cabin has (except for the custom house in Figure 63 which has the sign "notary public" on it).

Figure 62 was published in (San Francisco) The Examiner, July 18, 1897, p. 13; The Montreal Daily Star, July 27, 1897, p. 5; and La Presse, July 28, 1897, p. 5.

39 “AU PAYS DE L'OR : Scierie à Klondike pour scier le bois des cabanes de mineurs" (La Presse, July 28,1897 , p. 5).

40 Forty Mile was the village closest to Dawson City and the Klondike on the other side of the international boundary line. 
Figures 63 and 64 reinforce the idea that captions and engravings of log cabins were combined to create what B. Anderson (1991) has called "the 'format' of the colonial state and its institutions", which profoundly shaped the consciousness of the colonies (p. $175, n 21)$. The fact that some of the newspapers were American (i.e. not "colonial") does not nuance this rhetoric; the result is a visual vocabulary that spells out how Western civilization is making its imprint on the frontier, and how it is embedding culture into it.

Figure 65 helps expose the myth-making process in early Klondike news images. It is the photograph that was used as a primary source for Figure 64. As the writing on the photograph indicates, it was taken by Veazie Wilson in 1894, three years before the outbreak of the Klondike gold rush. It was then printed in his book Glimpses of Alaska : a collection of views of the interior of Alaska and the Klondike district published in Chicago in October 1897, exactly three months after the news image shown in Figure 64. ${ }^{41}$ As can be seen in Figure 65, the caption underneath the photograph reads "EXTERIOR OF SALOON AT FORTY-MILE showing the first horse brought into Forty-Mile" (Lyons, 1897, p. 51). This contrasts with the caption of Figure 64 which reads, "Library building at Forty-Mile". Today, it is impossible to know if the building depicted in Figures 64 and 65 was a saloon or a library building; On the one hand, during the archiving process, it is not uncommon for images to be incorrectly identified, and on

41 On the cover of the book, below its title Glimpses of Alaska : a collection of views of the interior of Alaska and the Klondike district and to the left of an image of a landscape is the following copy: "CONTAINING ONLY GENUINE VIEWS OF THE 'INTERIOR' OF ALASKA, PHOTOGRAPHED BY VEAZIE WILSON THE EXPLORER IN 1894 AND COPYRIGHTED IN 1895 [sic]". Below this is written, "Oriental Library, Vol. 1, No. 15, October 1897. Quarterly. Entered at Chicago Post Office as Second Class Matter" in Esther Lyons, (1897), Glimpses of Alaska : a collection of views of the interior of Alaska and the Klondike district (Chicago : Rand McNally), cover. 
the other hand, Veazie Wilson may have invented this caption for the iteration published in his book. Both these captions could be false. One of them could be true. But it is unlikely that both captions are true.

Moreover, the publication of Figure 64 in a daily periodical that purports to provide its readers with current news would have suggested to its readers that this line engraving represented a scene from July 1897, or at the very least from the year 1897 . Yet the source photograph was taken in 1894 as indicated on the cover of the book. Where are the facts and where is the fiction in these images and in the captions that describe them? This evidence demonstrates how myths can be shaped by images and their captions.

In the same line of thinking, Figure 66 gives a good example of discursive elements presented in a dialectical nature/culture relationship, which constitutes the very essence of mythological thinking (Levi-Strauss, 1976, p. 225) Nature is present in the images, but it is also visually occupied by cultural artifacts. The caption embedded in the image remarks that, "THE TRAVELER HERE BIDS ADIEU TO CIVILIZATION" (The Examiner, July 23, 1897, p. 3). It connotes that this physical place is a liminal zone holding both nature and culture in balance; that it is the very place where they meet; and that it is site of the transmutation of the frontier because beyond this point, there is no civilization. There is only nature and its unbridled forces.

\section{Law and order as a symbol of Anglo-Saxon nationhood}

As seen in Figures 17, 18, 19, and 20, the ancestor of the RCMP, namely the North West Mounted Police was also frequently represented in news images of the 
Klondike gold rush. There were group portraits of the law officers, but also images of their compound, the North West Mounted Police post in Fort Cudahy, right next to the Canadian town of Forty Mile (see Figure 67). Berton (1972) has remarked that the presence in great number of these Canadian law officers played a very big part in the history of how the international boundary line was established and consolidated:

The location of the border itself was a matter of dispute, and here the Canadian constabulary saved a portion of the Yukon for Canada. Because Charles Constantine was on hand at Fortymile to alert the Canadian government to the news of Carmack's strike before the world was aware of it, Ottawa was able to rush a second detachment of police to the North before the gold rush began. Inspector Scarth and nineteen constables reached Fort Constantine on the Yukon on June 12, 1897. (pp. xvi-xvii)

Yet, as Figure 19 shows, American newspapers also showed images of the North West Mounted police force in Klondike-related coverage. In fact, in the sampling frame of this case study, the North West Mounted police had roughly equal representation in Canadian and American newspapers. The penultimate column in Table B shows that four news images related to the North West Mounted police force appeared in Canadian newspapers while three appeared in American newspapers. Seeing that American newspapers used visual rhetoric devices in the representation of maps to create the impression that the Klondike gold fields belonged to the United States, it is most surprising that they would willingly represent, in the early stages of the Klondike gold rush, law and order as the domain of Canadian law forces. Yet, they did. There are no images in the American newspapers of this case study's sampling frame that depict American police forces. This suggests the blurring of a boundary between Canadian and American institutions since it is a fact that more American citizens participated in the 
gold rush (and arrived at Dawson City), than Canadian ones. Would it not be counterintuitive for Americans who were claiming property rights on Canadian land and mining zones to portray the North West Mounted police as the defender of law and order in the Klondike? It is, to say the least, intriguing.

What is perhaps even more intriguing is the depiction of flags in Canadian and American newspapers. The last column in Table B indicates that a total of five flags were found in the 353 news images of this case study. Three in American newspapers and two in Canadian newspapers. Notice the flag in Figure 67, which is circled by an ellipse [shape added]. It is impossible to tell if it is a Canadian flag or an American one, but since the news image was published in a Canadian daily, one would think that it would be a Canadian flag. However, in 1897, flags representing Canada were either the Union Jack or "The Red Ensign, a red flag with the Union Jack in the upper corner" (Canadian Heritage website), while the American Flag at that time looked much the same as it does today. ${ }^{42}$ With this in mind, which flag is circled in Figure 67: a Canadian flag or an American one? It seems very odd that the graphic artist did not make it clear at all which flag it was, especially considering the fact that flags are an important patrimonial artifact that act as a symbol of national identity. Like maps, they are a brand image, so to speak, of a nation.

If this were an isolated incident it might not be worth mentioning, but of the five flags that were depicted in this case study's sampling frame, no less than three cannot be

42 The Canadian Heritage website states that "The Red Ensign was the Canadian flag used from about 1870 to 1904 . An ımage of this flag can be retrieved at http://www.pch gc.ca/pgm/ceem-cced/symbl/df5eng.cfm by scrolling down the web page to the penultumate flag. 
designated as either Canadian or American. Two of these flags are in Canadian newspapers, the one in Figure 67 and another one in a similar North West Mounted Police post scene published on page 1 of The Montreal Daily Star on July 26, 1897. The third nondescript flag was published on page 3 of The Examiner in San Francisco in an image of Dawson City. This city was unequivocally on Canadian territory, yet because of how the flag bears down, the patterns are hardly visible and it is not clear if it is a Canadian or American flag.

Adding to this confusion is a news image representing a large log cabin at SixtyMile camp (see Figure 68). Although it was near the international border, Sixty-Mile was a mining settlement on Canadian territory. Yet this news image published on page 13 of the American newspaper, the San Francisco Chronicle, shows a distinctly American flag protruding upward from the cabin's front roof. Given the significant proportion of Americans on Canadian territory, perhaps this should not be considered unusual. It may simply be that Americans planted their flags wherever they settled without concern for Canadian or American territorial rights. One can also surmise that because Dawson and the Klondike were close to what was still a soft international border line, many frontiersmen were not aware of the cut-off point between Canada and the United States.

However, this does not do justice to the fact that in the representation of news images, there is a strange eclipsing/display of flags that suggests at times, a blurring, and at other times, the exchange of national emblems between the two North American Anglo-Saxon nations. If these news images do not provide a strong enough visual argument, then the archival photo shown in Figure 69 speaks to this point. It was taken on April 9, 1899, less than a year after the Yukon officially became a Canadian political 
entity within the Canadian federation. It shows Canadian and American law officers standing together under the Canadian Dominion's Union Jack flag and the American Stars and Stripes flag on the White Pass Summit which straddles the international boundary line separating Alaska and the Yukon territory. The White Pass was one of the two most popular trails during the Klondike stampede of 1897 . The photo may have been meant to represent the international boundary line, but there is no such boundary line to be seen in it. Instead, this photo creates a visual impression that the agents of law and order of two of the nations of the Anglo-Saxon family have come together under their flags placed side by side.

\section{Interlocking boundaries}

In the news images of this case study's sampling frame, ships, log cabins, institutions, and flags were a few examples of artifacts that served to build the grand narrative not only of a nation's history, but also of a race's history if one embraces the idea that an Anglo-Saxon rhetoric was pervasive at this time. Patrimony stretches this narrative back in time to an immemorial past, creating imagined temporal boundaries that are not part of a collective memory but of a process of myth-making. Boundaries are first and foremost the product of the human imagination and the rational mind. And as B. Anderson (1991) remarks, social boundaries, spatial boundaries, and temporal boundaries (i.e. "the census, the map and the museum") are interlocked (p. 184). The relationship between these different types of boundaries becomes clearer when maps are considered in their historicity, and patrimony is considered in its spatial presence. 
The social sciences tend to use the Enlightenment as the point of reference for rational thinking and the secular ordering of modern society. At first thought, it is tempting to suggest that boundary-setting strategies were the product of enlightenment thinking, or as Cronon, Miles \& Gitlin (1993) suggest, of frontier processes. One could think, for instance, that people felt compelled to set boundaries because as they went from living in a village to living in a global village, they needed to organize the overwhelming amount of space and of people. Setting boundaries would have been a way to adapt social life to larger communities. But setting boundaries is not a new sociopolitical practice that resulted from post-enlightenment anxiety.

Humanities scholars are trained to look as far back as traces of civilization exist to frame their discussion in a far-reaching historical context. A humanities scholar knows that boundaries were neither invented in the nineteenth century, nor during the Enlightenment, nor the Renaissance for that matter. Ancient Egypt had its social boundaries with its classes of Jewish slaves; Ancient Rome was known for the precision of its maps that drew and recorded on papyrus spatial boundaries (Thrower, 1999, p. 39); and Ancient Greece certainly had its share of monuments to narrate its mythical temporal boundaries. These are but a few examples.

Setting boundaries may be a practice as old as homo sapiens, but it is not enough to create a new order, a new grid of power. These boundaries must be recorded, ritualized, and re-enacted over and over again to be reified. Against Berton's (1972) argument that four major factors were influential in the Klondike gold rush, it has been argued in Chapter Three that two other factors largely contributed to the epic character of the event. The first one is that it happened in the context of what contemporary scholars 
call "frontier processes" and the second factor is how the market-based press presented new ways to reach larger audiences that became part of a historical myth-making process.

Drawing on Benedict Anderson's (1991) thesis in Imagined Community, this case study argues that the recording, ritualization and reproduction of news images in the efficient publishing and distribution circuits of 1897 daily newspapers in North America, served to create an "imagined community" who travelled together to the promised land of gold, a frontier where boundaries were soft between two still fledgling nations, and a sense of nationhood that was still in the making. More specifically, it is argued that the market-based press played an instrumental role in this process by acting as a system of production of human imaginings.

\section{Journalists as the guardians of temporal boundaries}

Schudson (1978) has noted that the story model of journalism in the late $1890 \mathrm{~s}$ heavily relied on self-advertisement strategies to boost circulation. He defines this in these words:

Self-advertisement, as I use the term, is anything about newspaper layout and newspaper policy, outside of basic news gathering, which is designed to attract the eye and small change of readers. One of the most important developments of self-advertising in this sense was the use of illustrations... another major development in self-advertisement was larger and darker headlines...newspaper self-advertising also had to do with the newspapers' promotion of their own exclusive feature. (pp. 95-96)

It is noteworthy that the two newspapers of this case study's sampling frame that are unequivocally in the category of the story model of journalism (see Table C2), the San Francisco Chronicle and The Examiner (from the same city), used these three strategies in synergy during the second week of the first Klondike-related news outbreak 
that triggered the stampede. Both these newspapers featured the journalists and photographers they were dispatching out to the Klondike on their front page a few days apart (see Figures 70, 71, and 72). In broad, bold headlines, The Examiner referred to this as “"The Examiner' expedition to famous Klondyke [sic]" (see Figure 70) and "Expeditionary forces of 'The Examiner”' (see Figure 71).

Both newspapers printed individual portraits of the "experts" who were being sent to the Klondike. Each portrait was identified by a full name, while an article on the same page explained in great detail how their respective skills and areas of expertise would be deployed in the service of the readership. Next to these portraits, The Examiner wrote,

"One of the highest functions of a newspaper is to inform the public fairly and fully on matters of general interest as to which the average man cannot readily gain information for himself. 'The Examiner' is about to discharge its duty in this regard, so far as the Klondyke gold region is concerned. It has arranged to send to the famous Northland a thoroughly equipped expedition which shall leave no room for doubt as to the character of the now famous district and the conditions surrounding life there." "'Personnel of the Northbound Party", The Examiner, July 22, 1897)

Most of the head and shoulder shots in both newspapers present the correspondents as well-groomed and dressed in suits. In both instances, The Examiner presented the portraits in circular frames over an image of a tall, sailing ship (see Figures 70 and 71), while The San Francisco Chronicle presented two series on the same page. The top ones consisted of close-ups of each correspondent's face in a circular frame next to a full body shot of them dressed up from head to toe in Artic expeditionary gear, which oddly included, for each correspondent, a long rifle (see Figure 72). The second series which horizontally lines the bottom of the page, presents "FOUR CAPABLE 


\section{OBSERVERS AND WRITERS WHO WILL ACT AS 'CHRONICLE'}

CORRESPONDENTS IN THE GOLD FIELDS" (see Figure 72). Why did these newspapers self-promote their news gathering activities in the context of the Klondike stampede?

Giving individual publicity to the journalists, photographers, and experts that were dispatched cannot be described as merely "basic news gathering" techniques to report the facts. In this sense, it is a very good example of what Schudson (1978) meant by the self-advertisement of story journalism in the 1890 s. However, the above quote from The Examiner claims that "one of the highest function of a newspaper is to inform the public fairly and fully". This suggests that even the most sensationalistic newspaper in this case study's sampling frame aspired to simply inform the public (see Table C2). Profit may have shaped how this was done. But the self-conscious rhetoric of The Examiner's responsibility to its readers cannot be dismissed because of its form. The story model of journalism was no less intent on providing its readers with news than its counterpart. It just used different strategies to narrate the news, and these strategies included making the newspaper itself part of the story.

The fact that the newspapers focus on constructing and revealing the individual identity of the correspondents is an instance of Hartley's (1982) second principle used to organize news-discourse, namely the use of individual persons as characters in the news story, which come to stand in for the event (p. 81). In this case, however, the individual persons are also the producers of the news-discourse. They are both the narrators and the narrated. 
It could be argued that this type of journalism is not impartial, neutral, or detached. However, a newspaper's self-promotion of its journalists has many advantages that information journalism does not. First, it offers a degree of self-reflexivity and transparency that information journalism does not have. The reader is not only being informed about the news, he/she is also being informed in detail on who gathers the news. This provides a context that the invisible narrator of a newspaper like The New York Times eludes. Second, as is evidenced in the journalists-cum-frontiersmen images of Figure 72, the correspondents become part of the story itself. And since the story is a historical event, they can be seen as both the characters and the producers of history. In fact, the correspondents portrayed in Figure 72 are not only represented as characters, they actually constitute an archetype of Klondike stampeders: the character as narrator. Third, it provides the readers with more than just information. It provides them with the possibility of participating in the event. This becomes more obvious when one reflects on the above quote by The Examiner, which specifies that its mission is to deliver information that "the average man cannot readily gain...for himself" ("Personnel of the Northbound Party", The Examiner, July 22, 1897).

The full-body images of journalists in Figure 72 invite the viewer to experience the stampede through The Examiner's coverage in the months to come. This device is widely used in cinema. Lightman (1946) writes that what is called the objective camera is like an impartial observer. Of course there is no such thing as an objective shot since there is always someone behind the camera. What Lightman (1946) means by objective is that the point of view of the camera is not showing the viewer what one of the characters in the film sees. This can be compared to the information model of journalism. 
Lightman's (1946) explanation of subjective and objective narrative techniques in cinema illuminates the different strategies used by information journalism and story journalism to reach the same end: informing the reader.

Usually the camera maintains the role of a detached observer of the story. It is not, in itself, a part of the action - so it simply stands by and records what goes on, assuming whatever angle will best portray that action. When this is the case, and the camera remains apart from the action itself, we say that the camera is "objective". A vast majority of the action in most photoplays is filmed with this approach.

Occasionally, however, the camera steps out of its role as casual observer and becomes a participant in the story. In so doing, it assumes the point of view of one of the characters, and what appears on the screen is what that particular character sees in a certain filmic situation. Thus, the camera actually becomes his "eye," and when this is the case we say that the camera is subjective [sic]. (Lightman, 1946, p. 46)

When the camera takes the point of view of one of the characters in the film, it is said to be subjective. Montage devices that juxtapose images of the character with his/her point of view help the viewer understand whose subjectivity he is invited to experience. In cinema, a point of view shot is almost always first introduced by a shot of the character whose point of view will be taken (Branigan, 1975, p. 55). This portraiture shot (sometimes done over the shoulder) is necessary to create a bridge in the viewer's mind between the character through whose eyes the viewer is about to see and this character's point of view (i.e. what the character sees).

An analogy can be made with story journalism. The subjective camera technique is used in Figure 72. Portraits of the journalists serve to intimately introduce readers to the people whose point of view he/she will be following throughout weeks, if not months 
of news coverage of this event. This creates a spatial and temporal link between the imaginings of the correspondents and the readers. It also guarantees continuity in the narration of a historical event. Because the journalists are presented as characters that actively participated in the event, the reader is allowed to identify with them. And to make history with them.

Figure 73 is an archival photograph showing stampeders posing for a studio photograph before they stampeded north. Berton (1983) described this photograph in these terms:

Posing against painted backgrounds in the studios of coastal photographers, thousands of aspiring adventurers, eager to get rich, demonstrated their optimism by commissioning portraits of themselves on the eve of their departure for the goldfields - mementoes for friends and families and visual proof that they had no intention of being left behind in the race. (Berton, 1983, p. 13).

Dressed in their city clothes, the studio setting is a fictional setup intended to evoke the Klondike. The man who lies on the fake fur is dreamily staring faraway, while the other men gaze straight at the camera with bravado. Before these men had even left the city, they were already weaving the Klondike myth. The recording and archiving of this image at the Provincial Archives of Alberta bears testimony to the fact that such repositories are museums of human imaginings.

By participating in the creation of such images of the mind, these stampeders were speaking the language of imagination, a language which knows no boundaries and is, per force, a mix of fact and fiction. Was their perception of the Klondike experience influenced by the early news images they saw? 


\section{CONCLUSION: RETHINKING JOURNALISM IN MYTHICAL TERMS}

\section{Mapping the boundaries of imagined nationhood}

This case study set out to investigate the possible functions of fiction in newsdiscourse by examining news images published in North American daily newspapers at the outbreak of the Klondike gold rush. The main objective of this research was to provide descriptive inference that could shed some light on how news images contribute in shaping and maintaining myths of nationhood. The main assumptions that have informed the theoretical and analytical framework are that the mind is the primary means of production of human experience and that news is a construction which is produced from a combination of factual and fictional elements.

Having established that one's sense of history and identity is shaped by both fact and fiction, it is important to understand the workings of the interplay between them to gain insight into how they enrich everyday life, relationships, one's sense of belonging, and one's creativity. The power of narrative, and more specifically, the power of myth, is not to be underestimated. The task that scholars face may be to uncover the facts, to establish what is true and what is not, but even when they prove that what has been historically recorded as a fact is a myth, often the myth has taken on such fantastic, epidemic proportions, that it continues to linger in the popular imagination well after it has been dispelled by academic communities as has been the case with the Klondike gold rush. Widely accepted beliefs have a way of crystallizing with time. But how can understanding this be useful? What has the study of the Klondike news images of this case study revealed? 
The first finding is that clear patterns emerged in the 353 news images surveyed in this case study's sampling frame. Quantitative and qualitative content analyses were used to isolate these visual patterns and define them as a series of themes. When examined under the lens of social boundaries of race, gender, and class, these themes took the forms of archetypes. When examined under the lens of spatial and temporal boundaries, many themes took the form of cultural artifacts, institutions or practices that had a strong symbolic value. The manifest repetition of such structural elements supported the idea that some of the narrative strategies found in news-discourse are the same as those found in myth. This, in turn, has helped to demonstrate that news-discourse covering the Klondike gold rush was more often than not a mix of fact and fiction.

The comparison of content from different sources and genres reinforced this idea. This supports the relevance of a discourse-historical approach that foregrounds intertextual and interdiscursive methods. Discussing the news images in their historical context by relating them to their historical source (i.e. the newspaper) as well as to other primary sources (i.e. photographs, articles) were instrumental in proving that many facts had been excluded from the news images. It became clear in the data that the rhetoric of exclusion was found to be one of the main strategies used in news-discourse. This finding is important because it confirms that the paradigmatic character of journalism directly relates to the idea that news-discourse is a mix of fact and fiction, calling into question modern journalism ethics of objectivity and factuality.

Another rhetorical strategy that recurred in this case study's sampling frame was the practice of juxtaposing text near the news images to create connotative meanings. Barthes's (1977) semiotic framework facilitated this analysis. In the context of this case 
study's assumptions about the relationship between fact and fiction in news-discourse, one could say that denotative meaning is closely related to the concept of factuality because it is purely descriptive, while connotative meanings give a fictional spin to this description by adding symbolic value to it. Such a use of symbolism in the construction of news-discourse underscores the mythical dimension of the representation of an event. Once again, the method of analysis was essential in demonstrating the dynamic, dialectical relationship between fact and fiction in news.

The most important finding, however, was that news-discourse could be conceptualized as a discursive matrix of overlapping social, spatial, and temporal boundaries that had a rhetorical function. In the context of the ideology of AngloSaxonism that prevailed during the Klondike gold rush, this matrix served to map the boundaries of a myth of imagined nationhood.

Drawing on B. Anderson's (1991) thesis, it was argued that the recording, ritualization, and reproduction of news images in the efficient publishing and distribution circuits of 1897 daily newspapers in North America served to create an "imagined community" of readers who travelled together to the promised land of gold, a frontier where boundaries were soft between two still fledgling nations, and a sense of nationhood...still in the making. More specifically, it was argued that the market-based press played an instrumental role in this process by acting as a system of production of human imaginings in which readers where invited to participate.

This, however, begs the question of who shaped such imaginings. One could argue that the imaginings were shaped by the artists that produced the images or the 
newspaper owners that allowed them to be published. But this case study purports that collective imaginings derived from news-discourse are a social process of myth-making made possible by all the social actors who are involved in the system of production of news. Thus, readers too take part in this process as creators and producers of news. The fact that news images can break language barriers may serve to expand this system of production. This is an idea worth investigating in journalism.

For images are a lingua franca. Perhaps the only lingua franca that printcapitalism has to offer, with the exception of brands. In journalism, news images are as much a language as written text is. Inasmuch as they are representations, news images cannot be made of pure facts, if such a thing could be said to exist. Therefore, images combine fact and fiction in pictorial news. Images can only offer a compromise between the real and the constructed. This Master's thesis has investigated how fiction in the lingua franca of news images can rhetorically appeal to readers in the context of the discursive construction of national identity. What the empirical data has revealed in this research is that boundaries of nationhood are not only imagined, they can also be imaged in illustrated news. The idea that news images can give visual form to national imaginings underscores the importance of graphic figuration's unique ability to generate iconic visual references in news-discourse and in the discursive construction of national identity.

\section{Reflections on different journalism practices in 1897}

This case study provided evidence that in the late nineteenth century, some, but not all, daily newspapers used news images to inform their readers. In the summer of 
1897, the news images in this case study's sampling frame were primarily line engravings that drew from photographs as primary sources. Sometimes, these photographs had been published in photo albums months or years earlier as was seen with Figures 64 and 65 . Given that such news images were being published in daily newspapers whose purpose is to provide current news to its readership, this raises many questions as to the factuality of news images made up of line engravings produced in the fast-paced system of daily news production in that period of history.

The empirical research performed in newspaper archives also showed that, in contrast to weekly or monthly newspapers, only a small proportion of North American daily newspapers were making use of news images in the summer of 1897 . This can seem surprising given that engravings had been widely used in some weekly and monthly newspapers since the 1950s (Brown, 2002, p. 22) and in some dailies since the mid-1880s (p. 235). Indeed, it seems even more surprising considering that Stephen H. Horgan had perfected the halftone technology in January 1897 (Campbell, 2006, pp. 21-22).

One would have expected to find more daily newspapers that made use of news images, and certainly more photographs than line engravings. This was not the case. Journalism history works purport that Horgan's invention changed journalism practices with regards to the use of images in daily newspapers but the empirical data examined in this case study suggests that this transformation did not take place overnight. Cost, technical know-how, the availability of skilled labor, and logistics may explain why it took many years for some daily newspapers to include news images. Campbell's (2006) claim that 1897 was a pivotal year in American journalism may be true, but the empirical data makes it apparent that paradigms of journalism did not change abruptly that very 
year. Only an investigation of daily newspapers done over several years after 1897 could reveal how and when the inclusion of news images in dailies became common practice. It is also important to consider that each newspaper's editorial policy would have determined whether or not news images should be used to tell news stories. It is a wellknown fact that yellow journals that practiced "story journalism" paved the way in this respect. $^{43}$

By using strategies of self-promotion, newspapers that tended to use "story journalism" practices were found to deploy narrative devices that encouraged readers to participate in the news stories. However, it was also demonstrated that newspapers that were more inclined to use "information journalism" practices resorted to other types of strategies that encouraged the reader to position him/herself in the context of the event, albeit in a more detached way. The difference seemed to be a matter of style. Simply put, "story journalism" was to "information journalism" what Hollywood filmmaking is to documentary filmmaking. Documentaries are also seen as narrative forms, and they always make use of narrative techniques, but the information is presented in a style that encourages the audience to believe that their imagining is real, rather than invented. Thus, paradoxically, story journalism was found to have more transparency because its methods of self-promotion and narrative techniques did not pretend to be factual; it offered some degree of self-reflexivity.

43 While the "New York Daily Graphic, in 1873, became the first American daily to regularly use illustrations", Pulitzer's World soon put it out of business by adopting this practice in the 1880s, in Michael Schudson (1978), Discovering the news : a social history of American newspapers (New York : Basic Books), p. 96. 
It is noteworthy that, generally speaking, more news images were used to cover the Klondike gold rush in newspapers that practiced "story journalism" than those that practiced "information journalism". If we consider images as a lingua franca, this implies that story journalism offered the possibility of reaching larger audiences, which may partly explain why the event took such massive and mythical proportions since "story journalism" newspapers were already very popular in the late nineteenth century. In the context of this case study, this is corroborated by the circulation figures in Tables A1 and $\mathrm{A} 2$ in reference to the relative index of story journalism in Table $\mathrm{C} 2$.

Although the event was intensely covered in the news for a period of a year, one can surmise that early Klondike-related news images in this case study's sampling frame would have created a first impression that later coverage would have continued to build on. This research was originally narrowed down to study only the coverage of the first 17 days of the outbreak of the event to see how much of the early news coverage shaped the myth that is still retold today. Exploratory in nature, this case study was intended to open up new areas of investigation. The work has just begun. Now remains the task of comparing the findings of this case study with coverage in different periodicals or works of popular culture to see how the myth of nationhood as represented in Klondike history has changed over time and in different genres.

The data that was collected on publications other than dailies during the preliminary research stage suggested that the examination and study of a sample made up of weeklies and/or monthlies would be an area of research that also merits further investigation. The richness of the articles and images, as well as idiosyncratic aspects of their news coverage that differ from journalistic practices used in dailies make this an 
area worthy of study. The news images in this case study's sampling frame could be compared to later coverage in dailies, but also to news images in weeklies or monthlies in the context of the American or Canadian historiography of illustrated news or visual culture.

Such research might help explain why Americans mythologized and appropriated this key chapter of Canadian history as one that has fostered their own sense of history and identity. As was demonstrated, some of the same news images were used in Canadian and American newspapers and most of these gave prominence to Anglo-American archetypes and symbols. This may be partly due to the fact that in the late nineteenth century, many North American dailies used the same sources to obtain their news, but it does not explain the blurring of social, spatial, and temporal boundaries between Canada and the United States that occurred in some of the news images. Many American readers were led to believe that the Klondike gold rush took place on American territory because as was shown, some of the news images represented the event this way, featuring American miners and presenting maps in ways that called attention to American territory while including images of the Canadian North West Mounted police in the same daily. This matter of fact is, to say the least, intriguing.

It is true that the first big Canadian gold strike had a rippling effect on the continent and beyond, but it is too often forgotten that its historical significance is the part it played in opening up the Canadian North West frontier. Chaplin's film The Gold Rush (1925) is actually based on the gold rush that occurred in the Klondike yet many Americans and Canadians have always imagined it in Alaska. In the past 100 years, poetry, literature, film, cartoons and the visual arts have drawn lavishly on Klondike 
history to create works of fiction intended for popular culture. The abundance of this material bears testimony to the fact that this gold rush constitutes one of the most popular and best-loved chapters of North American history whose imaginings are shared by Canadian and American audiences still today.

\section{The importance of shared imaginings in social life}

What purpose then, can such shared imaginings have?

From a cognitive perspective, sharing an imagining is the most fundamental condition for experiencing empathy for it simultaneously engages one's thinking and emotions (Goleman, 2006, p. 58). This is important because empathy is what promotes understanding in communication processes. If one construes imaginings as a means to establish a connection between people, how relevant is it that it be reality-based or valid, true or false? In social interaction, or what Goleman (1994) has called the "social arts", is being right more important than getting along?

Perhaps this is what the Ancients understood. The telling of myths were a way to create a connection, a bond of empathy with the whole of humanity across time and space which would help foster and nurture ways of perceiving oneself and others conducive to peaceful social life. Symbols engage the imagination, which connects the heart and the mind. And symbols do not pretend to be facts. They do not claim to be right. They simply

remind us that we are all human. That, as Lippmann (1922) once wrote, "Truth has an uncertain character" (p. 227). This is the lived experience of reality. In the day to day, there is no certainty, no security of facts. There is only change. There is only the realization that what we thought was true is not. 
In this light, what value can symbols and fiction have in myths of nationhood?

In the context of this case study, it was found that, as Arenson (2007) claimed, the ideology of Anglo-Saxonism had contributed in shaping the news-discourse of Klondike publicity. Canadian contemporary journalist, Andrew Nikiforuk (2011) once said "nations become what they produce". Although he was referring to current industrial development in Northwestern Canada, if news-discourse is viewed as a cultural product, could nations be said to be made in the images of the news they produce? This is, of course, a rhetorical question since the premise of a discourse-historical approach is that discursive acts and social reality are mutually constitutive of one another (Wodak, Cillia, Reisigl \& Liebhart, 2009, p. 8).

The question therefore needs to be reframed: How can an ideology such as AngloSaxonism serve a myth of nationhood that promotes peaceful social interactions? The word ideology often has a negative connotation. It is most often used to critically expose and explain social inequalities. Few scholars recognize that ideology, when construed in a cultural sense, is simply a matrix of social, temporal, and spatial boundaries that offers a stable structure for the organization of social life. If this ideology is embedded in a national mythology, then it also serves to create imaginings that can make people feel connected to one another.

True, any given ideology proposes an order in which there are winners and losers. In the context of this case study, the losers were those who were omitted from representation; those whose stories were not told; those whose voices were not heard; and those whose rights were not upheld. But the truth of the matter is the winners, in fact, did 
not exist, because there were no existing persons, no existing thing, that realistically corresponded to the archetypes and symbols as they were being represented in the news images under study. The winners were discursive symbols, not real people. And this is key in understanding how ideology can serve social life: It can be construed as a discursive act: a proposed order rather than an imposed form of discrimination; a process rather than a fixed structure. For if ideology has discursive roots, then it can be contested and changed. Ideology can simply be an imagined order that can be reimagined.

This underscores the importance of news-discourse that engages citizens in their heart and mind rather than only in dry, rational terms. News that speaks to people like myths do can serve to connect people by promoting shared imaginings. For this to be effective, for this not to become propaganda or mere entertainment, news must be construed as a form of narrative. The rhetoric of modern journalism objectivity must be called into question and exposed for what it is: a myth. Many scholars suggest that it may be simplistic to think that the Ancients believed their myths to be factual representations. Similarly, Schudson (1978) has made the argument that in the 1890 s, good journalism was expected to be an elegant blend of facts and fiction (pp. 78-83). Not surprisingly, in that era, some of the best journalists were considered "men of literary ambitions" (p. 81). One must consider the possibility that in the past, readers may have been far more aware than we are now that when they read the news, they were being told a story.

For this reason, this thesis's final conclusion is that the study and practice of news-making should not dismiss approaches that view journalism as a narrative form. Instead, one must consider the idea that news-discourse has a reach that can go far beyond the rational mind and reflect on how this can foster social peace. Of course, for 
this idea to be effectively applied, a plurality of voices must be heard to offer different views. This puts the 1dea of citizen journalism and blogs into a fresh perspective. For after all, public myths are collectively constructed. The myths of social life must be told and retold so that history is not lost, but updated. It can be rewritten into the present on a palimpsest.

\section{The modern newspaper as a palimpsest}

Deriving from the Latin palimpsestus and the Greek palimpsēstos which means "scraped again", the word 'palimpsest', refers to a medium such as "parchment or tablet used one or more tımes after earlier writing has been erased". "It evokes the image of a surface "written, erased, written over, with the older layer dimly visible under the newer". ${ }^{45}$ In recent years, authors like Margaret Atwood (1985) have used the word as a metaphor, "Canada, like any country, is a palimpsest, an overlay of classes and generations". In spite of its direct reference to writing, the palimpsest is not static and fixed, but always in transformation. Thus, the trope of the palimpsest alludes to the perpetuation of culture through the oral tradition in written form. In this perspective, culture cannot be written onto a tabula rasae. It necessarily presupposes an already existing support that is constantly being altered. The present is weaved into strands of the past, the former overlaying the fragile ever-disappearing and thinning fabric of the latter. The palimpsest inevitably suggests memory, but it does not do so in a nostalgic or

44 "palımpsest." Merrıam-Webster Onlıne Dictıonary 2009. Merrıam-Webster Onlıne. 26 October $2009<\mathrm{http} . / / \mathrm{www}$ merriam-webster com/dictıonary/palımpsest>

45 "palımpsest." Merrıam-Webster Dictionary of Englısh Usage, 1994, p 708. 
sentimental way. The palimpsest celebrates the past with the present and welcomes the future marks that will overwrite them both.

The current myth of Canadian multi-culturalism is evidence that the myths of nationhood of the nineteenth century have since been updated for one must remember that its roots were the ideology of Anglo-Saxonism as was seen in the news images under study in this Master's thesis. This ideology did not prevent minorities groups from emerging from the shadows; their voices have been heard in the past century in Canada. Social, spatial, and temporal boundaries are first formed in the imagination. Reified boundaries are like unspoken agreements. If discursive acts draw attention to them, they can be renegotiated peacefully in social conditions that promote free speech and social justice. For one must remember that human imagination knows no boundaries. As Joseph Campbell often told his students, "If you want to change the world, change the metaphor" (Moyers, 2009). In the context of an increasingly globalized world where geo-political boundaries are softening and collective identities may come to be defined by more than religious beliefs or national imaginings, modern journalism can play an important role in helping peacefully reshape the boundaries of social life. Rethinking journalism in mythical terms in the context of new media is a project worthy of consideration.

\section{New avenues for future investigation}

According to Martin and Rose (2003), discourse analysis can and should provide insights that assist in the emancipation of those who suffer injustice by "exposing power as it naturalizes itself in discourse" (p. 264). Wodak (2002) recommends that "results should be made available to experts in different fields and, as a second step, be applied, 
with the goal of changing certain discursive and social practices" (p. 15; item 10). Exploratory research often suggests new avenues of scholarly inquiry. The purpose of this case study has been to open up such possibilities for both theory and practice in more than one field of study.

First, although this case study has provided some insight on the news coverage of the Klondike gold rush, in the broad context of Canadian historiography and journalism history, and in the narrower context of Klondike history, it remains an area of study where still much work could be undertaken in the research domains of written news and illustrated news. Many works on the history of the Canadian or American press specifically mention the Klondike gold rush as a journalistic event in of itself (Campbell, 2006, pp. 51-58, pp. 150-156; Lang, 1999, pp. 60-61; Milton, 1989, pp. 171-189; Mott, 1941, p. 577; Mullikin Parcell, 2002, pp. 329-330), yet Arenson (2007) and Newell (1987) were the only works that critically focus on journalism practices in the context of this event. Empirical work could be done on dailies, but also on weeklies and/or monthlies which were also found to be rich sources that could further enrich the scholarship.

Second, in the domain of illustrated news, it has also been shown that no extant work has studied the coverage of an international news event by focusing on news images published in daily newspapers in the late nineteenth century. Given that this was a key period in journalism history which saw a slow, but steady increase in the use of images in daily newspapers, it would seem that empirical work on this subject is currently lacking. Such studies would in turn open up a great number of possibilities for research on illustrated news in relationship to visual culture. 
Third, this case study also suggests that the early news coverage of an event can influence how it later comes to be mythologized in the popular imagination. Research that helps to improve our understanding of this social process should be encouraged. Further explanation of how news images first shape the collective imaginings of an event are directly related to contemporary journalism practices in new media, including, amongst others, citizen journalism. Early news images of an event are now often taken with cell phone cameras and uploaded onto YouTube. This case study has presented journalism as a social practice that has the potential to accommodate a greater diversity of voices. This is now possible in the context of new media.

At last, this case study has suggested a theoretical framework that scholars might use and develop in future empirical research to investigate discursive practices in the context of ideology. In fact, this framework suggests that ideology in its broad cultural definition can be conceptualized as a matrix of overlapping social, temporal, and spatial boundaries that constitute a stable, but mutable structure for the organization of social life. One can hope that this may provide new insights into how discursive acts can empower and emancipate social actors. 


\section{APPENDIX A}

\section{WODAK'S (2002) TEN PROGRAMMATIC CLAIMS FOR CRITICAL DISCOURSE ANALYSIS}

(1) The approach is interdisciplinary Problems in our societies are too complex to be studied from a single perspective This entalls different dimensions of interdisciplinarity the theories draw on neighbouring disciplines and try to integrate these theories Teamwork consists of different researchers from different traditıonally defined disciplines working together Lastly, the methodologies are also adapted to the data under investigation

(2) The approach is problem-oriented, rather than focused on specific linguistic items Social problems are the items of research, such as "racism, identity, social change", which, of course, are and could be studied from manifold perspectives The CDA dimension, discourse and text analysis, is one of many possible approaches

(3) The theories as well as the methodologies are eclectic, $1 \mathrm{e}$, theories and methods are integrated which are adequate for an understanding and explanation of the object under investigation

(4) The study always incorporates fieldwork and ethnography to explore the object under investigation (study from the inside) as a precondition for any further analysis and theorizing This approach makes it possible to avold "fitting the data to illustrate a theory" Rather, we deal with bottom-up and topdown approaches at the same tıme

(5) The approach is abductive a constant movement back and forth between theory and empirical data is necessary This is a prerequisite for principle 4

(6) Multiple genres and multıple public spaces are studied, and intertextual and interdiscursive relationships are investigated Recontextualization is the most important process in connecting these genres as well as topics and arguments (topol) In our postmodern societies, we are dealıng with hybrid and innovatıve genres, as well as with new notions of "tıme", "Identity" and "space" All these notions have undergone significant change, for example, "fragmented" Identities have replaced the notion of "holistic identities"

(7) The historical context is always analyzed and integrated into the interpretation of discourses and texts The notion of "change" (see principle 6) has become inherent in the study of text and discourse

(8) The categories and tools for the analysis are defined in accordance with all these steps and procedures and also with the specific problem under investigation This entails some eclectıcism, as well as pragmatism Different approaches in CDA use different grammatical theories, although many apply Systemic Functional Linguistics in some way or other

(9) Grand Theories might serve as a foundation, in the specific analysis, Middle-Range Theories serve the aims better The problem-oriented approach entalls the use and testing of middle-range theories Grand Theories result in large gaps between structure/ context and linguistic reahzations (although some gaps must remain unbridgeable)

(10) Practice and application are aimed at The results should be made avallable to experts in different fields and, as a second step, be applied, with the goal of changing certain discursive and social practices

(Reproduced with permission from the author)

Source R Wodak (2002), Aspects of critical discourse analysis Zeitschrift fur Angewandte Linguistik 36, pp 14-15 
TABLE A - TABLES OFFERING A DESCRIPTIVE LIST OF THE 14 DAILY NEWSPAPERS IN THIS CASE STUDY

Table Al

Descriptive List of the Seven Canadian Daily Newspapers in this Case Study's Sampling Frame ${ }^{1}$

\begin{tabular}{|c|c|c|c|c|c|c|c|c|}
\hline Newspaper & Prov & $\begin{array}{c}\text { Founded } \\
\text { in }\end{array}$ & Editorial control ${ }^{2}$ & $\begin{array}{l}\text { Subscriptıon } \\
\text { price (yearly) }\end{array}$ & $\begin{array}{l}\text { Number } \\
\text { of pages }\end{array}$ & Circulation $^{3}$ & $\begin{array}{c}\text { Ideology } \\
\text { in } 1897\end{array}$ & $\begin{array}{c}\text { Readership } \\
\text { In } 1897\end{array}$ \\
\hline (Winnipeg) The Dally Nor'Wester ${ }^{4}$ & MB & 1894 & W F Luxton & $\$ 3$ & 4 to 8 & $7,874_{1897}$ & conservative & highbrow \\
\hline The Ottawa Free Press & ON & 1869 & C W Mitchell & $\$ 5$ & 4 to 12 & $5,400_{1899}$ & liberal & highbrow \\
\hline (Toronto) The Globe & ON & 1844 & George Brown & $\$ 5$ & 8 to 20 & $32,605_{1897}$ & liberal & highbrow \\
\hline (Montreal) La Presse & QC & 1884 & $\mathrm{~T}$ Berthaume & $\$ 3$ & 8 & $54,844_{1897}$ & independent & lowbrow \\
\hline The Montreal Dally Star & QC & 1869 & G Lanigan & $\$ 3$ & 12 to 24 & $45,729_{1897}$ & imperıalıst & lowbrow \\
\hline (Toronto) Dally Mall and Emptre & $\mathrm{ON}$ & 1895 & Riordan family & $\$ 4$ & 8 to 24 & $29,141_{1898}$ & conservative & highbrow \\
\hline The Toronto World & ON & 1880 & W F Maclean & $\$ 3$ & 4 to 8 & $25,110^{1898}$ & independent & lowbrow \\
\hline
\end{tabular}

1 Unless otherwise stated in a footnote, the primary sources used are the newspapers themselves, A McKim, (1899) The Canadian newspaper directory (Montreal A McKım \& Co, Publıshers), N W Ayer \& Son, (1897) N W Ayer \& Son's American Newspaper Annual (Philadelphı, P A N Y Ayer \& Son), P F W Rutherford, (1982) A Victorian authority the dally press in late nineteenth century Canada (Toronto University of Toronto Press), M Sotıron, (1997) From politics to profits the commercialızation of Canadian dally newspapers, 1890-1920 (Montreal McGıll-Queen's University Press)

2 The name listed in this column indicates the person who had the most editorial control or influence the year the newspaper was founded

3 Circulation figures are sourced directly from the newspapers durıng the third week of July 1897 If the daily did not publish the circulation returns, it is then taken from one of the primary sources identified in footnote 1, especially from The Canadian newspaper directory, either for 1898 or 1899, as indicated

4 Additional sources for the Datly Nor'Wester are L Girouard \& M Hansen, (April 20, 2011), personal communication [email], Reference Services, Legislatıve Library, Government of Manitoba, L Girouard, (July 7, 2011), personal communicatıon [email], Reference Services, Legislatıve Library, Government of Manitoba, J W Dafoe, (1930, April), Early Winnipeg Newspapers In Papers read before the Historical and Scientific Society of Manitoba (Vol 3, pp 14-24), (Winnipeg Historical and Scientific Society of Manitoba), D M Loveridge, (1981) A historical directory of Manitoba newspapers, 1859-1978 (Winnipeg University of Manitoba Press) The circulation figure is from N W Ayer \& Son, (1897) referenced in footnote 1 
Table A2

Descriptive List of the Seven American Daıly Newspapers in this Case Study's Sampling Frame ${ }^{1}$

\begin{tabular}{|c|c|c|c|c|c|c|c|c|}
\hline Newspaper & State & $\begin{array}{c}\text { Founded } \\
\text { in }\end{array}$ & Editorial control $^{2}$ & $\begin{array}{c}\text { Subscription } \\
\text { price (yearly) }\end{array}$ & $\begin{array}{l}\text { Number } \\
\text { of pages }\end{array}$ & Circulation $^{3}$ & $\begin{array}{c}\text { Ideology } \\
\text { in } 1897 \\
\end{array}$ & $\begin{array}{c}\text { Readershıp in } \\
1897 \\
\end{array}$ \\
\hline (Los Angeles) The Herald ${ }^{4}$ & $\mathrm{CA}$ & 1873 & W S Creighton & $\$ 5$ & 10 to 24 & $8,512_{1897}$ & democratic & lowbrow \\
\hline The New York Herald & NY & 1835 & J G Bennett & $\$ 8$ & 12 to 46 & $80,000_{1897}$ & independent & lowbrow \\
\hline The New York Times & NY & 1851 & A S Ochs 1896 & $\$ 8$ & 12 to 28 & $75,000_{1897}$ & democratic $^{5}$ & highbrow \\
\hline San Franctsco Chronicle & $\mathrm{CA}$ & 1865 & M H De Young & $\$ 670$ & 10 to 36 & $68,000_{1897}$ & independent & lowbrow \\
\hline (San Francisco) The Examiner & $\mathrm{CA}$ & 1865 & W R Hearst & $\$ 780$ & 10 to 36 & $75,930_{1897}$ & independent & lowbrow \\
\hline The Seattle Post-Intelligencer ${ }^{6}$ & WA & 1881 & Leigh S J Hunt ${ }_{1886}$ & $\$ 10$ & 8 to 20 & $12,000_{1897}$ & republican & highbrow \\
\hline The Washıngton Post & DC & 1877 & S Hutchıns & $\$ 6$ & 12 to 24 & $22,056_{1897}$ & independent & highbrow \\
\hline
\end{tabular}

1 Unless otherwise stated in a footnote, the primary sources used are the newspapers themselves, J W Campbell, (2001) Yellow journalism puncturing the myths, defining the legacies (Westport, Conn Praeger), N W Ayer \& Son, (1897) NW Ayer \& Son's American Newspaper Annual (Philadelphia, P A N Y Ayer \& Son), M Schudson, (1978), Discovering the news a social history of American newspapers (New York Basic Books)

2 Unless stated otherwise by a date, the name listed in this column indicates the person who had the most editorial control the year the newspaper was founded

3 Circulation figures are sourced directly from the newspapers during the third week of July 1897 If the darly did not publish the circulation returns, it is taken from N W Ayer \& Son, (1897) N W Ayer \& Son's Amerccan Newspaper Annual (Philadelphia, P A N Y Ayer \& Son)

4 Additional source used is University of Calıfornia, Riverside (2007, Jan 19), About Los Angeles Herald, Chronicling America historic American newspapers, The Library of Congress, Washington, D C Retrieved on July 3, 2011 from http //chroniclingamerica loc gov/lccn/sn85042462/

5 NW Ayer \& Son's American Newspaper Annual 1dentıfies the ideological leaning of the New York Times as democratic but Schudson (1978) and Campbell (2001) both describe it, along with The Washington Post, as caterıng to a conservatıve readership

6 Additional source used is C Tate (2009, March 16) Seattle Post-Intelligencer (1863 2009), HistoryLink org The Free Online Encyclopedıa of Washıngton State History [e-essay 8956] Retrieved July 1, 2011 from http //www historylınk org/ındex cfm?DisplayPage=output cfm\&file_1d=8956 


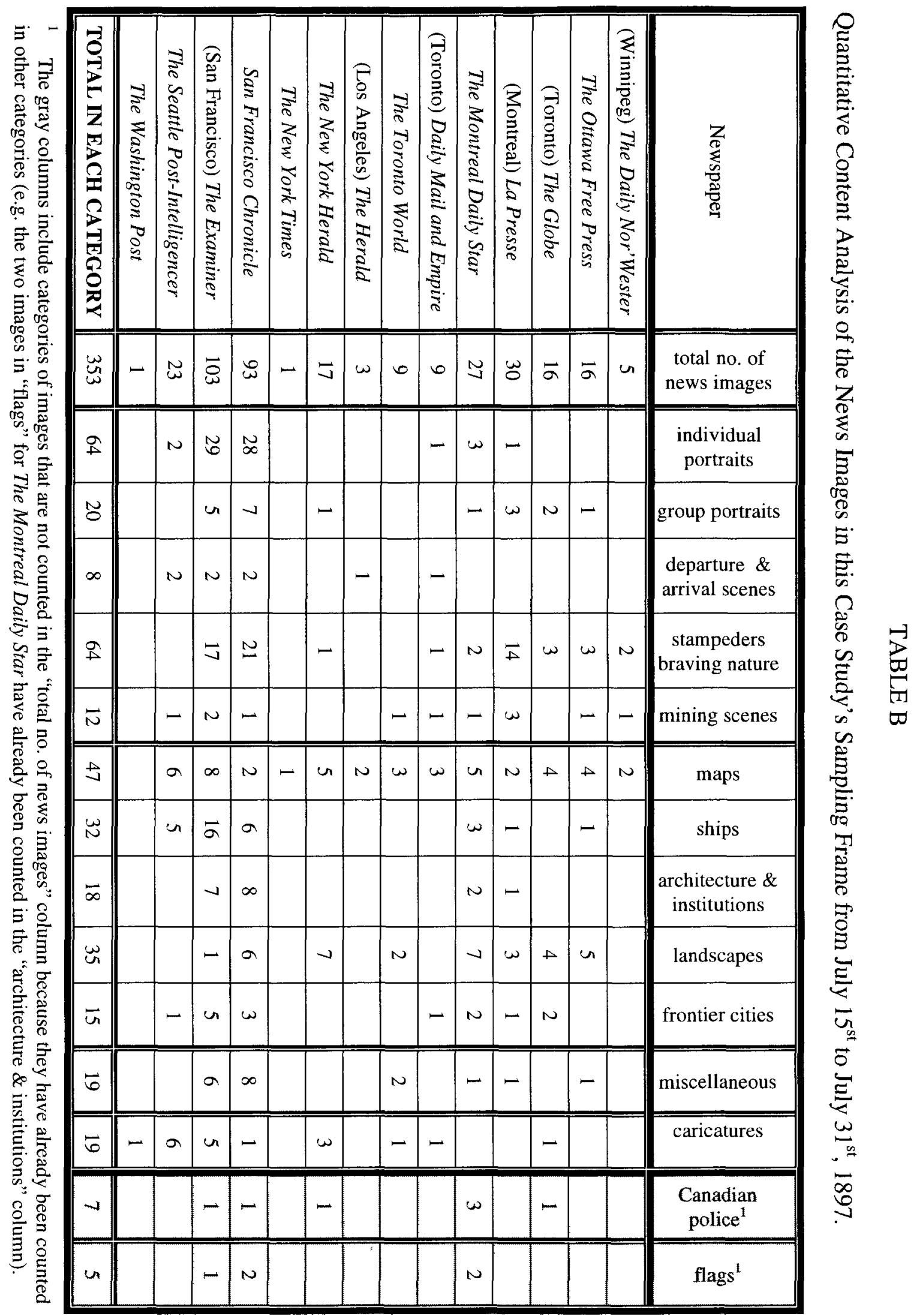


TABLE C - TABLES OF THE RELATIVE INDEX OF STORY JOURNALISM

\section{Table C1}

Calculation of the Relative Index of Story Journalısm of the Newspapers Included in this Case Study's Samplıng Frame.

\begin{tabular}{|c|c|c|c|c|c|c|}
\hline \multirow{2}{*}{ criteria used to calculate score ${ }^{1}$} & \multicolumn{3}{|c|}{ front page design ${ }^{2}$} & \multirow[b]{2}{*}{ 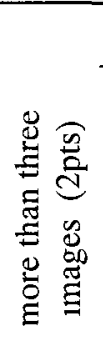 } & \multirow{2}{*}{ 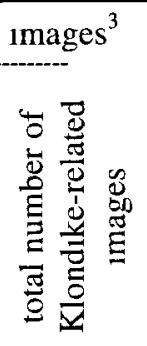 } & \multirow{2}{*}{ 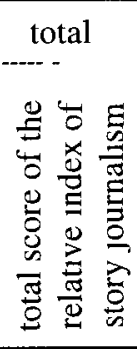 } \\
\hline & 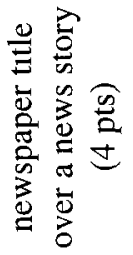 & 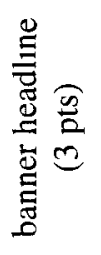 & 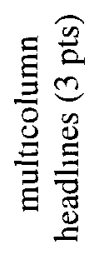 & & & \\
\hline (Winnipeg) The Dally Nor'Wester & 0 & 3 & 3 & 0 & 5 & 11 \\
\hline The Ottawa Free Press & 0 & 0 & 3 & 0 & 16 & 19 \\
\hline (Toronto) The Globe & 0 & 0 & 3 & 2 & 16 & 21 \\
\hline (Montreal) La Presse & 0 & 0 & 0 & 2 & 30 & 32 \\
\hline The Montreal Dauly Star & 0 & 0 & 3 & 0 & 27 & 30 \\
\hline (Toronto) Dally Mall and Emptre & 0 & 0 & 0 & 0 & 9 & 9 \\
\hline The Toronto World & 0 & 0 & 3 & 2 & 9 & 14 \\
\hline (Los Angeles) The Herald & 0 & 0 & 3 & 0 & 3 & 6 \\
\hline The New York Herald & 0 & 3 & 3 & 0 & 17 & 23 \\
\hline The New York Times & 0 & 0 & 0 & 0 & 1 & 1 \\
\hline San Francisco Chronicle & 4 & 4 & 3 & 2 & 93 & 106 \\
\hline (San Francisco) The Examiner & 4 & 3 & 3 & 2 & 103 & 115 \\
\hline The Seattle Post-Intelligencer & 0 & 0 & 3 & 0 & 23 & 26 \\
\hline The Washington Post & 0 & 0 & 0 & 0 & 1 & 1 \\
\hline
\end{tabular}

The criteria have been designed for the purpose of this case study The abundant use of images is associated with the story journalism paradigm rather than the information journalism paradigm For this reason, a great weight is given to the number of Klondike-related images used in the coverage of this event to determine the total score of the relative index of story journalism of each newspaper

2 This series of criteria used to evaluate a newspaper's story journalism index are specifically related to the graphic design of the front page Schudson (1978) argued that the story journalism paradigm resorted to self-promotion and sensationalism to increase their readership which translated in fancy designs (p 95) W J Campbell (2001) has devised a method to calculate a newspaper's sensationalism index by giving different scores to nine different criteria related to content and design (pp 153-160) The criterra used in these four columns have been adapted from this methodology in W J Campbell, (2001), Yellow journalism puncturing the myths, defining the legactes (Westport, Conn Praeger)

3 This count includes only news images that were published in each newspaper between July $15^{\text {th }}$ and July $31^{\text {st }}, 1897$ inclusively 
Table C2

Relative Index of Story Journalism of the Newspapers in this Case Study's Sampling Frame as Laid Out on a Spectrum Ranging from Lowest to Highest According to the Scores Obtained in Table C1.

\begin{tabular}{|c|c|c|c|c|c|c|c|c|c|c|c|c|c|c|}
\hline$\frac{a}{a}$ & 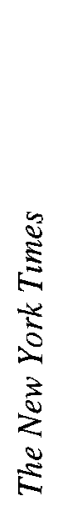 & 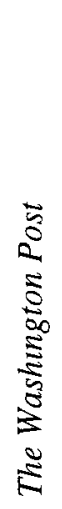 & 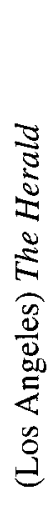 & 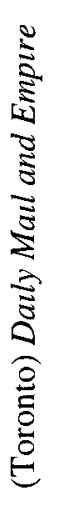 & 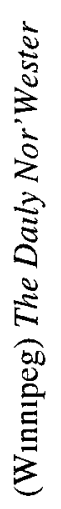 & 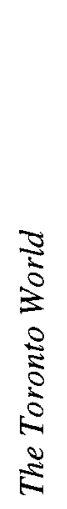 & 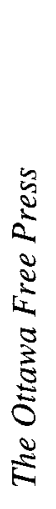 &  & 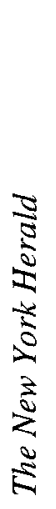 & 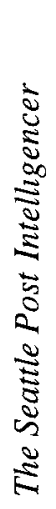 & 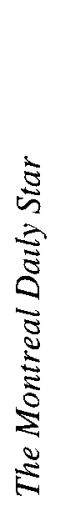 & 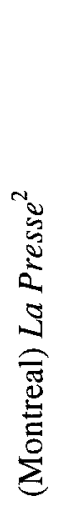 & 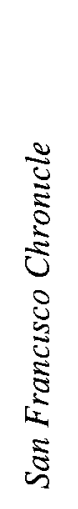 & 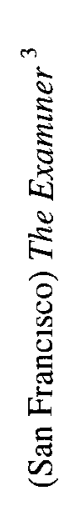 \\
\hline $\begin{array}{l}\text { total } \\
\text { score }\end{array}$ & $1^{1}$ & $1^{1}$ & 6 & 9 & 11 & 14 & 19 & 21 & 23 & 26 & 30 & 32 & 106 & 115 \\
\hline
\end{tabular}

Based on the two models of journalısm that existed in the 1990s according to Schudson (1978)

1 Given that The Washington Post and The New York Times scored exactly the same value, W J Campbell's (2001) method was used to determine which newspaper was less sensationalistic and thus closest to the information model W J Campbell (2001) had already established this in a study where he compared them both in 1899 The results of this study are published in W J Campbell, (2001), Yellow journalism puncturing the myths, defining the legacıes (Westport, Conn Praeger), p 159

$2 \quad$ La Presse yields a slightly higher story journalısm score than The Montreal Dally Star Although the latter is generally considered at the farther end of the spectrum of story journalism according to $\mathrm{M}$ Sotiron, (1997), From politics to profits the commercialization of Canadian dally newspapers, 18901920 (Montreal McGill-Queen's University Press), p 16, La Presse was "Canada's closest approximation to a yellow journal" according to P F W Rutherford, (1982), A Victorian authority the dally press in late nineteenth-century Canada (Toronto University of Toronto Press), p 69

3 The Examiner owned by William Randolph Hearst was considered as one of the most sensationalistic North American newspapers according to W J Campbell, (2001), Yellow journalısm puncturing the myths, defining the legactes (Westport, Conn Praeger), $\mathrm{p} 158$ 


\section{TABLE D}

Details of the First Klondike News Announcements in this Case Study's Sampling Frame from July 15 to July $31,1897$.

\begin{tabular}{|c|c|c|c|c|c|c|}
\hline Newspaper ${ }^{1}$ & $\begin{array}{l}\text { Publication of first } \\
\text { news article } \\
\text { announcing gold strike } \\
\text { in Klondike }\end{array}$ & Day $^{2}$ & $\begin{array}{c}\text { Article } \\
\text { includes } \\
\text { news } \\
\text { image }\end{array}$ & $\begin{array}{l}\text { Publication of first } \\
\text { Klondike-related news } \\
\text { image }\end{array}$ & Day $^{2}$ & Type of image(s) \\
\hline (Winnipeg) The Daily Nor'Wester & July 15,1897 / p. 2 & day 1 & & July 29,1897 / p.1 & day 15 & two scenes \\
\hline The Ottawa Free Press & July 16,1897 / p. 1 & day 2 & & July 21,1897 / p. 1 & day 7 & map \\
\hline (Toronto) The Globe & July $19,1897 /$ p. 12 & day 5 & & July 21,1897 / p.1 & day 7 & landscapes/scene \\
\hline (Montreal) La Presse & July 19,1897 / p. 3 & day 5 & & July 23,1897 / p.1 & day 9 & portraits/scenes/map \\
\hline The Montreal Daily Star & July $16,1897 /$ p. 4 & day 2 & & July $19,1897 /$ p. 8 & day 5 & map \\
\hline (Toronto) Daily Mail and Empire & July 19,1897 / p. 4 & day 5 & & July 21,1897 / p. 1 & day 7 & caricature \\
\hline The Toronto World & July $17,1897 /$ p. 8 & day 3 & & July 19,1897 / p. 2 & day 5 & map \\
\hline (Los Angeles) The Herald & July $19,1897 /$ p. 5 & day 5 & yes & July $19,1897 /$ p. 5 & day 5 & map \\
\hline The New York Herald & July $18,1897 /$ p. 5 & day 4 & yes & July $18,1897 /$ p. 5 & day 4 & map \\
\hline The New York Times & July 15,1897 / p. 1 & day 1 & & July 25,1897 / p. 9 & day 11 & map \\
\hline San Francisco Chronicle & July $15,1897 /$ p. 1 & day 1 & & July 16,1897 / pp. 1-2 & day 2 & portraits/landscape \\
\hline (San Francisco) The Examiner & July 16,1897 / p. 1 & day 2 & yes & July 16,1897 / p. 1 & day 2 & $\begin{array}{c}\text { portrait/landscape/ } \\
\text { boat/map }\end{array}$ \\
\hline The Seattle Post-Intelligencer & July $15,1897 /$ pp. 5-6 & day 1 & & July $17,1897 /$ p. 1 & day 3 & map \\
\hline The Washington Post & July 16,1897 / p. 1 & day 2 & & July $30,1897 /$ p. 1 & day 16 & caricature \\
\hline
\end{tabular}

1 The gray-shaded rows indicate the seven American dailies and the white-shaded rows indicate the seven Canadian dailies of the sampling frame. 


\section{ILLUSTRATIONS}

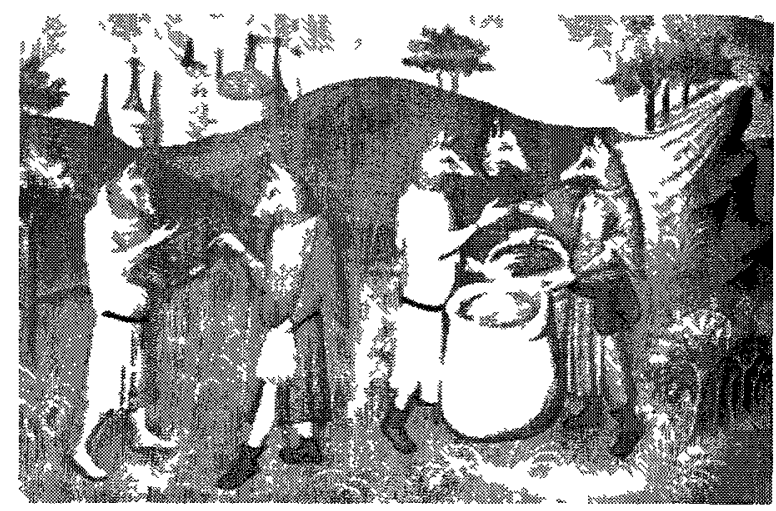

Fig. 1 Manuscript illustration of Book III, Chap. 18 of Polo's Books of the Marvels of the World. Workshop of the Boucicaut Master, ms fr 2810 , follo $76 \mathrm{v}, \mathrm{c} 15^{\text {th }}$ century (before 1413 ) Reproduced from Artstor

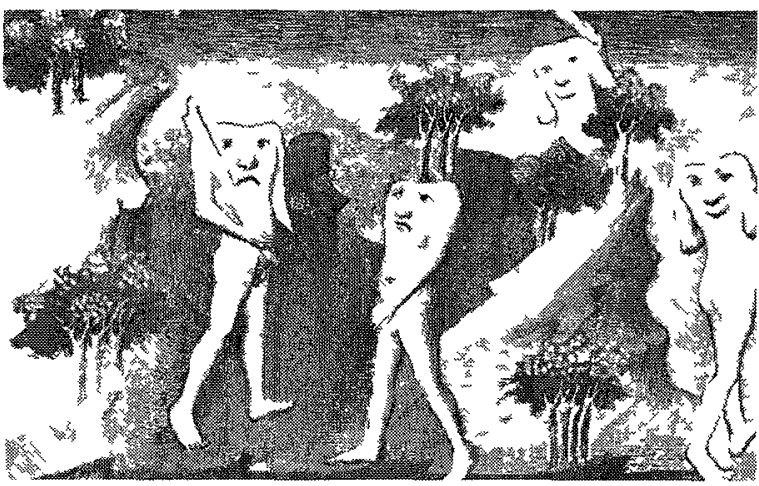

Fig. 3 Manuscript illustration of Book I, Chap. 57 of Polo's Books of the Marvels of The World. Workshop of the Boucicaut Master, folio $194 \mathrm{v}, \mathrm{ms}$ fr 2810 , c $15^{\text {th }}$ century (before 1413) Reproduced from Artstor

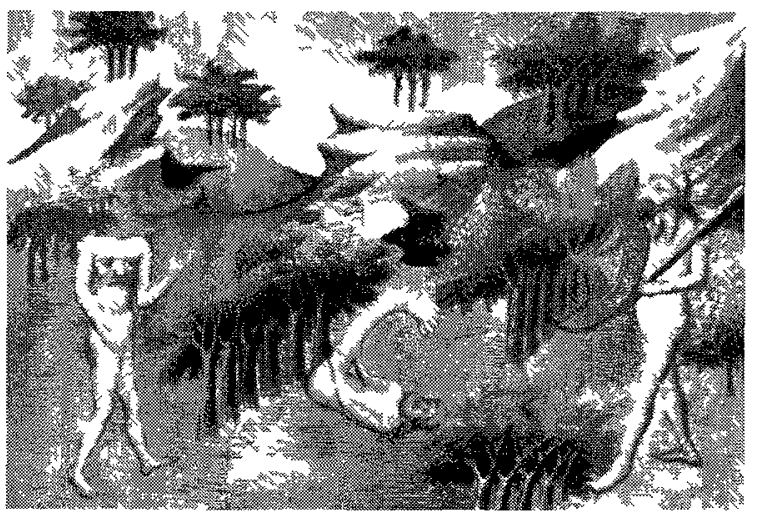

Fig. 2 Manuscript illustration of Book I, Chap. 51 of Polo's Books of the Marvels of The World. Workshop of the Boucicaut Master, ms fr 2810 , folo $29 \mathrm{v}, \mathrm{c} 15^{\text {th }}$ century (before 1413) Reproduced from Artstor

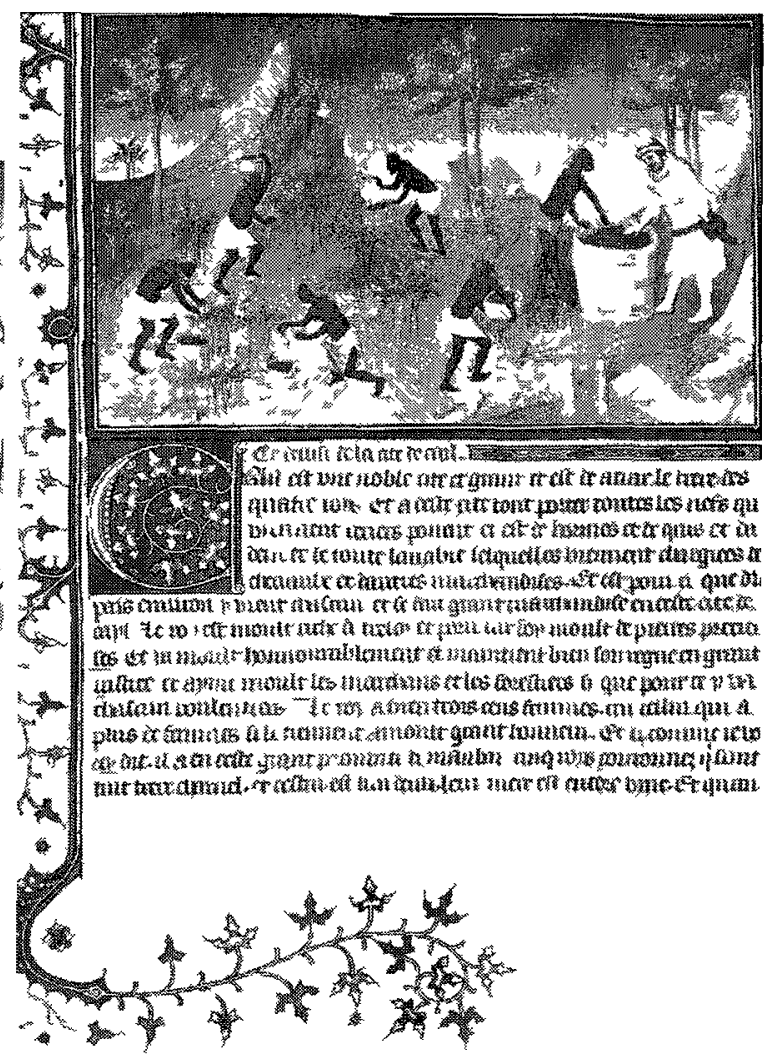

Fig. 4 Manuscript page of Book III, Chap. 25 of Polo's Books of the Marvels of the World. Workshop of the Boucicaut Master, folı $194 \mathrm{v}, \mathrm{ms}$ fr 2810 , c $15^{\text {th }}$ century (before 1413) Reproduced from Artstor 


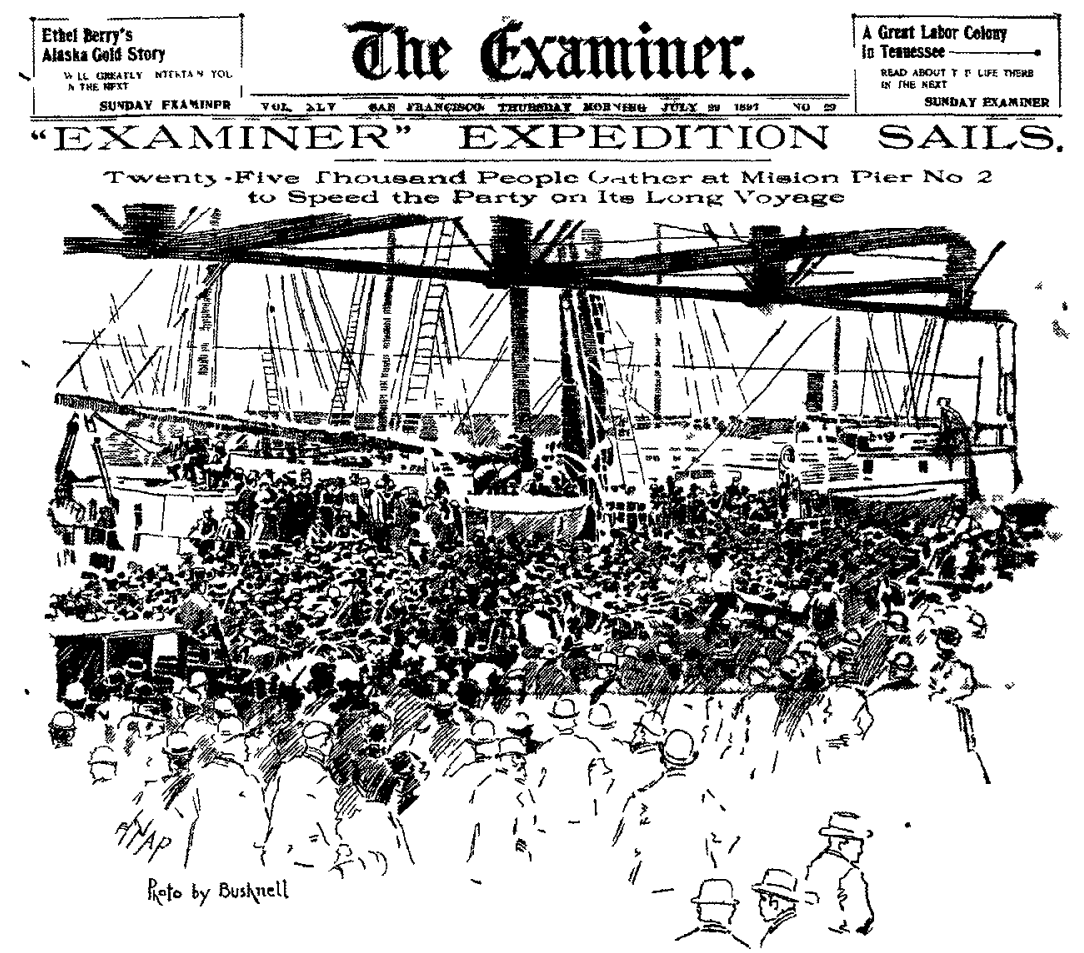

ALL SORTS AND CONDITIONS OF MEN COME TO SAY GOOD-BYE.

Fig. 5 The 'Excelsior' leaving for the Klondike.

(San Francisco) The Examiner, July 26, 1897, p 1

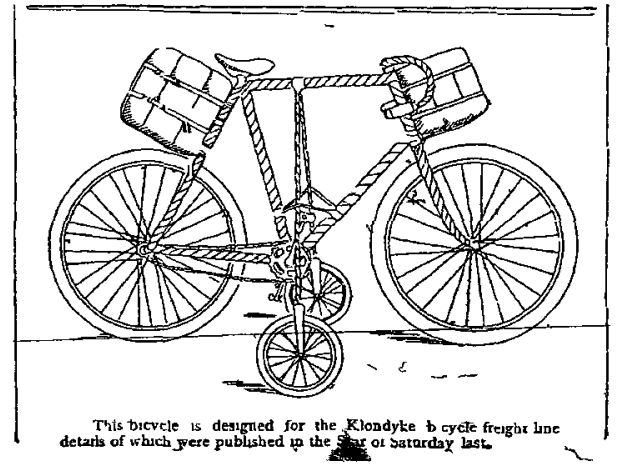

Fig. 6 Bicycle adapted for travel to Klondike.

The Montreal Dally Star, August 4, 1897, p 10

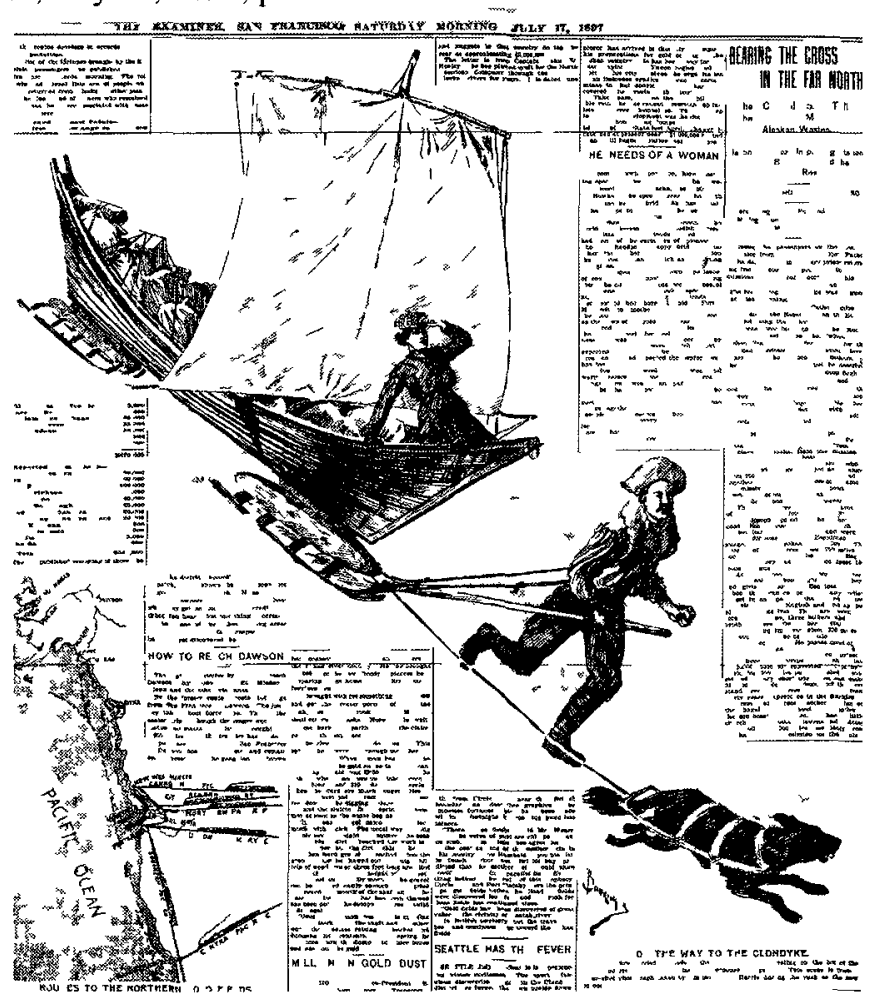

Fig. 7 Stampeders used many means of transportation. (San Franc1sco) The Examiner, July 17, 1897, p 14 


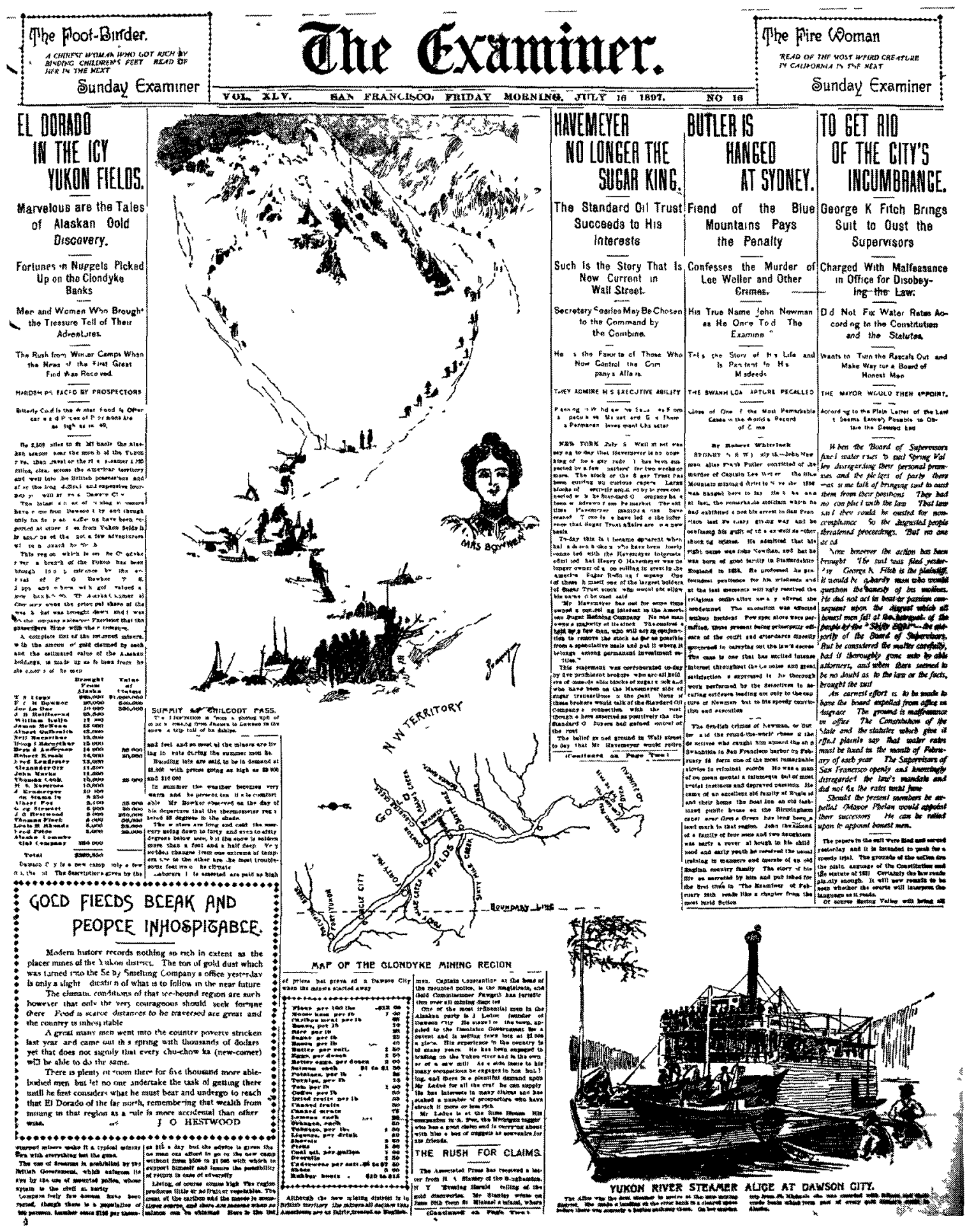

Fig. 8 The first news image published when the discovery of gold in the Klondike was announced. (San Francisco) The Examiner, July 16, 1897, p. 1. 


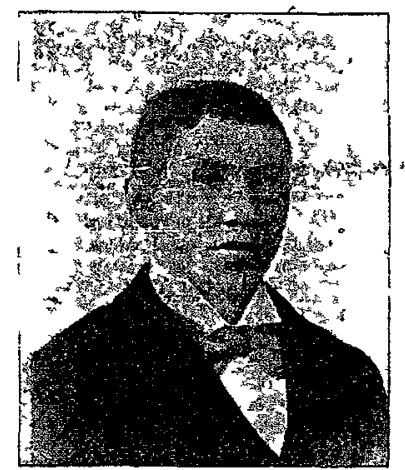

COLDN INKSTWR.

THLE FTRST MANTTOBANS TO REACH KLONDYKE.

Fig. 9 Two photographic portraits printed with the halftone process.

The Winnipeg Dally Tribune, July 27, 1897, p 1

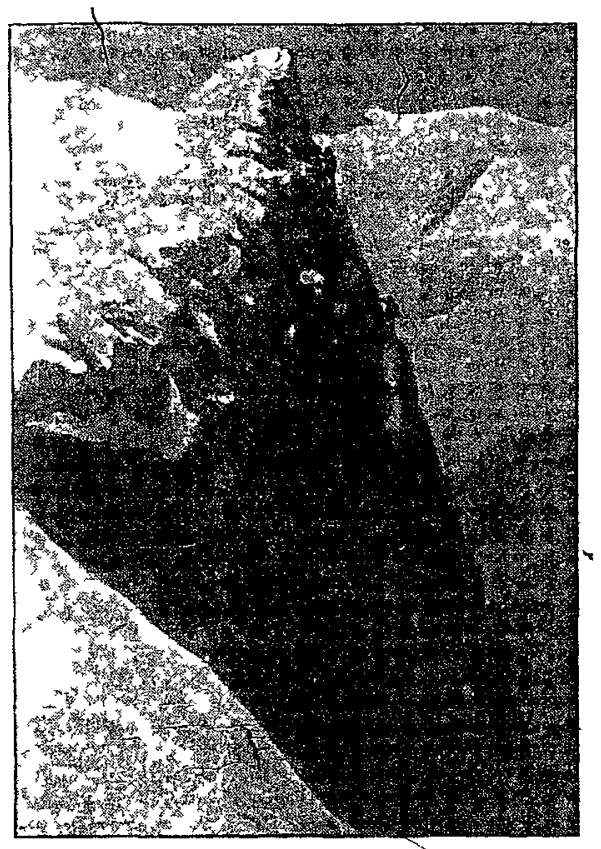

CHILCOTT PASS-TO THE YUKON

Fig. 10 Halftone reproduction of photograph of landscape.

The Winnipeg Dally Tribune, July 17, 1897, p 3

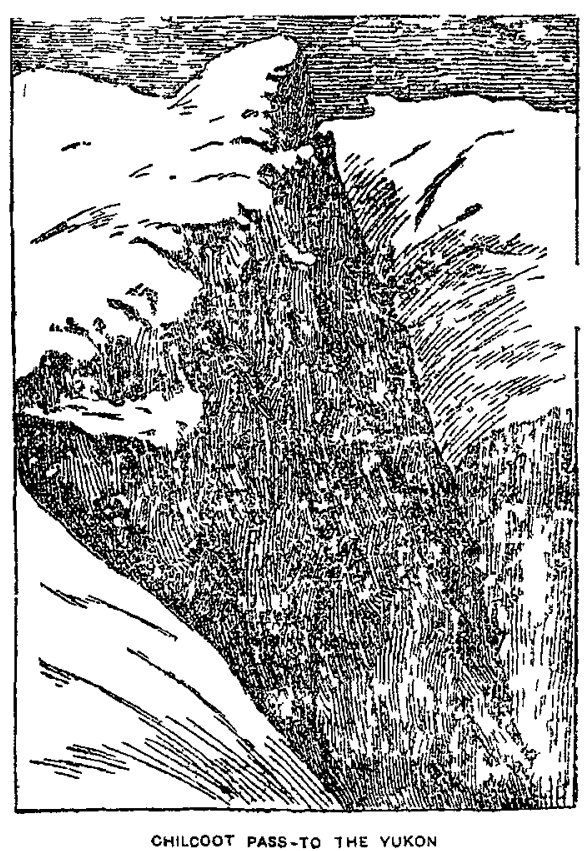

Fig. 11 Engraving made from photograph.

Ottawa Free Press, July 23, 1897, p 3

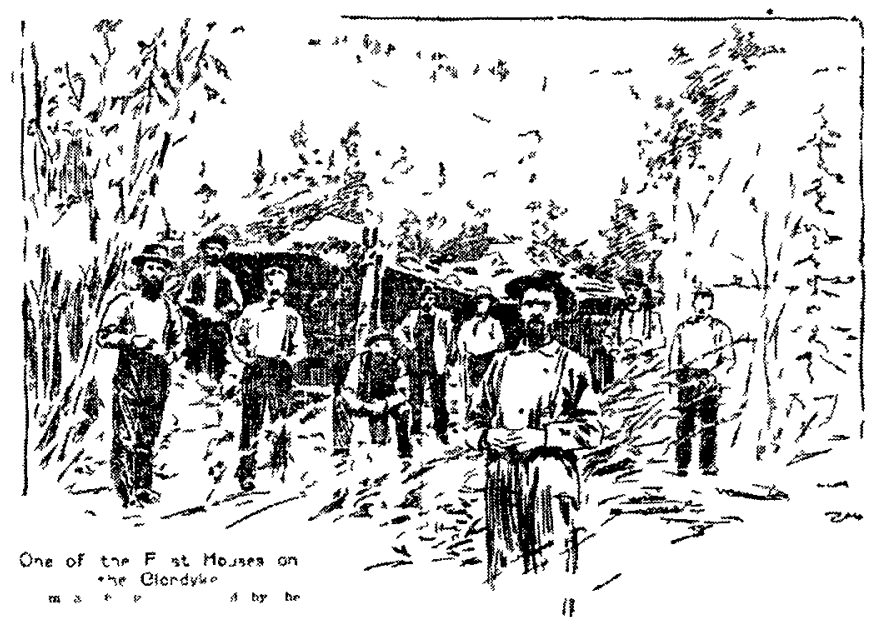

Fig. 12 Miners' camp in the Klondike, version 1. San Francisco Chronicle, July 17, 1897, p 1 


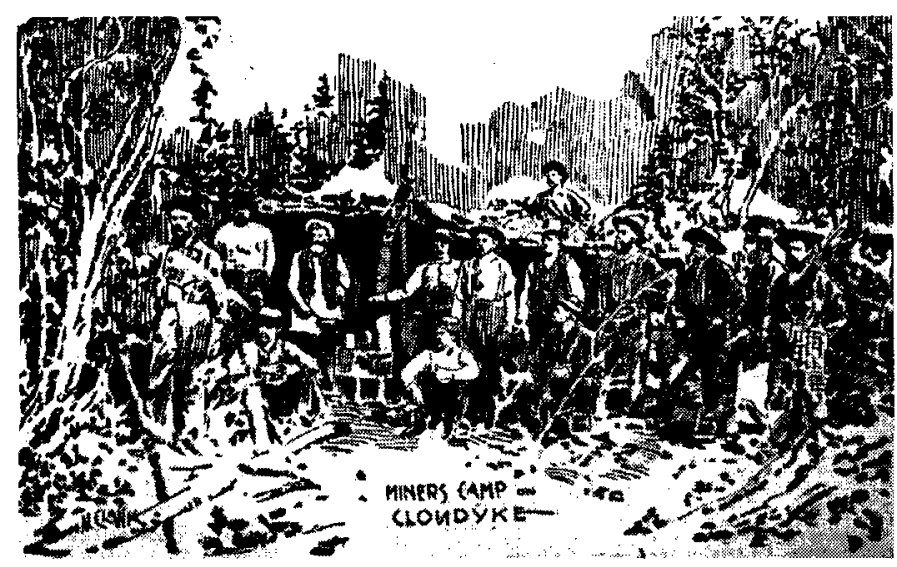

Fig. 13 Miners' camp in the Klondike, version 2.

(San Francisco) The Examiner, July 24, 1897, p. 3.

THE KLONDYKE AS IT REALLY IS.

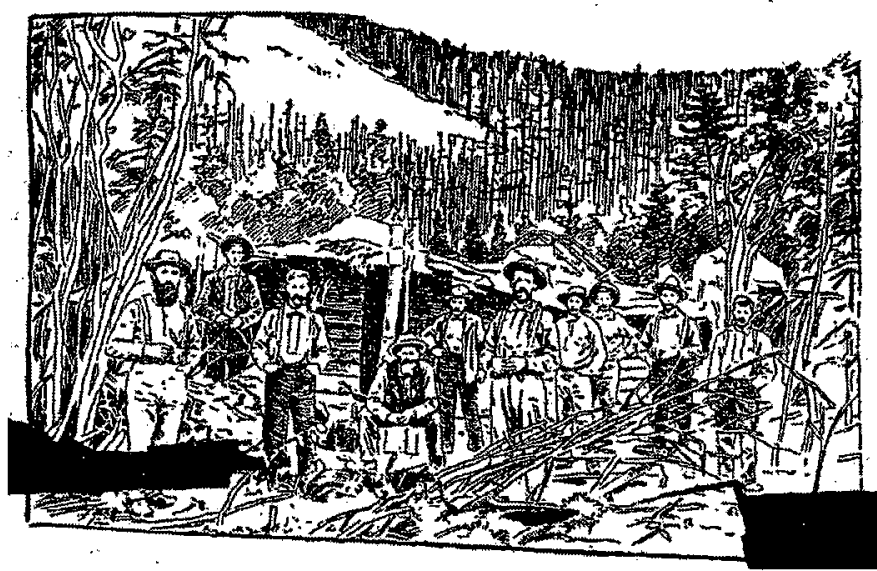

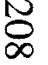

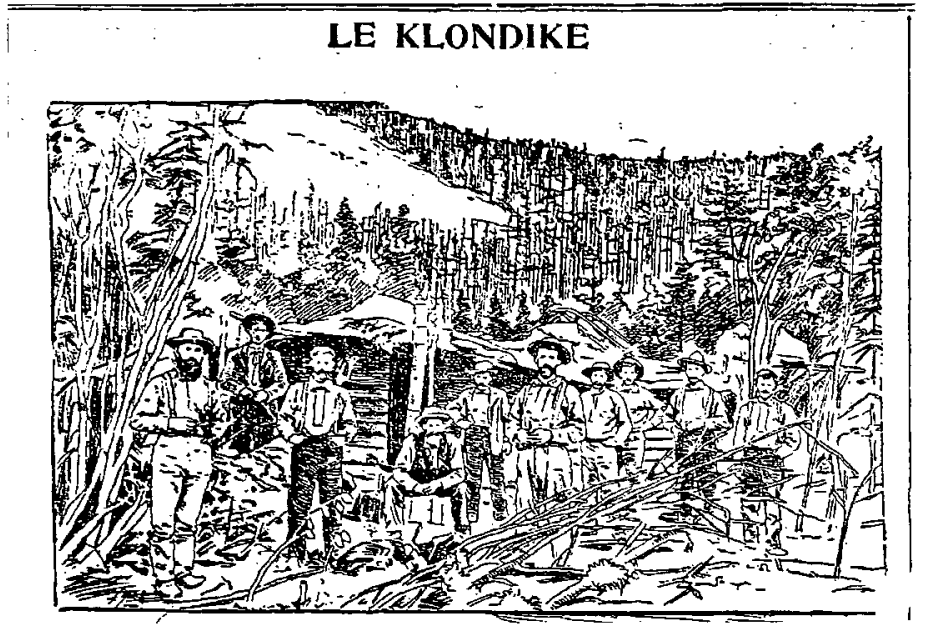

Fig. 14 Miners' camp in the Klondike, version 3.

(Montreal) La Presse, July 27, 1897, p. 1.

O'TTAWA DAIHY FREE PRESS, SATURDAY, JULY 31]

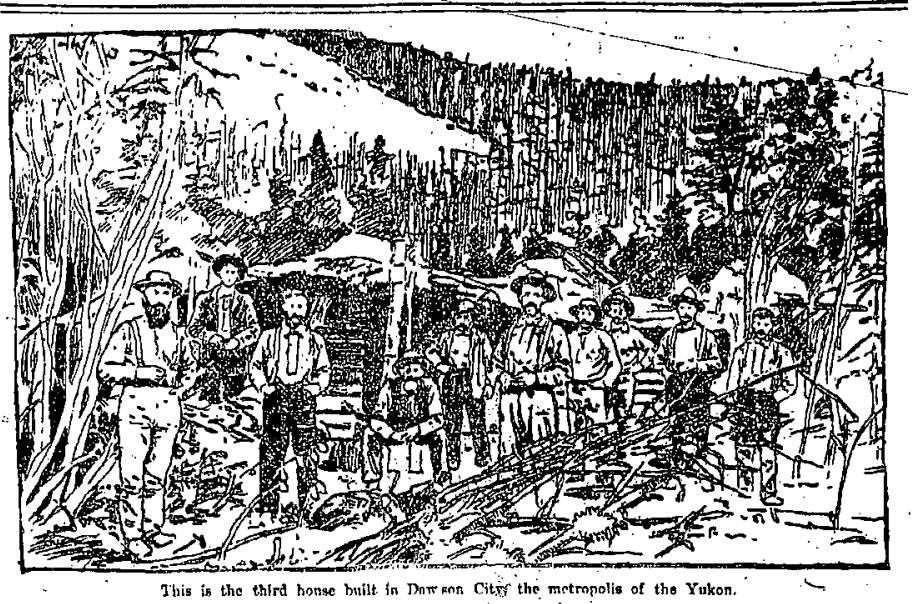

Fig. 16 Miners' camp in the Klondike, version 5.

The Ottawa Free Press, July 31, 1897, p. 9. 

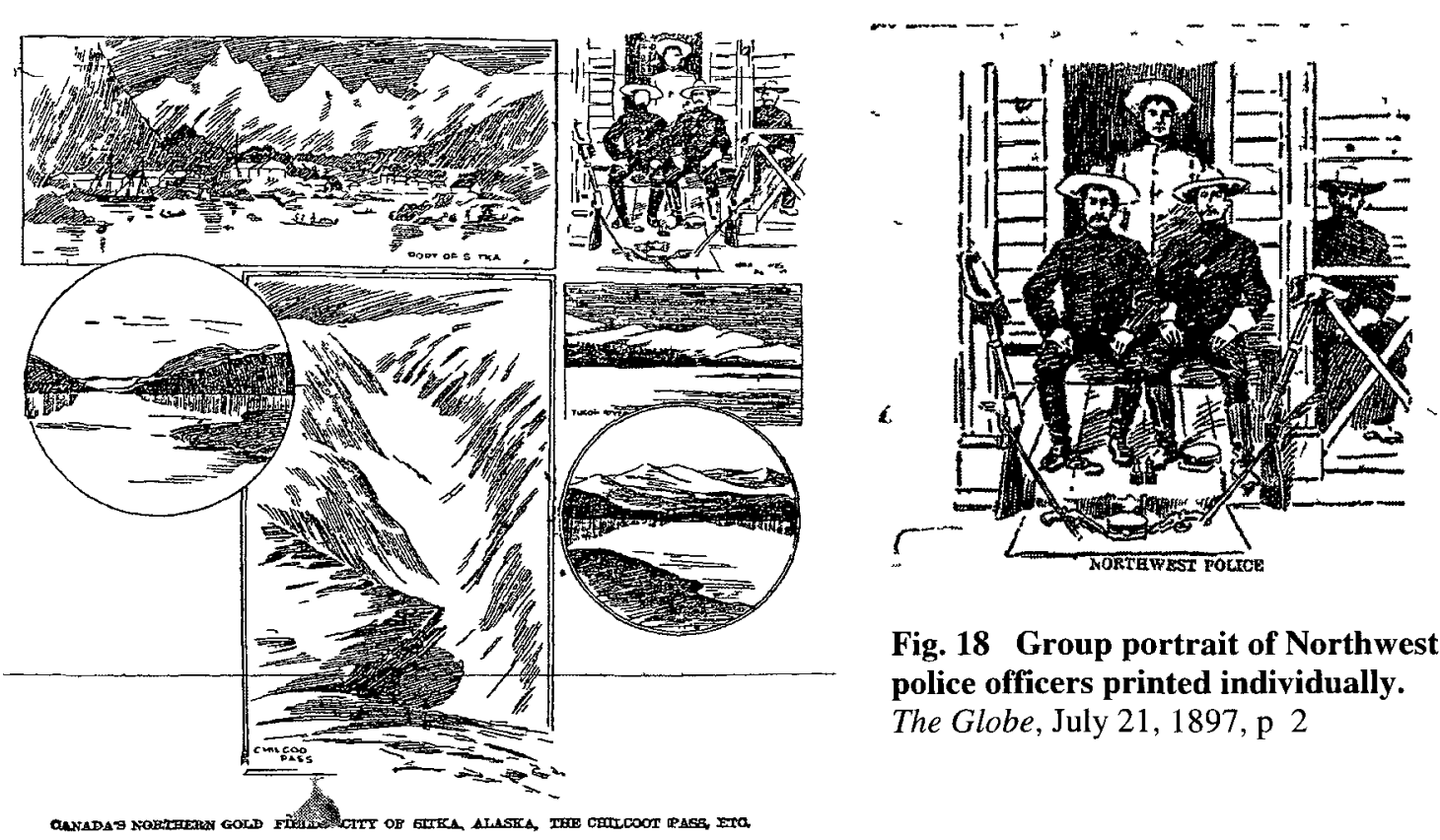

Fig. 18 Group portrait of Northwest police officers printed individually. The Globe, July 21, 1897, p 2

Fig. 17 Group portrait of Northwest police officers printed in montage of Klondike images.

The Montreal Dally Star, July 20, 1897, p 8
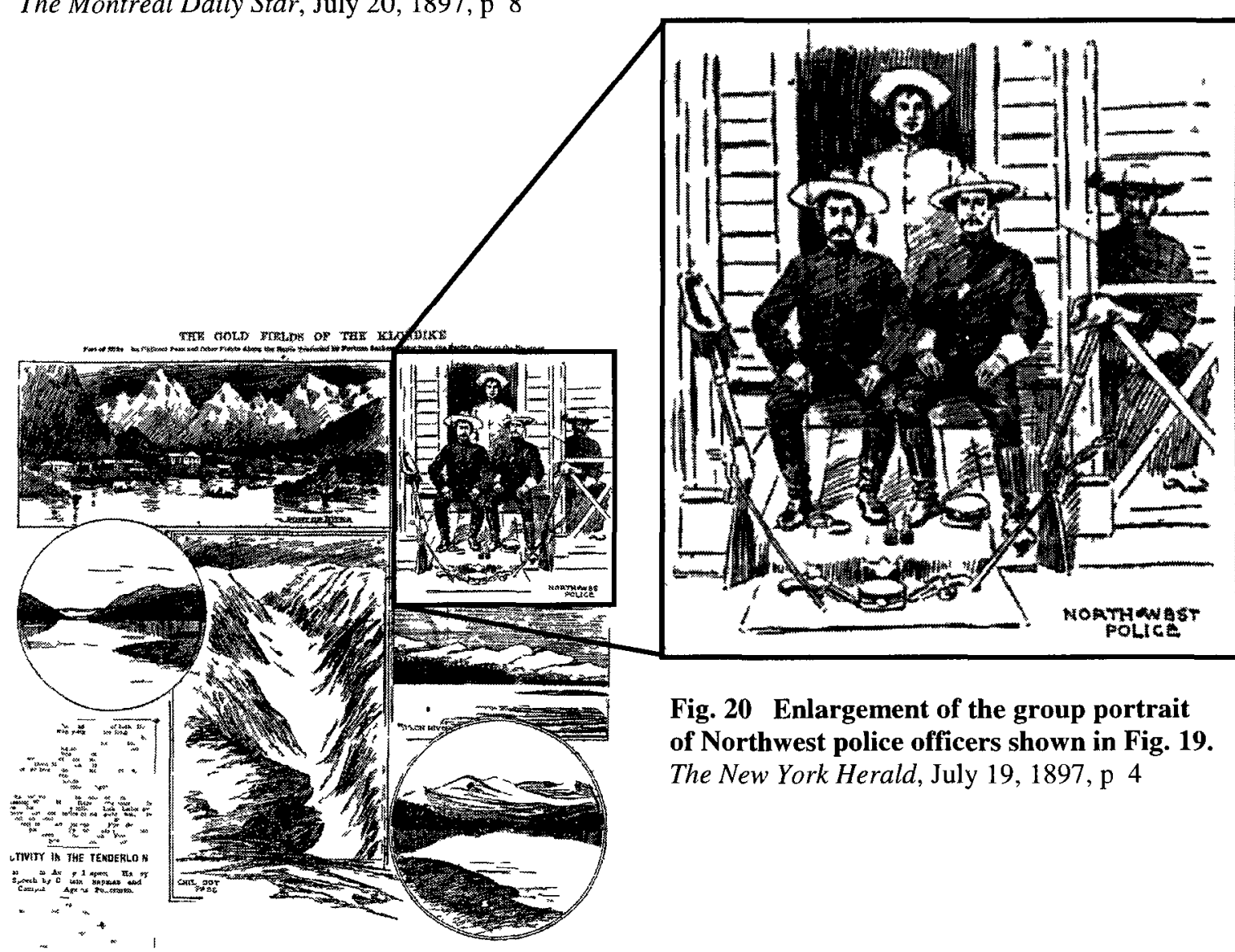

Fig. 19 Group portrait of Northwest police officers printed in montage of Klondike images.

The New York Herald, July 19, 1897, p 4

Fig. 20 Enlargement of the group portrait of Northwest police officers shown in Fig. 19. The New York Herald, July 19, 1897, p 4 


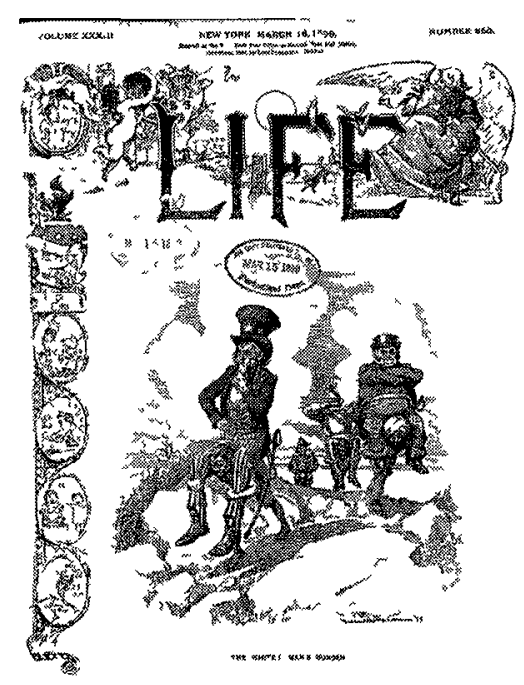

Fig. 21 Cartoon on cover of Life, Life, Vol. 33, March 16, 1899.

LA FIEVRE DE L'OR

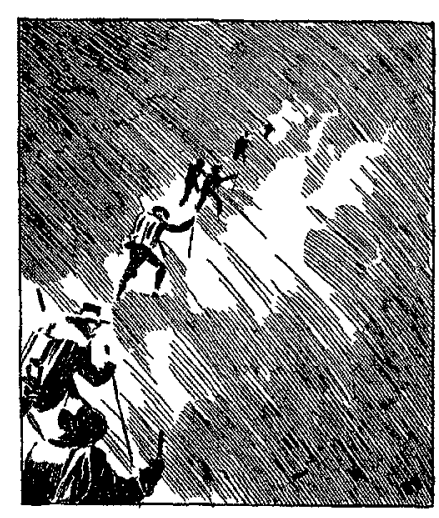

Fig. 22 Stampeders hiking.

N (Montreal) La Presse, July 23, 1897, p. 1.

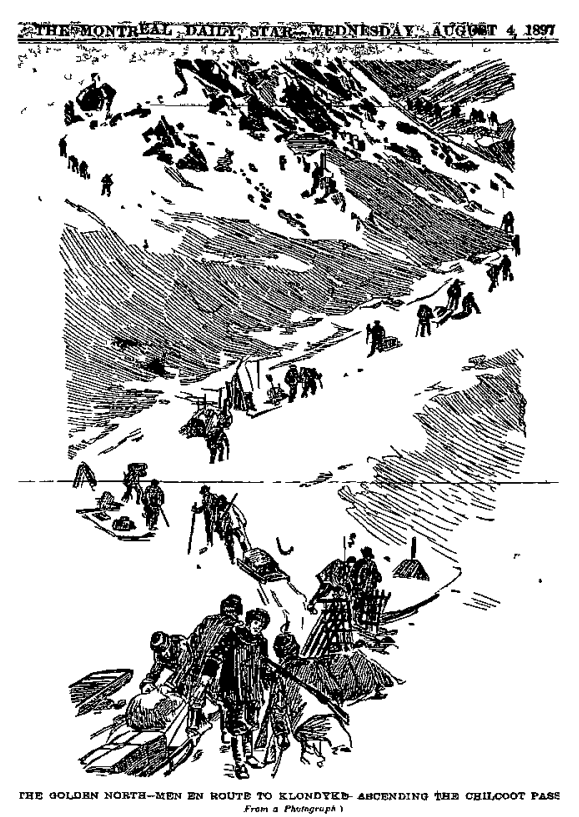

Fig. 23 Stampeders ascending the Chilcoot Pass.

The Montreal Daily Star , August 4, 1897, p. 10 .

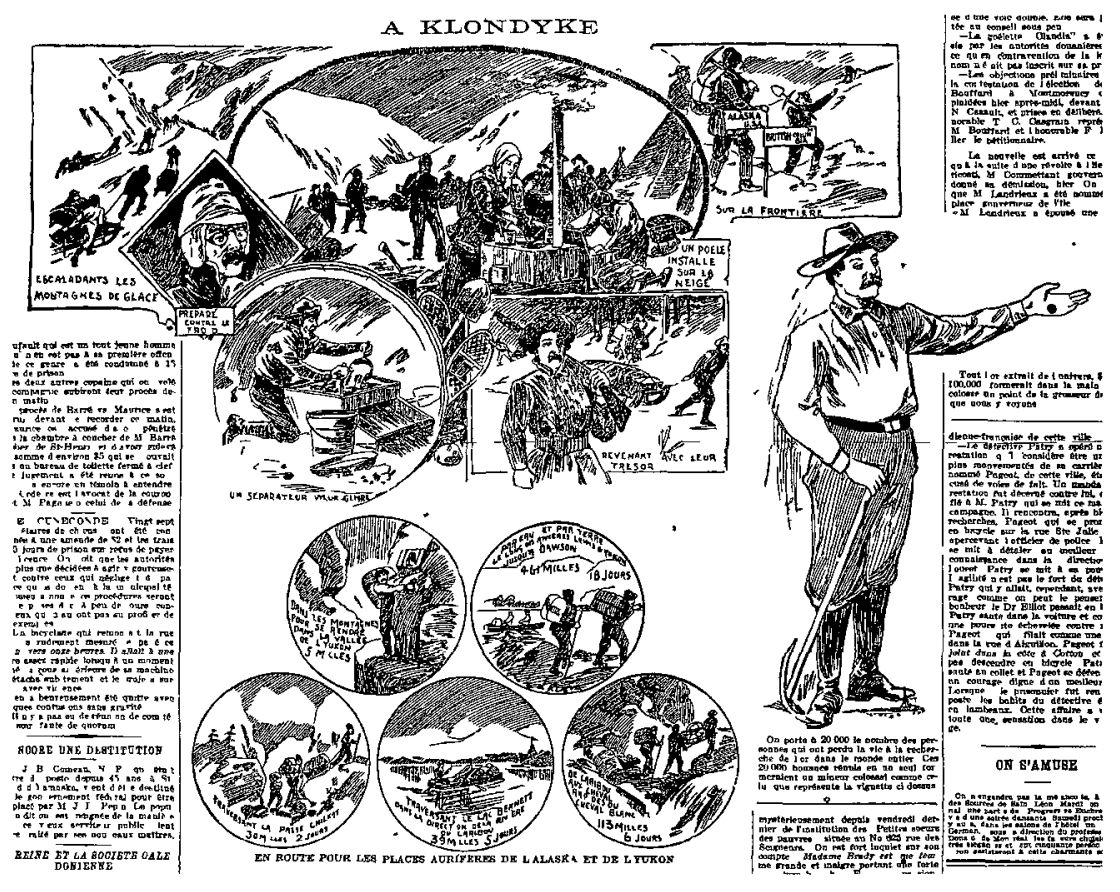

Fig. 24 Vignettes of stampeders heading for the gold fields. La Presse, July 28, 1897, p. 1. 


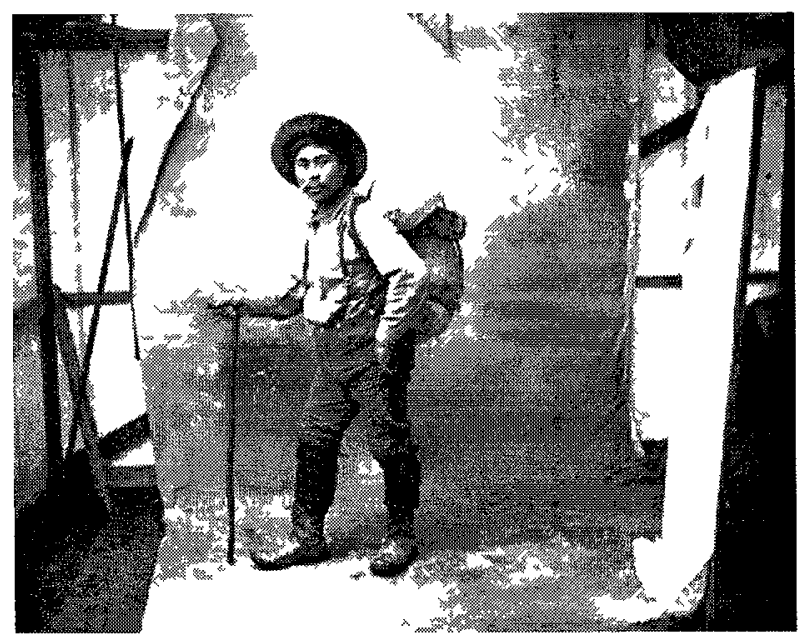

Fig. 25 Studio portrait of a Chilkat Indian posed as a packer for the Klondike, Alaska, c. 1897. Erıc A Hegg, Enic A Hegg Photograph Collection, University of Washington Libraries, Special Collections, Seattle, Washington, NA2346
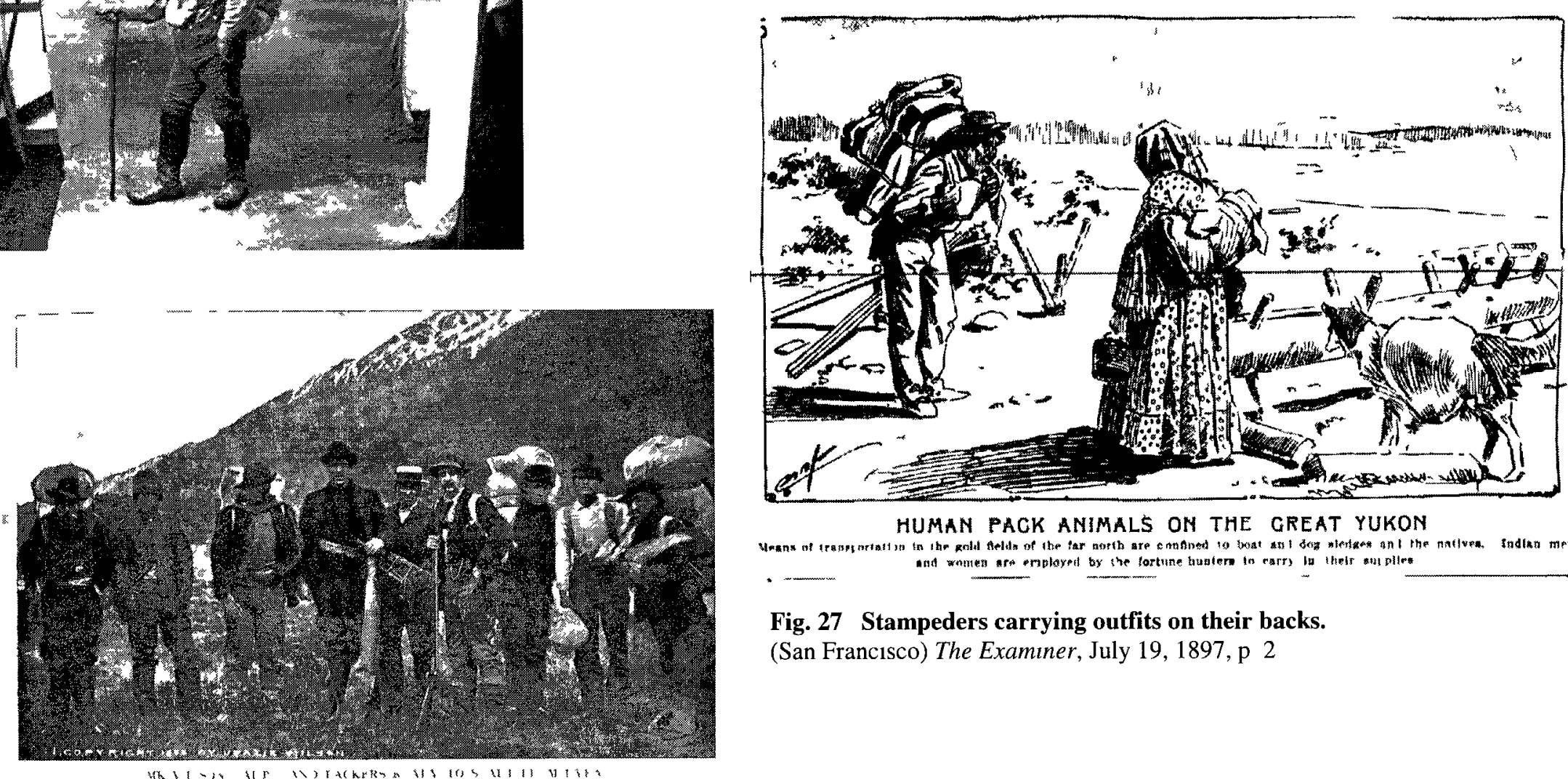

HUMAN PACK ANIMALS ON THE GREAT YUKON

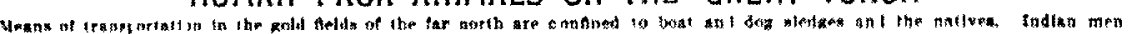
- ․․․m.m

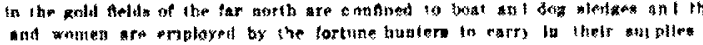

Fig. 27 Stampeders carrying outfits on their backs.

(San Francisco) The Examiner, July 19, 1897, p 2

Fig. 26 Veazie Wilson's party and First Nation packers heading for the Klondike district, c. 1895. 


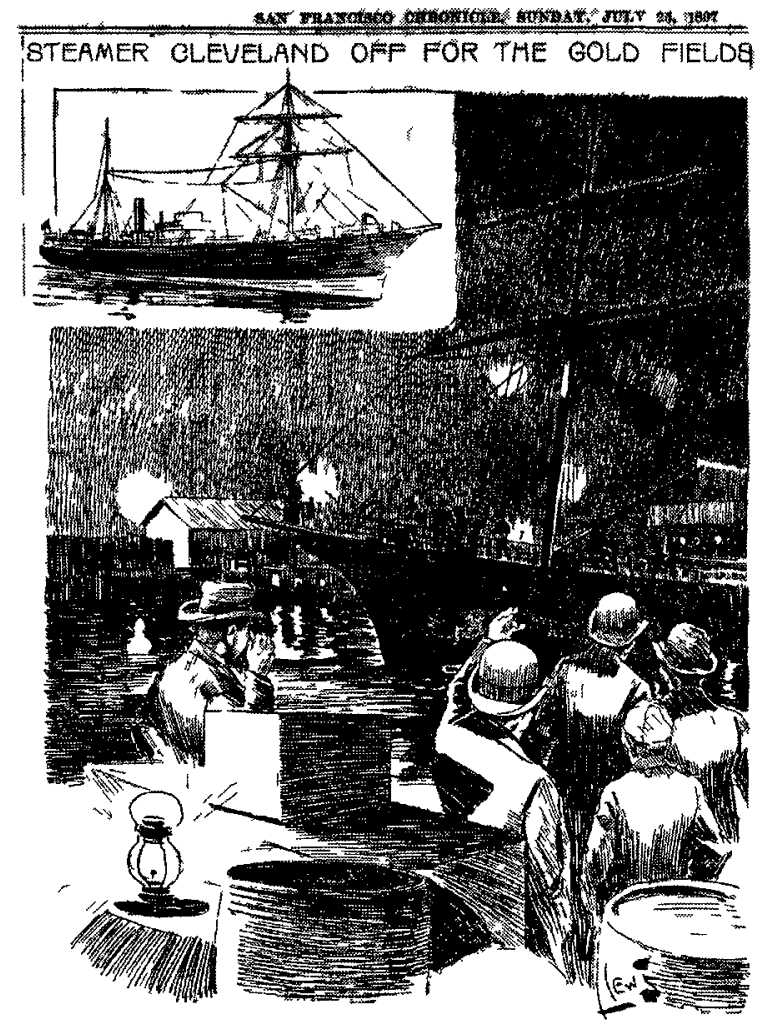

Fig. 28 The 'Cleveland' leaving San Francisco. San Francisco Chronicle, July 25, 1897, p 14

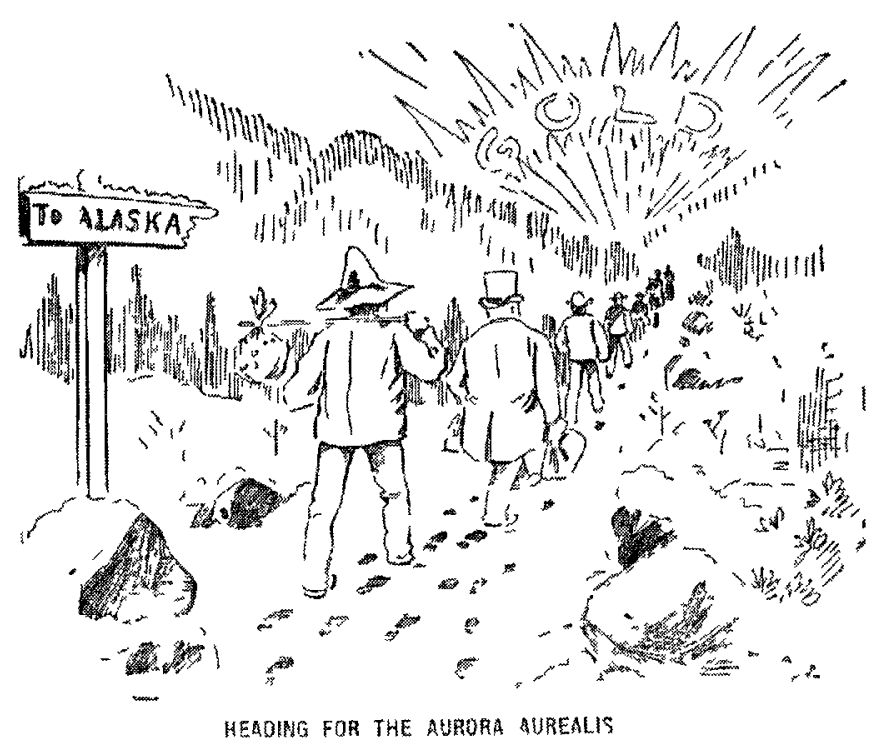

Fig. 29 Americans leaving for the Klondike. (Los Angeles) The Herald, July 25, 1897, p 1

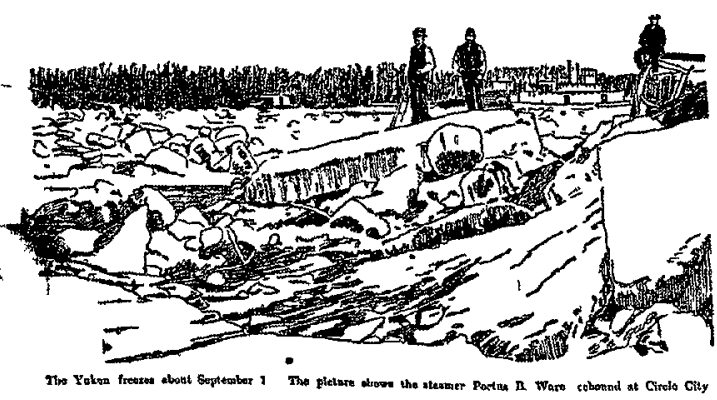

Fig. 30 Stampeders icebound on their way to Dawson City.

(Toronto) The Globe, July 29, 1897, p 6

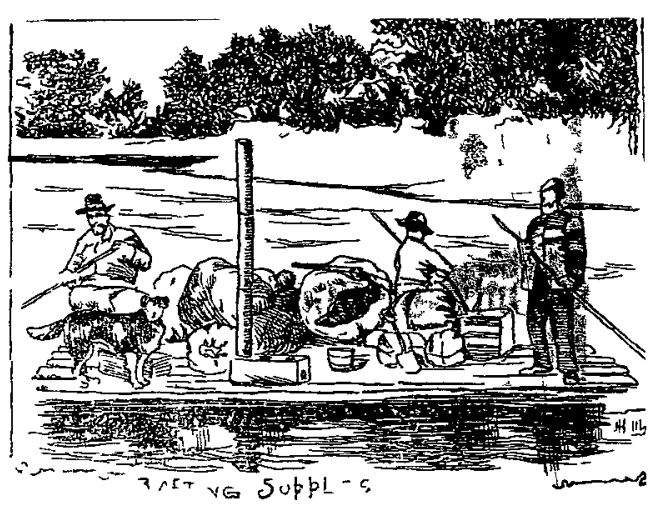

Fig. 31 Stampeders rafting up the Yukon River. (Winnipeg) The Dally Nor'Wester, July 29, 1897, p 1 


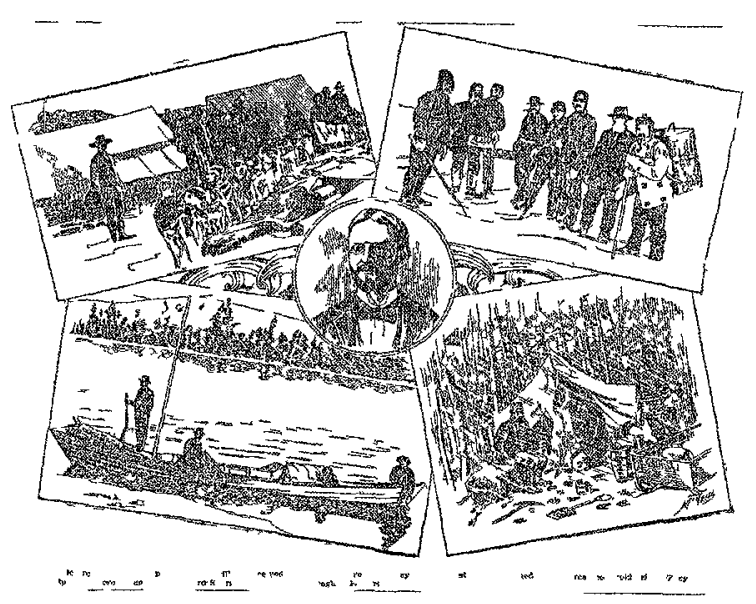

Fig. 32 Frontiersmen in the Klondike.

The Washington Post, August 1, 1897, p 17

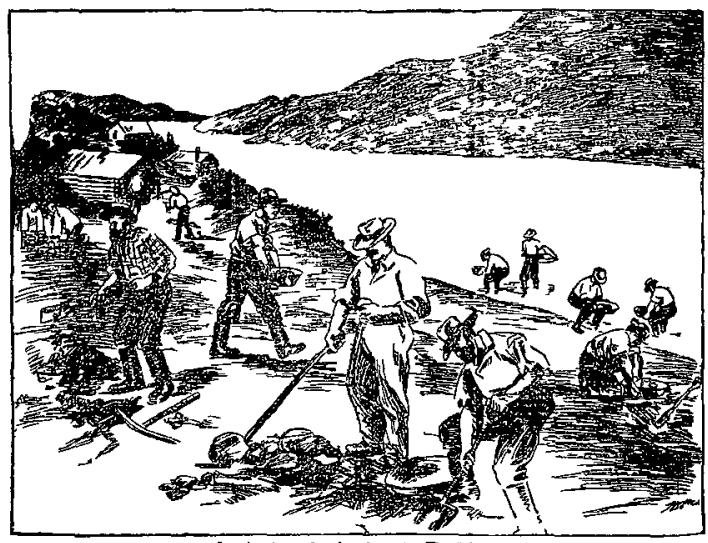

Fig. 34 Mining scene in the Klondike. (Montreal) La Presse, July 29, 1897, p 6

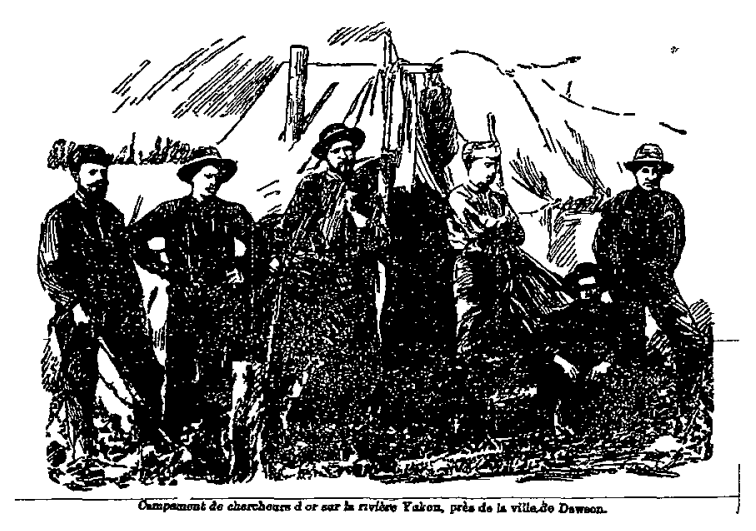

Fig. 33 Mining camp near Dawson City.

(Montreal) La Presse, July 29, 1897, p 1

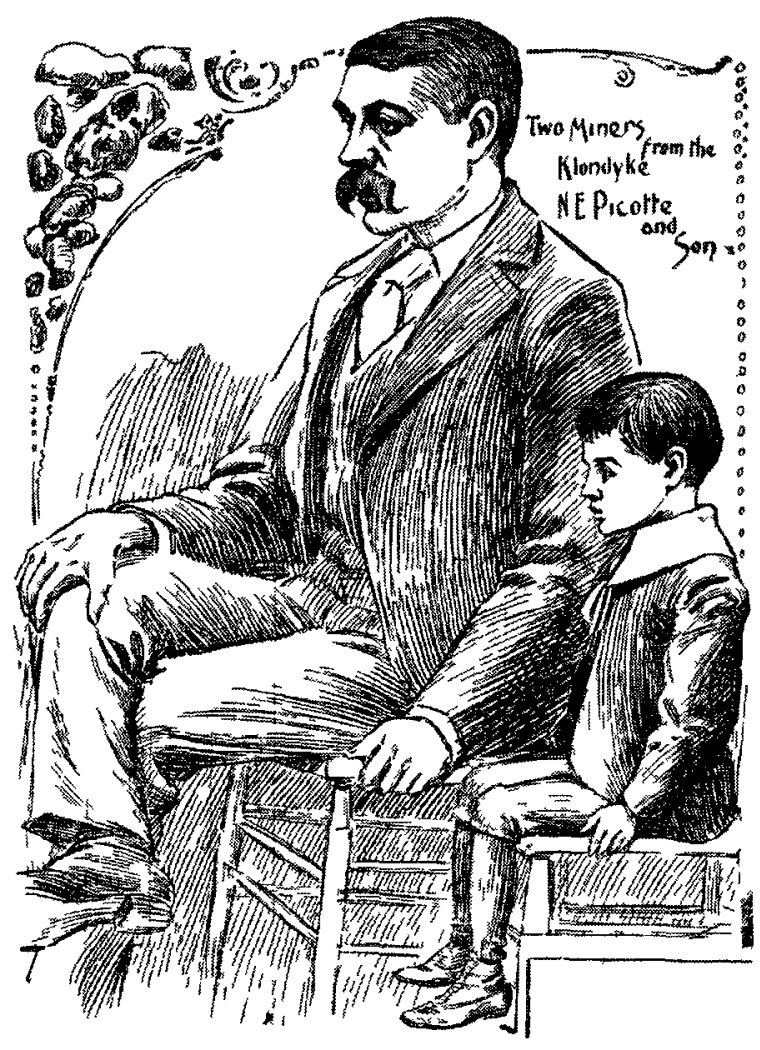

Fig. 35 Portrait of a miner and his son. San Francisco Chronicle, July 23, 1897, p 1 


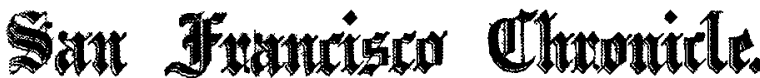

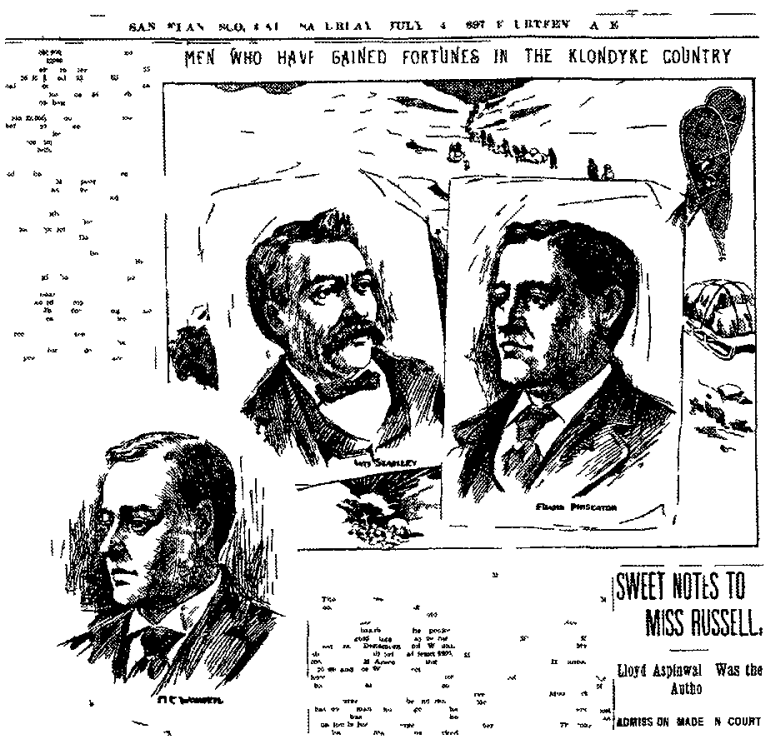

Fig. 36 Three portraits of rich Klondike miners. San Franctsco Chronicle, July 24, 1897, p 1

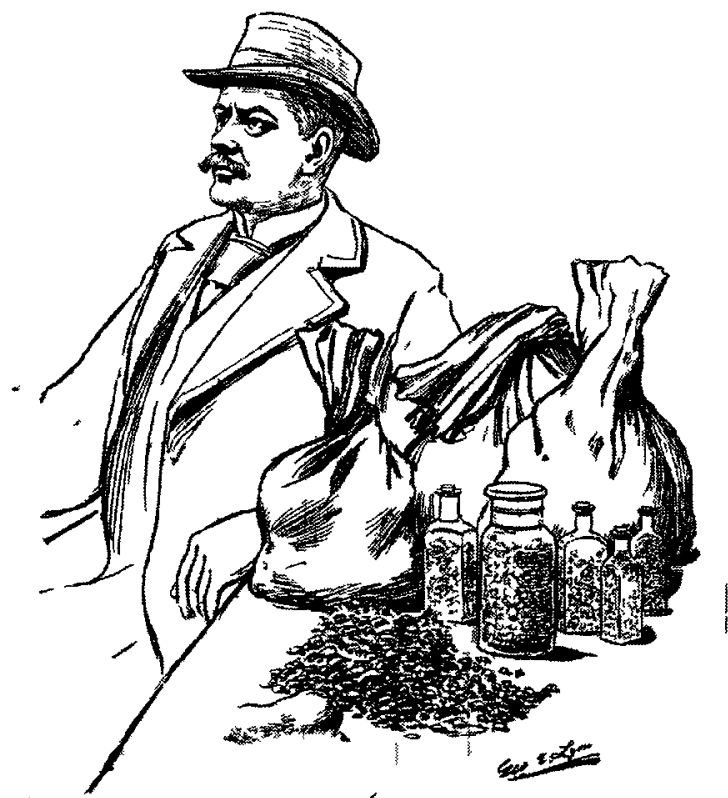

Young Clarenee Berry asju us colloption of Klondyke Nuggets

Fig. 38 Portrait of Clarence Berry.

San Francisco Chrontcle, July 21, 1897, p

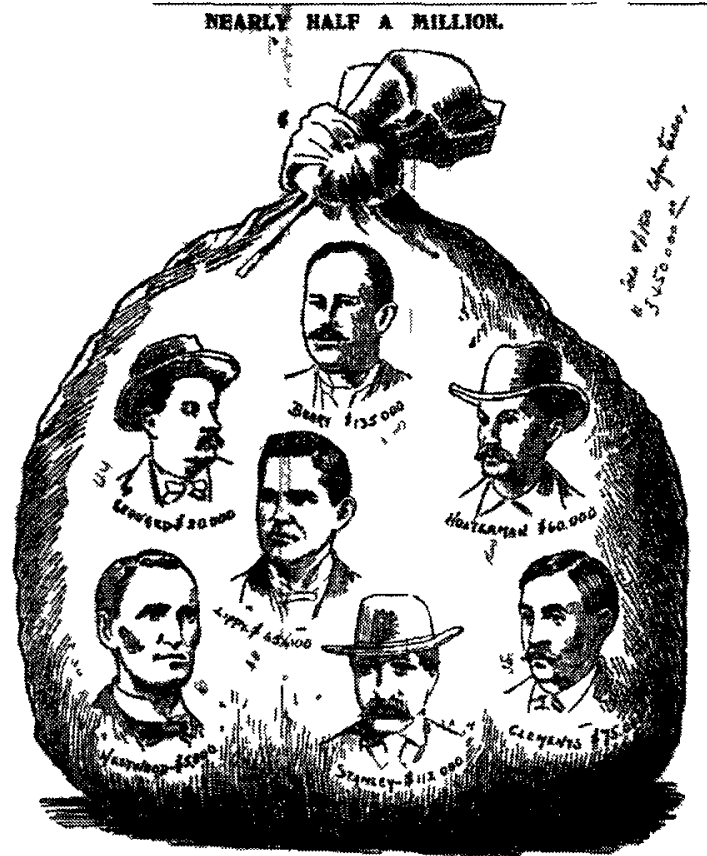

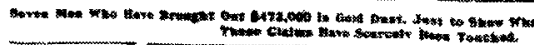

Fig. 37 Portraits of rich Klondike miners. Seattle Post-Intelligencer, August 1, 1897, p 6

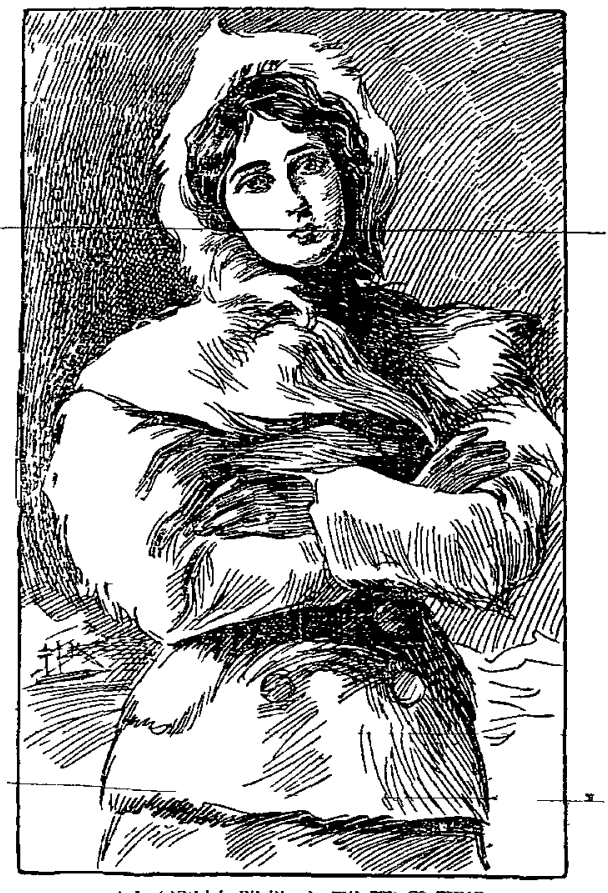

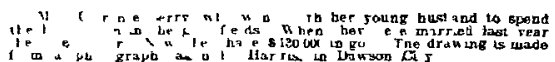

Fig. 39 Portrait of Mrs. Clarence Berry. The Montreal Dally Star, July 27, 1897, p 10 


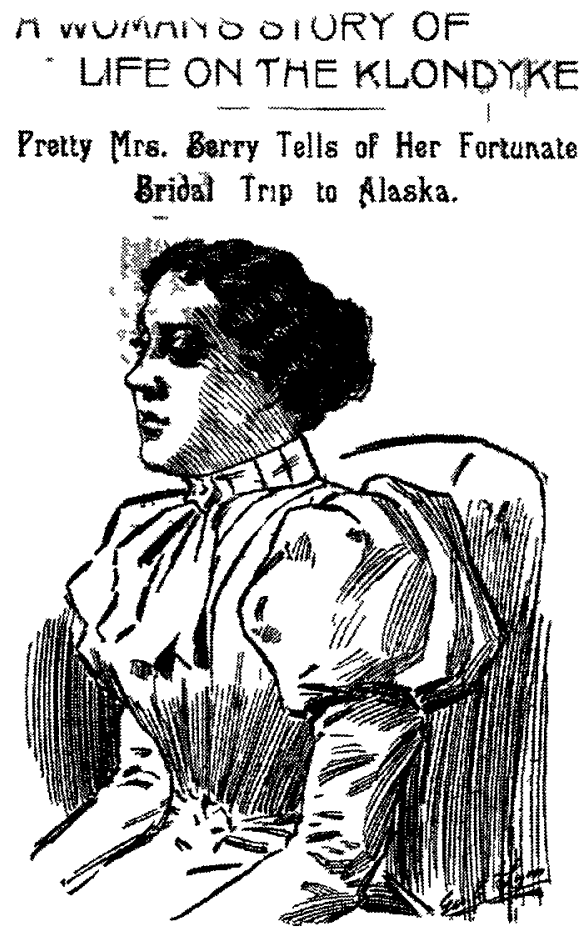

Fig. 40 Portrait of Mrs. Clarence Berry. San Francisco Chronicle, July 21, 1897, p 2

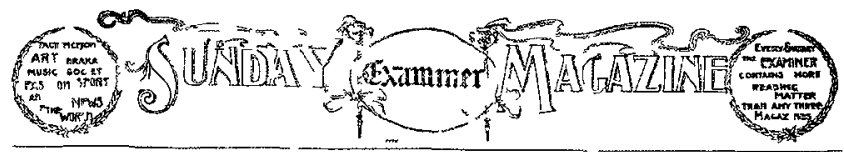

MOW I MUMED FOR GOLD ONTHE TYKE
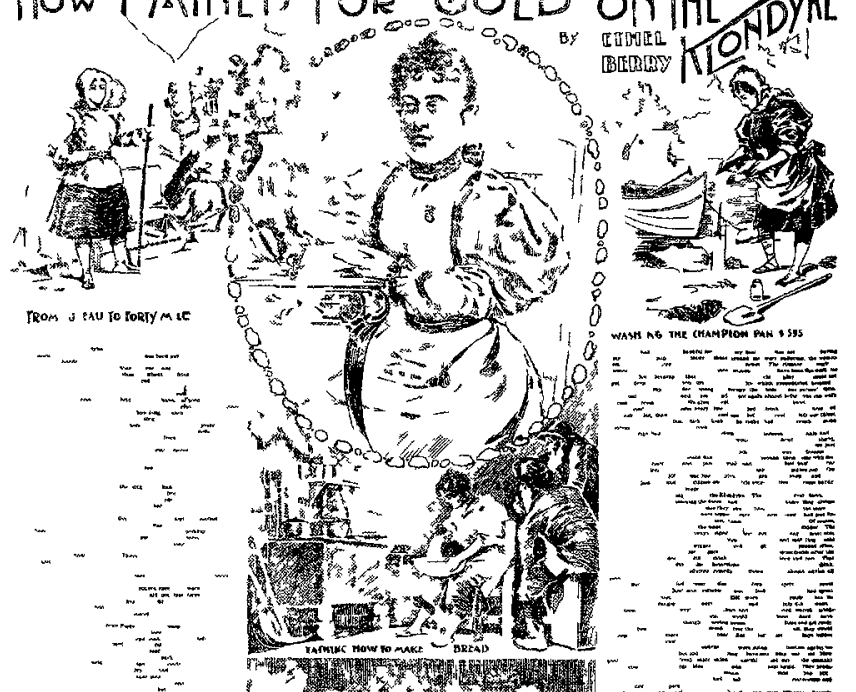

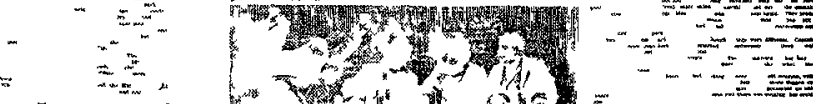

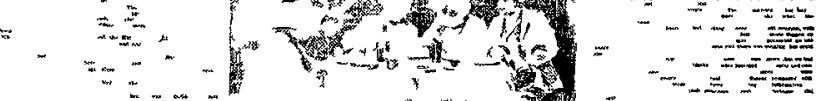

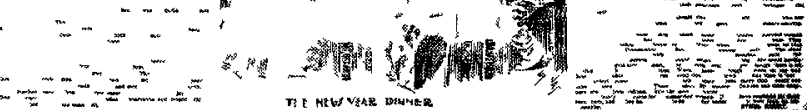

Fig. 41 Montage of images of Mrs. Clarence Berry.

Sunday Examiner Magazıne, August 1, 1897, p 1

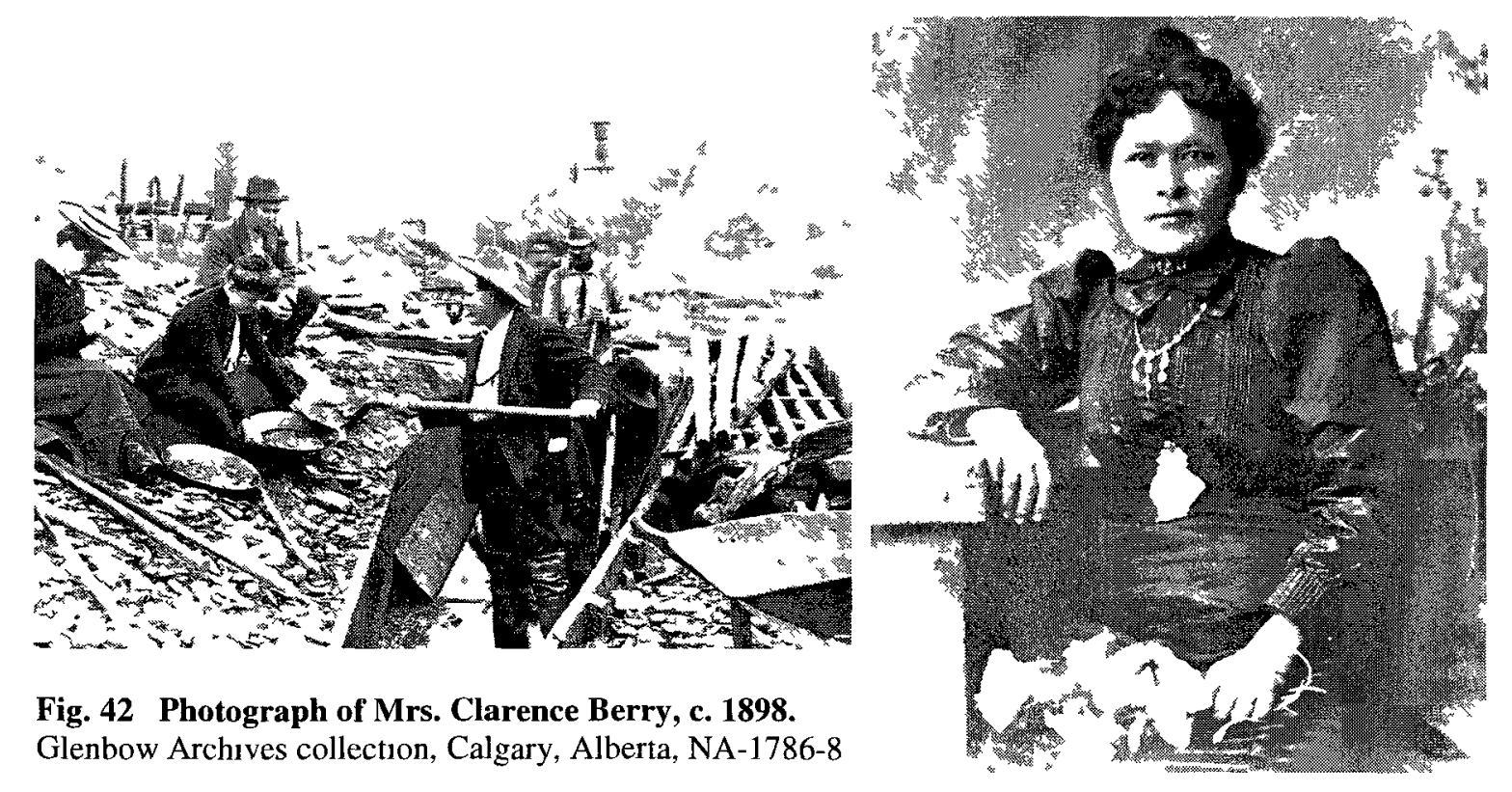

Fig. 43 Portrait of Mrs. Kate Carmack

flipped horizontally from left to right, c. 1898 . MacBride Museum of Yukon History collection,

Whitehorse, Yukon, Image Number 19911011 


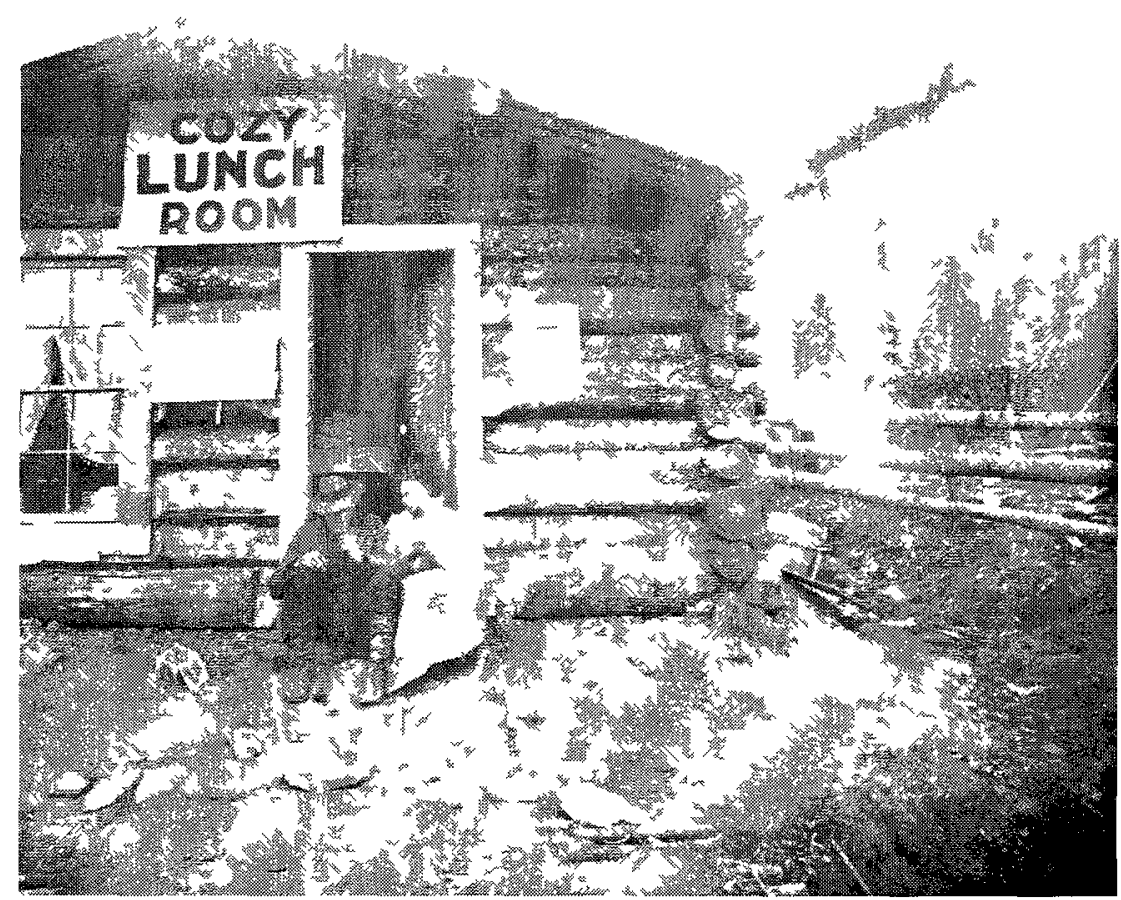

Fig. 44 African American woman at a lunch room in the Yukon, c. 1898. (Library and Archives Canada, Ottawa, Ontario, PA 170412)

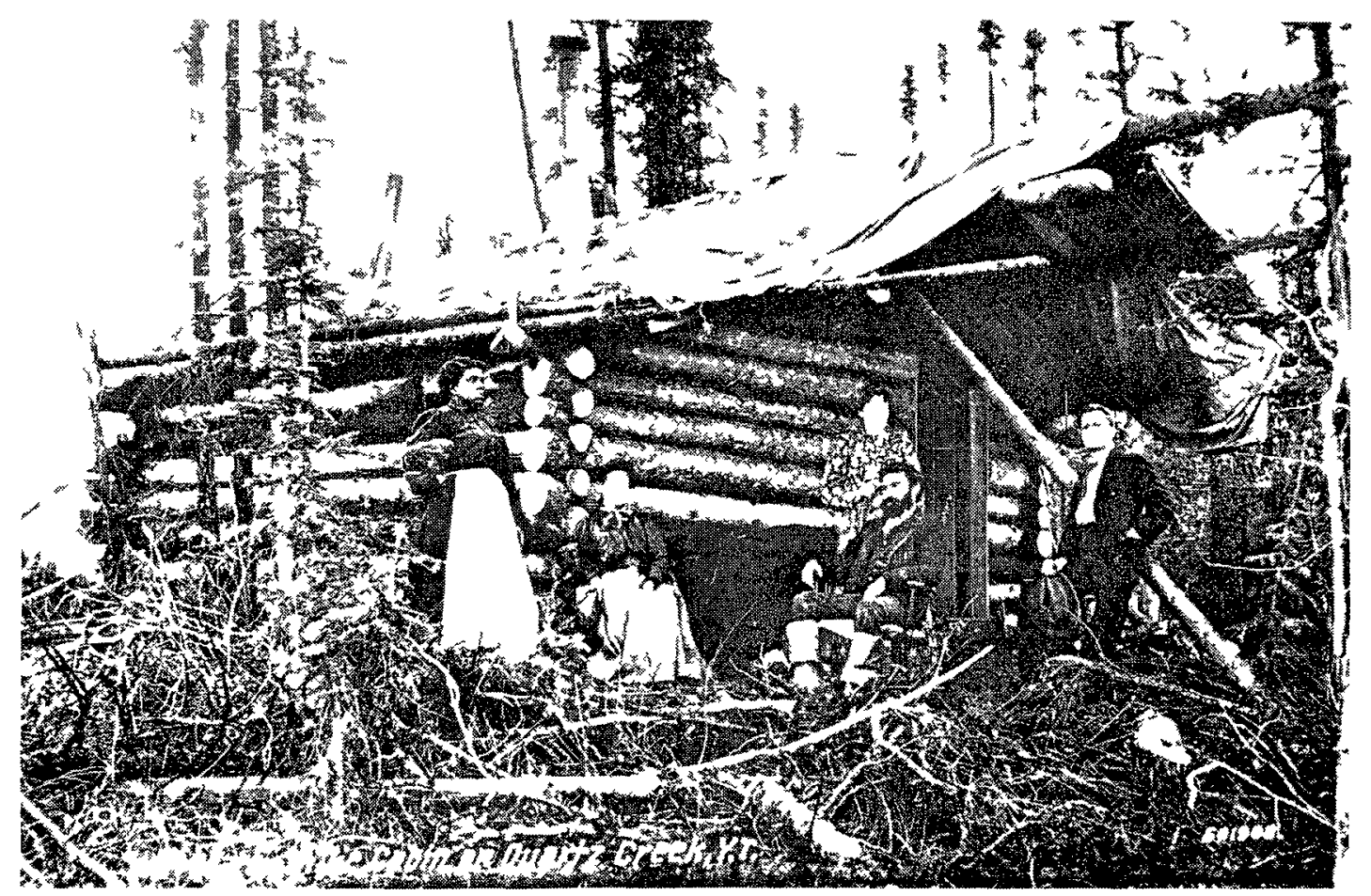

Fig. 45 Swift Water Willie's cabin at Quartz Creek, in the Yukon, c. 1897-1910.

(Library and Archıves Canada, Ottawa, Ontarıo, accession number 1955-057, item p 6, C-014550) 
The Wushington Nost.

WASIINGTON, FRIDAY, JULY 30, 1897-TEN PAGES.

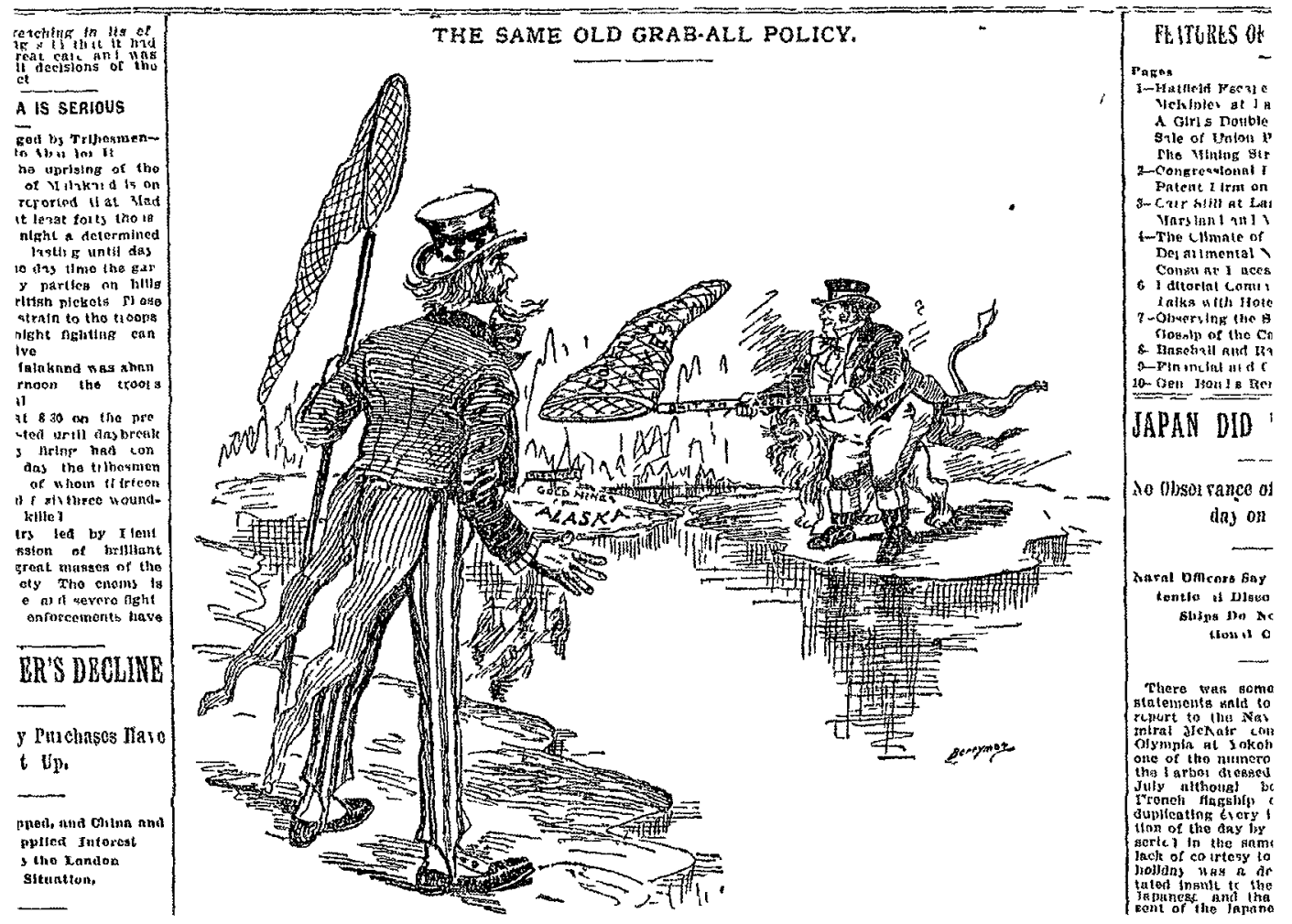

Fig. 46 Caricature taking an American perspective on territorial boundaries. The Washington Post, July 30, 1897, p 1

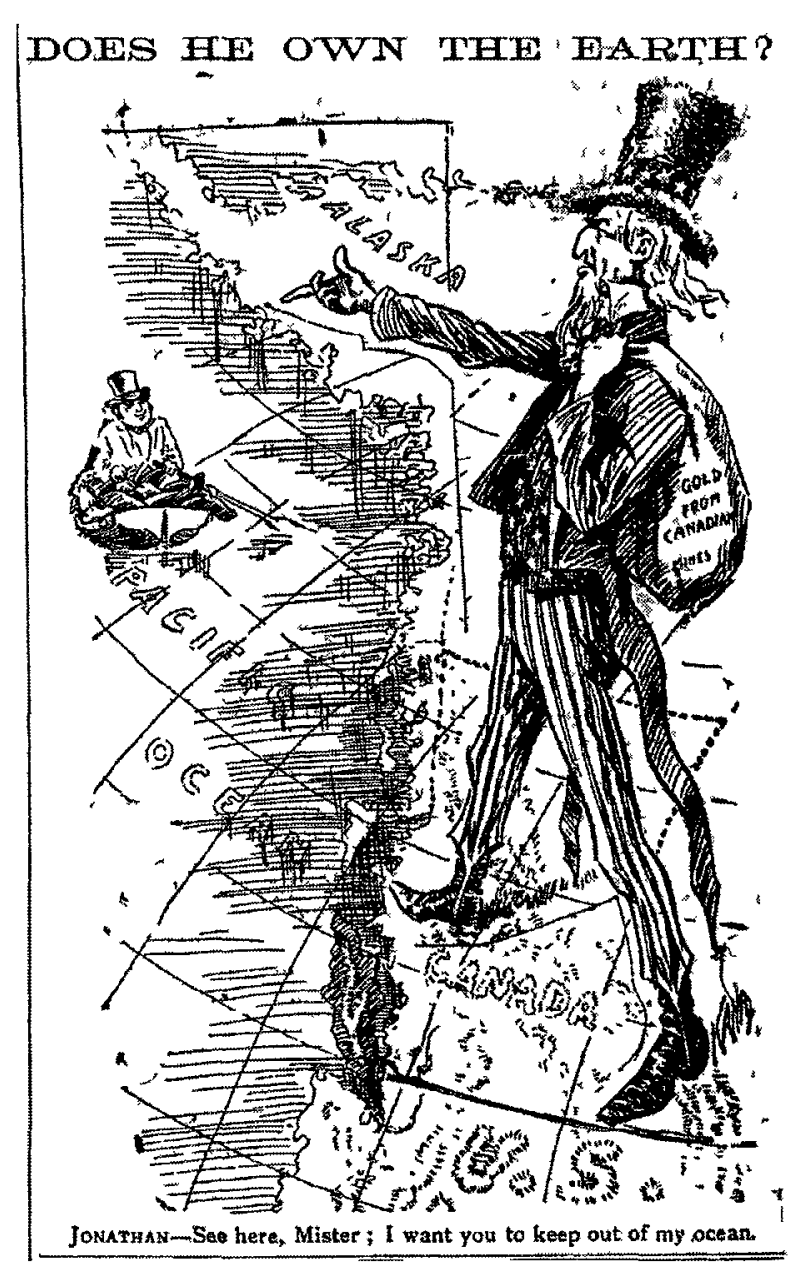

Fig. 47 Caricature taking a Canadian perspective on territorial boundaries.

(Toronto) Dally Mall and Empire, July 21, 1897, p 1 


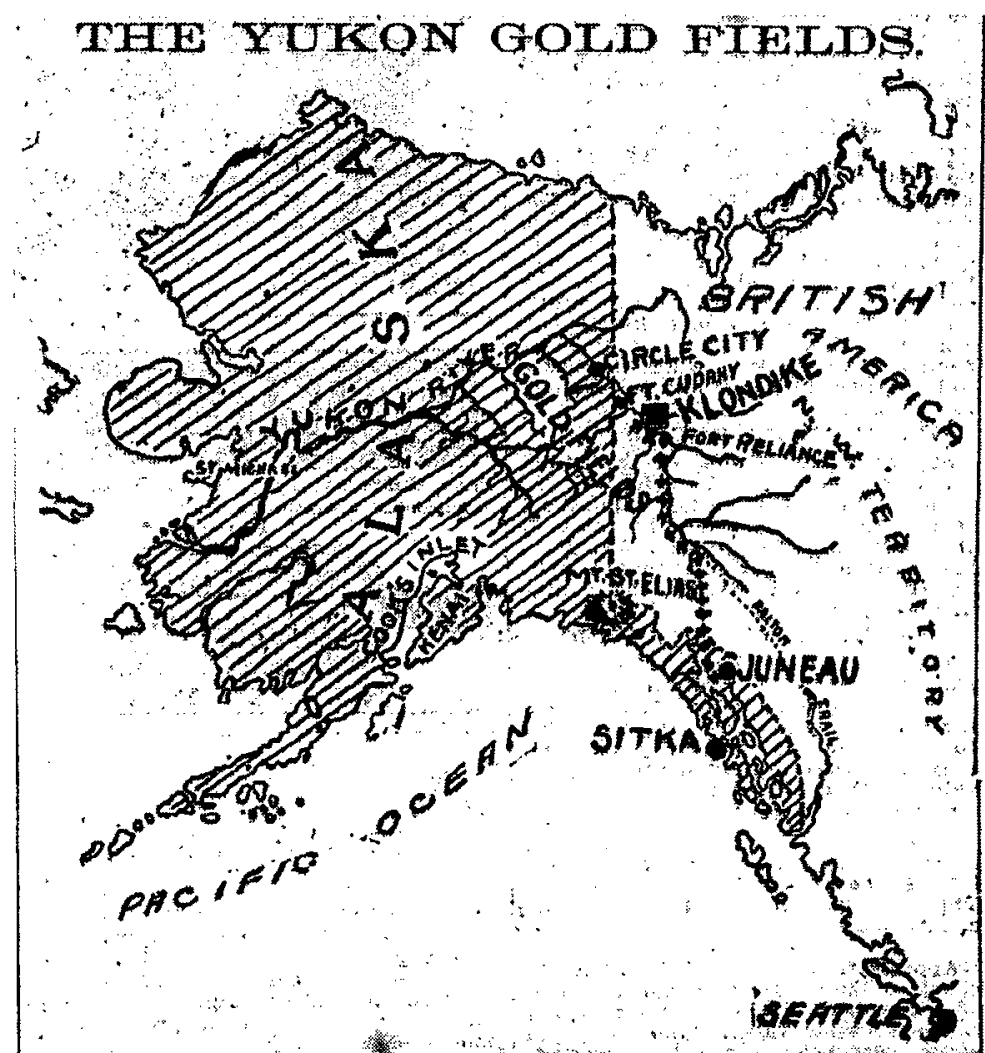

Fig. 48 Canadian map of Klondike.

(Toronto) Daily Mail and Empire, July 21, 1897, p. 7.

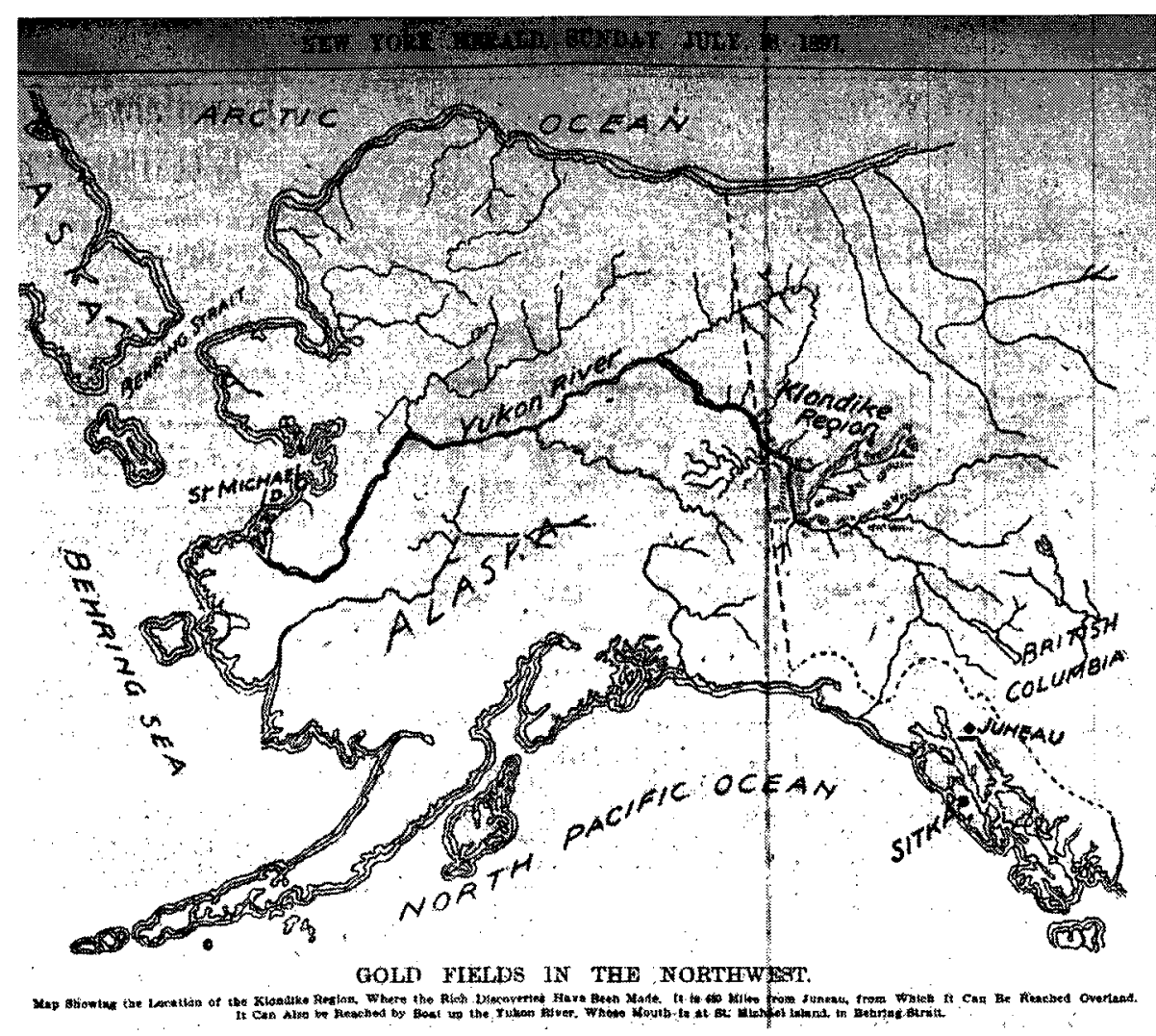

Fig. 49 American map of Klondike.

The New York Herald, July 18, 1897, p. 5. 


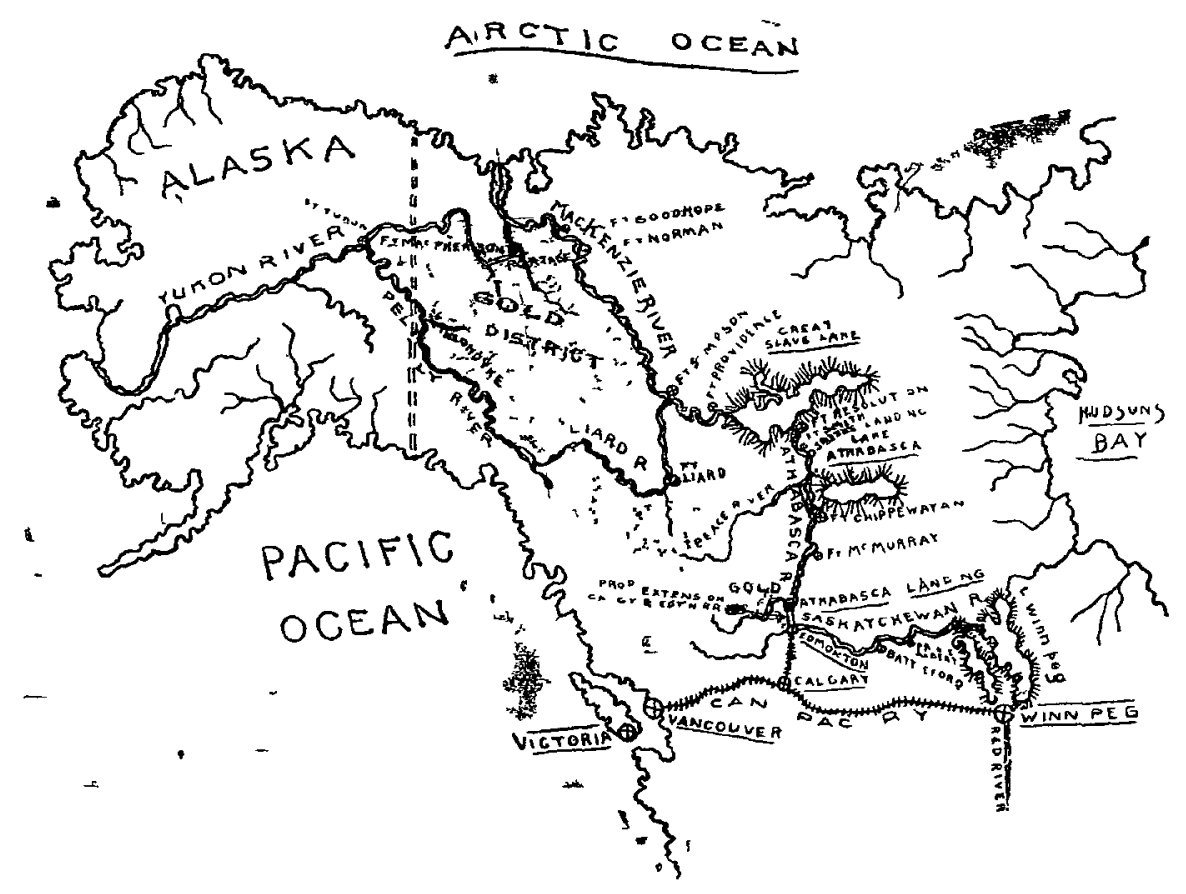

Fig. 50 Canadian map shading gold fields.

(Winnıpeg) The Dally Nor'Wester, July 31, 1897, p 1

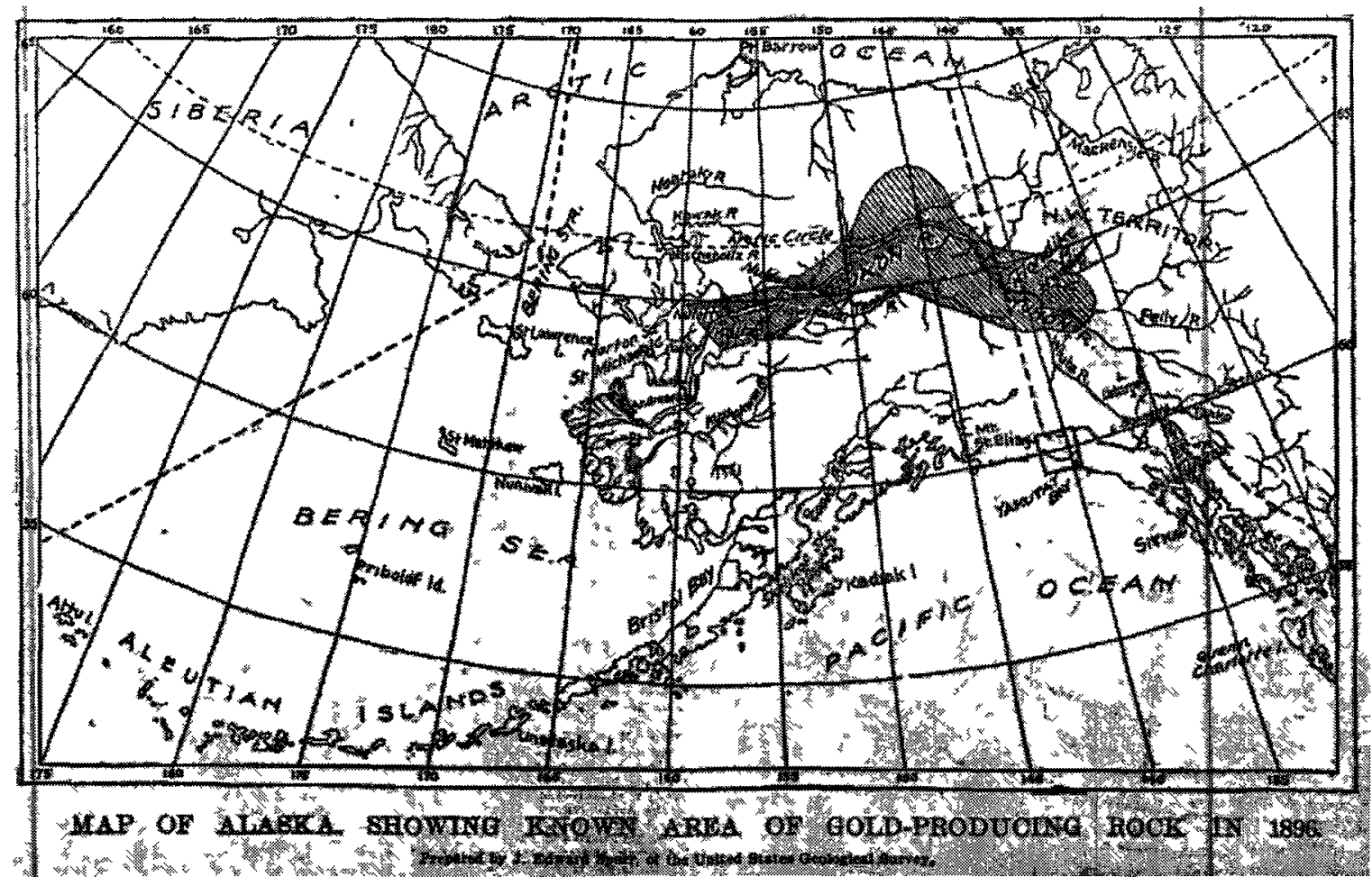

Fig. 51 American map shading gold fields.

The New York Herald, July 25, 1897, p 2 


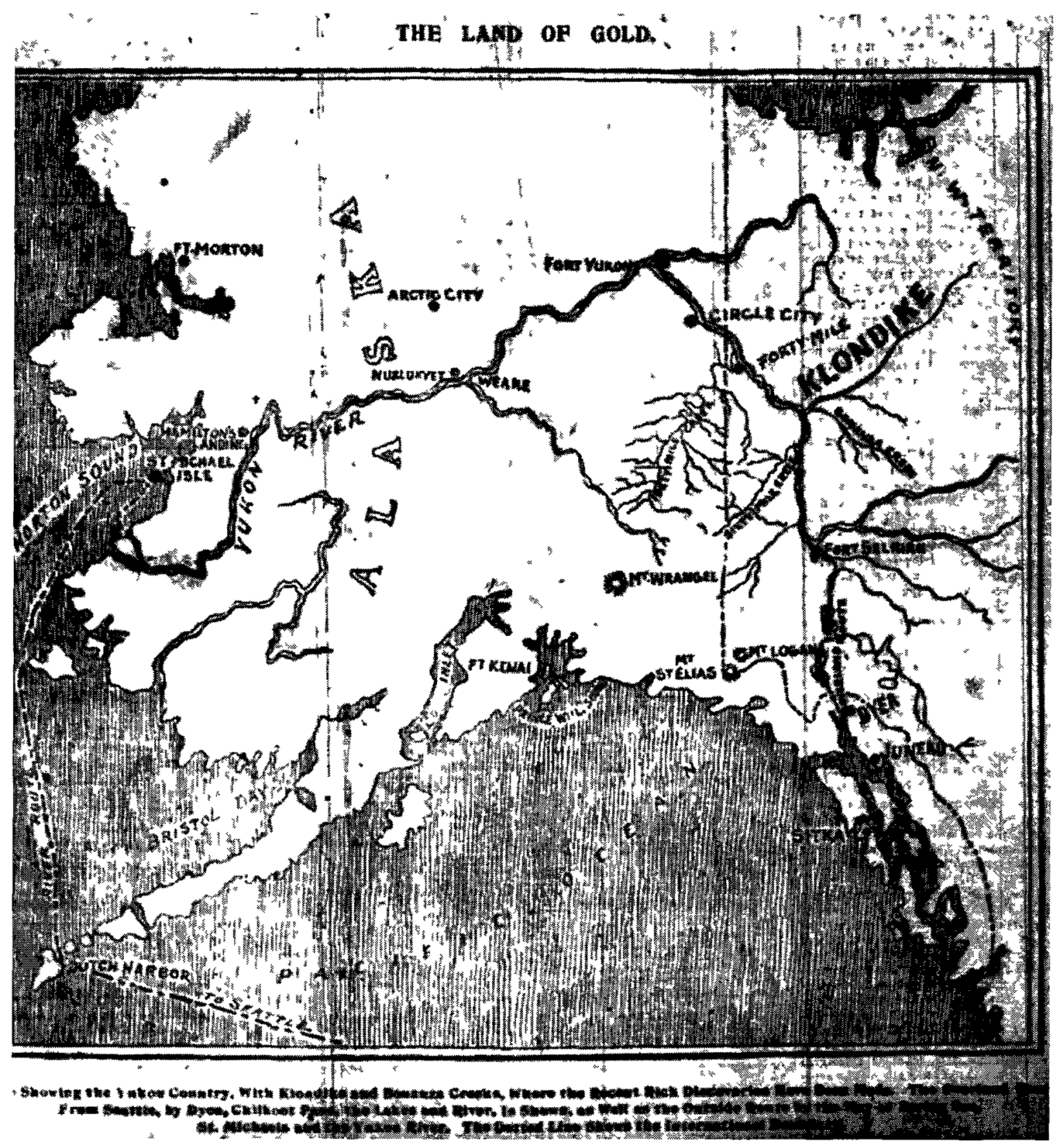

Fig. 52 American map representing the "Land of Gold". The Seattle Post-Intelltgencer, July 21, 1897, p 1 


\section{Pages 13 to 22. - The Examiner - Pages 13 to 22}

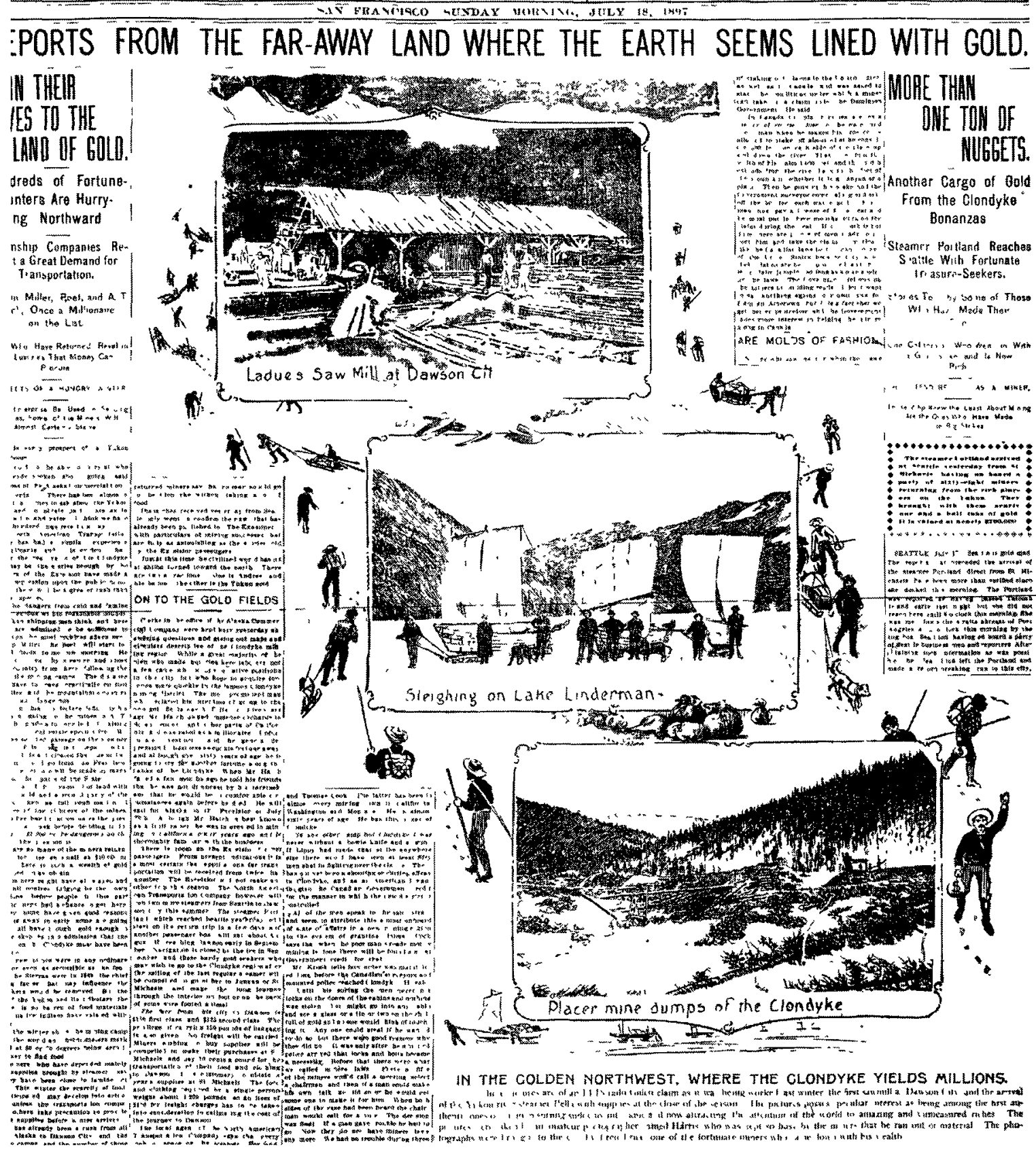

Fig. 53 Photomontage showing stampeders hiking around and behind three vignettes of Klondike . (San Francisco) The Examiner, July 18, 1897, p. 13. 


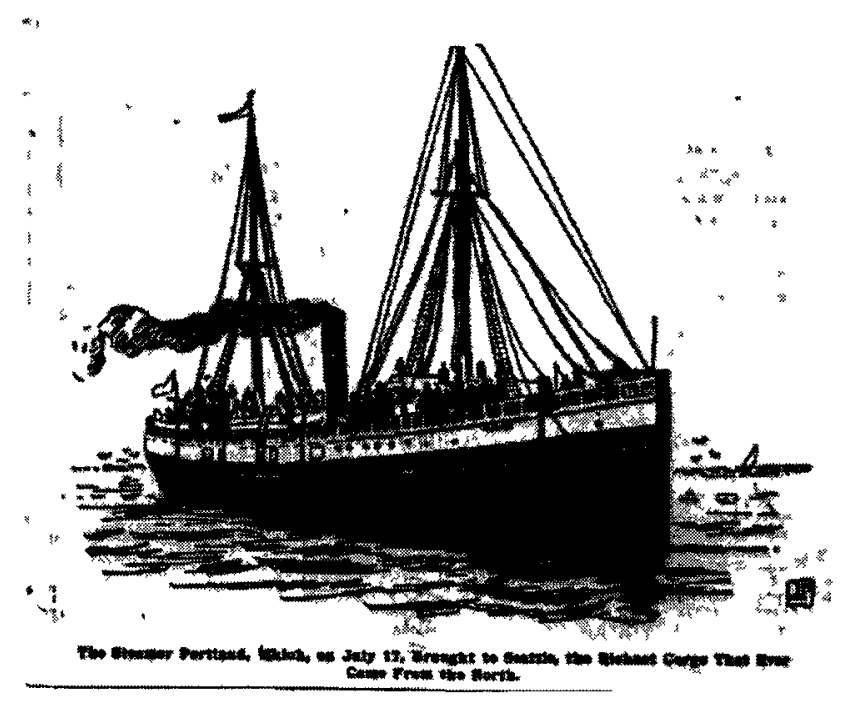

Fig. 54 Arrival of the 'Portland' in Seattle Seattle Post-Intelligencer, July 29, 1897, p. 2

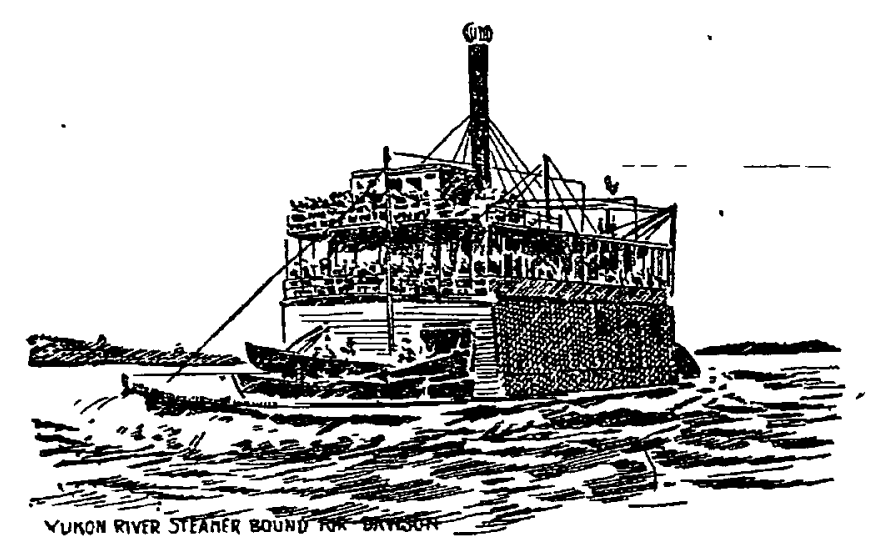

Fig. 56 The 'Alice' near Dawson City.

The Montreal Dally Star, July 26, 1897, p. 5

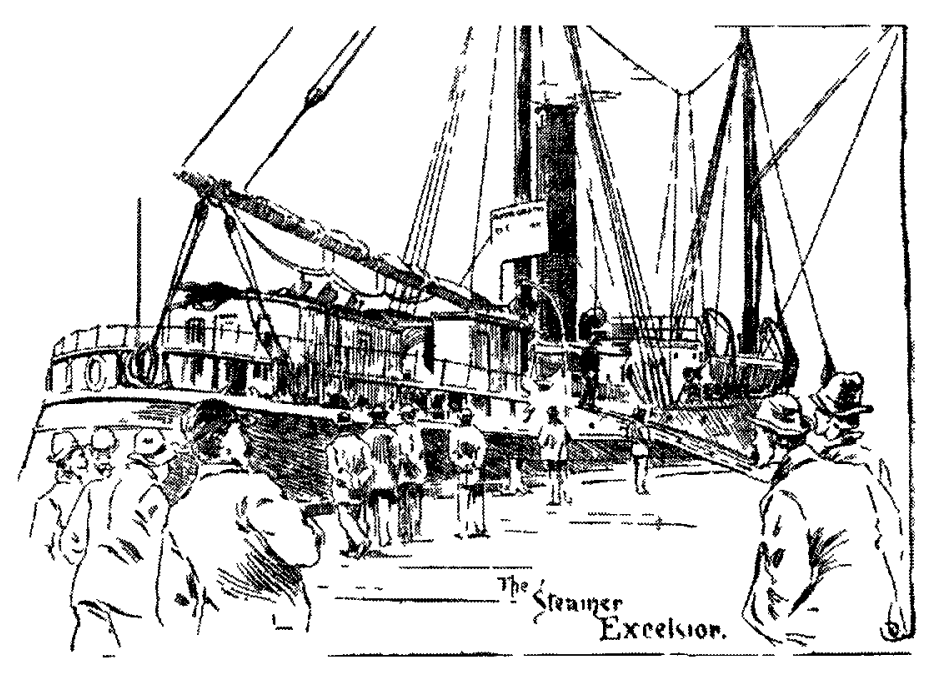

Fig. 55 Departure of the 'Excelsior' for the Klondike. San Francisco Chronicle, July 20, 1897, p 1

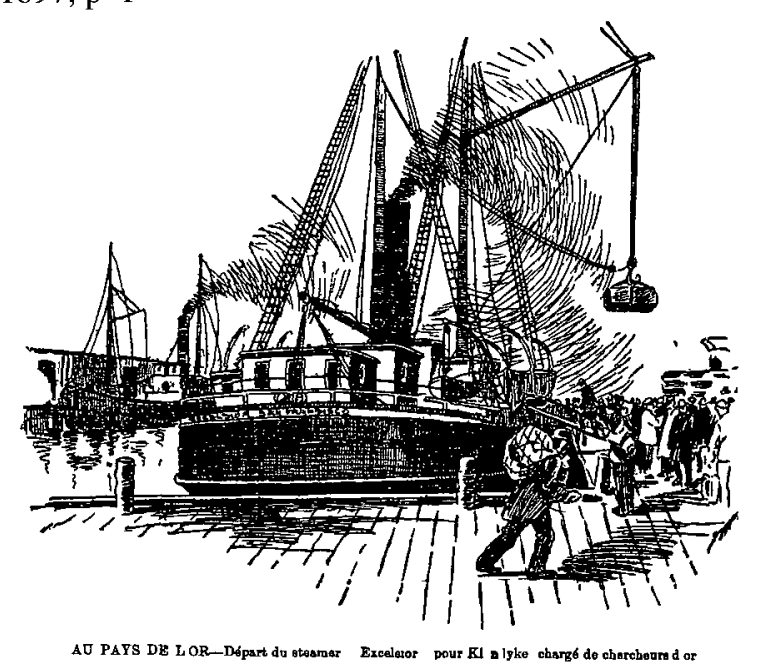

Fig. 57 Departure of the 'Excelsior' for the Klondike. (Montreal) La Presse, August 2, 1897, p. 7 


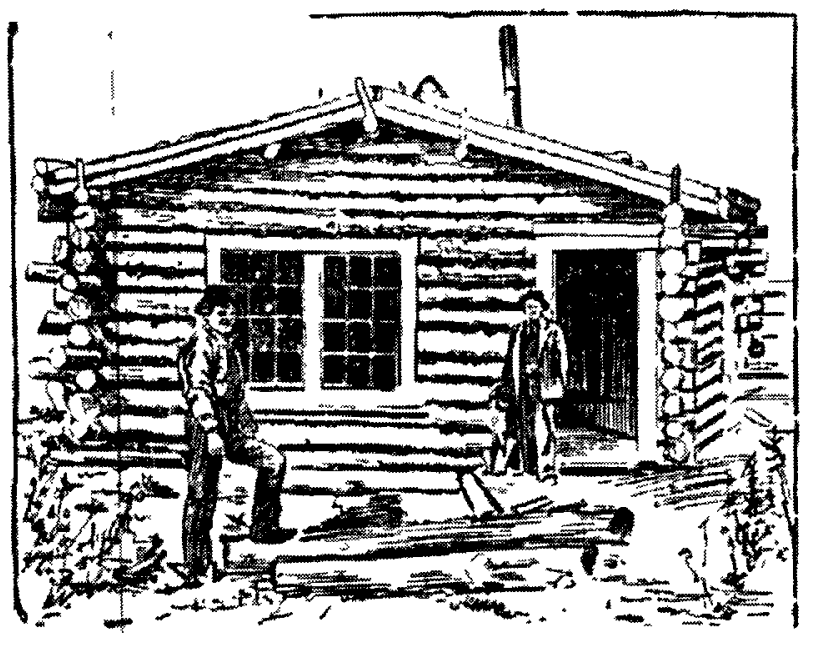

One of tha Hirst Houses Buit aty Cowson City.

Fig. 58 Log house in the Klondike.

San Francisco Chronicle, July 19, 1897, p. 1.

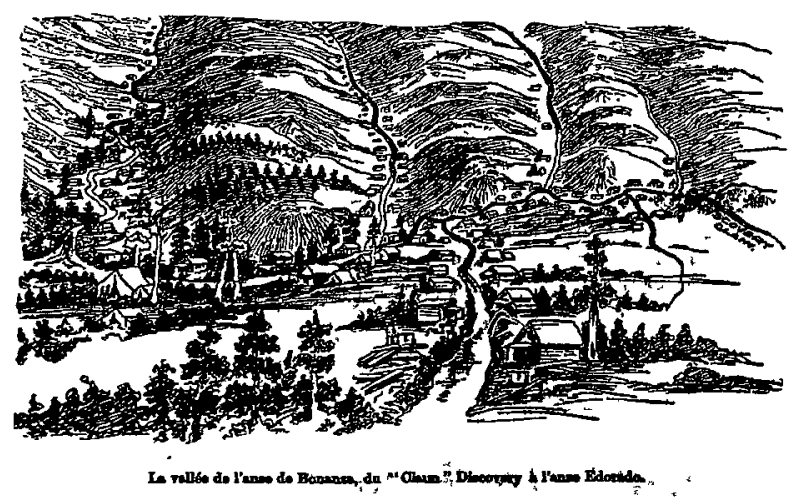

Fig. 60 Landscape in valley near Klondike claims. (Montreal) La Presse, August 2, 1897, p. 1.

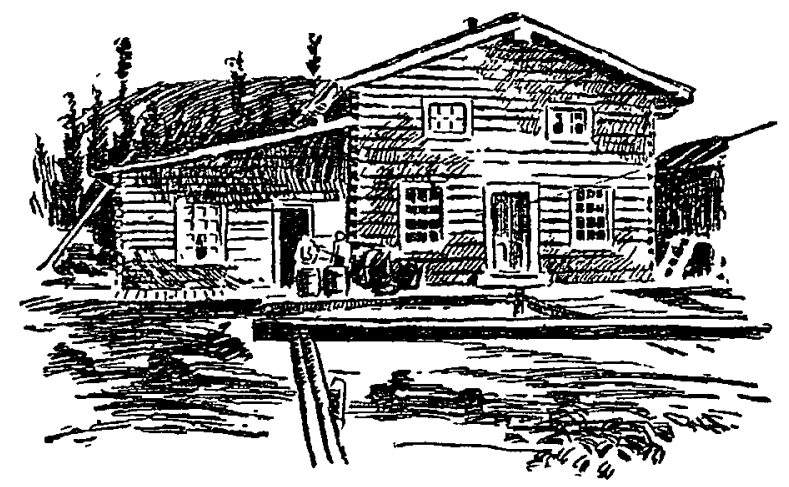

LA MAISON DE JOSEPH LADUE, (LEDOTIX), gar leg borda de ITTKon

Fig. 59 Home of one of the early Yukon pioneer who became rich through trade and real estate.

(Montreal) La Presse, August 2, 1897, p. 1.

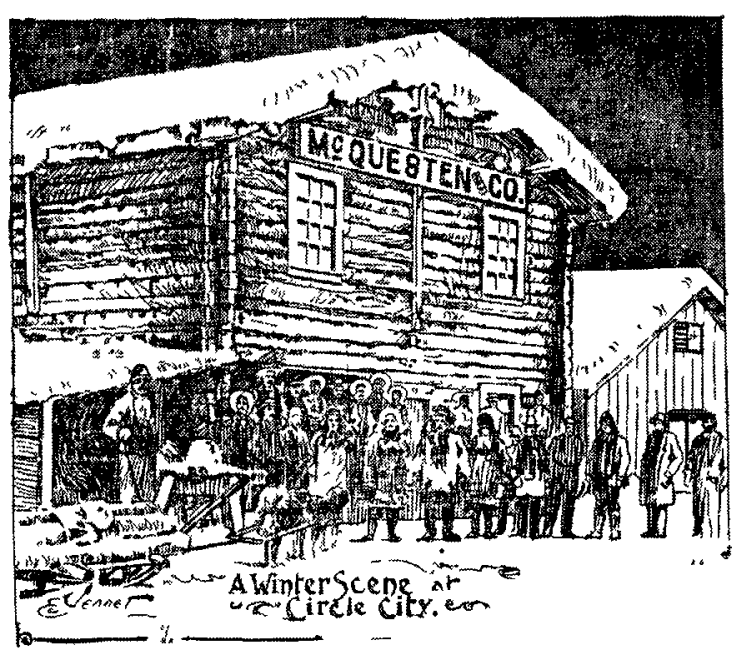

Fig. 61 American trading post supplying Dawson City in the early days of the gold rush. San Francisco Chronicle, July 21, 1897, p. 1. 


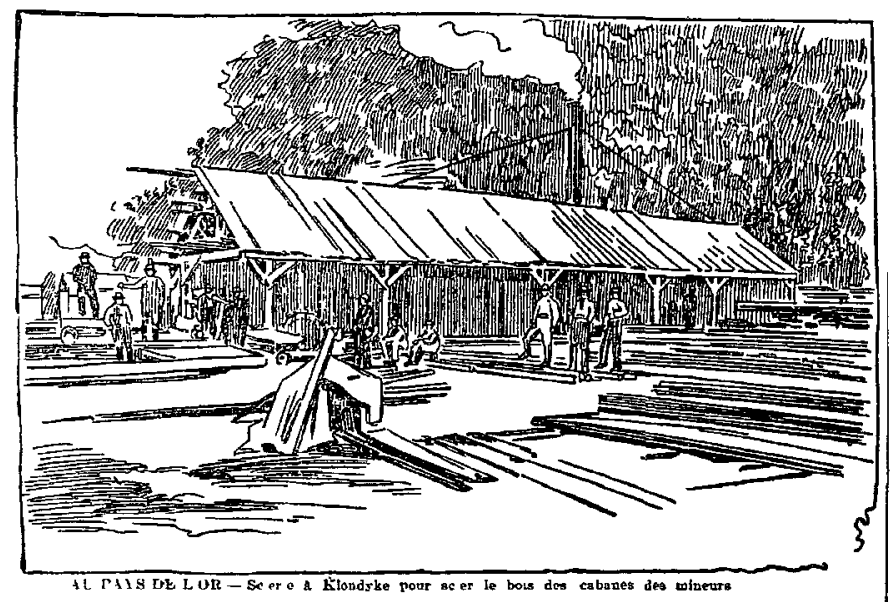

Fig. 62 The first saw mill at the diggings.

(Montreal) La Presse, July 28, 1897, p 5

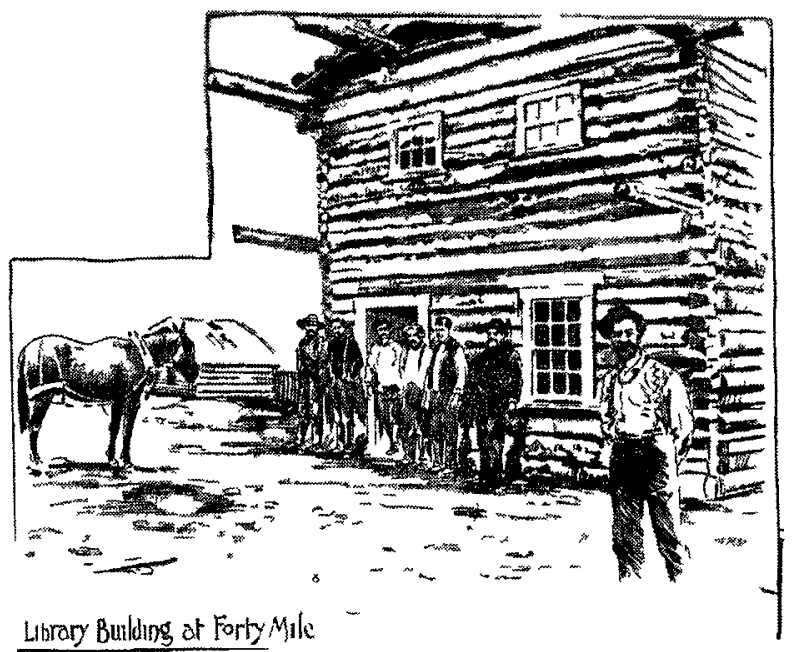

Fig. 64 Library building at Forty-Mile.

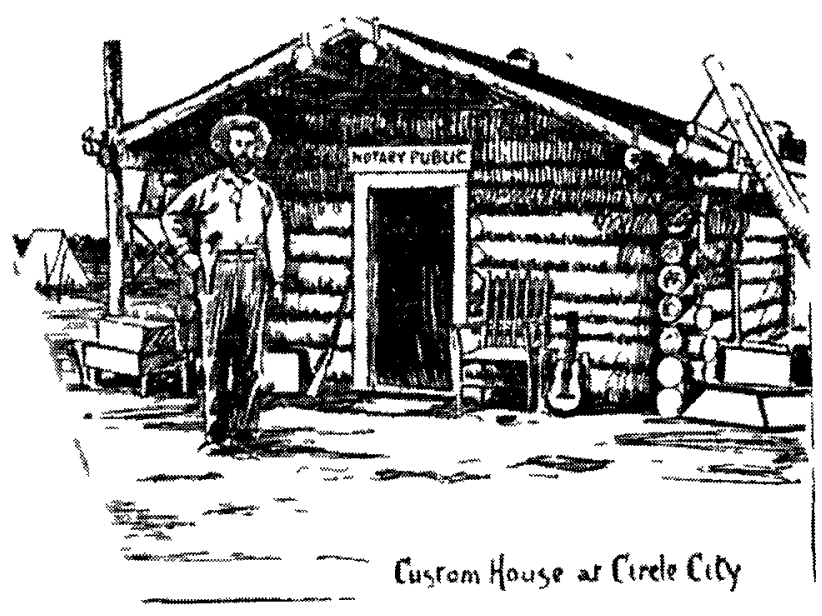

Fig. 63 Custom house near gold fields.

San Francisco Chrontcle, July 28,1897, p 1

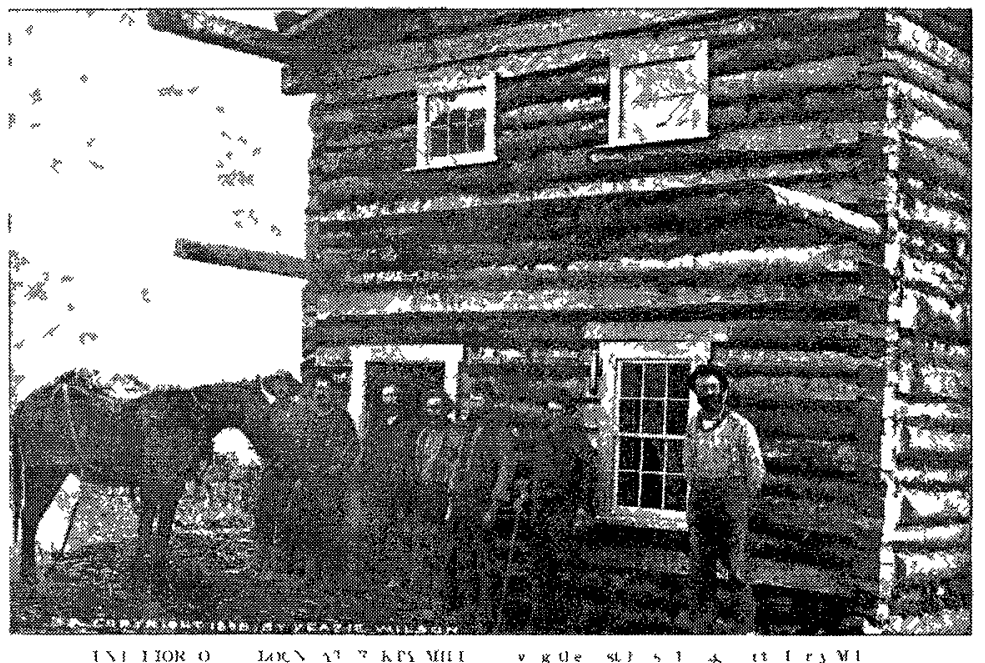

Fig. 65 Photograph used as a source for the "Library building at Forty-Mile" news image, c. 1895. Veazie Wilson Reproduced from Esther Lyons (1897), Glimpses of Alaska a collection of views of the interior of Alaska and the Klondike district (Chicago Rand McNally), p 51 Courtesy of Rare Books and Special Collections, McGill University Library, Montréal, Québec 


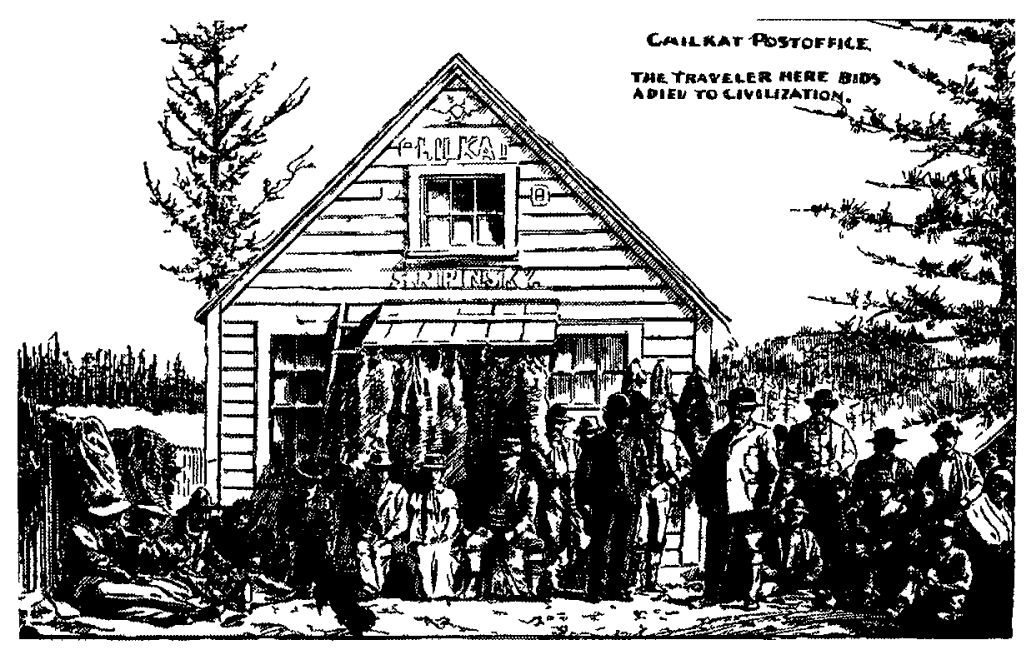

Fig. 66 Post office near gold fields.

(San Francisco) The Examiner, July 23, 1897, p 3

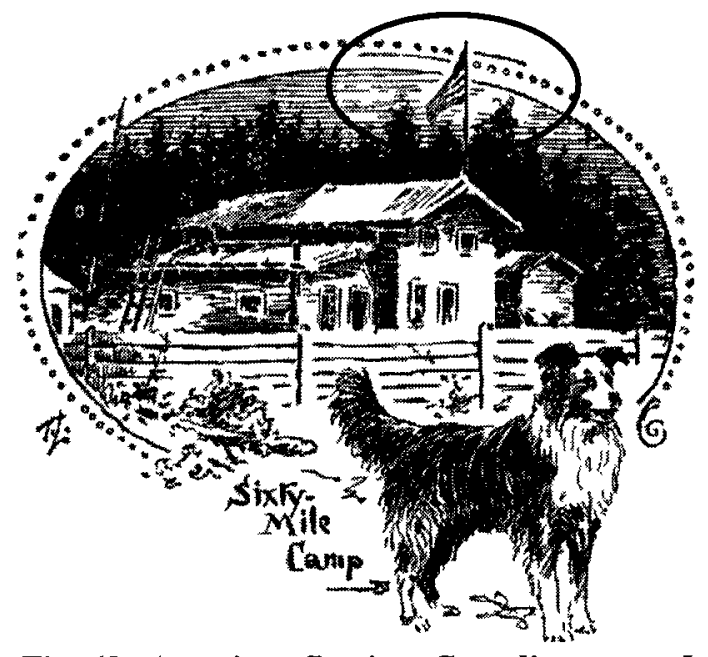

Fig. 68 American flag in a Canadian camp [ellipse added]. San Francisco Chronicle, July 25, 1897, p 13

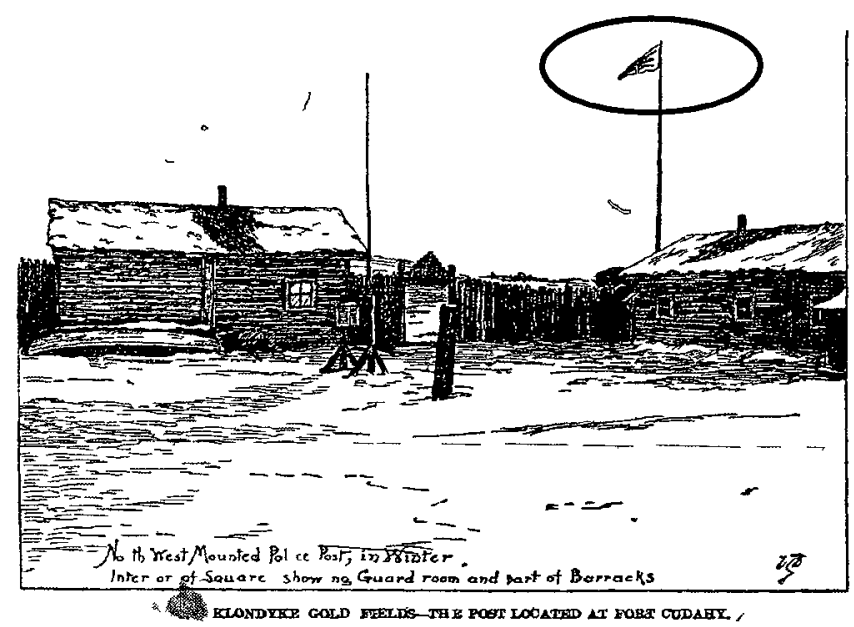

Fig. 67 North West Mounted Police post [ellipse added]. The Montreal Dally Star, July 26, 1897, p 8

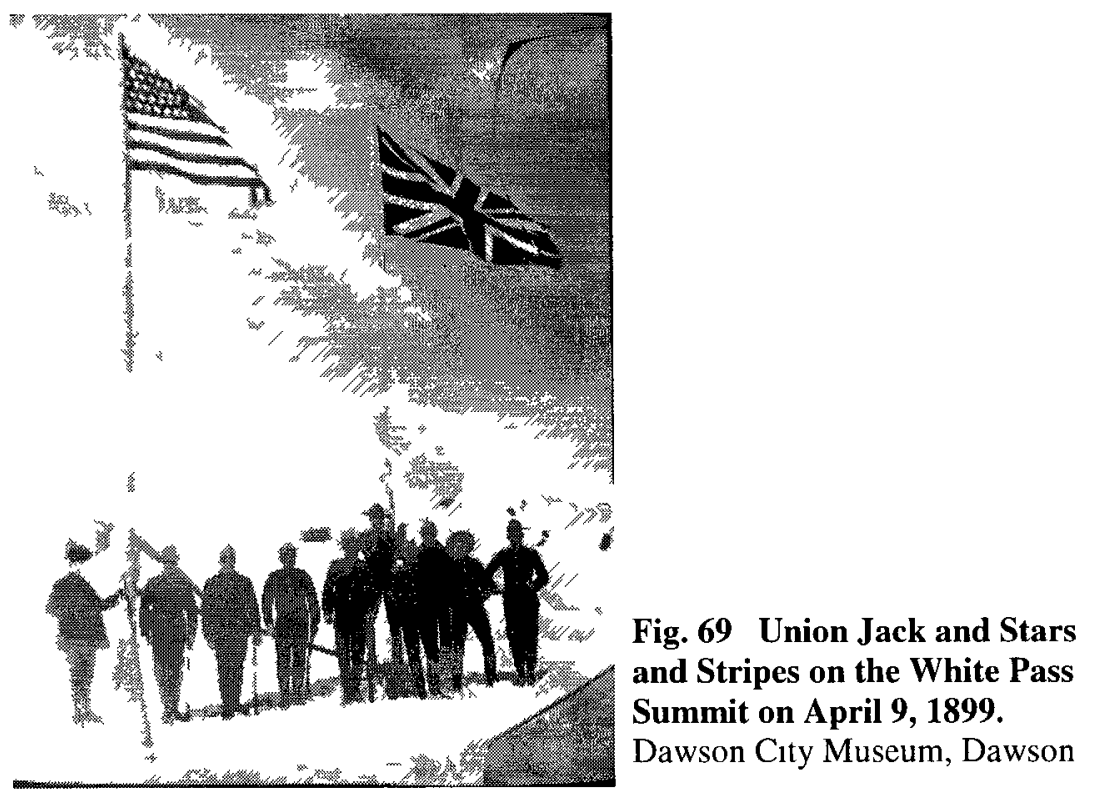




\section{THE EXAMINER" EXPEDITION TO FAMOUS KLONDYKE.}

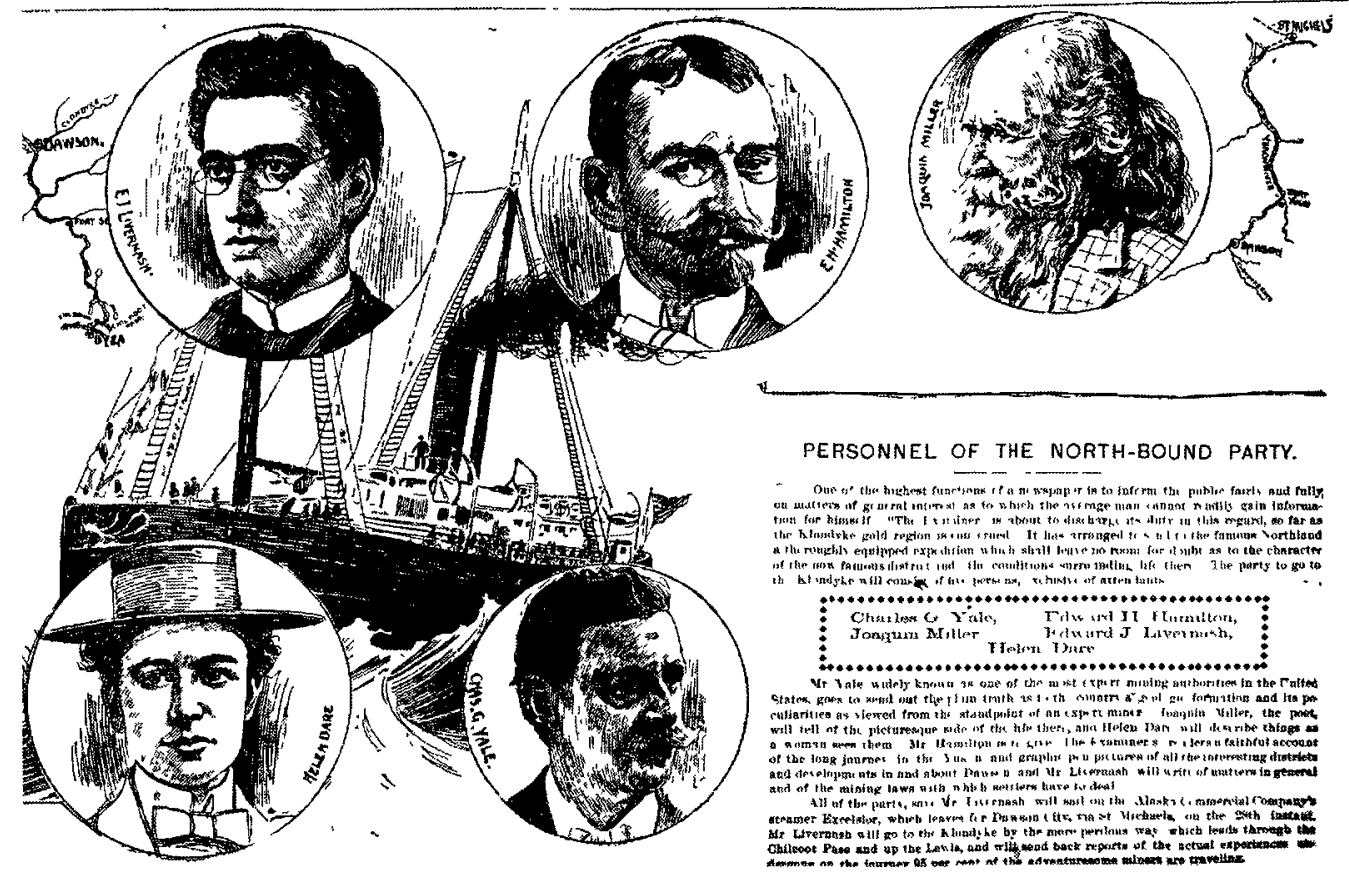

Fig. 70 Party of experts sent to the Klondike as correspondents for "The Examiner". (San Francisco) The Examiner, July 22, 1897, p. 1.

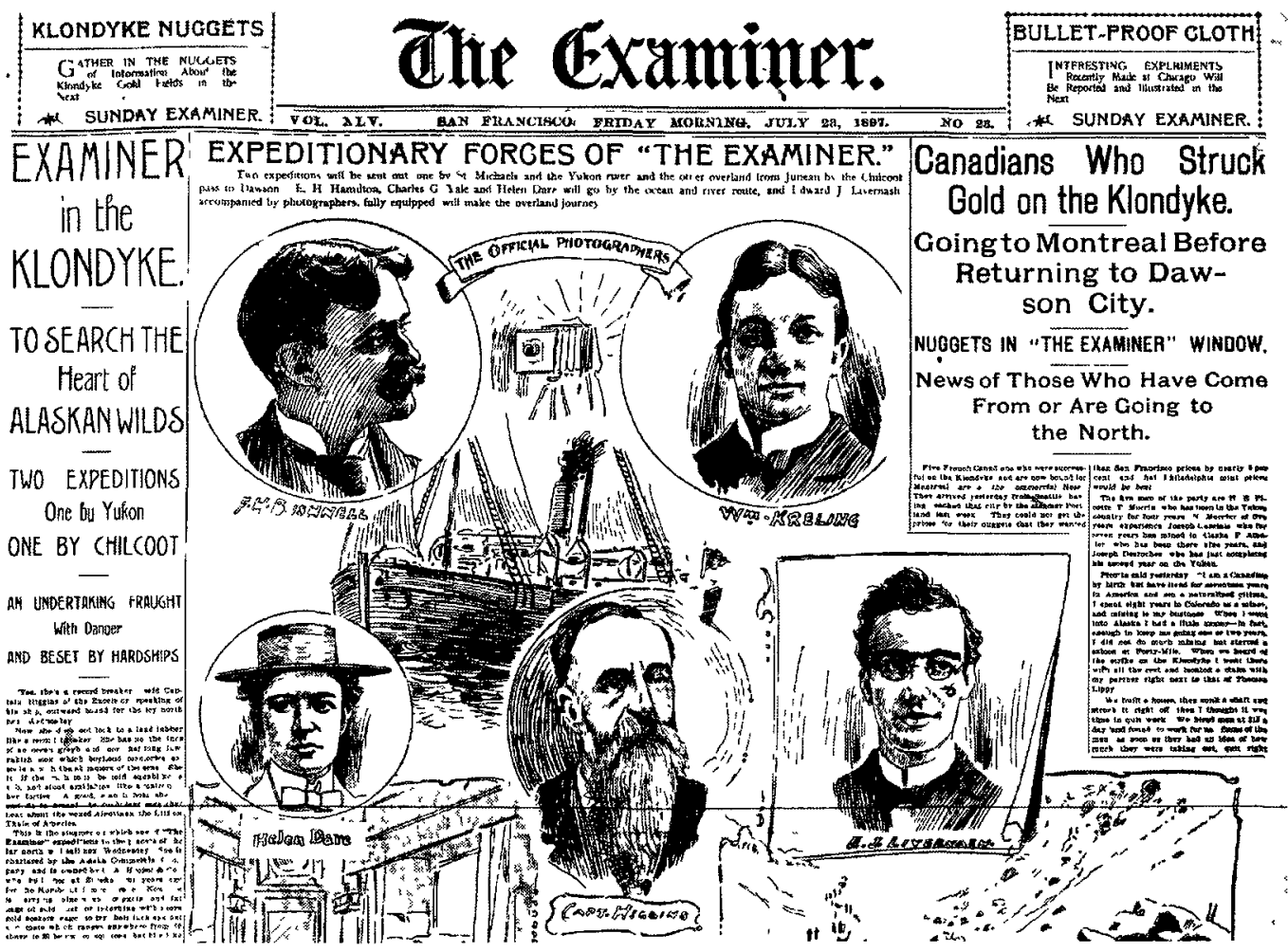

Fig. 71 More correspondents sent by The Examiner (including photographers).

(San Francisco) The Examiner, July 23, 1897, p. 1. 


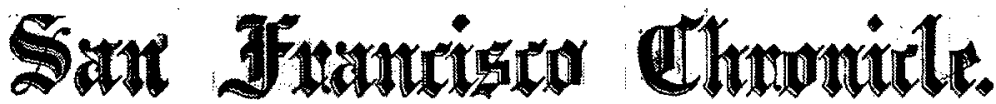

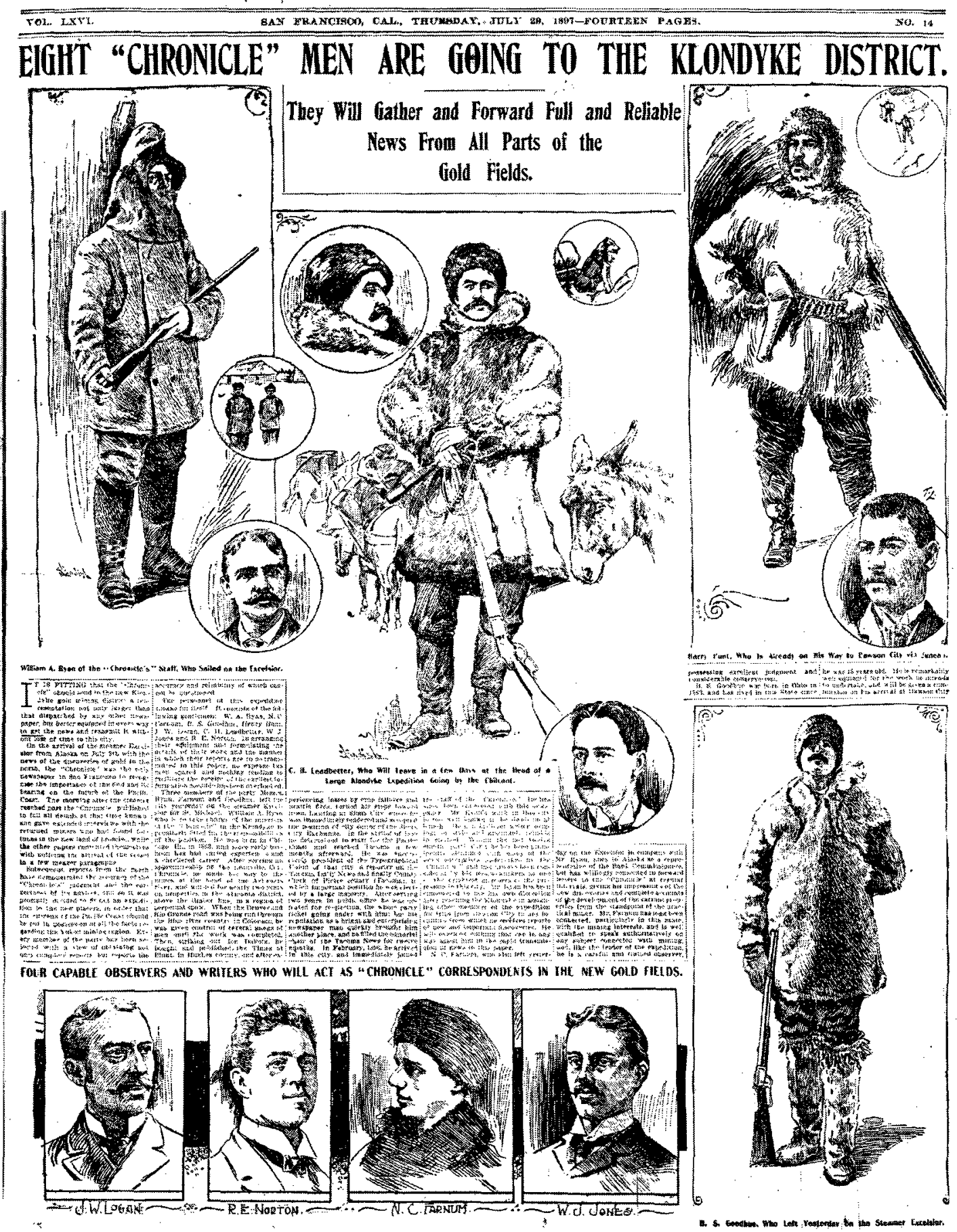

Fig. 72 Correspondents sent to the Klondike by the San Francisco Chronicle.

San Francisco Chronicle, July 29, 1897, p. 1. 


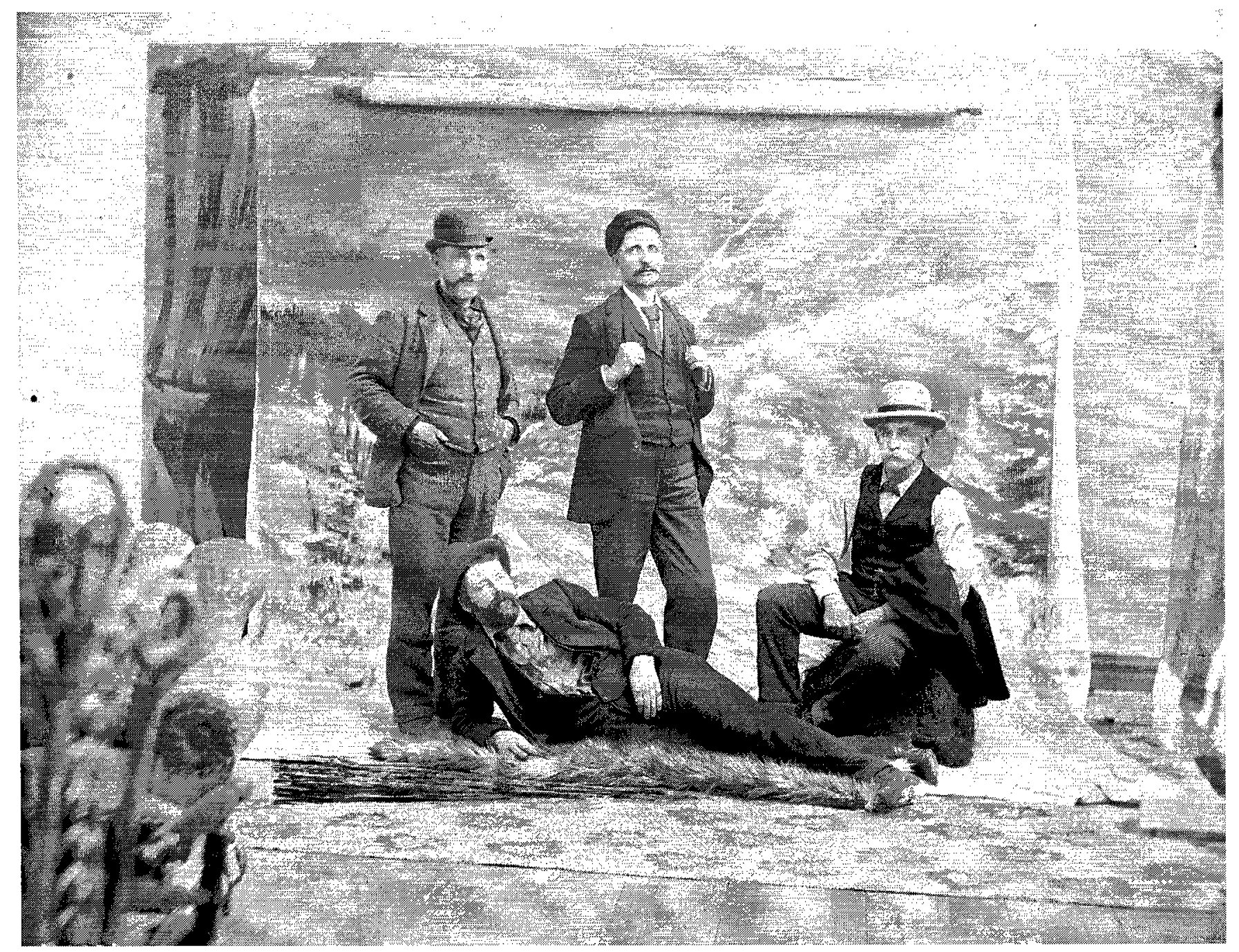

Fig. 73 Studio portrait taken of Klondike stampeders before their departure, c. 1897.

Provincial Archives of Alberta, Ernest Brown Collection, Edmonton, reference number B5278. 


\section{WORKS CITED}

Adney, T. (1994). The Klondike Stampede. Vancouver: UBC Press. (Original work published 1899).

Allen, S. L. (2005). Activist Media Anthropology: Antidote to Extremist Worldviews. In E. W. Rothenbuhler, M. Coman (Eds.), Media Anthropology (p. 285-294). Thousand Oaks, Calif. : Sage.

Anderson, B. (1991). Imagined communities : reflections on the origin and spread of nationalism (2nd ed.). London ; New York : Verso. (Original work published 1983).

Anderson, P.J. (1991). The printed image and the transformation of popular culture, 1790-1860. Oxford : Clarendon Press.

Anderson, S. (1978). Racial Anglo-Saxonism and the American Response to the Boer War. Diplomatic History 2 (3): 219-236.

Anderson, S. (1981). Race and rapprochement : Anglo-Saxonism and Anglo-American relations, 1895-1904. Rutherford [N.J.] : Fairleigh Dickinson University ; London : Associated University Presses.

Arenson, A. (2007). “Anglo-Saxonism in the Yukon: The Klondike Nugget and AmericanBritish Relations in the "Two Wests," 1898-1901." Pacific Historical Review 76 (3): 373 403. 
Atwood, M. (1985, March 10). The real North America, eh? The New York Times, p. BR3.

Aurenche, M.-L. (2002). Édouard Charton et l'invention du Magasin pittoresque, 1833-1870.

Paris : H. Champion.

A woman's story of life on the Klondyke. (1897, July 21). San Francisco Chronicle, p. 2.

Babe, R.E. (1990). Telecommunications in Canada: technology, industry, and government [ebook]. Toronto, Ont. : University of Toronto Press. Retrieved from http://site.ebrary.com.proxy.library.carleton.ca/lib/oculcarleton/docDetail.action?docID=102 00954

Bachelard, G. (1994) The poetics of space (M. Jolas, Trans.). Boston : Beacon Press.

Backhouse, F. (1995). Women of the Klondike. Vancouver : Whitecap Books.

Bacot, J.-P. (2001, mai-juin). Le rôle de la presse illustrée dans la constitution du nationalisme au $\mathrm{XIX}^{\mathrm{e}}$ et au début du XX $\mathrm{XX}^{\mathrm{e}}$ siècle, Réseaux 107, Hermès Science Publications, 265-293. Retrieved from http://www.cairn.info/article.php?ID_REVUE=RES\&ID_NUMPUBLIE=RES_107\&ID_A RTICLE=RES_107_0265

Bacot, J.-P. (2001, novembre-décembre).Trois générations de presse illustrée au xix ${ }^{\mathrm{e}}$ siècle. Une recherche en patternité. Réseaux 111, Hermès Science Publications, 216-234. Retrieved from 
http://www.cairn.info/article.php?ID_REVUE=RES\&ID_NUMPUBLIE=RES_111\&ID_A RTICLE=RES_111_0216

Bacot, J. P. (2005). La presse illustrée au XIXe siècle : une histoire oubliée. Limoges, France : Pulim.

Barnhurst, K. G. \& Nerone, J. (2001). The form of news : a history. New York : Guilford Press.

Barthes, R. (1957). Mythologies. Paris, Éditions du Seuil.

Barthes, R. (1977). The rhetoric of the image. In (S. Heath, Trans.) Image-Music-Text (pp. 3251) London: Wm. Collins Sons and Co.. (Original French essay published 1964).

Baudelaire, C. (1972). The Dandy. In P.E. Chavet (Trans.) Baudelaire : selected writings on Art and Literature (pp. 419-422). Harmondsworth : Penguin

Bell, D.S.A. (2003). Mythscapes: memory, mythology, and national identity. The British Journal of Sociology 54(1), 63-81. Retrieved from http://onlinelibrary.wiley.com/doi/10.1080/0007131032000045905/abstract

Benjamin, W. (1973). Illuminations. London, Fontana.

Berger, P. \& Luckmann, T. (1966). The social construction of reality; a treatise in the sociology of knowledge. Garden City, N. Y., Doubleday.

Berton, P. (1972). Klondike; The Last Great Gold Rush, 1896-1899 (Revised ed.). Toronto: McClelland and Stewart. (Original work published 1958 under title: The Klondike fever). 
Berton, P. (1983). The Klondike quest : a photographic essay, 1897-1899. Boston ; Toronto : Little, Brown.

Bird, S.E. \& Dardenne, R.W. (1990, Summer). News and Storytelling in American Culture: Reevaluating the Sensational Dimension. Journal of American Culture 13 (2), 33-37. Retrieved from http://onlinelibrary.wiley.com.proxy.library.carleton.ca/doi/10.1111/j.1542734X.1990.1302_33.X/pdf

Bird, S.E. \& Dardenne, R.W. (1997). Myth, chronicle and story: Exploring the narrative qualities of news. In D. Berkowitz (Ed.), Social meanings of news : a text-reader (pp.333-350). Thousand Oaks, Calif. : Sage Publications.

Bishop, J.D. (1977). The 'Illustrated London News' social history of Edwardian Britain. London : Angus \& Robertson.

Bolotin, N. (1980). Klondike lost: a decade of photographs by Kinsey \& Kinsey. Anchorage: Alaska Northwest Pub. Co.

Branigan, E. (1975, Autumn). Formal Permutations of the Point-of-View Shot. Screen 16(3), $54-64$.

Breen, M. \& Corcoran, F. (1982, June). Myth in the Television Discourse. Communication Monographs 49, 127-137. 
Brown, J. (1996, Fall). Reconstructing Representation: Social Types, Readers, and the Pictorial Press, 1865-1877. Radical History Review 66, 5-38. Retrieved from http://0rhr.dukejournals.org.mercury.concordia.ca/cgi/reprint/1996/66/5

Brown, J. (2002). Beyond the lines : pictorial reporting, everyday life, and the crisis of Gilded Age America. Berkeley : University of California Press.

Burant, J. (1998, Winter). Getting Gold from Silver: Photography of the Klondike Gold Rush from the 1890s to 1905. Northern Review 19, 204-217.

Burgess, J.S. (2010, March 31). Travel and Travel Literature in Antiquity. Lecture sponsored by the Dean of FASS at Carleton University in Ottawa, Canada.

Campbell, C.P.. (1995). Race, Myth and the News. Thousand Oaks, Calif. : Sage Publications.

Campbell, C.S. (1976). The transformation of American Foreign Relations, 1865-1900. New York: Harper \& Row.

Campbell, J. (1991). The power of myth. (B.S. Flowers, Ed.). New York : Anchor Books.

Campbell, R. (1991). 60 minutes and the news : a mythology for Middle America. Urbana : University of Illinois Press.

Campbell, W. J. (2001). Yellow journalism: puncturing the myths, defining the legacies. Westport, Conn. : Praeger. 
Campbell, W. J. (2006). The year that defined American journalism: 1897 and the clash of paradigms. New York : Routledge.

Canadian Press Association. (1908). A history of Canadian journalism in the several portions of the Dominion : with a sketch of the Canadian press association 1859-1908. Toronto : Murray Printing Company], 1908.

Carey, J.W. (1987). Media, myth, and narratives : television and the press. Beverly Hills, Calif. : Sage Publications.

Carey, J.W. (1998). Political ritual on television: episodes in the history of shame, degradation and excommunication. In T. Liebes \& J. Curran (Eds.), Media, ritual, and identity [e-book] (pp. 51-70). London; New York : Routledge. Retrieved from http://lib.myilibrary.com.proxy.library.carleton.ca/Open.aspx $? \mathrm{id}=33287 \& l o c=\&$ srch $=$ undefi ned $\&$ src $=0$

Carey, J. W. (2009). Communication as culture: essays on media and society (Revised ed.). New York: Routledge. (Original work published 1988).

Chalaby, J. K. (1996, Sept.). Journalism as an Anglo-American invention: a comparison of the development of French and Anglo-American journalism, 1830s-1920s. European Journal of Communication 11(3), 303-326.

Chalaby, J. K. (1998). The invention of journalism. Houndmills, Basingstoke, Hampshire : Macmillan Press ; New York : St. Martin's Press. 
The Gold Rush [silent b \&w $35 \mathrm{~mm}$ narrative film]. $91 \mathrm{~min}$. Produced and directed by Charlie Chaplin. Charlie Chaplin Productions.

Chartier, R. (1994). The order of books : readers, authors and libraries in Europe between the fourteenth and eighteenth centuries. Cambridge : Polity Press.

Coates, K. (1998, Winter). The Klondike Gold Rush in World History: Putting the Stampede in Perspective. Northern Review 19, 21-35.

Coates, K. \& Coates, C. (1998, Winter). The Klondike Gold Rush in International Perspective. Northern Review 19, 12-19.

Cole, S.A. (2001). Suspect identities : a history of fingerprinting and criminal identification. Cambridge, Mass. : Harvard University Press.

Coman, M. (2003). Pour une anthropologie des médias. Grenoble, France : Presses universitaires de Grenoble.

Coman, M. (2005). News stories and myth - The impossible reunion. In E. W. Rothenbuhler, M. Coman (Eds.), Media Anthropology (p. 111-120). Thousand Oaks, Calif. : Sage.

Cronon, W., Miles G. \& Gitlin, J. (Eds.). (1993). Under an open sky : rethinking America's Western past. New York : W.W. Norton.

Culler, J.D. (2001). The pursuit of signs : semiotics, literature, deconstruction [e-book]. London ; New York : Routledge. Retrieved from 
http://lib.myilibrary.com.proxy.library.carleton.ca/Open.aspx $? \mathrm{id}=25416 \& l o c=\& s r c h=$ undefi ned $\& \operatorname{src}=0$

Dafoe, J.W.. (1930, April). Early Winnipeg Newspapers. In Papers read before the Historical and Scientific Society of Manitoba (Vol. 3, pp. 14-24). Winnipeg: Historical and Scientific Society of Manitoba.

Davis, F. (1984, Spring). Decade Labeling: the Play of Collective Memory and Narrative Plot. Symbolic Interaction 7(1), 15-24. Retrieved from http://catalogue.library.carleton.ca/search $\sim$ S4?/tsymbolic+Interaction/tsymbolic+interaction/ $1 \% 2 \mathrm{C} 1 \% 2 \mathrm{C} 1 \% 2 \mathrm{CB} / \mathrm{c} 8561097558 \& \mathrm{FF}=$ tsymbolic+interaction $\& 1 \% 2 \mathrm{C} 1 \% 2 \mathrm{C} \% 2 \mathrm{C} 1 \% 2 \mathrm{C} 0$

Davis, J. F. (1998, Winter). The Klondike Gold Rush in World History: Putting the Stampede in Perspective. Northern Review 19, 36-46.

Dayan, D. (2005). The pope at Reunion (P. Grant, Trans.). In E. W. Rothenbuhler, M. Coman (Eds.), Media Anthropology (p. 165-175). Thousand Oaks, Calif. : Sage.

Dewey, J. (1927). The public and its problems. Denver: A. Swallow.

Diffley, K. (2007, Dec.) Splendid patriotism: How the "Illustrated London News" pictured the Confederacy. Comparative American Studies 5(4), 385-407.

Dilthey, W. (1976). Selected writings (H. P. Rickman, Trans. \& Ed.). Cambridge [Eng.] ; New York : Cambridge University Press. 
Does he own the earth? (1897, July 21). The Daily Mail and Empire, p. 1

Dowling, P. (1999, Dec.) Truth versus Art in Nineteenth-century Graphic Journalism: the colonial Australian case. Media History 5(2), 109-125. Retrieved from http://web.ebscohost.com/ehost/pdfviewer/pdfviewer?hid=18\&sid=b8a465b7-d4c3-425f8b62-f398d5652226\%40sessionmgr 13\&vid=3

Eisenstein, S.M. (1991). Towards a theory of montage. In M. Glenny \& R. Taylor (Eds.), M. Glenny (Trans.), S. M. Eisenstein : selected works (Vol. 2). Bloomington : Indiana University Press ; London : BFI.

Eliade, M. (1960). Myths, Dreams and Mysteries: The Encounter between Contemporary Faiths and Archaic Realities. (P. Mairet, Trans.), New York : Harper.

Fetherling, D. (1988). The gold crusades : a social history of gold rushes, 1849-1929. Toronto : Macmillan of Canada.

First "Canadian flags". (2008). Canadian Heritage Website. Ceremonial and Canadian Symbols Promotion section. Retrieved on February 26, 2011 from http://www.pch.gc.ca/pgm/ceemcced/symbl/df5-eng.cfm

Fish, S. (1989). Doing what comes naturally: change, rhetoric, and the practice of theory in literary and legal studies. Durham, NC : Duke University Press.

Fishkin, S.F. (1985). From fact to fiction : journalism \& imaginative writing in America. Baltimore : Johns Hopkins University Press. 
Fiske \& Hartley (2003). Reading television ( $2^{\text {nd }}$ ed.). London ; New York : Routledge.

Flew, A. (1997). Darwinian Evolution ( $2^{\text {nd }}$ ed.). New Brunswick, NJ, U.S.A. : Transaction Publishers. (Original work published 1984).

Fredrickson, G. M. (2002). Racism : a short history. Princeton, N.J. : Princeton University Press.

Gans, H. (1979). Deciding what's news. New York: Pantheon.

Gellner, E. (1983). Nations and nationalism. Ithaca : Cornell University Press.

Geertz, C. (1973). The interpretation of cultures; selected essays. New York : Basic Books.

Giffard, C.A. (1975-76, Winter). Ancient Rome's Daily Gazette. Journalism History 2(4), 106$109,132$.

Gitlin, T. (1980). The whole world is watching : mass media in the making \& unmaking of the New Left. Berkeley : University of California Press.

Goethals, G. (1993). Media mythologies. In A. Chris (Ed.), Religion and the media. Cardiff, Wales: University of Wales Press.

Goleman, D. (1995). Emotional intelligence. New York : Bantam Books.

Goleman, D. (2006). Social intelligence : the new science of human relationships. New York: Bantam Books. 
Government of Manitoba. (n.d.). Hudson's Bay Company history. Hudson's Bay Company Archives. Culture, Heritage, and Tourism. Government of Manitoba. Retrieved from http://www.gov.mb.ca/chc/archives/hbca/about/hbc_history.html

Government of Yukon. (n.d.). Yukon at a glance [brochure]. Retrieved from http://www.gov.yk.ca/pdf/yukon_at_a_glance_web2.pdf

Guénon, R. (1984). Les états multiples de l'être (4 ${ }^{\mathrm{i} \text { ème }}$ éd.). Paris : Éditions Guy Trédaniel : Véga. (Original work published 1932).

Guest, H. J. (1982). City of Gold: Dawson, Yukon Territory, 1896-1918. Ph.D. dissertation, University of Manitoba, Winnipeg, Manitoba, Canada. Retrieved April 16, 2011 from Dissertations \& Theses @ Carleton University. (Publication No. AAT NK54541).

Habermas, J. (1991). The structural transformation of the public sphere : an inquiry into a category of bourgeois society (T. Burger \& F. Lawrence, Trans.). Cambridge, Mass. : MIT Press.

Hall, S. (1988). The Rediscovery of 'Ideology': Return of the Repressed in Media Studies. In M. Gurevitch et al. (Eds.) Culture, Society, and the Media [e-book] (pp. 56-90). London: Methuen. (Original work published 1982). Retrieved from http://lib.myilibrary.com.proxy.library.carleton.ca/Open.aspx?id=11055\&loc=\&srch=undefi ned\&src $=0$

Hall, S. (1996) The question of cultural identity. In S. Hall et al. (Eds.) Modernity : an introduction to modern societies (p. 595-634). Cambridge, Mass. : Blackwell. 
Hall, S. (2000). Encoding/Decoding. In P. Marris \& S. Thornham (Eds.) Media studies : a reader ( $2^{\text {nd }}$ ed.) (pp. 51-61). New York : New York University Press. (Original essay published 1980).

Hammer, Anne. (2005). Weaving trickster: myth and tribal encounters on the world wide web. In E. W. Rothenbuhler, M. Coman (Eds.), Media Anthropology (p. 260-268). Thousand Oaks, Calif. : Sage.

Hartley, J. (1982). Understanding News. London; New York : Methuen.

Hedges, J. B. (1939). Building the Canadian West : the land and colonization policies of the Canadian Pacific Railway. New York : Macmillan.

Hibbert, C. (1975). The 'Illustrated London News' social history of Victorian Britain. London : Angus and Robertson.

Hobsbawm, E.J. (1992). Nations and nationalism since 1780 : programme, myth, reality $\left(2^{\text {nd }}\right.$ ed.). Cambridge [England] ; New York : Cambridge University Press. (Original work published 1990).

Hoffmann, C. (1970). The depression of the nineties; an economic history. Westport, Conn.: Greenwood Pub. Corp..

Hogarth, P. (1967). The artist as reporter. London: Studio Vista. 
Hogarth, P. (1972). Artists on horseback; the old west in illustrated journalism, 1857-1900. Toronto, General Pub. Co..

Hoover, S. (1988). Television, myth and ritual. In J. Carey (Ed.), Media, myth and narratives (pp. 161-178). London: Sage.

Hope of fortune animates the argonauts in the Williamette. (1897, Aug. 1, 1897). The Examiner, p.14.

Horsman, R. (1981). Race and manifest destiny : the origins of American racial anglo-saxonism. Cambridge, Mass. : Harvard University Press.

How I mined for gold on the Klondyke. (1897, Aug. 1). Sunday Examiner Magazine, p. 1.

Hughes, H.M. (1968). News and the human interest story. New York: Greenwood.

Jackson, M. (1969). The pictorial press: its origin and progress. New York : B. Franklin.

Jansen, S.C. (2008). Walter Lippmann, straw man of communication research. In (D. W. Park \& J. Pooley, Eds.) The history of media and communication research : contested memories (pp. 71-112). New York : Peter Lang.

Juhel, F., Gousset, M.-T. \& Laborderie, A. (2009). Marco Polo: Le livre des merveilles. Bibliothèque nationale de France. Site des expositions virtuelles. Bibliothèque des livres à feuilleter. Retrieved from the Bibliothèque nationale de France website: http://expositions.bnf.fr/livres/polo/index.htm 
Kesterton, W. H. (1984). A history of journalism in Canada; with a forward by Wilfrid

Eggleston. Ottawa: Carleton U. P., 1984. (Original work published 1967).

Kindleberger, C.P. (1978). Manias, panics, and crashes : a history of financial crises. New York : Basic Books.

Kitch, C. (2002, Summer). 'A Death in the American Family': Myth, Memory and National Values in the Media Mourning of John F. Kennedy Jr.. Journalism \& Mass Communication Quarterly 79(2), 294-309. Retrieved from http://0search.ebscohost.com.mercury.concordia.ca/login.aspx?direct=true $\& d b=u f h \& A N=7223507$ \&site $=$ ehost-live

Knight, G \& Dean, T. (1982, June). Myth and the structure of news. Journal of Communication 32 (2): 144-161. Retrieved from http://0onlinelibrary.wiley.com.mercury.concordia.ca/doi/10.1111/j.1460-2466.1982.tb00502.x/pdf

Koch, T. (1990). The news as myth : fact and context in journalism. New York : Greenwood Press.

Kovach, B. \& Rosenstiel, T. (2001). The elements of journalism : what newspeople should know and the public should expect. New York : Crown Publishers.

Kramer, P. A. (2002, March). Empires, exceptions, and Anglo-Saxons: Race and rule between the British and United States Empires, 1880-1910. The Journal of American History 88 (4), 1315-1353. Retrieved from http://www.jstor.org/stable/2700600. 
Kristeva, J. (1970) Le texte du roman; approche sémiologique d'une structure discursive transformationnelle. The Hague, Mouton.

Kuhn, M. (2006, Summer). Drawing Civil War soldiers: Volunteers and the draft in Harper's Weekly and Frank Leslie's Illustrated Newspaper, 1861-64. Journalism History 32(2), 96105. Retrieved from http://0web.ebscohost.com.mercury. concordia.ca/ehost/pdfviewer/pdfviewer?vid=3\&hid=104\&sid $=c 2 b 5 f c 2 f-044 d-45 d 7-856 a-d c 4 a 3 a f 204 f a \% 40$ sessionmgr 112

Kuzmiak, D.T. (1998, Winter). Capitalizing on the Klondike: American Entrepreneurship and the Klondike Gold Rush. Northern Review 19, 59-83.

Klondike Gold Rush. (2002, Sept 1) Royal Canadian Mounted Police Website. Origins of the RCMP section. Retrieved on April 10, 2010 from http://www.rcmp-grc.gc.ca/hist/orideb/debuts10-eng.htm.

Klondike Gold Rush: Thousands stampede to the Yukon with dreams of riches. (2001). CBC Learning Website. Canadian History section. Retrieved on April 10, 2010 from http://www.cbc.ca/history/EPISCONTENTSE1EP11CH1PA1LE.html

Lacroix, J.-G. \& Tremblay, G. (1997, October). The Emergence of Cultural Industries into the Foreground of Industrialization and Commodification: Elements and of Context. Current Sociology 45(4), 11-37.Retrieved from http://csi.sagepub.com/content/45/4/11.full.pdf+html

Lamar, H. \& Thompson, L. (Eds.) (1981). The Frontier in history: North America and Southern Africa compared. New Haven : Yale University Press. 
Lang, M.L. (1999). Women who made the news : female journalists in Canada, 1880-1945. Montreal : McGill-Queen's University Press.

Latour, B. (1986). Visualisation and Cognition: Drawing Things Together. In H. Kuklick (Ed.) Knowledge and Society Studies in the Sociology of Culture Past and Present (Vol. 6, pp. 140). Jai Press. Retrieved from http://www.bruno-latour.fr/articles/article/21-DRAWINGTHINGS-TOGETHER.pdf

Levi-Strauss, C. (1976). The Structural Study of Myth. In C. Jacobson \& B. Grundfest Schoepf, Trans., Structural anthropology (pp.206-231). New York, Basic Books. (Original work published 1963).

Lightman, H. A. (1946, February). The Subjective Camera. American Cinematographer, 46, 6667.

Link, A.S.. (1967). American epoch; a history of the United States since the 1890's. New York: Knopf. (First published in 1955).

Lippmann, W. (1922). Public Opinion. New York : MacMillan Company.

Loveridge, D. M.. (1981). A historical directory of Manitoba newspapers, 1859-1978. Winnipeg : University of Manitoba Press.

Lule, J. (2001). Daily news, eternal stories : the mythological role of journalism. New York: Guilford Press. 
Lule, J. (2002, Summer). Myth and terror on the editorial page: The New York Times responds to September 11, 2001. Journalism \& Mass Communication Quarterly 79(2), 275-293. Retrieved from http://0web.ebscohost.com.mercury.concordia.ca/ehost/pdfviewer/pdfviewer?sid=f9e92671-9d854974-aaca-8cb42f8a0f10\%40sessionmgr4\&vid=2\&hid=25

Lule, J. (2005). News as Myth: Daily News and Eternal Stories. In E. W. Rothenbuhler, M. Coman (Eds.), Media Anthropology (p. 101-110). Thousand Oaks, Calif. : Sage.

Lunn, A.J.E.. (1941, December). Bibliography of the history of the Canadian press. Canadian Historical Review 22, 416-433. Toronto: University of Toronto Press.

Lyons, E. (1897). Glimpses of Alaska : a collection of views of the interior of Alaska and the Klondike district. Chicago : Rand McNally.

Marien, M. W. (2006). Photography: a cultural history ( $2^{\text {nd }}$ ed.). Upper Saddle River, NJ : Prentice Hall.

Martin, J.R. and Rose, D. (2003) Working with Discourse: Meaning Beyond the Clause. London: Continuum.

Martin, M. (1997). Communication and mass media : culture, domination, and opposition. Scarborough, Ont. : Prentice Hall Allyn and Bacon Canada. (Original work published 1991). 
Martin, M. (2003, Spring). Conflictual Imaginaries: Victorian Illustrated Periodicals and the Franco-Prussian War (1870-71). Victorian Periodicals Review 36 (1), 41-58. Retrieved from http://www.jstor.org/stable/20083909

Martin, M. (2006). Images at war : illustrated periodicals and constructed nations. Toronto : University of Toronto Press.

Martin, M. \& Bodnar, C. (2009, May). The illustrated press under siege: technological imagination in the Paris siege, 1870-1871. Urban History 36(1), 67-85, Retrieved from http://0-

journals.cambridge.org.mercury.concordia.ca/action/displayFulltext?type=1\&pdftype=1\&fi $\mathrm{d}=5216316 \& \mathrm{jid}=\mathrm{UHY} \&$ volumeId=36\&issueId $=\&$ aid $=5216308$

Martin-Barbero, J. (1997). Mass media as site of resacralisation of contemporary cultures. In S. Hoover \& K. Lundby (Eds.), Rethinking media, religion and culture (pp. 102-116). London: Sage.

McEwen, I. K. (1993). "Daedalus and the discovery of order" and "Between movement and fixity : the place for order". In Socrates' Ancestor: An Essay on Architectural Beginnings (pp. 41-120). Cambridge, MA: The MIT Press.

McKim, A. (1892). The Canadian newspaper directory. Montreal : A. McKim \& Co., Publishers.

McKim, A. (1899). The Canadian newspaper directory. Montreal : A. McKim \& Co., Newspaper Advertising Agency. 
Mighetto, Lisa, Marcia Babcock Montgomery et al. (1998, November). "Hard Drive to the Klondike: Promoting Seattle During the Gold Rush." National Historical Park. National Park Service of the U.S. Department of the Interior. Klondike Gold Rush Seattle Unit. Retrieved April 9, 2010 from http://www.nps.gov/klse/historyculture/collections.htm.

Milton, J. (1989). The yellow kids : foreign correspondents in the heyday of yellow journalism. New York : Harper \& Row.

Morano, S. I. (2002). Newspaper design. In W.D. Sloan \& L. Mullikin Parcell (Eds.), American journalism : history, principles, practices (pp. 316-324). Jefferson, NC : McFarland \& Co.

Morford M. P. O. \& Lenardon, R.J. (1999). Classical Mythology (6 ${ }^{\text {th }}$ ed.). New York, NY: Oxford University Press. (Original work published 1971).

Morgan, M.C. (1973). One man's gold rush; a Klondike album. Vancouver : J.J. Douglas.

Morse, K. (2003). The nature of gold : an environmental history of the Klondike gold rush. Seattle : University of Washington Press.

Mott, F. L.. (1941). American journalism; a history of newspapers in the United States through 260 years: 1690 to 1950 . New York: Macmillan.

Moyers, B. (Narr.). (2009, May 15). Bill Moyers' Journal: Daniel Goleman. [tv interview]. 19 min. PBS. Princeton, N.J. : Films for the Humanities \& Sciences. 
Mullikin Parcell, L. (2002). Newspaper illustrations. In W.D. Sloan \& L. Mullikin Parcell (Eds.), American journalism : history, principles, practices (pp. 325-334). Jefferson, NC : McFarland \& Co.

Münster, S. (1544). Cosmographia. Münster in India: Page 1080 [electronic version]. Retrieved May 2, 2011, from Columbia University Web site: http://www.columbia.edu/itc/mealac/pritchett/00generallinks/munster/india/page1080.jpg

Nairn, T. (1977). Faces of nationalism : Janus revisited. London : Verso.

National Historic Sites of Canada in the Klondike. (2009, Nov 23). Parks Canada Website. Retrieved on April 10, 2010 from http://www.pc.gc.ca/eng/lhn-nhs/yt/klondike/index.aspx.

Neale, R.G. (1966). Great Britain and United States Expansion. East Lansing, Mich.: Michigan State University Press.

Nerone, J. (2006). The public and the party period. In J. Packer \& C. Robertson (Eds.), Thinking with James Carey: Essays on communications, transportation, history, (pp. 157-176). New York: Peter Lang.

Newell, D. (1987). The Importance of Information and Misinformation in the Making of the Klondike Gold Rush. Journal of Canadian Studies 22 (4): 95-111. Retrieved April 2, 2010, from the Carleton University Library ProQuest Database. 
Nikiforuk, A. (2011, March 17). Learning from...Calgary. Paper presented as part of the "Learning from..." conference talks at the Canadian Centre for Architecture in Montreal, Quebec, Canada.

N.W. Ayer \& Son. (1897). N.W. Ayer \& Son's American Newspaper Annual. Philadelphia, P.A.: N.Y. Ayer \& Son.

O'Donnell, M. (2003). Myth and meaning in the 'Sydney Morning Herald's Good Weekend': an analysis of narrative journalism. Unpublished M.A. thesis, University of Technology, Sydney, Australia. Retrieved from http://marcusodonnell.com/files/thesis2.pdf

O’Donnell, M. (2004). Preposterous trickster: Myth, news, the law and John Marsden. Media \& Arts Law Review 8(4), 282-305. Retrieved from http://possibleworlds.blogs.com/apocalyptics/files/malr_8.4\%20m_od.pdf

Ouspensky, P.D. (1969). Tertium organum; the third canon of thought, a key to the enigmas of the world ( $3^{\text {rd }}$ American ed.) (N. Bessaraboff \& C. Bragdon, Trans.). New York, A.A. Knopf. . (Original work published 1920).

Patterson, C. (2009). "Illustration of a picture": nineteenth-century writers and the Philadelphia pictorials. American Periodicals 19(2), 136-164. Retrieved from http://web.ebscohost.com/ehost/pdfviewer/pdfviewer?hid=18\&sid=b8a465b7-d4c3-425f8b62-f398d5652226\%40sessionmgr13\&vid=7 
Pauly, J. J. (1987). Rupert Murdoch and the Demonology of Professional Journalism. In J. Carey (Ed.), Media, myths, and narratives : television and the press (pp. 246-261). Beverly Hills, Calif. : Sage Publications.

Personnel of the north-bound party. (1897, July 22). The Examiner, p. 1

Peters, J. D. (1989). Democracy and American mass communication theory: Dewey, Lippmann, and Lazarsfeld. Communication 11(3): 199-220.

Pollack, J. \& Ryan, M. T.. (n.d.). Cultural readings: Colonization and Print in the Americas (Promotion \& Possession). Online exhibition. University of Pennsylvania Library. Retrieved from: http://www.library.upenn.edu/exhibits/rbm/kislak/promotion/hakluyt1.html

Polo, M. (1958). The travels of Marco Polo (Marsden-Wright, Trans.; Everyman's Ed.). New York, Orion Press.

Porsild, C. L. (1998). Gamblers and dreamers : women, men, and community in the Klondike. Vancouver: UBC Press.

Real, M. (1996). Exploring media cultures. London: Sage.

Rich men are going, too. (1897, July 24). The Toronto World, p.1.

Ricœur, P. (1981). Hermeneutics and the human sciences : essays on language, action, and interpretation. (J.H. Thompson, Ed., Trans.), Cambridge [Eng.] ; New York : Cambridge University Press ; Paris : Editions de la Maison des sciences de l'homme. 
Rosen, J. (1997). "We'll have that conversation" : Journalism and democracy in the thought of James W. Carey. In E.S. Munson \& C.A. Warren (Eds.), James Carey: a critical reader (pp. 191-206). Minneapolis Minnesota U.P.

Rosen, J. (2003, Sept. 8). PressThink basics: The master narrative in journalism [weblog post]. Press Think: Ghost of democracy in the media machine. Retrieved from http://archive.pressthink.org/2003/09/08/basics_master.html

Rothenbuhler, E. W. (2005). Ground zero, the firemen, and the symbolics of touch on 9-11 and after. In E. W. Rothenbuhler, M. Coman (Eds.), Media Anthropology (p. 176-187). Thousand Oaks, Calif. : Sage.

Russill, C. (2008, Nov.). Through a public darkly: Reconstructing pragmatist perspectives in communication theory. Communication theory 18(4), 478-505. Retrieved from http://0web.ebscohost.com.mercury.concordia.ca/ehost/pdfviewer/pdfviewer?hid=13\&sid=18b4d23 d-3722-4e 5b-ba0a-16fcccc4c128\%40sessionmgr10\&vid=3

Rutherford, P.F.W. (1975, June). The People's Press: The Emergence of the New Journalism in Canada, 1869-99. Canadian Historical Review 56(2). Retrieved from http://0utpjournals.metapress.com.mercury.concordia.ca/content/m2214125108755w2/fulltext.pdf

Rutherford, P.F.W. (1982). A Victorian authority : the daily press in late nineteenth-century Canada. Toronto : University of Toronto Press.

Sabin, P. (1997, August). Home and Abroad: The Two 'Wests' of Twentieth-Century United States History. Pacific Historical Review 66 (3): 305-335. 
Saint Louis University (2008). "What a Piece of Work is a Man" - Reading the Body in Medieval Manuscripts. Online Exhibition. Saint Louis University. Retrieved May 30, 2011, from Saint-Louis University online archives web site: http://slulink.slu.edu/archives/digcoll/manuscripta08/other.html

Schiller, D. (1981). Objectivity: The public and the rise of commercial journalism. Philadelphia: University of Pennsylvania Press.

Schmid, S. (2002). Byron and Wilde: The dandy in the public sphere. In U. Böker, R. Corballis, \& J. Hibbard (Eds.), The importance of reinventing Oscar : versions of Wilde during the last 100 years (pp. 81-89). Amsterdam; New York : Rodopi.

Schudson, M. (1978). Discovering the news : a social history of American newspapers. New York : Basic Books.

Schudson, M. (1999). The good citizen: A history of American civic life. Cambridge: Harvard University Press.

Schudson, M. (2002). News, Public, Nation. American Historical Review 107(2), 481-495.

Schudson, M. (2005). News as stories. In E. W. Rothenbuhler, M. Coman (Eds.), Media Anthropology (p. 121-128). Thousand Oaks, Calif. : Sage.

Silcock, W. B. (2002, Summer). Global news, national stories: Producers as mythmakers at Germany's Deutsche Welle television. Journalism \& Mass Communication Quarterly 79 (2): 339-352. Retrieved from http://0- 
search.ebscohost.com.mercury.concordia.ca/login.aspx $?$ direct $=$ true $\& d b=u f h \& A N=7223510$ \&site=ehost-live

Sinnema, P.W. (1995, Summer). Reading Nation and Class in the First Decade of the "Illustrated London News". Victorian Periodicals Review 28(2), 136-152. Retrieved from http://0www.jstor.org.mercury.concordia.ca/stable/pdfplus/20082841.pdf?acceptTC=true

Sinnema, P. W.. (1998). Dynamics of the pictured page : representing the nation in the Illustrated London news. Aldershot, Hants, England ; Brookfield, Vt. : Ashgate Pub..

Slater, J. (2002). Technologies of news gathering and transmission. In W.D. Sloan \& L. Mullikin Parcell (Eds.), American journalism : history, principles, practices (pp. 3-13). Jefferson, NC : McFarland \& Co.

Sloan, W. D. \& Mullikin Parcell, L. (Eds.). (2002). American journalism : history, principles, practices. Jefferson, $\mathrm{NC}: \mathrm{McFarland} \& \mathrm{Co}$.

Smith, A. D. (1999). Myths and memories of the nation. New York : Oxford University Press.

Smith, R.R. (1979, March). Mythic elements in television news. Journal of Communication 29 (1): 75-82. Retrieved from http://0onlinelibrary.wiley.com.mercury.concordia.ca/doi/10.1111/j.1460-2466.1979.tb01684.x/pdf

Smythe, D. W. (1977, Fall). Communications: Blindspot of Western Marxism. Canadian Journal and Social Theory 1 (3): 1-27 
Sotiron, M. (1997). From politics to profits : the commercialization of Canadian daily newspapers, 1890-1920. Montreal : McGill-Queen's University Press.

Splichal, S. (2000). Defining Public Opinion in History. In H. Hardt \& S. Splichal (Trans. \& Eds.), Ferdinand Tönnies on Public Opinion: Selections and Analyses (pp. 11-48). Lanham (MD): Rowman \& Littlefield Publishers.

Spurr, D. (1993). The rhetoric of empire : colonial discourse in journalism, travel writing, and imperial administration. Durham, N.C. : Duke University Press.

Stephens, M. (2007). A history of news ( $3^{\text {rd }}$ ed.). New York : Viking. (Original work published 1988).

Strong, J. (1889). The United States and the future of the Anglo-Saxon race [e-book]. London : Saxon and Co.. Retrieved from http://www.empire.amdigital.co.uk.proxy.library.carleton.ca/contents/documentdetail.aspx?sectionid $=72333$

Swigart, P. (Ed.) Chronological index of newspapers for the period 1801-1967 in the collections of the Library of Congress. (Volume 7: 1892-1908). Serial and publications division of the Library of Congress.

Sullivan, M. (1926). Our times; the United States, 1900-1925. Volume 1: The Turn of the Century. New York, Scribner's. 
Tate, C. (2009, March 16). Seattle Post-Intelligencer (1863-2009). HistoryLink.org: The Free Online Encyclopedia of Washington State History [e-essay 8956]. Retrieved July 1, 2011 from http://www.historylink.org/index.cfm?DisplayPage=output.cfm\&file_id=8956

The Cultures and History of the Americas. (Christopher Columbus's Account of 1492 Voyage). (n.d.) Online exhibition. Library of Congress. Retrieved from the Library of Congress website: http://www.loc.gov/exhibits/kislak/kislak-exhibit.html

The same old grab-all policy, (1897, July 30), The Washington Post, p. 1.

Thomas, W.I. \& Thomas, D.S. (1929). The child in America : behavior problems and programs ( $2^{\text {nd }}$ ed.). New York : Alfred A. Knopf. (Original work published 1928).

Thrower, N.J.W. (1999). Maps \& civilization : cartography in culture and society ( $2^{\text {nd }} \mathrm{ed}$.). Chicago : University of Chicago Press.

To the Klondike for pleasure. (1897, July 25). The New York Times, p. 2.

Tuchman, G. (1981). Myth and the Consciousness Industry: A New Look at the Effects of the Mass Media. In E. Katz \& T. Szecskö (Eds.), Mass Media and Social Change (pp. 83-100). London: Sage.

Turner, R. (2000, Nov). Bondi Cinderellas: Storytelling and Gatekeeping in the Press. Media International Australia Incorporating Culture and Policy 97, 105-212. 
University of California, Riverside. (2007, Jan. 19). About Los Angeles Herald. Chronicling America: historic American newspapers. The Library of Congress, Washington, D.C.. Retrieved on July 3, 2011 from http://chroniclingamerica.loc.gov/lccn/sn85042462/

Van Dijk, T.A. (2003). Critical discourse analysis. In D. Schiffrin, D. Tannen, \& H. E. Hamilton (Eds.), Handbook of discourse analysis (pp. 352-371). Malden, MA : Blackwell Publishing.

Virr, R. et al. (2001). In pursuit of adventure: The fur trade in Canada and the North West Company. Retrieved from McGill University, Library and Collections, Digital Collections website: http://digital.library.mcgill.ca/nw

Waldstein, C. (1899). The expansion of western ideals and the world's peace. New York: John Lane: The Bodley Head. Retrieved from openlibrary.org online at http://openlibrary.org/books/OL529610M/The_expansion_of_western_ideals_and_the_worl $\mathrm{d} \% 27 \mathrm{~s} \_$peace

Ward, S. J.A. (2004). The invention of journalism ethics : the path to objectivity and beyond. Montreal : McGill-Queen's University Press.

Watelet, J. (1999). La presse illustrée en France, 1814-1914. Thèse pour le Doctorat d'État en Sciences politiques, Régime 1974, Paris 2 (Paris), France. Villeneuve d'Ascq, France : Presses universitaires du Septentrion.

Weslager, C.A. (1955, July). Log houses in Pennsylvania during the seventeenth century. Pennsylvania History 22(3): 256-266. Retrieved from http://www.jstor.org/stable/27769605. 
Wilkinson, S.A.. (2011, Summer). The Living Monument: A Consideration of the Politics of Indigenous Representation and Public Historical Monuments in Québec. Unpublished master's thesis, Concordia University, Montreal, Quebec, Canada. (Copy obtained from the author).

Williams, J. H. (2002). The purposes of journalism. In W.D. Sloan \& L. Mullikin Parcell (Eds.), American journalism : history, principles, practices (pp. 3-13). Jefferson, NC : McFarland $\&$ Co.

Wilson, V. (c. 1895). Guide to the Yukon gold fields: where they are and how to reach them [microform]. Seattle [Wash.] : Calvert.

Winseck, D. W. \& Pike, R. M. (2008, April). Communication and empire Media markets, power and globalization, 1860-1910. Global Media and Communication 4(1), 7-36. Retrieved from http://0-gmc.sagepub.com.mercury.concordia.ca/content/4/1/7.full.pdf+html.

Winslow, K. (1951). Big Pan-Out The Story of the Klondike Gold Rush. New York, NY: W. W. Norton \& Company.

Wodak, R (2002). Aspects of critical discourse analysis. Zeitschrift für Angewandte Linguistik $36,5-31$.

Wodak, R., de Cillia, R., Reisigl, M. \& Liebhart, K. (2009). The discursive construction of national identity ( $2^{\text {nd }}$ ed.). (A. Hirsch, R. Mitten \& J.W. Unger., Trans.). Edinburgh : Edinburgh University Press. (Original work published 1999). 
Zelizer, B. (1990, Dec.). Achieving journalistic authority through narrative. Critical Studies in Mass Communication 7(4), 366-376. Retrieved from http://catalogue.library.carleton.ca/search $\sim$ S4?/Critical+Studies+in+Mass+Communication/ tcritical+studies+in+mass+communication $/ 1 \% 2 \mathrm{C} 1 \% 2 \mathrm{C} 1 \% 2 \mathrm{CB} / \mathrm{c} 8561093903 \& \mathrm{FF}=\mathrm{tcritical}$ +studies+in+mass+communication $\& 1 \% 2 \mathrm{C} 1 \% 2 \mathrm{C} \% 2 \mathrm{C} 1 \% 2 \mathrm{C} 0$

Zelizer, B. (1997). Has communication explained journalism? In D. Berkowitz (Ed.), Social meanings of news : a text-reader (pp.23-30). Thousand Oaks, Calif. : Sage Publications.

Zelizer, B. (1997). Journalists as interpretive communities. In D. Berkowitz (Ed.), Social meanings of news : a text-reader (pp.401-419). Thousand Oaks, Calif. : Sage Publications. 